\title{
Mammal Conservation status and Prospects for community-based wildlife management in coastal Guinea-Bissau, West Africa
}

\author{
Dissertation \\ zur Erlangung des Doktorgrades \\ der Mathematisch-Naturwissenschaftlichen Fakultäten \\ der Georg-August-Universität zu Göttingen
}

vorgelegt von

Charlotte KARIBUHOYE

aus Burundi

Göttingen 2004 
D 7

Referent: Prof. Dr. Michael Mühlenberg

Korreferentin/Korreferent: Prof. Dr. Gerald Gerold

Tag der mündlichen Prüfung: 


\section{Table of Contents}

Acknowledgements

Abstract

Zusammenfassung

Resumo

List of tables

List of figures

List of abbreviations

\section{PART 1}

$\begin{array}{ll}\text { I. Introduction } & 1\end{array}$

$\begin{array}{ll}\text { I.1. Background } & 1\end{array}$

I.2. Problem statement 4

$\begin{array}{lll}\text { I.3. Research questions } & 6\end{array}$

$\begin{array}{lll}\text { I.4. Aims and Objectives } & 7\end{array}$

$\begin{array}{lll}\text { I.5. Outputs and contributions } & 7\end{array}$

$\begin{array}{lll}\text { II. } & \text { Current state of research } & 8\end{array}$

II.1. Distribution and Conservation status of large and medium sized mammal in West Africa and Guinea Bissau 8

II.1.1. Primates 8

II.1.2. Ungulates 18

II.1.3. Proboscids 30

II.1.4. Sirenids 31

II.1.5. Other mammal species 33

II.2. Main threat factors for mammal species 34

II.3. Community-based wildlife management 40

II.3.1. About the concept $\quad 40$

II.3.2. Why Community-based wildlife management? 42

II.3.3. Categories of Community-based wildlife management 43

II.3.4. Community-based wildlife management as a tool for Conservation? $\quad 47$

II.3.5. Challenges and key questions to Community-Based Conservation 49

II.3.6. Conditions for Community-based wildlife management 52 


\section{PART 2}

III. Study area $\quad 55$

III.1. The coastal zone $\quad 55$

III.1.1. Geography and climate $\quad 55$

III.1.2. Vegetation 56

III.1.3. Human activities $\quad 60$

$\begin{array}{ll}\text { III.1.4. Conservation actions } & 61\end{array}$

III.2. The selected study sites

III.2.1. The Bolama-Bijagós Biosphere Reserve 63

III.2.2. The Cantanhez Forests 64

III.2.3. The Natural Park of the Cufada lagoons 64

III.2.4. The Natural Park of Cacheu mangroves 65

IV. Methods $\quad 66$

IV.1. Field data collection on mammal distribution and status 66

IV.1.1. Mammal field survey $\quad 66$

IV.1.2. Survey data analysis $\quad 68$

$\begin{array}{lll}\text { IV.2. Assessment of wildlife use and perception } & 71\end{array}$

$\begin{array}{ll}\text { IV.2.1. Village interviews } & 71\end{array}$

$\begin{array}{ll}\text { IV.2.2. Interview data analysis } & 72\end{array}$

\section{PART 3}

$\begin{array}{lll}\text { V. Results } & \mathbf{7 3}\end{array}$

V.1. Distribution and status of selected large mammals in the coastal zone 73

V.1.1. Primates 73

V.1.2. Even-toed ungulates $\quad 86$

V.1.3. Elephants $\quad 94$

V.1.4. Sirenids $\quad 95$

V.1.5. Carnivores 96

V.2. Wildlife conservation and use 101

V.2.1. Hunting activities $\quad 101$

V.2.2. Wild meat trade 106

V.2.3. Perception of general population trends of wild mammals 107

V.2.4. Perception of mammal conservation needs 109 
V.2.5. Conflicts with mammals

V.2.6. Perception of wildlife value

V.2.7. Wildlife in mythology and culture /Existing taboos on mammals $\quad 115$

V.2.8. Knowledge on existing hunting regulations 120

V.2.9. Knowledge and perceptions on existing protected areas 121

V.2.10.Perception on the importance of Wildlife monitoring 121

V.3. Examples of community-based conservation initiatives in Guinea Bissau 122

V.3.1. Participatory coastal resources management in the Formosa island group

V.3.2. Community-based conservation of the Cantanhez Forests

V.3.3. Experience of Community forests: the Green space management programme in Oio

\section{PART 4}

VI. Discussion

VI.1. Survey methods

VI.2. Mammals distribution and conservation status

VI.2.1. Status of Primates

VI.2.2. Comparison of the Primate Community with other African Forests

VI.2.3. Status of Ungulates

VI.2.4. Status of the elephant

VI.2.5. Status of the West African Manatee

VI.2.6. Status of some Carnivore species

VI.3. Trends in relative abundance of some large mammals

VI.4. Perceived versus real trends in animal abundance -

Attitudes towards wildlife

VI.5. Which are the mean threat factors for mammals in coastal Guinea Bissau?

VI.6. Do traditional cultural practices contribute to wildlife conservation?

VI.7. What about the non-tabooed, non charismatic or destructive species?

VI.8. Specific legal conservation measures

VI.9. Development and implementation of Community-based wildlife monitoring schemes in the study sites 
VI.9.3. Capacity-building of monitoring teams

VI.9.4. Data collection

VI.6. Towards community-based monitoring and management?

Opportunities and constraints for successful implementation of

long-term community-based wildlife monitoring and management

VI.6.1. Biological resources

VI.6.2. Legal framework

VI.6.3. Institutional level

VI.6.3. Technical aspects

VI.6.5. Financial resources

VII. Conclusions and implications for conservation 203

VII.1. Conservation status of mammals 203

VII.2. Development of community-based wildlife management schemes 205 


\section{Acknowledgements}

I would like to express my deep gratitude to Prof. Dr. Michael Mühlenberg for supervising this research and for the qualified support and advices during this study. I extend my gratitude to Prof. Dr. Gerold for kindly accepting to be the second supervisor of this thesis and for his valuable help.

My thanks to Dr. Jolanta Slowik, Dr. Matthias Waltert and all the all members of Zentrum für Naturschutz for helpful discussions, friendship and moral support during my stay at the centre. I gratefully thank Abílio Rachid Said for precious discussions, comments and suggestions, Bruno Paris and Pierre Campredon for valuable suggestions on the draft and helpful bibliography and Jonathan Cook for grammar corrections and comments on the contents.

My special thanks go to the following institutions management and staff in GuineaBissau, which kindly provided material, technical, logistical and moral support for the field research and the whole research : the Coastal Management Bureau (Gabinete de planificação costeira); the GIS Unit at the National Institute for studies and research (INEP/CEATA/SIG); the IUCN bureau in Bissau; the Protected Areas Unit (Núcleo das Áreas Protegidas); the NGOs (in alphabetical order) Acção para o Desenvolvimento "AD", "ADIM", "RADI", "Swissaid Bissau" and "Tiniguena".

I thank particularly the local communities in the surveyed sites, the park management and wardens in Orango, Cacheu and Cufada, the local technical agents in Formosa, Cantanhez, Canhabaque and Bubaque for hospitality, friendship and support during the field research.

This study was made possible thanks to a three and half a year scholarship provided by the Heinrich Boell Foundation, to which I express my deep recognition.

I would not have carried out this work successfully without the support, the patience and encouragements of my daughter Doussou and my husband Abílio, to which I would like to express my infinite gratitude. 


\section{Abstract}

In Guinea-Bissau, wildlife species in general and mammals in particular are suffering increasing pressure, mainly from overhunting and habitat reduction and fragmentation. The lack of reliable and updated data on wildlife distribution and population trends is an important constraint to an effective and wildlife management based on the conservation needs of the different species. Today there is a shift from the classical protection vision to a vision which integrates increasingly the human needs and activities. A growing number of conservation initiatives throughout the world are seeking, with variable success, to actively involve and empower local communities, in order to conserve wildlife, contributing to improve the livelihoods of local populations. This study has been conducted in order to assess the current conservation status of primates and other large- and medium-sized mammals in the coastal zone of Guinea-Bissau and to analyse the prospects for implementing community-based wildlife management schemes in that country.

Field surveys have been carried out in five different coastal sites: the Cantanhez forests, the Cufada Lagoons Natural Park and the Cacheu Mangrove Natural Park on the continental part; the Orango National park and the Formosa Islands group in the Bolama-Bijagós Biosphere Reserve. In the latter, brief additional surveys were carried out on the Canhabaque and the Bubaque islands. For the mammal species distribution and abundance assessment, ground surveys combining line transect sampling with reconnaissance walks were carried out in randomly selected locations within the study sites. Density estimates were obtained for primates in Cantanhez and Orango and for Bushbucks in Orango using the software Distance 3.5. and different manual calculation methods. For most species, a relative abundance was estimated using the encounter rate per surveyed kilometre. In order to investigates wildlife use patterns and perception by local communities, semi-structured group interviews were carried out in villages located within or around the surveyed sites. Informal interviews in the villages and with conservation projects staff and official authorities' representatives allowed gathering additional data.

The occurrence of about 44 large and medium-sized mammal species from 15 families was confirmed in the coastal area of Guinea Bissau. Not included in this 
study were the insectivores Insectivora, hares and rabbits Lagomorpha, rodents Rodentia and bats Chiroptera. All 11 primate species known to occur in GuineaBissau are present in the coastal region; forest species are distributed mostly in the Cantanhez forests and also in the Cufada region. About 22 ungulate species from four families and 11 carnivores' species from four families were also confirmed to occur in the coastal region, most observations being made in the Cufada Natural Park, and to a lesser extent in the Cacheu Natural Park. The conservation status of some very rare, cryptic or possibly extinct species such as the sooty mangabey $C$. $t$. atys, the greater spot-nosed monkey $C$. nictitans stampfilii, the pigmy hippopotamus $H$. liberiensis and the water chevrotain $H$. aquaticus could not be clearly assessed. The occurrence of the African Golden Cat $P$. aurata, a species which is not included in the official species list of Guinea-Bissau, was confirmed during this study.

Some species of high conservation value, particularly Chimpanzees $P$. troglodytes verus, Western pied Colobus C. p. polykomos and Red Colobus P. badius temminckii, still occur in restricted areas within and outside of existing protected areas. The comparison with other African forest sites have shown lower group density estimates for Chimpanzees and pied Colobus in southern Guinea-Bissau (Cantanhez) than in comparable forest sites in Upper Guinea (Tiwai Island in Sierra Leone and Tai National Park in Côte-d'Ivoire). In the case of chimpanzee however, the densities estimates are higher than those from some Central African lowland forests such as the Lopé Reserve in Gabon or the Korup support zone in Cameroon. Compared to Sierra Leone, the calculated density estimates for red Colobus is similar, whereas Campbell's monkeys density is much higher in Guinea-Bissau. The existence of relatively high primate species diversity in the forest patches of southern Guinea-Bissau confirms the importance of this still poorly known country for the conservation of endangered West African primates endemic to the Upper Guinea region.

However, there is evidence of the degradation of most mammals' conservation status in coastal Guinea-Bissau. Data from interviews and comparison with earlier studies show important declines in various mammal species. Species which are subject to higher hunting pressure such as large antelopes and duikers are mostly affected. There is increasingly a shift to smaller and traditionally not heavily exploited species 
such as smaller monkeys. Furthermore, some locally endangered species are not adequately protected by the existing traditional and legal measures.

Hunting is considered by interviewed local people as being the main reason for decreasing wildlife populations in Guinea-Bissau. Although a limited number of species does benefit from consumption and hunting taboos, immigration, poverty, crop raiding and limited access to fish and other sources of protein are leading to increasing pressure on other mammal species. Interviewed local people made the link between shrinking forest areas and dwindling mammal populations, but agriculture was seldom pointed out as one of the factors contributing to the destruction and fragmentation of natural habitat. Major land cover changes have resulted from commercial agriculture (mostly due to the expansion of cashew plantations and other cash crops areas), and also from subsistence and slash-andburn agriculture. In addition to these factors, insecurity on land tenure has greatly contributed to rapid natural forests' conversion to agriculture or plantation areas.

Some mammal species have benefited from local and traditional conservation practices and measures, for occupying an important place in the culture, mythology and religion of some ethnic groups. At present a few local community-based conservation initiatives have been seeking with some success at supporting and reinforcing local conservation structures and mechanisms and at rising awareness on wildlife and other resources conservation needs. Further opportunities favourable to the development of community-based wildlife management schemes in GuineaBissau include the increasing awareness in local communities on wildlife conservation value and on cultural, ecological and economic benefits from wildlife, the existence of traditional regulating mechanisms on some wildlife conservation issues and the existing valuable local knowledge on wildlife and other natural resources. Moreover, the principle of participatory management is officially recognised and accepted, and the actual legal framework on some conservation related issues provides an important juridical support for community-based wildlife and resource management initiatives.

However, important constraints remain which need to be urgently addressed, among which the increasing exploitation pressure and the rapid decline in wildlife resources, the lack of information on specific wildlife and ecological issues, the insufficient 
divulgation of traditional regulating mechanisms and the rapid weakening of traditional management structures. Furthermore, locally established bylaws and regulations are in general not officially recognised, remaining thus without a formal legitimacy, and in countries like Guinea-Bissau, official devolution mechanisms of management rights to local communities are still incomplete and partial.

There is a need of developing cost-effective wildlife monitoring programmes and long-term detailed studies in order to regularly update information on most endangered species and to provide in this way scientific basis to management measures. Additionally, the legal measures must be urgently reinforced, in order to improve the conservation status of some threatened species and ecosystems with high conservation value. Locally adapted strategies, including political/legal support to local and traditional management structures, economic and other incentives and scientific support to decision making are the key to successful implementation of viable community-based wildlife management schemes in Guinea-Bissau. 


\section{Zusammenfassung}

In Guinea-Bissau leiden Wildtiere im Allgemeinen und Säugetiere insbesondere unter zunehmendem Druck, hauptsächlich durch übermäßige Jagd und Habitatrückgang und -fragmentierung. Der Mangel an zuverlässigen und aktualisierten Daten über die Verteilung von Wildtierbeständen und über Populationstrends stellt ein wichtiges Hindernis für ein effektives, auf den Schutzanforderungen der verschiedenen Arten ausgerichtetes Wildtiermanagement dar. Heute findet ein Umdenken statt, von der klassischen Schutzvision, zu einer Vision die die menschlichen Bedürfnisse und Aktivitäten zunehmend integriert. Immer mehr Naturschutzinitiativen versuchen weltweit und mit unterschiedlichem Erfolg, die lokalen Gemeinschaften aktiv einzubinden, mit dem Ziel, die Wildtiere zu schützen und gleichzeitig die Lebensbedingungen der Bevölkerungen zu verbessern. Diese Studie wurde durchgeführt, um den Schutzstatus von Primaten und anderen großen und mittleren Säugetieren in den Küstengebieten von Guinea-Bissau zu ermitteln, und die Aussichten für die Entwicklung von Wildtiermanagementprogrammen, die von den lokalen Gemeinschaften und Institutionen getragen werden („community-based“), zu analysieren.

Es wurden Felduntersuchungen in fünf unterschiedlichen Standorten im Küstengebiet durchgeführt: die Cantanhez Wälder, der Naturpark der Cufada Lagune und der Naturpark der Cacheu Mangroven auf dem kontinentalen Landesteil; der Orango National Park und die Formosa Inselgruppe im Bolama-Bijagós Biosphärenreservat, wobei in letzterem zusätzliche kurze Tierbeobachtungen auf den Inseln von Canhabaque und Bubaque durchgeführt wurden. Für die Verbreitungsund Dichteermittlung bei Säugetierarten wurden Feldbeobachtungen durch kombinierte Transektbegehungen und Wegüberwachungen (,reconnaissance“ surveys) an zufällig ausgesuchten Standorten innerhalb des Untersuchungsgebiets durchgeführt. Die Dichten wurden mittels des Computerprogramms Distance 3.5. und verschiedener manueller Methoden für Primaten in Cantanhez und Orango und für Schirrantilopen in Orango berechnet. Für die meisten Arten wurde ein relativer Häufigkeitsindex mit Hilfe der Treffenrate pro besichtigtes Kilometer berechnet. Halbstrukturierte Gruppeninterviews wurden in Dörfern innerhalb oder um die Untersuchungsgebiete durchgeführt, mit dem Ziel, die Nutzungsformen und 
Vorstellungen der lokalen Gemeinschaften gegenüber Wildtiere zu ermitteln. Zusätzliche Informationen wurden durch informelle Interviews in den Dörfern und mit dem Personal von Naturschutzprojekten und Vertretern von offiziellen Behörden gesammelt.

Das Vorkommen von etwa 44 großen und mittelgroßen Säugetierarten aus 15 Familien wurde im Küstenbereich von Guinea-Bissau bestätigt. Insektenfresser Insectivora, Hasen Lagomorpha, Nagetiere Rodentia und Fledermäuse Chiroptera wurden nicht in diese Studie einbezogen. Alle in Guinea-Bissau bekannten 11 Primatenarten sind im Küstengebiet anwesend; Waldarten kommen hauptsächlich in den Cantanhez Wäldern und auch in der Cufada Region vor. Etwa 22 Huftierarten aus vier Familien und 11 Fleischfresserarten aus vier Familien wurden in der Küstenregion bestätigt, wobei die meisten Beobachtungen in dem Cufada Naturpark, und in geringerem Ausmaß auch im Cacheu Naturpark gemacht wurden. Der Schutzstatus einiger seltener, scheuer oder möglicherweise ausgestorbener Arten wie die Rauchgraumangabe $C$. atys, die große Weißnase $C$. nictitans stampfilii, das Zwergflusspferd $H$. liberiensis und das afrikanische Hirschferkel $H$. aquaticus konnte nicht deutlich ermittelt werden. Das Auftreten der afrikanischen Goldkatze P. aurata, einer Art die noch nicht in der offiziellen Artenliste von Guinea-Bissau enthalten ist, wurde während dieser Studie bestätigt.

Einige Arten mit hohem Schutzwert wie der Schimpanse $P$. troglodytes verus, der Bärenstummelaffe C. p. polykomos und der Rote Stummelaffen P. badius temminckii kommen in begrenzten Gebieten innerhalb und außerhalb von Schutzgebieten vor. Ein Vergleich mit anderen afrikanischen Waldgebieten hat niedrigere Dichtewerte für Schimpansen und Bärenstummelaffen im südlichen Guinea-Bissau ergeben als in vergleichbaren Waldgebieten in Oberguinea (Tiwai Island and Tai National Park). Jedoch sind diese Werte höher als in einigen zentralafrikanischen Tieflandwäldern wie das Lopé Reservat in Gabun und die „support zone“ um den Korup Nationalpark in Kamerun. Im Vergleich zu Sierra Leone ist die für Guinea-Bissau (Cantanhez) berechnete Dichte des Roten Stummelaffen vergleichbar hoch während sie bei der Mona Meerkatze deutlich höher liegt. Die relativ hohe Primatenartenviefalt in den Waldresten im südlichen Guinea-Bissau bestätigt die Bedeutung dieses noch wenig 
bekannten Landes für den Schutz der in Oberguinea endemischen, bedrohten, westafrikanischen Primaten.

Jedoch spricht vieles für die Verschlechterung des Schutzstatus der meisten Säugerarten in Guinea-Bissaus Küstengebiet. Die Ergebnisse der Interviews und ein Vergleich mit früheren Studien zeigen wichtige negative Trends in verschiedenen Säugerarten. Am meisten betroffen sind Arten wie die großen Antilopen und die Ducker, die unter einem stärkeren Jagddruck leiden. Es wird bei der Jagd zunehmend eine Verschiebung zu kleineren und traditionsgemäß nicht stark genutzten Arten wie den kleineren Affen beobachtet. Außerdem sind einige Arten örtlich gefährdet aber durch die existierenden traditionellen Schutzmechanismen und die Gesetzgebung nicht angemessen geschützt.

Die Jagd wird von den befragten, heimischen Leuten als die Hauptursache für die abnehmenden Wildtierpopulationen in Guinea-Bissau betrachtet. Obwohl einige Arten von den Eß- und Jagdtabus profitieren, führen Immigration, Armut, Feldzerstörungen durch die Tiere und mangelnder Zugang zu Fisch und anderen Eiweißquellen zu steigendem Druck auf andere Säugerarten. Die befragten Leute machten zwar auch die Verbindung zwischen den schrumpfenden Waldflächen und den abnehmenden Säugerpopulationen, jedoch wurde selten die Landwirtschaft unterstrichen als einer der Faktoren, die zu Habitatzerstörung und -fragmentierung beitragen. Wichtige Waldflächen wurden durch die kommerzielle Landwirtschaft (hauptsächlich durch die Ausbreitung der Flächen für Cashewplantagen und andere "cash crop" Kulturen) und auch durch die Subsistenzlandwirtschaft und den Wanderfeldbau umgewandelt. Zusätzlich zu diesen Faktoren hat auch die Unsicherheit über Landbesitzverhältnisse zu einer schnellen Umwandlung natürlicher Wälder in landwirtschaftliche und Plantagenflächen geführt.

Einige Säugerarten, die einen wichtigen Platz in der Kultur, Mythologie und Religion einiger ethnischen Gruppen haben, wurden durch lokale und traditionell Praktiken und Schutzmaßnahmen geschützt. Eine kleine Zahl an lokalen gemeinschaftlichen Naturschutzinitiativen versuchen heute mit einigem Erfolg, die lokalen Naturschutzstrukturen und -Mechanismen zu stärken und das Bewusstsein der Leute über die Schutzanforderungen von Wildtieren und anderen Ressourcen zu 
erhöhen. Weitere günstige Gelegenheiten für die Entwicklung von gemeinschaftlichen Wildtiermanagementmodellen bieten unter anderem das zunehmende Bewusstsein lokaler Gemeinschaften über den Schutzwert und über den kulturellen, ökologischen und wirtschaftlichen Nutzen von Wildtieren, die bestehenden traditionellen regulierenden Mechanismen, über einige Aspekte des Wildtierschutzes und die wertvollen lokalen Kenntnisse über Wildtiere und andere natürliche Ressourcen. Außerdem wird das Prinzip des partizipativen Managements offiziell anerkannt und angenommen, und die aktuelle Gesetzgebung über einige naturschutznahen Sektoren sichert eine gewisse legale Grundlage die für die Entwicklung von Initiativen für gemeinschaftliches Wildtier- und Ressourcenmanagement wichtig ist.

Jedoch bestehen noch wichtige begrenzende Faktoren, die dringend gelöst werden müssen, unter anderem: der zunehmende Nutzungsdruck und die rapide Abnahme der Wildtierressourcen, der Mangel an Informationen über Wildtiere und Ökologie, die ungenügende Verbreitung von traditionellen regulierenden Mechanismen und die rapide schwächer werdenden traditionellen ökologischen Managementstrukturen. Außerdem werden lokal erlassene Gesetze und Verordnungen im Allgemeinen nicht offiziell anerkannt und bleiben ohne formale Legitimität. In Ländern wie GuineaBissau sind die offiziellen Mechanismen der Dezentralisierung von Managementrechten für lokale Gemeinschaften sind noch unvollständig.

Es ist notwendig, kosteneffektive Monitoringprogramme für Wildtierarten und detaillierte Langzeitstudien zu entwickeln, um die Informationen über die am meisten gefährdeten Arten regelmäßig zu aktualisieren und auf diese Weise eine wissenschaftliche Basis für die Managementmaßnahmen zu liefern. Zusätzlich sollten die gesetzlichen Maßnahmen dringend verstärkt werden, um den Schutzstatus einiger bedrohter Arten und Ökosystemen mit hohem Schutzwert zu verbessern. Auf die lokale Lage zugeschnittene Strategien, einschließlich politischer/juristischer Unterstützung für die lokalen und traditionellen Managementstrukturen, ökonomische und andere Anreize, sowie die wissenschaftliche Unterstützung für die Entscheidungsfindung sind Schlüsselfaktoren für die erfolgreiche Entwicklung von gemeinschaftlichen Wildtiermanagementmodellen in Guinea Bissau. 


\section{Resumo}

$\mathrm{Na}$ Guiné-Bissau, as espécies de fauna selvagem em geral, e os mamíferos em particular, têm sido submetidas a uma pressão cada vez maior, devido principalmente à caça abusiva e à redução e fragmentação do habitat respectivo. A falta de dados fiáveis e actualizados sobre a distribuição e a evolução das populações da fauna constitui um grande constrangimento para uma gestão efectiva e necessária a conservação de diferentes espécies. Hoje assiste-se a uma reorientação da visão proteccionista clássica, para uma visão que integra cada vez mais as necessidades e as actividades humanas. Em diferentes partes do mundo, um número cada vez mais crescente de iniciativas de conservação têm lugar, nas quais, com sucessos variáveis, se procura envolver activamente e capacitar as comunidades locais, com vistas a conservar a fauna, mas contribuindo ao mesmo tempo, para a melhoria das condições de vida da população local. Este estudo foi conduzido com o objectivo de avaliar o actual estatuto de conservação dos primatas e outros mamíferos de grande e médio porte na zona costeira da Guiné-Bissau e de efectuar uma avaliação das possibilidades de implementação de modelos comunitários de gestão da fauna neste país.

Foram conduzidas investigações no terreno em cinco locais diferentes da zona costeira: as florestas de Cantanhez, o Parque Natural das Lagoas de Cufada e o Parque Natural do Mangal de Cacheu, localizados na parte continental; o Parque Nacional de Orango e o grupo de ilhas de Formosa na Reserva de Biosfera do Arquipélago Bolama-Bijagós, na parte Insular. Nessa última, foram realizados inventários adicionais muito breves nas ilhas de Canhabaque e Bubaque. Nos inventários terrestres para a avaliação da distribuição e da abundância dos mamíferos, foram combinados o método dos transectos lineares com o das caminhadas de reconhecimento ("reconnaissance" surveys), em sítios seleccionados ao acaso dentro da área de estudo. Dados relativos à densidade foram obtidos para os primatas em Cantanhez e em Orango e também para a Gazela pintada ( $T$. scriptus) em Orango, utilizando o programa informático "Distance 3.5." e diferentes métodos de cálculo manual. Para a maioria das espécies, foi estimada a abundância relativa na base do índice de observação pôr km percorrido. Com vista a analisar a utilização e a percepção da fauna pelas comunidades locais, foram realizadas 
entrevistas semi-estructuradas a grupos de indivíduos, em diferentes aldeias ("tabancas") situadas dentro ou à volta dos sítios de inventário. Dados adicionais foram recolhidos através de entrevistas informais nas tabancas e com agentes de projectos de conservação e representantes das autoridades do estado.

Foi confirmada a ocorrência de cerca de 44 espécies de mamíferos de médio e grande porte, pertencentes a 15 famílias. Neste estudo não foram incluídos os insectívoros Insectivora, lebres Lagomorpha, roedores Rodentia e morcegos Chiroptera. Todas as 11 espécies de primatas conhecidas na Guiné-Bissau estão presentes na zona costeira, tendo as espécies florestais como principal áreas de distribuição, as florestas de Cantanhez e a zona de Cufada. Foi igualmente confirmada a ocorrência, de cerca de 22 espécies de ungulados distribuídas por quatro famílias e 11 espécies de carnívoros distribuídas por quatro famílias e com a maioria das observações efectuadas no Parque Natural de Cufada e, com uma frequência muito menor, no Parque Natural de Cacheu. O estatuto de conservação de algumas espécies muito raras, crípticas ou possivelmente extintas como o Macaco cinzento (C. t. atys), o petaurista maior (C. nictitans stampfii), o hipopótamo anão ( $H$. liberiensis) e o cabrito aquático ( $H$. aquaticus) não pôde ser claramente determinado. A ocorrência do gato dourado africano ( $P$. aurata), uma espécie não incluída na lista oficial das espécies da Guiné-Bissau, foi confirmada durante esse estudo.

Algumas espécies com alto valor para a conservação tais como o chimpanzé ( $P$. troglodytes verus), o colobo real (C. p. polykomos) e o colobo vermelho ( $P$. b. temminckii) ainda ocorrem em áreas restritas dentro e fora de áreas protegidas. $A$ comparação da densidade estimada com outras zonas florestais da África indicou para o chimpanzé e o Colobo real no sul da Guiné-Bissau (Cantanhez) valores inferiores aos dados relativos a zonas florestais comparáveis da Alta Guiné (ilha de Tiwai na Sierra Leoa e Parque Nacional de Tai na Côte-d'Ivoire). No caso do chimpanzé, no entanto, esses valores são superiores aos dados de outras florestas baixas centro-africanas tais como as da Reserva do Lopé no Gabão e as da zona circundante do Parque Nacional de Korup, nos Camarões. Em comparação com a Sierra Leoa, a densidade calculada para o colobo vermelho é comparável enquanto que no caso do Macaco Mona ela é muito superior na Guiné Bissau. A existência 
duma diversidade de espécies de primatas relativamente elevada nas manchas florestais do sul da Guiné-Bissau, confirma a importância deste país, ainda que, pouco conhecido, para a conservação das espécies de primatas endémicas e ameaçadas nas zonas compreendidas entre a África ocidental e à Alta Guiné.

No entanto há uma evidência clara da degradação do estatuto da maioria dos mamífero na zona costeira da Guiné-Bissau. Os resultados das entrevistas e a comparação com estudos anteriores mostram um declínio importante de várias espécies de mamíferos. As espécies sujeitas a uma maior pressão da caça tais como os grandes e os pequenas antílopes e gazelas são os mais afectadas. Assistese a uma reorientacao do esforço da caça para as espécies mais pequenas e até aqui tradicionalmente pouco exploradas como as espécies mais pequenas de macacos. Além disso, algumas espécies são localmente ameaçadas e não são adequadamente protegidas pelas medidas de protecção tradicionais, assim como pelas leis e regulamentos actualmente em vigor.

Salienta-se pelas entrevistas que a caça é considerada pelas comunidades locais como a razão principal do declínio das populações de muitas espécies da fauna na Guiné-Bissau. Algumas espécies beneficiarem de alguma protecção através dos tabus tradicionais relativos ao consumo e à caca, mas a imigração, a pobreza, a destruição das culturas pêlos animais e o limitado acesso ao pescado e outras fontes de proteínas têm conduzido a uma pressão cada vez maior sobre outras espécies de mamíferos. As populações locais entrevistadas fizeram também a ligação entre a diminuição das áreas florestais e a redução das populações da fauna, mas a agricultura foi raramente apontada como uma das causas da destruição e fragmentação do habitat natural. Importantes modificação do cobertura vegetal têm sido, no entanto, provocadas pela agricultura comercial (principalmente através da expansão das plantações do cajú e das áreas de outras culturas de renda), como também pela agricultura itinerante e de subsistência. A insegurança em relação à propriedade fundiária é um outro factor importante que tem estado na origem da rápida conversão das florestas naturais em zonas de cultivo e/ou de plantações. 
Algumas espécies de mamíferos têm beneficiado de práticas e de medidas locais e tradicionais de conservação, pôr ocuparem um lugar importante na cultura, mitologia e na religião de algumas etnias locais. Actualmente e com algum sucesso um número reduzido de iniciativas locais de conservação têm procurado, apoiar e reforçar as estruturas e mecanismos locais de conservação e a melhorar a conscientização sobre as necessidades de conservação da fauna e de outros recursos. Outros factores que melhoram a oportunidade de implementação de modelos de gestão comunitária da fauna na Guiné-Bissau ainda salientam-se: a crescente conscientização das comunidades locais sobre o valor da conservação da fauna e sobre os benefícios culturais, ecológicos e económicos da fauna; a existência de instituições tradicionais que regulamentam alguns aspectos ligados a conservação da fauna selvagem e a existência de um precioso acervo de conhecimentos locais sobre a fauna e outros recursos naturais. Além disso, o princípio da gestão participativa é oficialmente reconhecido e aceite e no quadro legal em vigor em alguns sectores ligadas à conservação e já garante uma certa base jurídica importante para as iniciativas de gestão comunitária da fauna e dos recursos naturais.

Alguns factores limitam ainda o desenvolvimento dessas iniciativas e que urge ultrapassar, entre as quais se salientam: a intensificação da exploração e o rápido declínio dos recursos faunísticos; a falta de informações sobre aspectos específicos da ecologia e da fauna; a fraca divulgação dos mecanismos de regulamentação tradicionais e o rápido enfraquecimento das estruturas tradicionais da sua gestão. Em geral não se reconhecem oficialmente as leis e regulamentos estabelecidos localmente ficando estas assim sem uma legitimidade formal e além do mais, nos países como a Guiné-Bissau, são muito incompletos e parciais os mecanismos oficiais de descentralização dos direitos de gestão para as comunidades locais .

Há uma necessidade de desenvolver actividades de monitorização da fauna a baixo custo, assim como de efectuar estudos detalhados de longo prazo, com vista a actualizar regularmente os dados sobre as espécies mais ameaçadas e deste modo, fornecer uma base científica para as medidas de gestão. As medidas legais devem ser reforçadas com urgência, com vista a melhorar o estatuto de conservação de algumas espécies e ecosistemas ameaçados, e de alto valor para a conservação. 
Estratégias adaptadas a situação local, o apoio político/legal às estruturas de gestão tradicional e local, medidas de incentivo económicas e o apoio científico à tomada de decisão são factores chaves para o sucesso da implementação de modelos viáveis para a gestão comunitária da fauna na Guiné-Bissau. 


\section{List of tables}

Table1. Primate species occurring in Guinea-Bissau

Table2. Duiker species of Guinea-Bissau

Table3. Some components of the different categories of community-based conservation

Table4. Mammal diversity and humid zone index at different continental coastal sites

Table5 Mammal sampling location and field survey effort

Table6. Village interviews on wildlife use and perception

Table7. Data on primate species distribution in the coastal forests

Table8. Primates' relative abundance and density in Cantanhez and Orango

Table9. Data on ungulate species distribution in the coastal forests

Table10. Data on the distribution of other large mammal species in the coastal forests of Guinea-Bissau

Table11. Data on large- and medium-sized carnivore species observations in the coastal forests of Guinea Bissau

Table12. Some characteristics of hunting activities in the study area

Table13. Most hunted mammal species in the coastal region

Table14. Wild meat trading prices in different regions of the country

Table15. Perception on population trends of some mammal species in the coastal forests

Table16. Mammal species considered as most threatened

Table17. Main crop raiding mammal species

Table18. Perceived value of wildlife in coastal forests

Table19. Examples of medicinal and protective use of some wildlife species

Table20. Examples of taboos on wildlife species

Table21. Examples of community-based conservation initiatives in Guinea Bissau

Table22. Density estimates of Chimpanzees in different West and Central African forests

Table23. Comparison of group density of some primate species between coastal Guinea-Bissau and some African forests

Table24. Comparison of forest primate communities of southern Guinea-Bissau with other similar African sites

Table25. Comparison of Bushbuck density in different African forests 
Table26. Comparison of relative abundance of some primate species (in group observations/km) between 1989 and 2002

Table27. Comparison of relative abundance (group observations $/ \mathrm{km}$ ) of some large and medium sized mammals between the coastal and non-coastal regions

Table28. Potential local flagship species in coastal Guinea-Bissau

Table29. Actual and proposed protected status of some endangered large- and medium-sized mammals

Table30. Example of required survey effort for line transect sampling in Cantanhez and Imbone/Orango for different levels of precision

Table31. Required total survey effort for 60 to 100 observation of some species

Table32. Example of data collection schedule for a community-based monitoring programme

Table33. Important aspects of the biological resources for the implementation of community wildlife management in Guinea-Bissau

Table34. Legal aspects related to the implementation of community wildlife management in Guinea-Bissau

Table35. Institutional characteristics related to the implementation of community wildlife management in Guinea-Bissau

Table36. Technical aspects related to the implementation of community wildlife management in Guinea-Bissau

Table37. Financial aspects related to the implementation of community wildlife management in Guinea-Bissau 


\section{List of figures}

Figure1. Location of Guinea-Bissau

Figure2. Humid forests - Cantanhez

Figure3. Mangrove forests -Formosa

Figure4. Mangrove forests - Ambuduco (Orango)

Figure5. Palm forest on the Canhabaque Island

Figure6. Human population density in the coastal zone

Figure7. Official and proposed PA in coastal Guinea-Bissau

Figure8. Study area with some census sites

Figure9. Chimpanzee nests in Elaeis guineensis palm trees

Figure10. A chimpanzee group crossing the main road between Buba and Quebo

Figure11. A chimpanzee group crossing the main road between Buba and Quebo

Figure12. Colobus monkey - Cantanhez

Figure13. Relative abundance (groups $/ \mathrm{km}$ ) of primates species observed in the coastal forests

Figure14. Campbell's monkey - Cantanhez

Figure15. Lesser spot-nosed monkeys - Canhabaque

Figure16. Buffalo footprints in the Lautchande forest (Cantanhez)

Figure17. Relative abundance of some large- and medium-sized Bovids in the coastal forests

Figure18. The Lagoon of Angôr - an important concentration site for common hippopotamus in the Orango NP

Figure19. Footprints of common hippopotamus-Imbone

Figure20. Relative abundance of some large- and medium-sized ungulates in the coastal forests

Figure21. Skin of a golden cat from the Djalicunda forest

Figure22. Clawless Footprints - Formosa Island

Figure23. Relative abundance of some carnivore species observed in the coastal forests 


\section{List of abbreviations}

AD Acção Para o Desenvolvimento

ADIM Associação para o Desenvolvimento Integral da Mulher

ADMADE Administrative Management Design for Game Management Areas

AESG African Elephant Specialist Group -

Afric. conv. African Convention on the Conservation of Nature and Natural Resources

CAMPFIRE Communal Areas Management Programme for Indigenous Resources Project

$\mathrm{CBC} \quad$ Community-Based Conservation

CBD Convention on Biological Diversity

CBNRM Community Based Natural Resource Management

CBWM Community-based Wildlife Management

CCAs Community Conserved Areas

CEATA Centro de estudos ambientais e tecnologias apropriadas

$\mathrm{Cl} \quad$ Conservation International

CITES Convention on International Trade in Endangered Species of Wild Fauna and Flora

CM Co-management

CMPA Co-Managed Protected Area

CWM Community Wildlife Management

DGFC Direç̧ão Geral das Florestas e Caça

ESW Effective strip width

FIBA Fondation Internationale du Banc d'Arguin

GIE Grupo de interesse económico

GIS Geographic information system

GPC Gabinete de planificação costeira

IBA Important Bird Areas Programme

ICD Integrated conservation and development

ICDP Integrated conservation and development projects

ICN Instituto de Conservação da Natureza

IGA Income generating activities

IIED International Institute for Environment and Development

INEP Instituto nacional de estudos e pesquisa 
IUCN World Union for Nature

MAFCP Ministério da Agricultura, Florestas, Caça e Pecuária

MDRA Ministério do desenvolvimento rural e agricultura

MTAA Ministério do Turismo, ambiente e artesanato

NGO Non gouvernemental organisation

NP National Park

PA Protected area

PASP Projecto Agro-silvo-pastoril

PRCM Programme Régional de Conservation de la Zone Côtière et Marine

RADI Rede Africana para o desenvolvimento integrado

RAMAO Renforcement des Aires marines protégées de l'Afrique de l'Ouest

SIG Sistema de informação geográfica

SNV Netherlands Development Organization

SSC Species Survival Commission

Swissaid Swiss foundation for international cooperation

UNEP United Nations Environment Programme

WCMC World Conservation Monitoring Centre

WWF Worldwide Fund for Nature 


\section{Introduction}

\section{I.1. Background}

\section{I.1.1. Ecology, biodiversity and mammal species richness of West African Forests}

Five different floristic regions are distinguished in West Africa, with natural forest vegetation occurring originally in the Guineo-Congolian regional zone and in the regional transition zone between Guineo-Congolian and the Sudanian zone (White 1983). More than 70 percent of the Guineo-Congolian original forest cover is lost (Conservation International 2001). Within this regional zone, Upper Guinea Forest, which extends from Guinea to eastern Sierra Leone, and through Liberia, Côte d'Ivoire and Ghana into western Togo, is classified as a biodiversity hotspot (Myers 1988). The Guinean Forest ranks fifth among the 25 hotspots in terms of original extent, and fourth in terms of the area still intact (Conservation International 2001).

The Guinea Forest Ecosystem hosts 551 mammal species, which represents the highest figure among the world's 25 biodiversity (Mace and Balmford 2000, Conservation International 2001), and represents almost half of the 1,150 mammal species that are native to continental Africa. Eight percent of the Guinean Forests mammals (45 species) are endemic, and many of them have highly restricted local distributions, making them extremely vulnerable to forest destruction.

At least 22 species of primates are found within the West African hotspot and eight of these are endemic to this region (Oates 1996). Three subspecies that inhabit the eastern part of the Upper Guinea forest block are considered endangered: the Roloway Monkey Cercopithecus diana roloway, the black-and-white colobus Cercopithecus polykomos vellerosus and the white-napped mangabey Cercocebus atys lunulatus. Inhabiting the same range, Miss Waldron's' red colobus Piliocolobus badius waldroni, was considered extinct in the wild in the year 2000 (Oates et al. 2000), but according to posterior references still to be confirmed, the species could still occur in Côte-d'Ivoire (Anon. 2004). Upper Guinea also has populations of two of Africa's great apes, including small and scattered populations of Western chimpanzees Pan troglodytes 
verus and a small population of lowland gorillas Gorilla gorilla gorilla on the NigeriaCameroon border (Oates 1996).

The Guinean Forests are also home of 15 species of even-toed ungulates, such as the rare pygmy hippopotamus Hexaprotodon liberiensis, several species of forest duikers Cephalophus subspecies, forest elephants Loxodonta africana cyclotis, three endemic squirrels and 190 rodent species (Eves \& Bakarr 2001, Conservation International 2001).

\section{I.1.2. Ecological and socio-cultural importance of wildlife}

Wild animals represent a natural resource of great significance for most forest-dwelling and also for other rural communities. They also play a very important role in maintaining the natural environment (Redford et al. 1995). As seed dispersers, wild herbivores and frugivores, they are recognised to play an important ecological role in the forest regeneration process and in the regulation of community structure, thus influencing the compositions and structure of vegetation (Howe 1984, Stiles 1992, Payne 1995, Redford et al.1995, Andresen 2000).

Wild vertebrate species are hunted for food, sale, social and cultural reasons, for medical use and because they may be in some cases agricultural pests. Wild mammals are important as food and one of the major sources of protein in many regions (Asibey 1974, Prescott-Allen 1982, Chardonnet 1995, Caspary 1999, Bennett and Robinson 2000).

Hunting is also a major source of income for subsistence hunters and rural communities, and increasingly as a commercial activity for non rural communities (Redford et al.1995, Bennett and Robinson 2000). It is often difficult to make a distinction between subsistence and commercial use of wildlife, since for many tropical forest people meat from the forest supplements both diets and incomes (Bennett and Robinson 2000). On the other side, hunting plays an important socio-cultural role for many tropical forest people (Redford et al.1995, Bennett and Robinson 2000). In some cultural groups, wildlife has an important place for religion and spiritual health (NtiamoaBaidu 1987, Mc Donald 1993, Redford et al.1995, Colding \& Folke 2001). 


\section{I.1.3. Importance of Guinea Bissau for the conservation of wildlife diversity in West Africa}

Guinea Bissau is located in the regional transition zone between the Guineo-Congolian and the Sudanian regional zones, and which is dominated by secondary grass- and woodlands as a consequence of the destruction of most forests by fire and cultivation, whereas some forest remnants are still present close to the semi-evergreen rainforests of the Guineo-Congolian zone (White 1983).

Due this situation and to the location on the coast, Guinea-Bissau presents a variety of ecosystems, which could explain the relatively high diversity of animal species encountered there. As a transition zone, it also plays an important role in maintaining animal biodiversity of West Africa, as this zone supports not only various forest and non forest species, but also has a key role as seasonal corridor or refuge zone for numerous species. The eastern and south-eastern parts of the country constitute an important seasonal migration corridor between Guinea-Bissau, Senegal and the Republic of Guinea for numerous large mammals such as forest elephants, buffaloes Syncerus caffer, Roan antelopes Hippotragus equinus, western Hartebeest Alcelaphus bucelaphus and Waterbuck Kobus ellipsiprymnus defassa (Silva Naga \& Serra 2001)

Data on wildlife diversity of Guinea Bissau indicate a relatively high species number for such a small country. Depending on the authors, mammal species numbers for Guinea Bissau vary from 102 (UNEP-WCMC 2004) to 108 (Limoges \& Robillard 1989) and 109 (Stuart et al. 1990, Chardonnet 1995). Data on bird species number vary from 374 (Limoges \& Robillard 1989) to 460 (UNEP-WCMC 2004) to 625 species (Chardonnet 1995).

The "Casamance and Fouta Djalon Region", which covers Southern Senegal, the Gambia, Guinea-Bissau and the western part of Guinea, was identified as one of the 11 important regional communities of African primates (Oates 1996). In this region, 5 of the 11 extant primate species are endemic of West Africa. The region is home of some significant populations of chimpanzees Pan Troglodytes verus, the least abundant form of the savannah baboon Papio papio and the Temmincki form of the red colobus Piliocolobus badius temminckii (Oates 1996). Guinea-Bissau hosts the most western population of the endangered western Chimpanzee (Gippoliti \& Dell'omo 1995) and is 
one of the few areas in which sympatrie and polyspecific association between red and western pied colobus Colobus polykomos have been documented (Gippoliti \& Dell'omo 1996). Guinea-Bissau is beside Côte d'Ivoire, Guinea, Liberia, and Sierra Leone, one of the five African countries where small isolated populations of the pigmy hippopotamus may still be present (UNEP-WCMC 2004), a species which is considered vulnerable (IUCN 2002).

The mangroves and coastal flats of Guinea Bissau form the largest areas of this type of habitat in Africa (Robertson 2001). Guinea Bissau plays an important role not only for the conservation of mammals, such as marine hippopotamus Hippopotamus amphibius (one of the few places where hippopotamuses have adapted to sea) and West African manatee Trichechus senegalensis, but the island region is important for the conservation of endangered marine turtles species, crocodiles and birds (especially Palaearctic species).

Eight sites are considered important bird areas - IBA (Robertson 2001) in that country. According to a WWF study (1983/84), the coast of Guinea Bissau represents the second most important place for wintering Palearctic waders on the West African coast, after the Banc d' Arguin in Mauritania.

\section{I.2. Problem statement}

Today wild meat represents increasingly one of the most important sources of protein for the rural population in Guinea Bissau. It is a traditional food, which is additionally more accessible for most families in the country. Factors contributing to the increase of wild meat consumption in rural areas are among, difficult access to domestic meat (which is more expensive than wild meat), limited access to other sources of animal protein such as fish, increasing poverty and lack of alternative sources of income. Another important factor is that livestock mainly has a wealth status symbol and is considered rather a capital than a consumption product. Commercial hunting is thus rapidly developing, as demand for wild meat increases also in the urban centres. Sport hunting has also strongly evolved in the last years on an uncontrolled way, with several sport hunting clubs being installed in different regions of the country. 
Large mammal populations have additionally suffered from habitat loss. The decrease of the forest surfaces in Guinea Bissau had several causes: first of all colonial policy strongly promoted the peanut monoculture in the 70's, which led to the destruction of large forest surfaces particularly in the centre of the country. At that time, wet rice production was also widely developed by the state, with devastating effects on the forests, particularly on mangroves.

The policy of the economical liberalisation supported by the International Monetary Fund and the World Bank in the 80's led to increasing logging activities, which led to the disappearance of whole forest surfaces in the North and Northeast. This liberalisation politics led also to wild speculations with the land property and thus to the destruction of large forest surfaces. Actually the cultivation of cashew and other cash fruits for export is being strongly promoted, not only at the expense of forest surfaces, but also of surfaces which were used for the food production. With the reduction of the forest surfaces and the depletion of the soils, the extent of the shifting cultivation and bush fire increased, causing again the intensified destruction of the forests.

Since the last wildlife census by Limoges and Robillard (1989/90), no further countrywide survey or monitoring measures of large mammals took place, despite the obvious reduction of many species. It was often referred to the need for updating the knowledge in this area (Said \& Maretti 1993, Oates 1996, da Silva 1997, Robertson 2001). It is yet generally recognised that the lack of reliable data on the status and the evolution trends of wildlife populations is an obstacle for their effective management (Mac Kinnon et al.1986, Rabinowitz 1993). These background data form the basis for a responsible evaluation of the sustainability and management of this important resource. It is thus necessary to develop and to implement monitoring programs for faunal populations, in order to reduce this knowledge gap.

Until today, the experience has shown that many development and conservation projects failed because they did not involve (or some of them even excluded) the local population in the appropriate way (Murphree 1994, Strum 1994). For the development and implementation of long-term wildlife management programmes, the active collaboration of the real managers of these resources, i.e. the local population and institutions, is of highest importance, if this is to be a long lasting process (Mühlenberg 
et al. 1995, Olsen et al. 2001). Their knowledge of existing resources and its use must be consequently valued and their interests must be taken into consideration.

Today, there is a shift from the classical protection vision to a vision which integrates more human needs and activities. If decisions are to be made over the use of natural resources which are important for the daily life of the population, last should take part to the entire process, i.e. from the analysis of existing resources and problems up to the formulation of concrete strategies and the implementation and evaluation of the impact of those measures. A growing number of conservation initiatives are seeking to involve actively and empower local communities, in order to conserve wildlife, and to mobilise wildlife resources for their own benefit (Kiss 1990, Western 2001).

Community-based wildlife management initiatives have been implemented in a number of African countries, with variable success, and they are generally considered to represents an advance over past practices that ignored rural people (Little 1994). Since most biodiversity is found outside parks and reserves, conservation efforts must also focus on these areas, which are under some form of ownership; and this means that local communities must participate in conservation effort in a meaningful way; any other approach would be politically unfeasible and unrealistic (Little 1994, Western 2001).

\section{I.3. Research questions}

The following specific research questions arise from the above stated general problem:

1. What is the current conservation status of wildlife in coastal Guinea-Bissau?

2. How are the population trends of large- and medium-sized mammals in the coastal forests of Guinea-Bissau?

3. What are the main threatening factors for mammal populations in coastal Guinea Bissau?

4. Which role do traditional practices and culture play for wildlife conservation?

5. Which are the opportunities, constraints and strategies for the successful implementation of community-based wildlife management in Guinea-Bissau? 


\section{I.4. Aim and Objectives}

The main objective of this research is to assess the current conservation status of primates and other large- and medium-sized mammals in the coastal region Guinea Bissau and to analyse the prospects for the implementation of community-based wildlife management schemes in that country.

Specifically, this study aims at:

- updating the existent information on the occurrence and conservation status of selected wild mammals in the coastal forests of Guinea Bissau;

- assessing the perception of wildlife by selected local communities;

- analysing the specific opportunities and constraints at different levels (biological, legal, institutional, technical, and financial) for the implementation of communitybased wildlife management;

- making recommendations for the local implementation of participatory community-based wildlife monitoring schemes.

\subsection{Outputs and contributions}

This research is the first assessment of the actual status of mammal in the coastal forests of Guinea Bissau since the last survey almost fifteen years ago. This is additionally the first attempt to analyse the conditions for the implementation of community-based wildlife management schemes in Guinea-Bissau, taking into consideration the biological wildlife conservation needs, the social and cultural characteristics and the existing legal and institutional frame.

The obtained results will thus constitute an important working instrument, particularly for decision makers, parks and reserve managers and local communities, in the area of wildlife conservation initiatives and policy and of protected area management.

The results will also offer an important basis for further investigations in the field of wildlife biology and management, in the coastal forests but also in the other regions of the country with a high conservation value, that are not included in this research. 


\section{Current state of research}

\section{II.1. Distribution and Conservation status of large and medium sized mammals in West Africa and Guinea-Bissau}

The first inventories of wild animals in Guinea-Bissau were carried out by the colonial zoological missions (Monard 1938, Frade et al. 1946, Frade 1950), which found the faunal diversity of Guinea-Bissau to have more affinities with that of the southern neighbour Republic of Guinea than with the fauna of Senegal (Monard 1938, Frade 1949). The most recent nation-wide wildlife survey in that country was implemented between 1989 and 1991 (Limoges 1989, Limoges \& Robillard 1991). A study was carried out on wild mammal species by Reiner and Simðes in the year 1991, whose results were published in 1999. Other studies have focused on determined regions, i.e. on the Cufada region (Crawford Cabral 1990, 1997), on the Dulombi area (Thibault 1993) and on the south-eastern trans-boundary region (Silva 2002). Others have been restricted to determined species, i.e. manatees (Almeida e Silva 1998), birds (Araujo 1994), on herpetofauna (Boesl 1995), or marine turtles (Fortes et al. 1998).

\section{II.1.1. Primates}

Eleven regional communities of African primates are distinguished in Africa (Oates 1996b). Six of these are located within the low land forest region and five outside of this region, but with marked endemism in their primate fauna at the specific or sub-specific level (Oates 1996b). In West Africa, Upper Guinea and the Casamance and Fouta Djalon region constitute the most important primate communities.

Upper Guinea's Western subregion supports a number of endemic primate species: $C$. polykomos, $C$. atys atys, C. diana diana, C. nictitans stampfilii, C. petaurista buettikoferi, C. campbelli campbelli and $P$. badius badius.

Most of these primate species endemic to western Upper Guinea are known to be present in Guinea-Bissau, where 11 species were definitively proven to occur (Oates, 1996b) and within its coastal zone (Table1). Of theses 11 species, seven are integrally protected at the national level: $P$. Troglodytes verus, $P$. badius temminckii, $C$. polykomos polykomos, the lesser white nosed monkey $C$. petaurista buettikoferi, the 
greater spot-nosed monkey $C$. nictitans stampfilii, the sooty mangabey $C$. atys atys, and the Senegal galago G. senegalensis.

The remaining four species are partially protected: the Campbell's monkey C. campbelli, the Callithrix monkey $C$. aethiops sabaeus, the Pata monkey $E$. patas patas and the Guinea Baboon P. papio papio. Chimpanzee, the two colobus species, sooty mangabey and baboons are since 2004 also included in the Red List of threatened species of Guinea-Bissau (MAFCP/DGFC 2004).

Limoges (1989) mentioned C. nictitans stampfilii as occurring in the region of Cufada. However, there seems to be some confusion between this species and C. petaurista (see below). Occurrence of two forest species of prosimians, the Dwarf Galago G. demidovii and the Potto Perodicticus potto in Guinea-Bissau is mentioned in the literature (Robillard 1989, Kingdon 1997, Stuart \& Stuart 1997), but the presence of these two species have not been definitively proved (Oates 1996b, Gippoliti \& Dell'Omo 1996).

According to the IUCN Primate Conservation Action Plan (Oates 1996b), P. troglodytes verus and $P$. badius temminckii are considered the taxa of conservation concern in Guinea-Bissau, mainly due to the rapid reduction of remaining closed-canopy forests. The same action plan recommended primate populations surveys and the development of reserves to protect these endangered species.

\section{II.1.1.1. Chimpanzee Pan troglodytes verus (Schwarz, 1934)}

Four subspecies of chimpanzee are recognised to occur in Africa: the eastern form $P$. $t$. schweinfurthi between Tanzania and Zaire, the central form P. t. troglodytes between Zaire and Nigeria, the Nigerian form P. t. vellerosus restricted to Nigeria and Cameroon, and the western form $P$. t. verus between Nigeria and Senegal. The two western forms are the most threatened subspecies; $P$. $t$. verus sub-populations have become small and highly fragmented and their number may not exceed 12.000 (Bowen-Jones 1998). The main threat factors to this species are habitat loss, hunting for food and biomedical trade. Western Chimpanzees are categorised as endangered (EN A3cd) by the IUCN (2003) and are listed in the appendix I of the CITES. 
Table1. Primate species occurring in Guinea-Bissau

\begin{tabular}{|c|c|c|c|c|c|}
\hline Family & Scientific name & English name & $\begin{array}{l}\text { "Crioulo"l or } \\
\text { Portuguese name }\end{array}$ & \begin{tabular}{|l|} 
Status Guinea- \\
Bissau a)
\end{tabular} & $\begin{array}{l}\text { Cites/African convention / } \\
\text { IUCN Redlist } 2003\end{array}$ \\
\hline Hominidae & P. troglodytes verus & Western Chimpanzee & "Dari"/Chimpanzee & Rare/IP & $\begin{array}{l}\text { - Cites I, } \\
\text { - Afric. conv. B } \\
\text { - Endangered EN A3cd }\end{array}$ \\
\hline Colobidae & C. p. polykomos & $\begin{array}{l}\text { Western pied colobus/ } \\
\text { Black-and- white } \\
\text { Colobus }\end{array}$ & $\begin{array}{l}\text { "Fidalgo"/ Macaco } \\
\text { fidalgo preto }\end{array}$ & Rare/IP & $\begin{array}{l}\text { - Cites II, } \\
\text { - Afric. conv. B } \\
\text { - LR/nt }\end{array}$ \\
\hline \multirow[t]{6}{*}{ Cercopithecidae } & C. campbelli & Campbell monkey & $\begin{array}{l}\text { "Canculma"/ Macaco } \\
\text { mona }\end{array}$ & Common/PP & $\begin{array}{l}\text { - Cites II } \\
\text { - Afric. conv. B } \\
\text { - LR/lc }\end{array}$ \\
\hline & $\begin{array}{l}\text { C. petaurista } \\
\text { buettikoferi }\end{array}$ & $\begin{array}{l}\text { Lesser putty-nosed } \\
\text { monkey }\end{array}$ & $\begin{array}{l}\text { "Nariz branco", } \\
\text { "santcho bijagó"/ } \\
\text { Petaurista menor }\end{array}$ & Rare/IP & $\begin{array}{l}\text { - Cites II } \\
\text { - Afric. conv. B } \\
\text { - LR/lc }\end{array}$ \\
\hline & $\begin{array}{l}\text { C. aethiops } \\
\text { sabaeus }\end{array}$ & Vervet, grivet monkey & $\begin{array}{l}\text { "Santcho preto", } \\
\text { "santcho de tarrafe"/ } \\
\text { Macaco verde) }\end{array}$ & Common/PP & $\begin{array}{l}\text { - Cites II } \\
\text { - Afric. conv. B } \\
\text { - LR/lc }\end{array}$ \\
\hline & Papio papio & Guinea Baboon & $\begin{array}{l}\text { "Cão"/ Babuino da } \\
\text { Guiné }\end{array}$ & Common/PP & $\begin{array}{l}\text { - Cites II } \\
\text { - Afric. conv. B } \\
\text { - LR/nt }\end{array}$ \\
\hline & $\begin{array}{l}\text { C. nictitans } \\
\text { stampfilii }\end{array}$ & Putty nosed Monkey & "Nariz branco" & $\begin{array}{l}\text { Rare (existent?) } \\
\text { / IP }\end{array}$ & $\begin{array}{l}\text { - Cites II, } \\
\text { - Afric. conv. B } \\
\text { - LR/lc }\end{array}$ \\
\hline & C. atys atys & Sooty Mangabey & Macaco cinzento & Extinct???/IP & $\begin{array}{l}\text { - Cites II, } \\
\text { - Afr. Conv. B } \\
\text { - LR/nt }\end{array}$ \\
\hline Galagonidae & G. senegalensis & Senegal galago & "Concanhe"/ Chinchila & Abundant/PP & - Cites II \\
\hline
\end{tabular}

a) Limoges 1989 and MAFCP/DGFC 2004; IP: integrally protected; PP: partially protected, Afric. conv.: African Convention on the Conservation of Nature and Natural Resources. 
Chimpanzees of Guinea-Bissau are present in the southern part of the country, in the south-eastern sector of Boé and in the Quinara and Tombali southern regions (Limoges 1989, Thibault 1993, Gippoliti \& Dell'Omo 1995). They occupy savannahforest mosaics, secondary and gallery forests (Limoges 1989, Crawford Cabral 1990, Thibault 1993, Gippoliti \& Dell'Omo 1995, 1996). They build their nests principally in oil palm trees Elaeis guineensis, but also in other tree species (Gippoliti \& Dell'Omo 1995, 1996, Crawford Cabral \& Verissimo 1997). Barnett \& Prangley (1994) have also observed such nesting behaviour by Chimpanzees in the neighbouring Guinea. Although a review of chimpanzee nesting behaviour by Baldwin et al. (1981) does not mention this form of nest building, it is possible that this behaviour is restricted to those marginal chimpanzee populations in West Africa as, so far, all records of this behaviour are from populations living in forest-savannah mosaic and not lowland forest with continuous canopy cover (Barnett \& Prangley 1994).

Chimpanzees are recognised to be rare in Guinea-Bissau, but they are considered as not endangered in this country by some authors (Limoges 1989, Thibault 1993, Gippoliti \& Dell'Omo 1995). However, in spite of the fact that chimpanzees do benefit from local existing consumption taboos (Robillard 1989) due to their strong similarity to humans, they are threatened, mainly by habitat loss due to deforestation for timber extraction and for agriculture (Gippoliti \& Dell'Omo 1995, da Silva Naga \& Sera 2001). The population size of this species has never been estimated in any area within the country. Gippoliti et al. (2003) suggest however, that $600-1000$ chimpanzees may still live in Guinea-Bissau. This species is actually listed as integrally protected in Guinea-Bissau (MAFCP/DGFC 2004).

\section{II.1.1.2. Colobus Monkeys}

\section{Western Red Colobus P. badius temminckii (Kuhl, 1820)}

One red colobus species is known in West Africa (Procolobus badius), with three subspecies: Procolobus badius temminckii in Senegal, the Gambia, Guinea-Bissau and North-western Guinea, Procolobus badius badius in Sierra Leone, Liberia, Guinea and Ivory Coast and Procolobus badius waldroni in Ghana and Eastern Ivory Coast (Kingdon 1997). 
Red Colobus have suffered heavily from bush meat hunting and habitat loss. The subspecies $P$. b. waldroni is extinct or close to extinction and is listed as critically endangered and the subspecies badius and temminckii are endangered (IUCN 2003, see Table1). All subspecies are listed in the Appendix I of CITES.

In Guinea-Bissau, Procolobus badius temminckii is present only in the south, the south-west and in parts of the north of the country and in areas with still intact forests and gallery forests (Limoges 1989, Gippoliti \& Dell'Omo 1996). Groups of 25-30 (Gippoliti \& Dell'Omo 1996) and up to 35 individuals (Limoges 1989) can be observed, often in association with western pied colobus (Gippoliti \& Dell'Omo 1996, Crawford Cabral 1997). The distribution area and abundance of this species has strongly diminished in comparison to the situation 50 to 60 years ago, due to the destruction of its habitat (Limoges 1989); this species was recently included in the list of integrally protected species and in the national Red List of Guinea-Bissau (MAFCP/DGFC 2004).

\section{Western pied colobus C. polykomos polykomos (Zimmermann, 1780)}

Three subspecies are recognised in West Africa: C. p. polykomos is distributed from the R. Sassandra westwards to Guinea-Bissau; C. p. dollmani occurs from East of R. Sassandra to the R. Bandama in Côte d'Ivoire and is considered by some authors to be a hybrid with $C$. vellerosus (Oates 1994). Western pied colobus were until recently a quite common and widespread species. The total range is considered to be still extensive, but habitat loss and hunting have confined the remaining animals to decreasing scattered vestigial populations (Kingdon 1997). However, the species is listed as of low risk and near threatened (IUCN 2003), but it is classified in the Appendix II of the Cites.

In Guinea-Bissau, white and black colobus occur in the extreme southern forest zone of the country (Limoges 1989, Gippoliti \& Dell'Omo 1996) and in the southern region of Xitole near the River Corubal and the Cufada Natural Park (Monard 1938, Frade \& Silva 1980, Limoges 1989). They are often seen in association with red colobus (Gippoliti \& Dell'Omo 1996, Crawford Cabral 1997). Western pied colobus are rare in Guinea-Bissau; they are integrally protected and are listed in the national Red List of threatened animals (MAFCP/DGFC 2004). 


\section{II.1.1.3. Guenons}

\section{Campbell's monkey C. campbelli (Waterhouse, 1838)}

Campbell's monkeys form a part of the Cercopithecus mona super species, together with the species pogonias and mona. Two subspecies of Campbell's monkey are recognised : C. c. campbelli which occurs west of the Cavally river, from South of Senegal to the East of Liberia and C.c. lowei east of the Sassandra Nzo, from the R. Cavally to the East of Ghana (Oates 1994, Haltenorth \& Diller 1985). Although range and numbers have greatly decreased, this species is considered to be still widespread and is listed as not endangered (IUCN 2003) but is classified in the appendix II of the Cites.

Observations of Campbell's monkeys have been made in Guinea-Bissau mostly in the north-eastern and southern regions of the country's continental part, where forests and mangroves are still present. Campbell's monkeys are not present in the northern and eastern savannah regions (Limoges 1989). The presence of this species was also reported by local residents on one island (Caravela) in the Bijagós Archipelago (Limoges \& Robillard 1991), but up today this could not be confirmed by field observations. Campbell's monkeys were considered by some authors as one of the most common primate species of Guinea-Bissau (Limoges 1989, Gippoliti \& Dell'Omo 1996). However, due to evidence of decline in this species' population, they were recently officially listed as partially protected (MAFCP/DGFC 2004).

\section{Lesser white-nosed monkey C. petaurista buettikoferi (Schreber, 1774)}

C. petaurista is a member of a super species, the cephus group, which also includes C. erythrogaster, C. erythrotis, C. cephus and C. ascanius (Oates 1988). Two subspecies are recognised: C. p. petaurista and C. p. buettikoferi, with latter occurring in the western Upper Guinea. Lesser white-nosed monkeys have their western distribution limit in Guinea-Bissau (Monard 1938, Frade, 1949, Haltenorth \& Diller 1985) and the eastern limit in Benin (Oates 1988). They are considered to be still common and widespread in West Africa and are internationally listed as of lower risk and least concern (Table1) (IUCN 2003).

In Guinea-Bissau, this species is observed in the southern Corubal region (Frade et al. 1946, Frade 1949; Crawford Cabral 1997) and in the Bijagós Archipelago, 
especially on the islands of Bubaque, Rubane, Galinhas, Canhabaque, Uno, Uracane, Caravela and Eguba (Monard 1938, Frade 1949, Limoges \& Robillard 1991). No records were made in the sub-humid forests of Cantanhez (Limoges 1989, Gippoliti \& Dell'Omo 1996). This species is legally protected for being considered to be rare in Guinea-Bissau (MDRA/DGFC 1988, MAFCP/DGFC 2004).

\section{Stampf's Greater putty-nosed monkey C. nictitans stampfilii (Linnaeus, 1766)}

Putty-nosed monkeys are members of the nictitans super species, together with the gentle monkey C. mitis (Kingdon 1997). Three subspecies are recognised: $C$. $n$. nictitans, C. n. martini and C. n. stampfilii (Oates 1988); however discussions on the taxonomy of this species are still on going. Putty-nosed monkeys are the largest of the African forest guenons. Their main distribution range is considered to be located in Western Central Africa, with C. $n$. nictitans and C. n. martini being present in that region, whereas $C$. $n$. stampfilii is endemic to the Upper Guinea region (Haltenorth \& Diller 1985, Oates 1996b). The SSC Primate Specialist Group taxonomic discussions left the taxonomic position of this monkey unresolved; it may be a subspecies, but the Western Greater Spot-nosed Monkeys as a whole require further research. The sub-species $C$. $n$. stampfilii is very rare in West Africa, and is listed as Critically Endangered by the IUCN, because of its very patchy distribution in an area of heavy hunting pressure (IUCN 2000).

The presence of this species in Guinea-Bissau was mentioned on the basis of field observations in the Cufada region (Limoges 1989) and in the Corubal area (Chardonnet 1983), and also of verbal records from the same region (Crawford Cabral 1997). However, the fact that the same local name ("Nariz branco" in Crioulo, i.e. white nose) is used for both this species and the lesser spot-nosed monkey (Limoges 1989, Limoges \& Robillard 1991) contributes to some confusion. Moreover, the same authors also used for this species, the same local name ("Macaco Bijagós", i.e. the Bijagós monkey) that is given to the lesser putty-nosed monkey, which is known to occur in the Bolama-Bijagós archipelago (see also Limoges and Robillard 1991, Crawford Cabral 1999). For "the occurrence of this species being considered doubtful in Guinea-Bissau, in particular possibly due to recent extinction" (MAFCP/DGFC 2004), Stampf's greater putty-nosed monkey was included in the new approved list of integrally protected species. 


\section{Callithrix monkey C. aethiops sabaeus (Linnaeus, 1766)}

Callithrix monkeys are one of five members of the savannah monkey super species known in Africa, C. aethiops (Kingdon 1997). This group includes Vervet monkey $C$. (a.) pygerythrus, grivet monkey C. (a.) aethiops, Bale monkey C. (a.) djamdjamensis, Tantalus monkey $C$. (a.) tantalus and Callithrix monkey $C$. (a.) sabaeus. These monkeys are considered to be the most widespread and numerous monkeys in Africa, ranging throughout the non-desert and non-forest areas of the continent (Kingdon 1997, Stuart \& Stuart 1997). C. (a.) aethiops and C. (a.) djamdjamensis are limited to North - East Africa, while C. (a.) pygerythrus occur in most of southern savannahs and woodlands. C. (a.) tantalus and $C$. (a.) sabaeus are distributed in the northern savannahs, with former occurring from Ghana to Uganda and latter from Senegal to Ghana. Savannah monkeys inhabit savannahs, woodlands and forestgrassland mosaics, more typically on tree/grassland edges along drainage lines (Haltenorth \& Diller 1985, Kingdon 1997, Chapman et al. 1999). Callithrix monkeys are also known to frequent mangrove forests (Galat \& Galat-Luong 1977). This species group is considered to be at low risk, but the sub-species $C$. (a.) djamdjamensis is classified as data deficient (DD) by the IUCN (2000).

In Guinea-Bissau, Callithrix monkeys still occur almost throughout the whole country (Limoges 1989) and also on some islands of the Bijagós Archipelago with extensive mangrove areas, such as Formosa, Orango, Bubaque, Rubane, Enu and Carache (Limoges \& Robillard 1991). This species is considered to be common and one of the principal crop raiders (Limoges 1989). Callithrix monkeys are listed in the Appendix II of Cites, and since 2004 they are also partially protected by law in Guinea-Bissau (MAFCP/DGFC 2004).

\section{Patas Monkey C.(E.) patas patas (Schreber, 1775)}

Patas monkeys are distributed in open, wooded steppes and savannahs south of the Sahara. Up to 4 subspecies are referred to (Kingdon 1997): E. (p.) baumstarki, E. (p.) pyrrhonotus, E. (p.) villiersi, and E. (p.) patas. Only latter occurs in West Africa, mainly in the Sahel region from Mauritania to Western Ethiopia. Patas monkeys are not listed as endangered by the IUCN, but like other primates, they are classified in the Appendix II of the Cites and are also protected by the African Convention.

In Guinea-Bissau, Patas monkeys are distributed throughout the national territory, excepting the coastal and humid forests in the south (Limoges1989, Gippoliti \& 
Dell'Omo 1996). Reference on their occurrence in the southern forest zone is however made by Alho (1990 cited by Rainer \& Simões 1997). This species was considered to be common and was not protected in that country (MDRA/DGFC 1988) until 2004, as it was listed as partially protected (MAFCP/DGFC 2004).

\section{II.1.1.4. Baboons}

\section{Guinea Baboon P. papio (Desmarest, 1820)}

Five major populations are recognised and treated as species by some authors (Kingdon 1997). Only two species occur in West Africa: P. papio, which is limited to the area between South Mauritania and Sierra Leone and $P$. anubis which is distributed from South Mauritania to the Sudan and southwards to the Democratic Republic of Congo and Tanzania (van Hooff 1988, Kingdon 1993). This two species may be hybridising along the eastern limit of the Guinea Baboon (Kingdon 1997), which also includes parts of Guinea-Bissau. Guinea Baboons are listed as at low risk and near threatened (IUCN 2003)

Guinea Baboons occur in most of Guinea-Bissau's territory, excluding the northwestern part (Cacheu region) and the Bijagós-archipelago. This species is more abundant in the eastern part of the country, where it is the commonest primate species and benefits from consumption taboos from the local mostly Islamic population (Limoges 1989). Baboons are however considered to be the most devastating species and are killed when raiding crops. This species has been subject to increasing commercial hunting, leading to evident population decline (Crawford Cabral 1997). In the year 2004, it was included in the new list of partially protected animals in Guinea-Bissau (MAFCP/DGFC 2004).

\section{II.1.1.5. Mangabeys}

\section{Sooty Mangabey C. atys atys (Audebert, 1797)}

Sooty mangabey is the only species belonging to the group of Drill mangabeys Cercocebus, which is restricted to Upper Guinea. The other species are distributed in Western Central Africa (C. torquatus), in the Congo Basin (C. agilis, C. chrysogaster) and in very limited areas of East Africa (C. galeritus, $C$. sanjel). Two sub-species are distinguished (Kingdon 1997): C. a. atys west of the R. Sassandra, from Liberia to 
Senegal (Struhsaker 1971) and C. a. lunulatus between R. Sassandra and R. Volta. Both subspecies are listed as at lower risk and near threatened (IUCN 2003) but are protected by the African convention and are listed in the Appendix II of Cites.

The first and up to now unique mention of this species in Guinea-Bissau was made by Frade et al. (1946), who obtained a specimen in Gadamael, in the southern Cantanhez forest zone. This species was observed neither during the faunal survey by Limoges (1989) nor during the primate survey by Gippoliti \& Dell'Omo (1996). Limoges (1989) recommended considering this species as extinct, until its presence has not been confirmed by new studies. As for the greater spot-nosed monkey, the presence of Sooty mangabey is considered doubtful in Guinea-Bissau, possibly due to recent extinction, and for this reason the species is listed as integrally protected in Guinea-Bissau (MAFCP/DGFC 2004).

\section{II.1.1.6. Prosimians}

\section{Senegal Galago G. senegalensis (E. Geoffroy, 1796)}

Galagos are nocturnal, arboreal and inconspicuous prosimians belonging to the family of Lorisidae. Greater Galagos (Otolemur), Needle-clawed Galagos (Euoticus), Squirrel Galagos (Galago), Lesser Galagos (Galago) and Dwarf Galagos (Galagoides) form this group (Kingdon 1997). Only the lesser Galago and the Dwarf Galago are known to occur in West Africa.

Four lesser Galago sub-species are known (Kingdon 1997): the Senegal Galago (Galago senegalensis), the South-African Galago (G. moholi), the Somali Galago ( $G$. gallarum) and the only forest-dwelling Spectacled Galago (G. matschiei). The Senegal Galago is the commonest and most widespread of the bush babies (Estes 1991): it is distributed from Senegal to Ethiopia and Tanzania in the East. Different races are recognised, with $G$. s. senegalensis occurring in West Africa. Senegal Galagos are widespread and common. They are considered as not endangered. Although this species is observed in rare occasions, there is evidence of occurrence of lesser Galago in Guinea-Bissau (Limoges 1989), where this species is listed as integrally protected (MDRA/DGFC 1988, MAFCP/DGFC 2004). 


\section{II.1.2. Ungulates}

About 23 even-toed ungulates from 4 families are known to occur in Guinea-Bissau (UNEP-WCMC 2004); the family of Bovidae is the most important with 18 species.

\section{II.1.2.1. Hippopotamuses}

Two species of hippopotamus occur in West Africa: the common hippopotamus $H$. amphibius and pigmy hippopotamus $H$. (C.) liberiensis.

\section{Common hippopotamus $\boldsymbol{H}$. amphibius (Linnaeus, 1758)}

Despite their overall range, hippopotami are very vulnerable to hunting and suffer continuing local extinction (Kingdon 1997). The species appears to be most at risk in West Africa through low numbers in small, scattered populations, most of which are showing declines; it is also there that enforcement of legislation is least observed (Eltringham 1993). Many of the groups in West Africa include less than 50 animals each, which is below the minimum considered viable (Eltringham 1993). This species was classified as Vulnerable in the IUCN Redlist 2000, but was recently listed as at low risk and least concern (IUCN 2003). Hippopotami are vulnerable because of their specialised ecology, which renders this species incapable of adapting to certain potential changes in its environment, such as the drying up of water courses or loss of feeding grounds (Eltringham 1993). According to the same author, populations in the West - Guinea, Guinea-Bissau and Senegal - probably contain the bulk of the West African hippopotamus with total numbers likely to be in the region of a few thousand.

Although small in area, Guinea-Bissau supports a substantial population, which is particularly abundant on the islands of the Bijagós Archipelago and along the numerous inland rivers (Limoges 1989, Limoges \& Robillard 1991; Eltringham 1993). Several groups are observed in the coastal inshore and around several islands of the Bijagós Archipelago. There may be large groups of about 20-50 individuals in the NW islands group of Caravela - Carache - Porco and an estimated population of about 100-200 in the Orango NP (Limoges 1989, Limoges \& Robillard 1991). The species is abundant in the R. Corubal (Araujo Ferreira 1948, Limoges 1989, Crawford Cabral 1997) but has disappeared in the R. Cacine (Limoges 1989), where it was formerly abundant and has given its name to one of the affluents of this river, the Rio Meldabom (which means hippopotamus in the Sosso dialect) (Tiniguena 1997). 
Hippopotami are known to raid crops, especially rice fields; this has led to conflicts with local human populations within their range (Limoges 1989, Robillard 1989, Limoges \& Robillard 1991). Until recently this species could be hunted with a professional license (Decreto 21/80), but in 2004, it was listed as integrally protected (MAFCP/DGFC 2004).

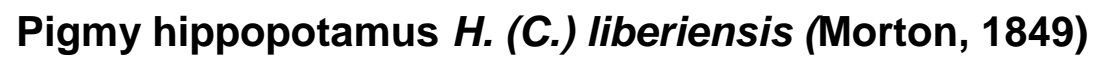

A single species of pigmy hippopotamus occurs in Africa into two separate populations: H. I. liberiensis is restricted to the forests between the Rio Corubal in Guinea-Bissau and the Rio Bandama in Côte-d'Ivoire and H. I. heslopi between the Rio Cross and the Rio Niger deltas (Kingdon 1997). Throughout its range, the species is present at low densities and is probably decreasing in numbers except in Guinea where the population was considered to be almost stable (Eltringham 1993). According to this author, the greatest numbers of this species are believed to occur in Liberia. The pygmy hippopotamus is increasingly fragmented as a result of habitat loss and hunting, and is classified as vulnerable (IUCN 2003).

A population of $\mathrm{H}$. liberiensis has been reported from the Corubal River in GuineaBissau (Cristino 1958, IUCN 1992b, UNEP-WCMC 2004), but its occurrence there is considered to be doubtful by some authors (Stuart \& Stuart 1997, Eltringham 1993) No mention of this species was made in none of the wildlife surveys in the last years (Limoges 1989, Crawford Cabral 1990, Crawford Cabral \& Verissimo 1997, Rainer \& Simões 1997). Since the presence of this species in Guinea-Bissau is still to be proved and a recent extinction can not be excluded, this species is officially listed as integrally protected as a precautionary measure (MDRA/DGFC 1988, MAFCP/DGFC 2004).

\section{II.1.2.2. Suids - Pigs and Hogs}

Two wild pig species are generally recognised to occur in Guinea-Bissau (Monard 1938, Araujo Ferreira 1948, Chardonnet 1983, Limoges 1989, Crawford Cabral 1990, Vercammen and Mason 1993, Crawford Cabral \& Verissimo 1997). A third species, the Giant forest hog, has been often referred to by local population in the Cufada region (Crawford Cabral \& Verissimo 1997) but its presence has not yet been confirmed by visual observations. However this species does occur in the 
neighbouring Guinea (Ziegler et al. 2002) and its presence in Guinea-Bissau needs to be assessed accurately.

\section{Common warthog $P$. africanus (Gmelin, 1788)}

Common warthogs are considered Africa's most frequently observed wild pigs (Stuart \& Stuart 1997). This species is distributed throughout the savannah and semi-arid areas of sub-Saharan Africa, occupying mostly open grass and woodland savannahs (Kingdon 1997). In recent past, this species was considered as endangered (IUCN 2000), but actually it is listed as at low risk and of least concern (IUCN 2003).

Warthogs are abundant in Guinea-Bissau: they are one of the most frequently observed species and are known to cause serious damages to various crops, most notably rice-fields and peanut crops (Chardonnet 1983, Limoges 1989, Robillard 1989). They are distributed throughout the whole country, excepting in the Bijagós archipelago. This species is more frequently observed in areas with high proportion of Moslem population where it is not consumed (Limoges 1989). Warthogs were not protected until 2004 (MDRA/DGFC 1988). They have suffered heavy hunting pressure and evidence of their declining populations has led to their inclusion in the list of partially protected species in Guinea-Bissau (MAFCP/DGFC 2004.

\section{Red river hog Potamochoerus porcus (Linnaeus, 1758)}

Red river hogs occur in most forest habitats throughout the Congolean forest block and in the West African forest areas (Kingdon 1997). They also occupy well-wooded savannah, but are rarely encountered far from substantial cover (Stuart \& Stuart 1997). They are considered still abundant and not endangered, although forest fragmentation has had detrimental effects on them (Stuart \& Stuart 1997). Although habitat destruction is not considered a major threat to the survival of this species at the present time, deforestation coupled with intense hunting pressure has inevitably resulted in marked range contractions in some countries/regions (Vercammen et al. 1993). This species is listed as at low risk (IUCN 2003).

Red river hogs are abundant throughout Guinea-Bissau, excepting in the Bijagós archipelago, the Northwest and the eastern savannahs (Limoges 1989). The species is considered to be less abundant and to cause less damage than warthogs (Limoges 1989). Until recently, red river hogs were not protected by law in Guinea- 
Bissau (MDRA/DGFC 1988), but since 2004, they were included in the list of protected species (MAFCP/DGFC 2004).

\section{Giant forest hog Hylochoerus meinertzhageni (Thomas, 1904)}

Three sub-species are recognised in Africa, with the largest form $H . m$. meinertzhageni occurring in East Africa, H. m. rimator in northern Central Africa and the smallest form H. m. ivoriensis in West Africa. In common with the red river hog, Hylochoerus is more dependent on forest than the other African suids (d'Huart 1993). Giant forests were considered to be vulnerable (IUCN 2000), but since 2003, they are listed as not endangered (IUCN 2003)

The existence of this species in the southern Guinea-Bissau has still to be proved by field observations. According to d'Huart (1993), records from Guinea-Bissau (Ansell 1972 cited by P. Grubb 1993) are not sufficiently detailed to be acceptable. However, this species is observed in the neighbouring Republic of Guinea (Barnett \& Prangley 1997, Ziegler et al. 2002; Brugière \& Magassouba 2003). In that country, giant forest hogs are considered to be widespread and although occurring at low densities, they may be locally abundant (d'Huart 1993). In the year 2004, the species was introduced in the new list of protected species of Guinea-Bissau (MAFCP/DGFC 2004).

\section{II.1.2.3. Bovids - horned ungulates}

\section{African Buffalo Syncerus caffer (Sparrman, 1779)}

According to the African Antelope Database of the IUCN/SSC Antelope Specialist Group (1998), four subspecies of the African buffalo are commonly recognised: the forest dwarf buffalo S. c. nanus, the West African savannah buffalo $S$. $c$. brachyceros, the Central African savannah buffalo S. c. aequinoctialis and the southern savannah or Cape buffalo, S. c. caffer. A further subspecies, S. C. mathewsi, the relict "mountain buffalo" is recognized by some authors (Kingdon, 1997, East 1999).

The most significant threats to African buffaloes are Illegal hunting, loss of suitable habitat and diseases (Stuart \& Stuart 1997) such as Rinderpest, charbon, mouth and foot disease and theileriosis (East, 1999). The 2000 IUCN Red List classifies the 
African savannah buffalo as at lower risk and conservation dependent and the forest buffalo as at lower risk / near threatened. Buffaloes have been eliminated from many parts of their former range; this species is extinct in the Gambia and is decreasing in Senegal and the Republic of Guinea (East 1999).

Buffaloes are rare in Guinea-Bissau but they occur widely in the southern and southeastern parts of the country and in some scattered localities in the North (Limoges 1989). Intermediate forms between the West African savannah buffalo and the forest buffalo are thought to occur in that country (Limoges 1989). A specimen collected by Frade \& Silva (1980) from the southern Buba was identified as the forest subspecies, while Chardonnet (1983) observed the savannah form in Dulombi in the south-east. Also according to Crawford Cabral (1997), specimens which are observed within the Cufada Natural Park seem to be of greater dimensions than those observed in the southern Cantanhez forest region. Despite their rarity, buffaloes were not officially protected in Guinea-Bissau until 2004, as they were listed as partially protected (MAFCP/DGFC 2004).

\section{Antelopes}

Sub-Saharan Africa supports a total of more than 70 antelope species. Although most antelopes still exist in large numbers, up to $75 \%$ of the species present in that region are in decline and about $25 \%$ are threatened or extinct (East 1999). Threats to the survival of antelopes arise fundamentally from the rapid growth of human and livestock populations, and from the consequent degradation of natural habitats and overhunting (East 1999).

Of the 86 key locations which were identified for the conservation of antelope communities in sub-Saharan Africa (East 1999), about 20 are located in West Africa.

\section{Spiral horned Bovines}

Tragelaphines are found throughout sub-Saharan Africa in virtually all kinds of wooded habitats. Four species occur in coastal West Africa: the bushbuck $T$. scriptus, the marshbuck T. spekii, the Derby eland T. derbianus and the Bongo $T$. eurycerus. Tragelaphines are dependent on cover and, excepting the elands, they 
also depend on water (Estes 1991). Of these four species, T. scriptus, T. derbianus and $T$. spekii are known to occur in Guinea-Bissau.

Bushbucks T. scriptus (Pallas, 1766) are considered to be quite common and are listed as at lower risk and of least concern (IUCN 2003). However, their numbers are gradually decreasing as hunting pressure increases in most of their range (East 1999). The West and Central African subspecies, T. s. scriptus (Harnessed bushbuck) was described as abundant and the most widespread mammal species in Guinea-Bissau (Limoges 1989). It occurs in the whole country including the islands of Orango, Imbone, Meneque and Canogo on the Bijagós archipelago (Limoges \& Robillard 1990). In Guinea-Bissau bushbucks are heavily hunted. In the year 2004, this species was introduced in the list of partially protected species (MAFCP/DGFC 2004).

Sitatunga T. spekii (Sclater, 1863) are listed as at lower risk and near threatened by the IUCN (2003), but they are rare or endangered locally. This species is protected by the African convention (Class B) and is listed in the Appendix III of CITES.

In Guinea-Bissau, the western and central African subspecies T. s. gratus is restricted to the mangrove swamps on the northern coast, around the Cacheu River, where it occurs in small numbers (Limoges 1989; East 1999). There are some doubts on mentions of its occurrence in the Corubal basin, in the southern part of the country (Limoges 1989) and which were also made by Menezes Ferreira in the year 1949 (cited by Rainer \& Simões 1997). As in the neighbouring Senegal and Guinea, the population of this rare antelope is decreasing (East 1999). In Guinea-Bissau, Sitatunga are rare and threatened by the destruction of their habitat for agriculture and by hunting (Limoges 1989). They are integrally protected in Guinea-Bissau (MAFCP/DGFC 2004).

The Giant Elands T. derbianus (Gray, 1847) is a highly nomadic species with very large ranges and is very vulnerable to hunting and habitat destruction. Derby's elands are also very susceptible to Rinderpest (Estes 1991, Kingdon 1997). The R. Niger builds the boundary between the western race ( $T . d$. derbianus) and the eastern race ( $T$. d. gigas). Giant Elands are listed as not threatened (lower risk conservation dependent) (IUCN 2003). This species has been virtually exterminated 
over a large part of its range (Kingdon 1997). T. d. derbianus is considered to be extinct in Guinea and in Gambia but still occurs widely and sparsely in the Niokolo Koba National park in southern Senegal, where the only reasonably secure population occurs (Kingdon 1997, East 1999). Total numbers of Western Giant elands are unknown but may not exceed 100-200, with most of the surviving animals in Senegal (East 1999).

In Guinea-Bissau Western Giant elands were thought to be extinct (Limoges 1989) but a specimen was observed in the year 1991 in the southern savannahs of Dulombi by Rainer \& Simões (1997). T. $d$. derbianus however occurs mainly as very rare vagrants, in the eastern and southern savannah woodlands of the country (Chardonnet 1983, East 1999), presumably through wanderers from the northern neighbour Senegal. The population of this rare and officially protected species (MAFCP/DGFC 2004) is considered to decrease in Guinea-Bissau (East 1999) and it does not occur in the coastal regions of the country.

The Western Bongo T. eurycerus (Ogilby, 1837) is considered to be extinct in Guinea-Bissau (Limoges 1989) and is listed as integrally protected (MAFCP/DGFC 2004).

Hippotragines: Horse-like antelopes

\section{Roan antílope Hippotragus equinus (Desmarest, 1804)}

Formerly widespread throughout savannah woodlands and grasslands in SubSaharan Africa, Roan antelopes have decreased in most parts of their initial range (Kingdon 1997). Effective protection and management have led to a stabilisation or improvement of their numbers in some protected areas (East 1999). Their status is considered to be at lower risk and conservation dependent (IUCN 2003). In the Republic of Guinea, observations of Roan antelopes have become increasingly scarce over the last pas 10 years and the migration patterns are disturbed by the numerous human settlements (Brugière \& Magassouba 2003). In Guinea-Bissau, this species has disappeared from more than half of its former range in the north (East 1999). According to Frade et al. (1946), this species was quite widespread in the past in the region around Buba in the South and Pitche in the East. Roan antelopes still occur in small scattered populations in the east and the south, being locally common in areas such as the Corubal River (Limoges 1989, Thibault 1993, East 1999). This 
species is listed in the Appendix II of CITES and is also integrally protected in Guinea-Bissau (Decreto 21/80, DGFC/MDRA 1988, MAFCP/DGFC 2004).

Reduncines, Kobs

The members of this group are distributed in well-watered areas of Africa (Kingdon 1997), with three species representing the genera Reedbucks and Kobs in West Africa: the Bohor Reedbuck R. r. redunca (Pallas, 1767), the Western (Buffon's) Kob K. k. kob and the waterbuck K. ellipsiprynus defassa (Ogilby, 1833). These three species are grazers and water-dependent and they inhabit floodplains, but waterbucks are also found on woodland/ grassland edge (Estes 1991, Kingdon 1997). Reduncines' inability to disperse exacerbates the fluctuations in their numbers, which is provoked by their habitat's instability due to flooding, drought and fires; these seasonal changes lead to short-distance movements that also cause crowding (Kingdon 1997). Although these three species have been eliminated from most of their former range (East 1999), their status is considered to be at lower risk and conservation dependent (IUCN 2003).

Buffon's Kobs $K . \boldsymbol{k}$. kob (Erxleben, 1777) are very susceptible to hunting: they have been eliminated from most of their former range (Kingdon 1997) and are still decreasing in most part of their remaining range (Stuart \& Stuart 1997). They survive now mainly in and around protected areas; the species now extinct in the Gambia and is very rare in the Republic of Guinea it is very rare and localised (East 1999). Habitat destruction for rice cultivation and overhunting have eliminated Buffon's cob from most part of coastal Guinea-Bissau. They were formerly distributed in riverine areas all over the country but they are now restricted to the Cufada area in the southern centre, the north-western Cacheu region and the island of Galinhas in the Bijagós archipelago (Limoges 1989, Limoges \& Robillard 1991). They also occur in the eastern savannahs of Dulombi and Boé (Thibault 1993, Rainer \& Simões 1997). Buffon's kob was not protected by law until recently (Decreto 21/80, MDRA/DGFC 1988); the species was now included in the official list of integrally protected species (MAFCP/DGFC 2004). 
Defassa waterbucks $K$. ellipsiprynus defassa (Ogilby, 1833) shows overall decreasing population trends; this species has been eliminated widely within its former range (East 1999), so in the northern and north-eastern Guinea-Bissau. It has been already exterminated in the neighbouring Gambia and it is now restricted to the south-eastern protected area of Senegal and to a few scattered localities in the Republic of Guinea (East 1999). In Guinea-Bissau, Defassa waterbucks still occur in the southern Cantanhez forest and in the Corubal and Boé savannah region but their numbers are decreasing (Limoges 1989, Thibault 1993). This species was already protected by the previous law on hunting (Decreto 21/80), however recently it was listed as partially protected (MAFCP/DGFC 2004).

Bohor Reedbuck redunca redunca (Pallas, 1767) do survive in overexploited areas (Kingdon 1997), their distribution and numbers however are in gradual decrease due to habitat destruction and overhunting associated to human settlement growth (East 1999). In West Africa, they are now generally increasingly uncommon or rare, but they are considered still to occur in viable populations in some countries such as Mali, Burkina Faso, Senegal and Guinea-Bissau (East 1999). There is commonly some confusion between Buffon's kob and Bohor Reedbuck in GuineaBissau (see also Limoges 1989), where both species do share the same common local name ("Gazela de lala", literally "Grassland gazelle"). However, there is evidence that Bohor Reedbuck was eliminated from most part of its former range (Monard 1938, Ferreira 1973, Frade \& Silva 1980), including the coastal part of the country (Limoges 1989). This partially protected species (MAFCP/DGFC 2004) is mainly distributed in the eastern savannah woodlands, its population being considered as uncommon and decreasing (Thibault 1993, Estes 1999).

Other large antelope species present in Guinea-Bissau

Some other antelope species are known to occur mainly in the eastern and southeastern grasslands savannahs of Guinea-Bissau, where they survive in small numbers. This is the case of the oribi Ourebia ourebi quadriscopa (Zimmermann, 1783) and the western hartebeest Alcelaphus buselaphus major (Pallas, 1766) (Limoges 1989, Thibault 1993). Formerly widely distributed (Monard 1938, Menezes Ferreira 1946, Araujo Ferreira 1973, Frade \& Silva 1980 and Alho 1990), these two 
species are decreasing and don't occur in the coastal part of the country. Like in the neighbouring Senegal, Gambia and Republic of Guinea, they have been also eliminated from most part of their range (East 1999) and are officially protected (MAFCP/DGFC 2004).

Red-fronted antelope Gazela rufifrons (Gray, 1846) and Damaliscus lunatus korrigum (Burchell, 1823) are listed as occurring in Guinea-Bissau by UNEPWCMC (2004), but not in the African antelope Database (East 1999). These two species were neither observed during the more recent nation wide mammal survey (Limoges 1989), nor registered in the south-eastern woodland savannah of Dulombi (Thibault 1993). The Korrigum was formerly wide distributed in the flood lands and other grasslands but it has disappeared from great part of its range. This species died out in Gambia and Senegal already at the beginning of the $20^{\text {th }}$ century (East 1999). The red-fronted gazelle also formerly occurred widely throughout dry grasslands and Sahelian bushlands, but they have been reduced to scattered remnant populations all over their range, so in Senegal, due to overhunting, habitat destruction caused by overgrazing and severe drought (East 1999).

Tragulids, Chevrotains

\section{Water chevrotains Hyemoschus aquaticus (Ogilby, 1841)}

This species suffers intensive hunting and is susceptible to disturbance. Its distribution range has contracted significantly and water chevrotains have become rare in many parts of their range (Kingdon 1997, East 1999). The status of the Water Chevrotain is not well known on a national basis across its extensive range. There is some evidence that it is declining in specific areas, but first-hand information is scarce. Water chevrotains populations are generally in decline and if present trends continue, this species will eventually disappear outside a few protected forests (East 1999). There is also no information on past distribution and the species is listed as data deficient (IUCN 2003).

There are actually no data on occurrence of water chevrotains in Guinea-Bissau, nor in the neighbouring Senegal and Gambia (East 1999). This species however occurs in the southern neighbouring Republic of Guinea (Bruguières \& Magassouba 2002). As for other species, whose presence in Guinea-Bissau is not clearly proved, water 
chevrotains are officially listed as integrally protected, as a precautionary measure (MAFCP/DGFC 2004).

\section{Duikers}

About 17 forest duikers and one bush duiker species are known to occur in Africa, the majority of them being found in the Equatorial rain forest, more specifically along the Gulf of Guinea. Among them, eight forest duikers and the bush duiker species are found in Upper Guinea, the former occupying different forest habitats (Estes 1991, Kingdon 1997). Four forest duiker species and the bush duiker are known to be present in Guinea-Bissau (Table2).

Table2. Duiker species of Guinea-Bissau

\begin{tabular}{|l|l|l|l|}
\hline & Species & $\begin{array}{l}\text { Conservation status IUCN } \\
\text { Redlist/ Cites }\end{array}$ & Range \\
\hline Blue duikers & $\begin{array}{l}\text { C. } \\
\text { maxwellii }\end{array}$ & $\begin{array}{l}\text { - Lower Risk - near threatened } \\
\text { (LR/nt) }\end{array}$ & Senegal to Nigeria \\
\hline Red duikers & C. rufilatus & $\begin{array}{l}\text { - Lower Risk - conservation } \\
\text { dependent (LR/cd) }\end{array}$ & $\begin{array}{l}\text { Senegal to NW } \\
\text { Uganda }\end{array}$ \\
\hline Fibre duikers & C. dorsalis & $\begin{array}{l}\text { - Lower Risk - near threatened } \\
\text { (LR/nt) } \\
\text { - CITES II }\end{array}$ & $\begin{array}{l}\text { Senegal to Lake } \\
\text { Tanganyika }\end{array}$ \\
\hline Giant duikers & $\begin{array}{l}\text { C. } \\
\text { silvicultor }\end{array}$ & $\begin{array}{l}\text { - Lower Risk - near threatened } \\
\text { (LR/nt) } \\
\text { - CITES II }\end{array}$ & $\begin{array}{l}\text { Senegal to SW } \\
\text { Sudan and to W } \\
\text { Kenya }\end{array}$ \\
\hline Grey duikers & S. grimmia & $\begin{array}{l}\text { - Lower Risk - least concern } \\
\text { (LR/lc) }\end{array}$ & $\begin{array}{l}\text { Savannahs and } \\
\text { Woodlands of sub } \\
\text { - Saharan Africa }\end{array}$ \\
\hline
\end{tabular}

The small Blue duikers present the most conservative traits of this genus and are widely distributed. C. maxwellii is included in this group together with its equatorial counterpart C. monticola. C. maxwellii has a discontinuous distribution between Senegal and Nigeria, mostly in rainforest galleries and remnants and in moist tree savannahs. Despite of heavy hunting pressure all over their range, Maxwell duikers show a potential higher population density than most duikers (Bakarr et al 2001). Although this species is still widespread and is not considered to be threatened, its 
population is being strongly affected by the combination of overhunting and severe habitat reduction. Maxwell's duikers occur throughout the country, excepting in the drier north-eastern savannahs and they are also present on some islands of the Bijagós archipelago (Canhabaque, Caravela) (Limoges 1989). This species is included in the national red list of Guinea-Bissau and is partially protected.

Red duikers form a more generalised and diverse group which occupy marginal forest areas (Kingdon 1997). C. rufllatus, C. zebra and C. niger belong to this group.

Red-flanked duikers $C$. rufilatus (Gray, 1846) live in forest relicts and riverine thickets within the savannah. In presence of suitable habitat, they are known to be more resilient to heavy hunting pressure than many other duiker species and still show a broad range (Kingdon 1997). Their status outside of protected areas is continuously degrading due to habitat destruction and overhunting, but they are still listed as at low risk and conservation dependent (IUCN 2003). C. rufilatus is considered to have a wide range in Guinea-Bissau (Chardonnet 1983, Limoges 1989). Its population is however declining and the species is partially protected (MAFCP/DGFC 2004).

Fibre duikers are more confined to primary rainforests, where they rely on hard, fibrous fruits. These high forest specialists group include the Olgiby's duiker $C$. olgibyi, the Jentink's duiker $C$. jentinki and the Bay duiker $C$. dorsalis.

Bay duikers $C$. dorsalis (Gray, 1846) are considered as the most widespread species of this group, occurring in the entire equatorial lowland forest block from Senegal to L. Tanganyika (Kingdon 1997). However, they are already rare in most areas other than within protected areas, as a consequence of heavy hunting pressure and forest destruction (Bakarr et al. 2001). C. dorsalis' presence in GuineaBissau was first documented in 1983 by Chardonnet. This species occurs in small numbers within forest patches all over the country (Limoges 1989). As all duikers, also this species has been suffering from increasing hunting pressure and habitat destruction in the last years, which has lead to evident population declines. Bay duikers are considered to be threatened and are integrally protected in GuineaBissau (MAFCP/DGFC 2004). 
Giant duikers have more flexible diet and habitat requirements, occurring in rainforests and forest-savannah mosaic areas.

The Yellow-backed duiker C. silvicultor (Afzelius, 1815) is a member of this group. This species' population is declining and it has become rare in some countries (Bakarr et al. 2001). However, it is classified as at low risk and near threatened (IUCN 2003). In Guinea-Bissau, C. silvicultor is restricted to some existing forest areas, mainly in the southern part of the country. Already in 1946, this species was considered to be rare (Frade 1946), but it is meant to be quite common in its area of occurrence (Limoges 1989).

The Grey duiker Silvicapria grimmia (Linnaeus, 1758) is the only non forest duiker species of West Africa: It is quite widespread in sparse forests, savannahs and woodland areas, but absent from forests and deserts. This species is common and considered as not endangered. In Guinea-Bissau, it is also considered to be widely distributed (Chardonnet 1983, Limoges 1989), and is partially protected (MAFCP/DGFC 2004).

\section{II.1.3. Proboscids, elephants}

\section{African elephant Loxodonta africana (Blumenbach, 1797)}

Two sub-species of elephants are recognised to exist in Africa: the larger savannah sub-species $L$. africana africana and the smaller forest elephant $L$. a. cyclotis. Elephants formerly occupied virtually all habitats in sub-Saharan Africa, but today population have become increasingly fragmented, with principal concentration located in Central, East and the Northern part of Southern Africa and small isolated numbers are surviving in West Africa (Stuart \& Stuart 1997). Free ranging elephant herds are rare: illegal hunting for the ivory tusks has led to massive declines of elephant population during the last decades of the $20^{\text {th }}$ century. Actually, range and habitat loss as a result of rapidly growing human populations constitute the main threat factor to elephants. This has been more dramatically the case in West Africa, according to the African Elephant Specialist Group - AESG (1999), which states that many of the remaining elephant populations are so small and in such fragmented habitat that they are probably not viable. 
Also in Guinea-Bissau, forest elephants did suffer heavy hunting pressure for ivory trade during the colonial period. Elephants were reported to occur throughout the country, inclusively in some of the Bijagós islands (Lopes Lima cited by Frade 1949 and Cardoso cited by Frade 1949). Already in the forties they were considered to be restricted to the southern Cantanhez forest zone and to be threatened with extinction (Frade 1949). This species was still present in Guinea-Bissau in the eighties as a herd was reported by Douglas Hamilton (1988) with a population estimate of 40 individuals. Chardonnet (1983) made observations on this species in the Dulombi region and Limoges (1989) confirmed its presence in the south of the R. Corubal and in the eastern part of the Cantanhez forests. Yet in 1991, wildlife agents observed fresh prints in the Dulombi region (MDRA/DGFC 1991). In Cantanhez, Da Silva Naga and Sera (2001) identified a migration corridor of this species, which is thought to cross the area between the R. Canjafra in Dulombi, along the vicinity of the R. Balana, and the plateau of Forrea. Footprints were also observed within the Natural Park of Cufada along the R. Corubal, during the rainy season in 2001 by park rangers (Nadum J., personal communication).

The distribution area of elephants in Guinea-Bissau is restricted to two zones: the Cantanhez forests and the Dulombi-Corubal region (MDRA/DGFC 1991). They are thought to migrate seasonally, particularly during the rainy season, in the area close to the border between Guinea-Bissau and the Republic of Guinea (Frade et al. 1946, Limoges 1989, MDRA/DGFC 1991). Elephants are integrally protected by law in Guinea-Bissau (MAFCP/DGFC 2004).

\section{II.1.4. Serenids}

\section{West African manatee Trichechus senegalensis (Link, 1795)}

Three species of manatee are distributed world-wide, with the West African manatee T. senegalensis occurring from Senegal to Angola, mainly in rivers, estuaries, lagoons and coastal regions. The range extends over at least 20 nations, although it may now be close to extinct in some of them (Perrin 2001). Although this species is not commonly exploited in some West African regions, due to human attitudes and perceptions towards it (Grigione 1996), the numbers of West African manatees continue to decrease throughout their range. The population decline has been attributed largely to hunting and incidental capture in fishing nets and to coastal 
wetlands destruction (Almeida and Silva 1998, Perrin 2001). Mangrove woodcutting, forest clearance upstream resulting in increased sedimentation that silts up lagoons and estuaries, and increase in salinity e.g. due to reduced rainfall, affect growth of vegetation and manatee habitat.

The West African species is considered to be the most threatened of all manatee species; the destruction of coastal wetlands and mangrove forest clearance affect this species. Manatees are considered vulnerable (IUCN 2003) and are listed on Appendix II of CITES and in the Class A of the African Convention. Manatees are considered to be severely depleted and threatened in Senegal; they are considered close to extinction and have not been observed for many years in most areas of that country (Navaza and Burnham, 1998). In the Gambia, Manatees have been hunted extensively and are thought to have declined, however they might be still numerous in the River Gambia (Perrin 2001). The species is known to occur in the Republic of Guinea (Powell 1996), but no systematic studies have been carried out (Barnett and Prangley, 1997).

Guinea-Bissau was considered at one time to be one of the last sanctuaries of the manatee, because of the relatively undisturbed state of its mangroves, wetlands and river systems (Schumann 1995; Powell 1996). Major rivers inhabited include (North to South) the Rio Cacheu, Rio Mansoa, Rio Geba, Rio Grande de Buba, Rio Tombali, Rio Cacine (Limoges 1989, Crawford Cabral \& Verissimo 1997, Almeida e Silva 1998), This species also occurs throughout the Bijagós Archipelago (Limoges \& Robillard 1991, Crawford Cabral \& Verissimo 1997, Almeida e Silva 1998), where it is more abundant, occurring even in the outermost islands such as Unhocomo and Unhocomozinho (Almeida e Silva 1998). However, throughout Guinea-Bissau, the Rio Geba is thought to be the most important area for the West African manatee, which does not occur in the eastern region of the country (Schuhmann 1995, Almeida e Silva 1998).

The main conflicts between manatees and local people result more essentially from fishing net destruction by this species and to a lesser extend from some rice field raiding by this species (Almeida e Silva 1998). Illegal hunting of this species seems to decline in Guinea-Bissau, but incidental by-catch seems to be the most significant 
threat to this species (Schuhmann 1995, Almeida e Silva 1998). Manatees are integrally protected in Guinea-Bissau (MAFCP/DGFC 2004).

\section{II.1.5. Other mammals occurring in the coastal zone}

The aardvark Orycteropus afer (Pallas. 1766) occurs in different regions of GuineaBissau, excepting in the Bijagós archipelago (Frade e Silva 1980, Limoges 1989, Thibault 1993).

Three pangolin species are considered to be mainly distributed in the south of the country: the long-tailed pangolin Manis (Uromanis) tetradactyla (Linnaeus, 1766), the giant pangolin Manis (Smutsia) gigantea (Illiger, 1815) and the rare white-bellied tree pangolin Manis tricuspis (Rafinesque, 1821) (MDRA/DGFC 1988, Rainer \& Simões 1991).

About 20 carnivore species are recognised to exist in Guinea-Bissau, of which some occur in the coastal zone (Limoges 1989): the lion Panthera leo, (Linnaeus, 1758) which may occur occasionally in the South-eastern Cantanhez, the leopard Panthera pardus (Linnaeus, 1758), the serval Felis (Leptairulus) serval (Schreber, 1776), the spotted hyena Crocuta crocuta (Erxleben, 1777) and the African clawless otter Aonyx capensis (Schinz, 1821).

Also the genets Genetta thierry (Matschie, 1902) and Genetta tigrina (Schreber, 1776), the African civet Viverra (civettictis) civetta (Schreber, 1776) and the palm civet Nandinia binotata binotata (Gray, 1830) are observed in the coastal zone (Limoges 1989). Limoges (1989) did not cite the golden cat Profelis aurata (Temminck, 1827) as occurring in Guinea-Bissau, but Stuart et al. (1990) mention its presence. However, this species is not included in the lists of mammals of GuineaBissau (MDRA/DGFC 1988, MAFCP/DGFC 2004).

Two cetaceans, the Atlantic humpbacked Dolphin Sousa teuszii (Kükenthal, 1892) and the Bottle-nosed Dolphin Tursiops truncatus (Montagu, 1821) are also to known to occur in Guinea-Bissau. 


\section{II.2. Main threat factors for mammal species}

In West Africa, threats to conservation are inextricably linked to poverty, which drives urgent short-term needs that eliminate long-term opportunities (Conservation International 2001). Much of the region's population is closely dependent on the forest's resource base. The most common threatening factors for mammal are habitat loss, particularly for primate species, and overhunting, which is more prevalent in artiodactyls and other ungulates (Mace \& Balmford 2000).

Steady decline of forest areas as a consequence of logging and agricultural activities is rapidly leading to decreases in wildlife populations (Bennett \& Robinson 2000, Chapman et al. 2000, Skorupa 1997, Struhsaker 1997, Wilkie et al. 1992; 2000). Different forms of human-induced disturbance such as selective logging, slash-andburn agriculture and fragmentation often occur at the same time and operate synergistically with hunting (Peres 2001). Habitat disturbance inevitably leads to hunting intensification and aggravates its effects, so that wildlife species within forest fragments face overhunting and habitat fragmentation.

Logging alone has been proven to affect negatively mammal populations. Although some primate species can survive in forests that have suffered light selective logging (Johns \& Skorupa 1987 cited by Chapman et al. 2000, Oates 1996a, Struhsaker 1997), heavy mechanised logging has been shown to affect negatively primate populations (Skorupa 1987). A study on the long-term effects of logging on primates in Uganda showed that almost three decades after heavy logging, most primate densities either continued to decline or recovered only slowly (Chapman et al. 2000). In a study on primates in altered habitats, Chapman and Lambert (2000) observed, that the only species seen to use degraded forests were the red colobus, black-andwhite colobus, red tails, and chimpanzees.

Diverse authors have found out, that logging is associated with increased accessibility and hunting pressure in isolated areas, and that both human presence and hunting remain high even after logging has stopped, affecting strongly recovery of primates species (Grieser Johns \& Grieser Johns 1995, Cowlishaw \& Dunbar 2000). A correlation have been shown between logging activity and increased 
bushmeat trading, principally as a result of linking once-remote forest areas to commercial centres, via logging roads and trucks (Bennett \& Robinson 2000, Wilkie et al. 1992; 2000) and also combined with an increased demand or even hunting activities by the workers of logging companies (Bowen-Jones \& Pendry 1999). Increased access of the forests reduces refuge areas for wild animals and also facilitates increased market hunting (Wilkie et al. 1992, Bowen-Jones \& Pendry 1999, Bennett \& Robinson 2000, Wilkie et al. 2000). Logging thus play a crucial role, since it makes forests not only more accessible, but because loggers also contribute to intensification of hunting by supplying local hunters with shotguns and cartridge and by facilitating the transport of bushmeat from forest regions to urban centres (Wilkie et al. 1992).

In cultivated mosaics, hunting can also lead to dramatic decreases in primate populations (Marchesi et al. 1995, Rosenbaum et al. 1998). In Madagascar, a negative association was observed between lemur species richness and individual abundance, which is attributed to the combined effect of habitat degradation and hunting (Smith et al. 1997).

Increased human populations with increased sedentarism lead to increased game meat demand and hunting pressure and market involvement (Bennett \& Robinson 2000). Immigration leads not only to increased population densities but also to changes in the pattern of wildlife harvests: immigrants tend to hunt a narrower range of species and to disrespect local taboos and practices regarding wildlife (Oates 1995, Bennett \& Robinson 2000). Other factors related to overhunting are the breaking down of social taboos, the disappearing of the system of traditional hunting territories, the declining of traditional hunting methods and practices, and advances in hunting technologies with the spread of shotguns and wire snares (Muchaal \& Ngandjui 1999, Bennett \& Robinson 2000). Hunting becomes more and more a commercial activity and results in increased hunting intensity not only by local people but also by non resident commercial hunters.

Eves \& Ruggiero (2002) state that in West and Central Africa, the husbandry of selected species may be a viable alternative in urban centres but is likely to be an inefficient alternative in rural areas, for those communities in forest regions, 
depending upon wildlife as their primary source of protein. "There will be nothing left to conserve if people are not assisted in meeting their daily needs. Lasting changes will come from fundamental alterations in attitude and behaviour" (Fa et al. 2000).

Different studies have shown that hunting can constitute a much greater threat for primates than many forms of habitat disturbance (Oates 1996a, Cowlishaw \& Dunbar 2000, Peres 2001). Hunting has been shown to provoke local extinction of some species, having a greater impact than small-scale disturbances such as rubber tapping (Peres 1991, cited by Cowlishaw \& Dunbar 2000). Cullen et al. (2001) analysed the ecological consequences of hunting in Atlantic forest patches in Brazil. They found out, that hunting was changing the ecological structure at the hunted sites by depriving those areas of much of the terrestrial mammalian biomass, and more particularly of ungulates. Hunting appears to be thus the most important factor affecting small and fragmented animal populations, leading to the extirpation of largeand medium-sized mammals from forest fragments, which in turn, affects ecological relationships (Cullen et al. 2001; Peres et al. 2001).

In a study on hunting in Amazonian forests, Peres et al. (2001) found out, that with the exception of social species living in large, wide-ranging groups that occur at low densities, various Neotropical mammal species could persist in forest fragments, in the complete absence of hunting. In many countries and in West Africa in particular, overhunting is leading to serious depletion of the population of many forest animal species. Although people has been hunting wildlife since they first inhabited tropical forest some 40,000 years ago, today such hunting is rarely sustainable (Bennett \& Robinson 2000). Over the last decades, various studies have shown the impacts of hunting on wildlife (i.e. Ntiamoa-Baidu 1987, McGraw 1998, Bowen-Jones 1999, Oates 1999, Fa et al. 2000, Oates et al. 2000, Perez-Carlos 2000, Cullen et al. 2001, Eves \& Bakarr 2001, Fischer \& Linsenmair 2001, Hearn \& Morra 2001). Hunting, being it subsistence or commercial, has been shown to have inevitably a negative impact on animal densities.

Redford (1992) found out that mammal densities in areas subject to moderate hunting in the Neotropics were 80.7 percent lower than in unhunted or lightly hunted sites. In Gabon, Lahm (1996) found out higher decrease in relative abundance of 
chimpanzees and gorillas (92 and 100\% respectively) and of large ungulates (83\% for Sitatunga and $100 \%$ for yellow-backed duiker) between non-hunted and sites with village hunting. But also smaller ungulates showed strong reduction $(78 \%$ for chevrotain and $79 \%$ for bush pig) in the same area.

Yet the reduction in mammalian densities in hunted areas is far more dramatic than would be accounted for by the temporary reduction associated with offtake (Robinson \& Redford 1994). Large-bodied animals can least sustain heavy hunting, due to their lower reproductive rates (Barnes 2002) and species with low intrinsic rate of reproduction are less able to withstand overhunting and are much more susceptible to local extinction. Some species however, have much lower intrinsic rate of increase than would be expected from their body size alone. This is the case for primates for instance (Robinson \& Redford 1986), which are very susceptible to overhunting.

Large-bodied species tend to be preferred targets and expensive shotgun shells encourage hunters to focus on the larger game species (Robinson \& Redford 1994, Entwistle \& Stephenson 2000), mainly the larger ungulates and primates (Robinson \& Bennett 2000). Medium- and large-bodied species are thus threatened by both hunting and habitat disturbance; however differences are observed among them, which could be related to body size and population size (Cowlishaw and Dunbar 2000). Although both Colobine and Cercopithecine monkeys seem to suffer more from hunting than from logging, former appear to be more sensitive than latter (Davies 1987, cited by Cowlishaw and Dunbar 2000). Among the Cercopithecines, Campbell's monkey was shown to be more resilient and in the Colobine group, blackand-white colobus showed a greater resistance (Davies 1987 cited by Cowlishaw \& Dunbar 2000, Chapman and Lambert 2000).

Primates are particularly vulnerable to overhunting, due to their low reproductive rates and to their locally low population densities and for being often found in groups (Fitzgibbon et al. 1995). They are more vulnerable than ungulates, which tend to maintain comparable biomass in unhunted and moderately hunted Amazonian forests (Bodmer et al. 1988, 1994 cited in Fitzgibbon et al.1995). In Neotropical forests, densities of non-primate mammal species have been shown to decrease $80.7 \%$ under moderate hunting, and $93.7 \%$ under heavy hunting, when compared 
with similar unhunted sites (Redford 1992). According to the same author, large primate density also dropped $80.7 \%$ in hunted areas, when compared with similar, unhunted sites. In a study on susceptibility of mammals to hunting in Amazonian forests, Bodmer (1995) also observed that rodents and artiodactyls did show little differences in their densities, whereas primates showed considerable differences in densities between slightly and persistently hunted sites. In Equatorial Guinea, mostly primates and ungulates were found to be hunted unsustainably (Fa et al. 1995).

In various African forest regions, duikers are the most commonly hunted animals (Infield 1988, Lahm 1993, Fa et al. 1995, Muchaal and Ngandjui 1999, Fotso \& Ngnegueu 1997). As large mammal populations decrease, wildlife offtake shifts to smaller species. Fa et al. (2000) observed, the appearance of a larger number of carcasses of the smaller-bodied species on bushmeat markets in Equatorial Guinea, including rodents and blue duiker, whereas this increase was accompanied by a strong reduction in the larger-bodied species. These results, along with those from mammal surveys, indicate that the larger monkeys and the larger duiker are becoming scarce in that region (Hearn \& Berghaier 1996, cited by Fa et al. 2000).

According to Barnes (2002), in a multi-species hunting system, large animals are more likely to be driven to local extinction, than in a system where they are the only prey. Some species mostly small-sized or which are considered not tasty, benefit from hunting through the removal of their predators or competitors (Freeze et al. 1982). Barnes (2002) argues that large harvests of a prey species can be obtained over many years, but that a population collapse can happen suddenly without any period of gradually declining harvest. This process may be accelerated in forests with high rates of deforestation and fragmentation.

Hunting techniques also affect differently the hunted species ( $\mathrm{Fa}$ et al. 1995, Fitzgibbon et al. 1995). According to Fa et al. (1995), species such as arboreal guenons and baboons, which are actively stalked by hunters throughout the forest, are overexploited. For species that are only trapped, the centre of the forest acts as a refuge from harvesting, since trapping occurs primarily toward the edge of the forest (Fitzgibbon et al.1995). In a study on subsistence hunting in Kenyan coastal forests, the same authors found out, that while trapping could substantially reduce the local 
density of prey (e.g. four-toed elephant shrews) on the periphery of the forest (by $40 \%$ each year), only a relative small proportion of the targeted species' population (4\%) was affected. On the other side, the larger species of ungulates and primates, which are hunted as well as trapped, have no refuge. Fitzgibbon et al. (1995) thus consider that stopping primate hunting while allowing trapping around the forest edge could be one way to reduce excessive harvesting of primates. In a study on the impact of cable snare hunting, Noss (1998) found out that all mammals were captured in cable snares in the Central African Republic, but $75 \%$ of snare captures were of three duiker species and the brush-tailed porcupine.

For many species, and in most areas, hunting in tropical forests today is not sustainable, even in many indigenous societies which hunt only for subsistence (Bennett \& Robinson 2000). In the few cases where hunting is sustainable, specific conditions apply such as the position outside any market economy, exclusion of hunters from outside and particularly low human population densities (Bennett \& Robinson 2000). 


\section{II.3. Community- Based Conservation}

A growing number of conservation initiatives projects seek to motivate and organize communities to conserve wildlife, and to mobilize wildlife resources for the benefit of local communities (Kiss 1990). Many lessons can be learnt from development projects which were implemented in the last decades: success in community development has been much greater when decisions, plans and implementation of projects involve community members (Murphree 1994). Although not all bottom-up projects based on community participation succeed, almost all top-down projects that exclude community involvement failed (Strum 1994).

Today's world is human-dominated and is facing social, economic and political changes. "Where set -asides, preservation, ecological containment and enforcement made headways for decades, today they are necessary but wholly insufficient measures" (Western 2001). As Newmark and Hough (2000) state, the challenge is to design strategies that not only will ensure the long-term viability of species and ecosystems, but also will be politically and economically acceptable to local communities.

\section{II.3.1. About the concept}

The term community conservation has been increasingly used in the international environmental lexicon, involving a broad spectrum of approaches and programmes, often with their corresponding acronyms, such as Integrated Conservation and Development (ICD), Community-Based Conservation (CBC), Community Based Natural Resource Management (CBNRM), Community Wildlife Management (CWM), Community-based Wildlife Management (CBWM), Collaborative (or Co-) Management (CM), and Protected Area Outreach Projects, these approaches exhibiting differences of intent, emphasis and substance (Barrow \& Murphree 1998, Roe \& Jack 2001).

There is no unique definition and there is a diversity of approaches to CBC, which illustrates the many actors involved and their different point of views. Whereas "conservation" includes protection, maintenance, rehabilitation, restoration, 
enhancement and sustainable use of population and ecosystems (IUCN 1991), the meaning of "community" varies with context, and perceptions of nature vary around the world (Mac Donald 2003, Hulme 1997, Western \& Wright 1994, Barrow \& Murphree 1998).

Western and Wright (1994) consider that "community-based conservation covers both new and traditional conservation efforts that originate within or outside a community, so long as the outcome benefits the community", thus including natural resources or biodiversity protection "by, for and with the local community". For these authors, the coexistence of people with nature is the central precept of CBC.

The term 'collaborative management' (also referred to as co-management, participatory management, joint management, shared-management, multistakeholder management or round table management) is used to describe situations in which some or all of the relevant stakeholders in a protected area are involved in a substantial way in management activities" (Borrini-Feyerabend 1996). Collaborative management "entails a conscious and official distribution of responsibility, with the formal vesting of some authority" (Renard 1997) and thus is different from community-based management "because it recognises that it is neither generally possible nor desirable to vest all management authority in the community" (Renard 1997). According to this author, the state should and will always retain some responsibility, if only for the provision of an overall policy framework for conservation and management.

Barrow \& Murphree (1998) give a generic definition to the concept of 'community conservation', as "a broad spectrum of new management arrangements and benefit sharing partnerships for the involvement in natural resource management by people who are not agents of the State, but who, by virtue of their collective location and activities are critically placed to enhance the present and future status of natural resources, and their own well being".

According to Newmark (2000), CBNRM differs from the ICD-approach in that it devolves management responsibility for natural resources/wildlife, instead of offering development services in exchange for conservation. Little (1994) states that "if a local's population's role is to stay out of certain (protected) land area or to stop certain management practices (e.g. herding or hunting) in order to preserve biodiversity, accepting compensation or development benefits in exchange, then... such a program is not CBC". 
Roe et al. 2000 define community-based wildlife management as the regulated use of wildlife populations and ecosystems by local 'stakeholders', whereby local stakeholders may be a village, or group of villages; an individual, or group of individuals with a shared interest in the resource. For these authors, the important factor is not how the community is defined, but the fact that stewardship over wildlife resides at the local rather than the state level.

\section{II.3.2. Why Community-based management?}

The overall goal of community-based wildlife management is to make rural people an integral part of conservation efforts (Western \& Wright 1994). In general, communitybased wildlife conservation programs do this by (1) allowing people living near protected lands to participate in land-use policy and management decisions; (2) giving people proprietorship or ownership over wildlife resources; and (3) giving local people economic benefit from wildlife conservation (Hackel 1999).

According to Western (1994), the main strengths of CBC are related on one side to the limited number of stakeholders, which prevents open-access abuses and makes that costs and benefits of conservation are localised and personalised, so that individuals can be directly influenced. The same author considers on the other side, that vested interest, ownership and sense of belonging created in a CBC programme lead to more commitment, sense of pride, custodianship, community-wide monitoring and enforcement based on social ostracism. Finally, CBC can draw on the deep knowledge, traditions, ethics and adaptive practices of rural communities. Increased cost-effectiveness of wildlife law enforcement and management, and positive perceptional and attitudinal changes among local people may be other advantages of community-based conservation approaches (Lewis et al. 1990).

$\mathrm{CBC}$ is partly seen as an alternative to the more exclusionary protectionist policies of the past, which often alienated rural people from conservation efforts (Hackel 1999, Newmark 2000). Some authors (Owen-Smith 1993) consider CBC not only as a response to both alienating protectionist policies of the past, but also to the economic concerns that many rural people face. Community-based conservation seeks to empower local people to manage their own resources sustainably, to create the 
enabling legal and policy instruments, to establish mechanisms for local ownership and responsibility for the process and ensure that benefits accrue responsibly and equitably.

However, benefit sharing should not compromise protected areas agenda (Barrow et al. 1995a); the benefits for rural resource users are not only economic, and many benefits from protected areas are not obvious (Barrow et al. 1995a/b). Communitybased conservation is likely to be sustainable ecologically, economically and socially only if the overall management scheme can be made sufficiently attractive to local people for them to adopt it as a long term livelihood strategy (Pimbert and Pretty 1997).

\section{II.3.3. Categories of community conservation}

Barrow \& Murphree (1998) identify three categories of community conservation, based on land tenure, that have emerged in Africa, with each being housed in a different tenurial / access regime: Protected area outreach, Collaborative management and Community-Based Natural Resource Management (Table3).

Protected area outreach seeks to enhance the biological integrity of parks by working to educate and benefit local communities and enhance the role of a protected area in local planning (e.g. Integrated Conservation and Development projects - ICDP's). Many of protected areas were established prior to, or just post independence with little consultation with rural people (Adams and Hulme 1998). Protected area outreach is a more recent and pragmatic attempt to improve long-term conservation goals, in recognition of the importance of involving those land users who border protected areas (Barrow \& Murphree 1998). Protected area outreach and benefits are linked to contributing to conservation as the primary objective; rural livelihoods are of secondary importance. According to the same author, protected area outreach functions within a framework whereby the protected area is a nationally gazetted legal entity managed by some form of state conservation authority, for example national parks or forest reserves (Barrow \& Murphree 1998).

Collaborative management seeks to create agreements between local communities or groups of resource users and conservation authorities for negotiated access to 
natural resources which are usually under some form of statutory authority. CoManaged Protected Areas (CMPAs) can be broadly defined as officially designated Protected Areas (as per IUCN categories I-VI) where decision making power is shared between state agencies and the indigenous and local communities that depend on that area culturally and for their livelihood (Borrini-Feyerabend 1996; 2003). While the focus is on protected areas, collaborative management can apply to areas which do not have protected area status and can apply to virtually all types of natural resources (Borrini-Feyerabend 1996).

Table3. Some components of the different categories of community-based conservation (from Barrow \& Murphree 1998)

\begin{tabular}{|c|c|c|c|}
\hline Component & $\begin{array}{l}\text { Protected area } \\
\text { outreach }\end{array}$ & $\begin{array}{l}\text { Collaborative } \\
\text { management }\end{array}$ & $\begin{array}{l}\text { Community-based } \\
\text { Conservation }\end{array}$ \\
\hline Dominant objective & $\begin{array}{l}\text { Enhanced } \\
\text { conservation and } \\
\text { integrity of protected } \\
\text { area }\end{array}$ & $\begin{array}{l}\text { Conservation, } \\
\text { however increases } \\
\text { access and use of } \\
\text { resources }\end{array}$ & $\begin{array}{l}\text { Rural livelihoods needs } \\
\text { met, but conservation } \\
\text { values integrated }\end{array}$ \\
\hline $\begin{array}{l}\text { Destiny of the } \\
\text { conservation } \\
\text { resource }\end{array}$ & $\begin{array}{l}\text { Maintained as part of } \\
\text { State's Conservation } \\
\text { heritage }\end{array}$ & $\begin{array}{l}\text { Maintained as part of } \\
\text { State's Conservation } \\
\text { heritage, however } \\
\text { may be overused, or } \\
\text { use may affect other } \\
\text { species }\end{array}$ & $\begin{array}{l}\text { Resource likely to be } \\
\text { maintained, the more } \\
\text { culturally or economically } \\
\text { valuable the resource is. } \\
\text { Where insignificant to } \\
\text { rural economics or } \\
\text { cultural, it will be lost. }\end{array}$ \\
\hline Agenda definition & $\begin{array}{l}\text { Dominantly protected } \\
\text { area; neighbours as } \\
\text { partners }\end{array}$ & $\begin{array}{l}\text { Dominantly protected } \\
\text { area; going to joint }\end{array}$ & Community, local level \\
\hline $\begin{array}{l}\text { Ownership of the } \\
\text { process }\end{array}$ & Protected area & $\begin{array}{l}\text { Legally the state; but } \\
\text { towards joint } \\
\text { management and use }\end{array}$ & Community \\
\hline Planning & $\begin{array}{l}\text { Joint (for outreach } \\
\text { activities) }\end{array}$ & Joint & $\begin{array}{l}\text { Community, often with } \\
\text { assistance of others }\end{array}$ \\
\hline Controlling & Protected area & Joint & Community \\
\hline $\begin{array}{l}\text { Ownership of } \\
\text { resources, area }\end{array}$ & Protected area & Protected area & $\begin{array}{l}\text { De facto community or } \\
\text { individual, but legally } \\
\text { depends on how tenure is } \\
\text { vested }\end{array}$ \\
\hline $\begin{array}{l}\text { Value of local rules } \\
\text { and regulations }\end{array}$ & $\begin{array}{l}\text { Slight, related to how } \\
\text { positive the } \\
\text { relationship to the } \\
\text { local communities is }\end{array}$ & $\begin{array}{l}\text { Can be great, } \\
\text { depending on how } \\
\text { local rules are joined } \\
\text { with Park rules and } \\
\text { who enforces }\end{array}$ & $\begin{array}{l}\text { Local rules will govern } \\
\text { access and use of } \\
\text { resources, by whom and } \\
\text { to what conditions }\end{array}$ \\
\hline
\end{tabular}

Although collaborative management arrangements cover certain types of resource use, it is likely that the conservation objectives are still the driving force. Use will contribute directly to rural poverty alleviation, but will normally be confined to those 
who live relatively close to the protected area (Barrow \& Murphree 1998). According to (Borrini-Feyerabend 2003), the co-management governance model has three main integrated objectives for some of its practitioners: 1 ) the conservation of the natural and cultural patrimony of the site at stake; 2) the participation of civil society in that very process (an objective per se), and 3 ) the equitable distribution of the relevant benefits and costs.

Community-Based Natural Resource Management (CBNRM) implies the sustainable management of natural resources through returning control over, or responsible authority for these resources to the community as the chief objective. Conservation is by the people to manage responsibly in a way that is "sustainable" and benefits them (Barrow \& Murphree 1998). Once rural livelihoods are the primary objective, contributing to conservation objectives is usually, in reality, a secondary objective (Barrow \& Murphree 1998). Economic value may be more than just cash based, but could include cultural, aesthetic values, on which the land users are prepared to accept (Barrow \& Murphree 1998).

Borrini-Feyerabend (2003) emphasizes a further category, which is universally relevant, and of importance for community empowerment in conservation: Community Conserved Areas (CCAs). According to this author, these represent territories and resources directly conserved and managed by indigenous and local communities and can be defined as "natural and modified ecosystems including significant biodiversity, ecological services and cultural values voluntarily conserved by concerned indigenous and local communities through customary laws or other effective means".

Taboos represent one of those means. Regardless the debates over the utility of taboo in conservationist practice, it is recognised that taboos have played an important direct and indirect role for the protection of threatened and ecologically important species (Colding and Folke 1997; 2001, Borrini-Feyerabend 2003). According to Ntiamoa-Baidu (1995), wild animals with spiritual and cultural uses fall into three main categories: (1) Totem species are regarded as symbols of an existing relationship and are accorded respect and considered sacred; they may not be killed or eaten; (2) Tabooed species are regarded as sacred or holy because of some protection, guidance or help accorded to the ancestors, or because they are 
regarded as unclean due to some misfortune in the past associated with the species; eating, killing or even touching of such animals may be forbidden; and (3) Sacrificial and/or ceremonial species are used in specific cultural rites and ceremonies. Colding and Folke (2001) distinguish six categories of resource and habitat taboos, which may be related to particular population segments, to certain time periods, to specific methods, to some animal life history stages, to specific species and to habitats.

Many CCAs are entirely based on customary rules and agreements, with no intervention of government agencies or relation to official policies, remaining basically informal and officially unrecognised. Still according to Borrini-Feyerabend (2003), those areas, which usually relate closely to the community sense of identity and culture and with the community long-term livelihood strategies, also usually involve areas and resources under common property and possess relatively simple procedures for administration and decision-making. Examples of communityconservation areas are the restricted access areas in the Bijagós archipelago, Guinea Bissau (Borrini-Feyerabend 2003), the Kaya forests in Kenya (Robertson and Luke 1993, Bassi 2003), the Batoufan Sacred Forests, Cameroon (Nelson and Gami 2003).

In a regional review of CWM initiatives in the West African region, Zeba (1998) distinguishes 6 categories of initiatives, which he classifies into 3 groups, on the basis of the degree of responsibility and participation.

(i) Most of the case studies analysed in that study falls into the group of CWM initiatives which were engaged by the State institutions, and which are linked to the conservation of national classified reserves. According to the same author 4 types of "participation" can be included into this category : a) Passive Participation, where people participate by being told what is going to happen or has already happened, without any listening to people's responses; b) Instrumental Participation, where people participate by providing resources, for example labour, in return for food, cash or other material incentives. These two categories do not fill into a CWM model, since they do not concede any share in decision-making; c) Transformative Participation, in which people take part in joint analysis, which leads to action plans and the formation of new local groups or the strengthening of existing ones; and d) Self-Mobilisation where people participate by taking initiatives independent of external institutions to change systems, as in the case of the Popenguine reserve in Senegal, which is managed in the context of the Ker Cupaam women association. 
(ii) The second group identified by Zeba (1998) includes CWM initiatives engaged by local communities, which then request the authorisation and the "participation " of Government and other partners, such as NGOs and other donors. In such cases, the involved area is not a classified protected reserve, but rather as a site which has a traditional value respected by people. This is the category for examples like the Buabeng-Fiema monkey sanctuary in Ghana and the Mamunta Mayoso wildlife sanctuary in Sierra Leone.

(iii) Finally, the same author considers a third group which includes cases where the CWM initiative is a donor-driven project, engaged by conservation organisations (NGO, international institutions) or private investor. The approach can be instrumental or transformative, and project location can include a protected area or not. An example for this category is the project for the conservation of the Banc d' Arguin national park in Mauritania, which was initiated by an International Foundation for the Banc d' Arguin national park (FIBA).

\section{II.3.4. CBWM as a tool for conservation?}

\section{II.3.4.1. Environmental impacts of CWM}

In a study on CBWM initiatives, Roe et al. 2000 consider that the positive environmental impacts of CWM can be broadly divided into three categories: impacts on wildlife, impacts on habitat and impacts on attitudes and practice. According to this author, in a large number of case studies examined in Africa and Asia, wildlife numbers were found to either have increased, to have stabilised following earlier declines, or to have been maintained.

In the majority cases analysed by Roe et al. (2000), it was shown that even where species conservation is not the sole purpose of a CWM initiative, wider habitat protection activities can nevertheless have significant effects on wildlife populations, and in a number of cases wildlife species have returned to areas that were previously degraded. A number of CWM initiatives have made a positive contribution to conservation by increasing the amount, or diversity, of wildlife habitat available. In other areas CWM has not increased the amount of land available to wildlife but has ensured its continuity by reducing the threat of land transformation. 
Community-based wildlife conservation can enhance the sustainability of hunting through restricting the access of outsiders to the resources, decreasing immigration into the region, strengthening traditional resource use systems, resisting increased commercialisation, establishing local protected areas and dispersing the location and intensity of hunting (Bennett and Robinson 2002)

Roe et al. (2000) also observed changes in attitudes and practices of communities and conservation managers in various CWM initiatives reviewed, e.g. the breaking down the suspicions and mistrust between protected area staff and local peoples; increased environmental awareness amongst both indigenous groups and scientists; regulation of resource use and the introduction of community monitoring of wildlife populations as impacts of CWM, changing policy at national levels, and appeals by NGOs or country delegates for greater CWM provisions to be built into international agreements such as the CBD, Convention on Biological Diversity.

\section{II.3.4.2. Weaknesses of CBWM as a tool for conservation}

CBWM also faces some important weaknesses as an agent for conservation. Bennett and Robinson (2000) consider that CBWM is less successful, where the wildlife resources are not adequate to support hunting, such as in most low productivity tropical forests. According to Roe et al. (2000), the most common of CBWM weaknesses is continued poaching or use at unsustainable levels, and in many cases this reflects a problem that CWM has failed to address or that is beyond the scope of the initiative: lack of law enforcement, which constitutes a critical factor in continued illegal use. The same regional study on CWM initiatives in SouthernAfrica has shown that "one of the reasons why law enforcement appears to be a low priority is because communities believe that wildlife resources are abundant (Roe et al. 2000). As Schaller (2002) states, "local control over resources will not alone assure sustainability; ...communities need technical assistance to determine the biological limits to harvesting resources and of monitoring and managing them".

Another reason for weak enforcement in CBWM initiatives is that most wildlife departments and parastatals in Southern-Africa have experienced significant budget cuts over the past decade. Not only does this prevent them from policing resources, but "monitoring rarely takes place and where it does, it is infrequent" (Roe et al. 2000). Newmark (2000) observes, that conservation and development project 
managers are often not willing to incorporate significant research component into these projects, as research is often viewed as a hindrance to action and an expensive luxury. However, research is essential to conservation and development initiatives, "if the ecological and social dynamics encompassing each project are to be accurately defined, and if conservation and development are to be truly integrated" (Newmark 2000). The role of enforcement in CBC programmes has not always received the adequate attention (Metcalfe 1994). In CAMPFIRE for example, anti poaching rules have been externally (poorly) enforced and communities could control subsistence hunting but need external help from government to contain commercial poaching (Metcalfe 1994).

In other cases illegal or unsustainable use of wildlife and its subsequent decline is a result of the lack of rights and responsibilities of local communities for wildlife. Gibson (1999) argues that, despite the benefits offered to residents to encourage locals to protect rather than to hunt animals, the ADMADE Programme in Zambia failed to address the poaching problem, not only because they failed to link those benefits with individual behaviour, but also because locals did not own or control their wildlife resources and their use of wildlife remains illegal. Illegal use may also be a result of the community's inability to regulate the behaviour and activities of some individuals within or outside the community (Roe et al. 2000). In some cases, CWM appears to have failed to instil in local communities a sense of the value of wildlife: in some regions, wildlife populations continue to decline as farmers continue to clear land for cultivation rather than wildlife (Emerton and Mfunda 1999 cited by Roe et al. 2000), while in others overgrazing by livestock continues to threaten the forest habitat (Shresth 1999 cited by Roe et al. 2000).

\section{II.3.5. Challenges and key questions to community-based wildlife conservation}

Some challenges and threats to community conservation have been identified (Robinson \& Redford 1994, Western \& Wright 1994, Gibson 1999, Hackel 1999, Bennett and Robinson 2000, Borrini-Feyerabend 2003): loss of tenure security, weakening of local institutions due to the alteration of community social structures, the breakdown of traditional societies, monetisation of the economy, the spreading of modernist practices (cash cropping, taxation systems, international markets for raw 
materials), linked with pricing policies and marketing structures outside of the control of communities, and rapid human growth. Further challenges include lack of awareness, knowledge, skills and enforcement; the existing diversity of interests in the local communities, which can lead to nepotism and corruption; widespread poverty or the prevalence of survival needs above all else, which encourage overexploitation and environmental destruction (Western \& Wright 1994) and the coexistence of conflicting modern and customary law on land ownership (Hakizumwami 1998, Zeba 1998, Borrini-Feyerabend 2003).

Western \& Wright (1994) consider CBC to be the biggest conservation challenge of all, as the issue is "how to deal with the vast majority of the earth's surface, where there are no parks and where the interests of local communities prevail". For community conservation to be successful there has to be a sense of responsibility and ownership, or proprietorship devolution at the community and resource user level; without this, incentives for conservation become marginal and ad hoc (Murphree 1998).

Nevertheless conservation should remain a major objective in CBC. As Salafski (1994) states, CBC should involve resource conservation as at least one of its outcomes and it should be linked to some benefit on the part of resource user(s). $\mathrm{CBC}$ thus requires a balance between meeting human needs on one hand and ensuring that biological losses are not excessive on the other (Robinson \& Redford 1994). CBC approach to wildlife use only meets conservation criteria, if exploited species are used sustainably (Robinson \& Redford 1994), but sustainable use only occurs when the rights of different user groups, including use rights for local communities are specified, human needs of local communities are met and the losses in biodiversity and environmental degradation are acceptable (Robinson 1993).

Newmark (2000) states that the assumption that improving living standards of people living adjacent to protected areas will necessarily enhance conservation within the protected area does not always hold. The author thus argues that "encouraging landscape-wide compatible land use adjacent to protected areas may be more important for conserving species in protected areas than simply stimulating local 
economic development". Some authors consider, that conservation and development objectives should not be linked, because the mixed objective does not serve either objective well (Oates 1995, Newmark 2000, Redford \& Sanderson 2000). Oates (1995) recognises that "reserves and parks are indeed more likely to be effective if they involve people living near them" but he considers that it would be more appropriate "to involve people in protection work, in tourism, in sustained-yield forestry and in research than to encourage their agricultural activity within reserves".

Other authors (e.g. Songorwa 1999; Roe et al. 2000, Murphree 2002, Wilshusen et al. 2002) defend another position and argue that, if community conservation has failed, it is not due to the weakness or impracticality of the concept, but rather to its inadequate implementation, especially with regard to the devolution of authority and responsibility. The lack of real community involvement and leadership in management of the resource is a major constraint to the success of CBWM initiatives (Takforyan 1994, Lewis \& Phiri 1998). The non devolution of appropriate authority status to communities in some regions of Zimbabwe and the subsequent marginalisation of communities in wildlife management and planning aside with the unequal benefit sharing resulted in hostility to the Campfire programme, increasing intolerance of wildlife and a continued lack of communal environmental control (Murphree 1996). The sense of empowerment of local communities is a more critical incentive for conservation than material, cultural and aesthetic reasons (Roe et al. 2000).

Safalski (1994) presents some important key questions for conservation, when implementing a $\mathrm{CBC}$ programs:

(1) the definition of conservation goals for the CBC program; here Roe et al. 2000 distinguish several types of approaches including strict protection, ecosystem restoration and / or conservation, consumptive use, non-consumptive use and genetic resource use;

(2) the question on who sets the goals (also Adams and Hulme 2001, but see Western 2001), this being particularly important, when both communities and external institutions are involved;

(3) how to measure the success of the CBC programme with regard to biodiversity conservation; 
(4) how to select the conservation actions to be implemented (also Adams and Hulme 2001, but see Western 2001), taking into consideration the biological needs of target species, potential conflicts between humans and the natural world;

(5) how to monitor the results (see also Metcalfe 1994, Kremen et al. 1994 and Newmark 2000): monitoring techniques will depend on a trade-off between accuracy of the results and the costs, and finally

(6) the need for developing the positive existence value that humans place on the survival of natural world. Salafski (1994) also argues that CBC projects will have to create systems in which people have a vested interest in wildlife and to include conservation education not only in the rural areas but also in the urban regions.

\section{II.3.6. Conditions for CBWM}

The CBC approach calls for great reforms in land-use policy. If the conservation focus is to switch to the community, the focus must change from a top-down to a bottom-up approach (Western 1994). Devolving increasing responsibility and authority to land users is however not easy for government institutions (Western 1994), but when local resource users gain responsible authority, they show that they are capable of managing natural resources in a responsible manner (Barrow \& Murphree 1998). Also following Western and Wright (1994), CBC implies not only the recognising of resource use rights of local communities, but also requires a sense of responsibility and the appropriate management capacity. In all cases responsibility and authority have to be linked (Murphree 1995).

Community's rights to ownership and tenure of wildlife resources are crucial to sustainable wildlife management (Western 1994, IIED 1994, Bennett \& Robinson 2000, Adams \& Hulme 2001), but serious problems are also encountered about the devolution of authority over wildlife. Many governments simply keep such authority carefully centralised, and some assign some rights to lower levels, but generally in a limited and conditional way (Borrini-Feyerabend 2003).

Most of CBC programs have treated participation as a means of achieving conservation objectives rather than as a goal in itself that empower local communities have greater control over their lives and resources (Kiss 1990, Little 
1994, Pimbert \& Pretty 1997). An example from the Peruvian Amazon shows that informal legislation developed by rural communities apparently is more successful than government legislation, but community regulations must concur with government legislation and therefore require government approval or sanctions that are difficult for rural inhabitants to obtain (Bodmer 1994). Empowerment of communities, both legally and in practice is thus of great importance.

Because most of the success stories in Africa have been much greater in areas with tourist potential than where the resource is primarily of interest for local consumption, some authors (Kremen et al. 1994, Hackel 1999, Adams \& Hulme 2001) consider that community-based conservation programs are a more realistic policy in areas that have big game animals. Hackel (1999) considers the ability to draw sport hunters or tourists in sufficient numbers to be the key element, and thus that such programs may not be applied generally in rural Africa. The main reasons invoked are: the limited revenue-generating potential in areas without big game animals, the fact that rural people may consider eventually that the amount of revenue received is too low and that the widespread application of CBC programs requires significant changes in the relationship between central governments and rural areas.

Also Brown (1998) analysed the implementation strategy of CBC in low tourist potential areas of tropical Africa. According to this author, alternative resources schemes identified and developed to replace existing livelihood strategies (alternative income-generating activities IGA) have a number of limitations: they often lack any direct association with the goal of conservation (see also Newmark 2000) and even where they prove successful, there is no guarantee that the population will accept them as alternative rather than additional sources of income, still less that they will contribute to the conservation of the valued resource. The same author underlines the constraints to paying compensations for the extra costs incurred by conservation activities due to the high costs and the limitations for tourism in most parts of West and West-Central Africa (lack of tourist infrastructure, game more thinly spread and less conditioned to the human presence). Benefits that can be derived from tourism development and allied activities (sport hunting, for example) as a motor for development are thus very limited in such cases. 
However, it should be noted that many community-based conservation initiatives are non-utilitarian (Roe et al. 2000, Kothari 2001, Borrini-Feyerabend 2003), and are generated by cultural factors (e.g. conservation of sacred spaces) or for ecological functions (e.g. forests as water catchments).

The implementation of community-based conservation initiatives is influenced by a number of factors, which are essential for their success: an enabling legal framework, the clarification of tenure rights and modes of access to the resources, the adoption of adapted management structures, an adequate conservation and development policy and the availability of financial resources (Wells and Brandon 1993, BorriniFeyerabend 1996, Roe et al. 2000).

There is no unique method able to conserve the world's biodiversity alone. Following Western (2001), CBC is no exception to the limitations of each method, and only in combination are state driven and community-based conservation initiatives, as complementary strategies, likely to achieve major success. As Wilshusen et al. (2002) emphasize, beside conservation science, greater recognition of the deep political and social complexity inherent in conservation work is needed for safeguarding biodiversity. 


\section{Study area}

\section{III.1. The coastal zone}

\section{III.1.1. Geography and climate}

The Republic of Guinea-Bissau is a $36,125 \mathrm{~km}^{2}$ large country, which is located at the West African coast between Senegal in the north and Guinea Conakry in the southeast. To the national territory of this small country belong also the Atlantic Archipelago Bolama Bijagós (Figure1). Guinea-Bissau is located in the transition zone between the Sudano-guinean and the Guineo-Congolean zone (White 1983); the East and the North-East are part of the Sudano-guinean zone, whereas the coastal and the island region are located within the Guineo-Congolean zone (da Silva \& Said 1997).

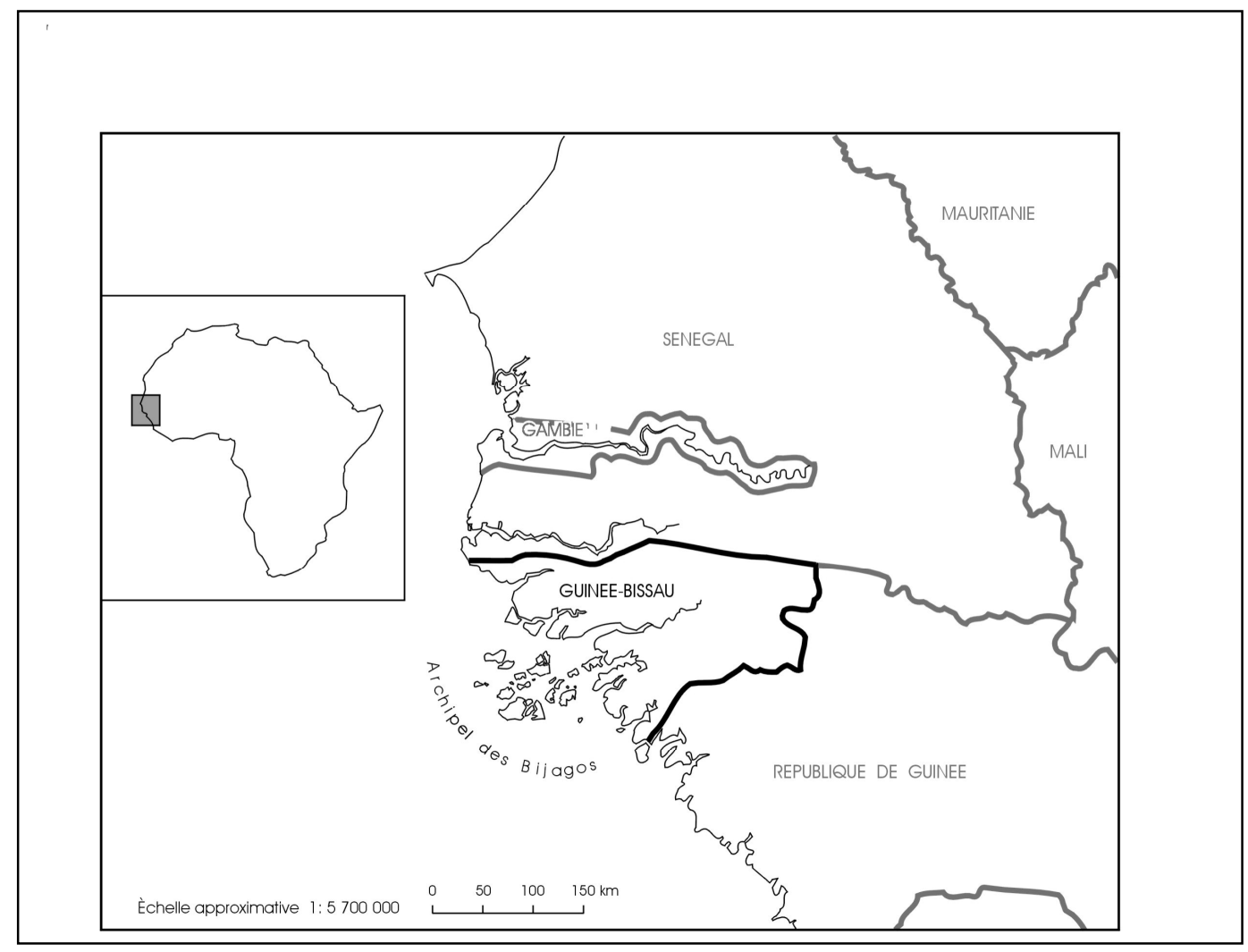

Figure 1. Location of Guinea-Bissau

Largest sections of the country form a coastal plain, which changes to the east into a low plateau of 200 to $300 \mathrm{~m}$. Latter constitutes a continuation of the Fouta Djalon Mountains from the Republic of Guinea. The almost $300 \mathrm{~km}$ long coastal line is 
crossed by numerous rivers, which form large flood areas; the sea water penetrates up to $100 \mathrm{~km}$ within the continental part of the country (IUCN/MDRA-DGFC 1993).

The climate is moist tropical, characterized by one dry season which lasts from November to June and one rainy season which begins in June and ends in November. The average temperatures are situated between 28 and $30^{\circ} \mathrm{C}$ and the annual precipitation between 1500 in the north and $2700 \mathrm{~mm}$ in the extreme Southwest. However, there is evidence of a decrease in rainfall quantity and duration for some years in the country.

\section{III.1.2. Vegetation}

The country's vegetation, originally a mosaic of lowland forests and woodland savannah, was widely modified by forest destruction, soil erosion and overgrazing. The landscape of Guinea-Bissau's coastal zone is characterised by an extensive interpenetrating of terrestrial and aquatic environments, including vast estuaries, a large archipelago and seasonally flooded coastal plains. The main vegetation types occurring in the coastal zone include mangroves, grasslands, wooded savannahs, dry and semi-dry forests, palm groves and sub-humid lowland forests (IUCN/DGFCMDRA 1993).

Today, forests still exist in the lowland and along the coast, often as gallery forests. Humid semi-deciduous lowland forests are still represented with small areas, particularly in the north-west and in the south of the country, where they stay in connection with the forest areas of Guinea Conakry, Liberia and Sierra Leone (Malaisse, 1996). In the year 1993, humid forests only covered approximately 5.2\% of the coastal zone (Géosystèmes 1993, cited by da Silva and Said 1997).

Humid forest areas have been submitted to rapid deforestation in the last two decades, mostly due to conversion for subsistence agriculture and cash crop production, immigration and the reduced productivity in traditional mangrove rice culture systems (IUCN/DGFC-MDRA 1993).

Dry and semi dry forests are present in the centre-southern and the centre-northern part. Together with savannahs, dry and semi dry forests are the dominant vegetal formations of Guinea-Bissau. They are converted for slash-and-burn agriculture ("m'pam-pam"), and have been submitted to overexploitation by industrial logging 
activities, mostly concentrated on Khaya senegalensis. These forest areas also continue to be exploited for charcoal production (IUCN/DGFC-MDRA 1993, Dias 2000). They are considered to cover about $26.3 \%$ of the coastal zone (Géosystèmes 1993, cited by da Silva and Said 1997).

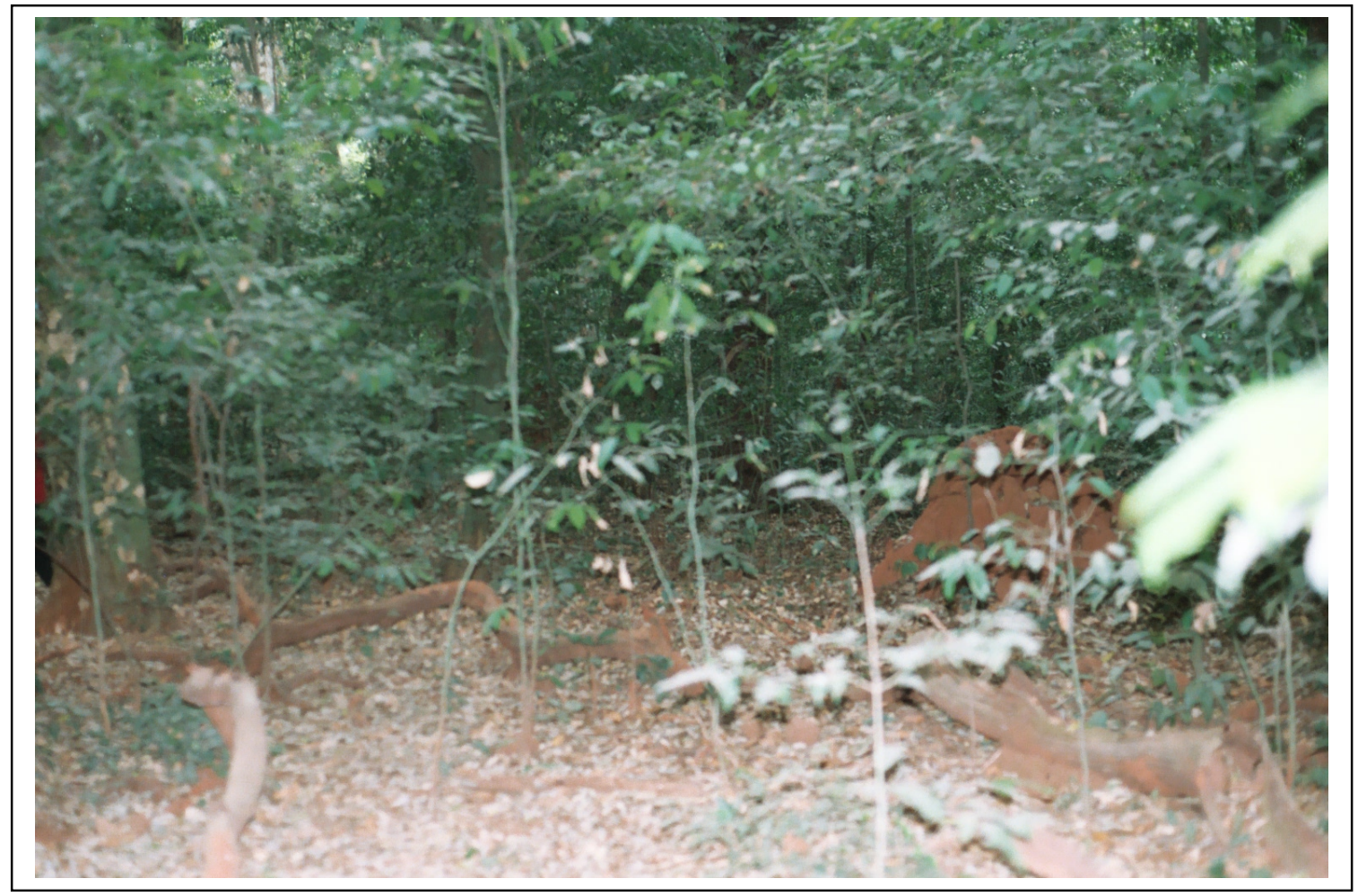

Figure 2. Humid forests - Cantanhez (C. Karibuhoye)

The more humid slopes and valleys are covered by gallery forests, which are also characterised by a higher proportion of Elaeis guineensis palm trees. Gallery forests are frequently associated with food crop areas, and are converted mainly for rice production (IUCN/DGFC-MDRA 1993). This vegetation form is situated essentially in the north-western region and occupies $2.75 \%$ of the coastal area (Géosystèmes 1993, cited by da Silva and Said 1997).

Along the coast and around the islands of the Bijagós Archipelago there are large surfaces of mangrove forests. With a mangrove area over $2000 \mathrm{~km}^{2}$, which achieves a height of $10 \mathrm{~m}$, Guinea is an important reproduction site for sea fish (Martin 1989). Mangroves ("tarrafe") cover 7\% of the country's area (Géosystèmes 1993, cited by da Silva and Said 1997) and almost a third of the coastal zone's area. The largest areas are found in the north-west along the Cacheu River, in the south-west along the Rio Cacine and Cumbidja, and around the Orango and the Formosa islands 
groups. The following species are present in Guinea-Bissau: Avicennia africana, Avicennia nitida, Rhizophora mangle, Rhizophora racemosa, Laguncularia racemosa and Conocarpus erectus (Malaisse 1996, da Silva and Said 1997). Large mangrove areas have been converted for rice production ("bolanha de tarrafe"), but this production system has shown a progressive degradation, mostly due to decreasing rainfall and lack of manpower induced by rural exodus.

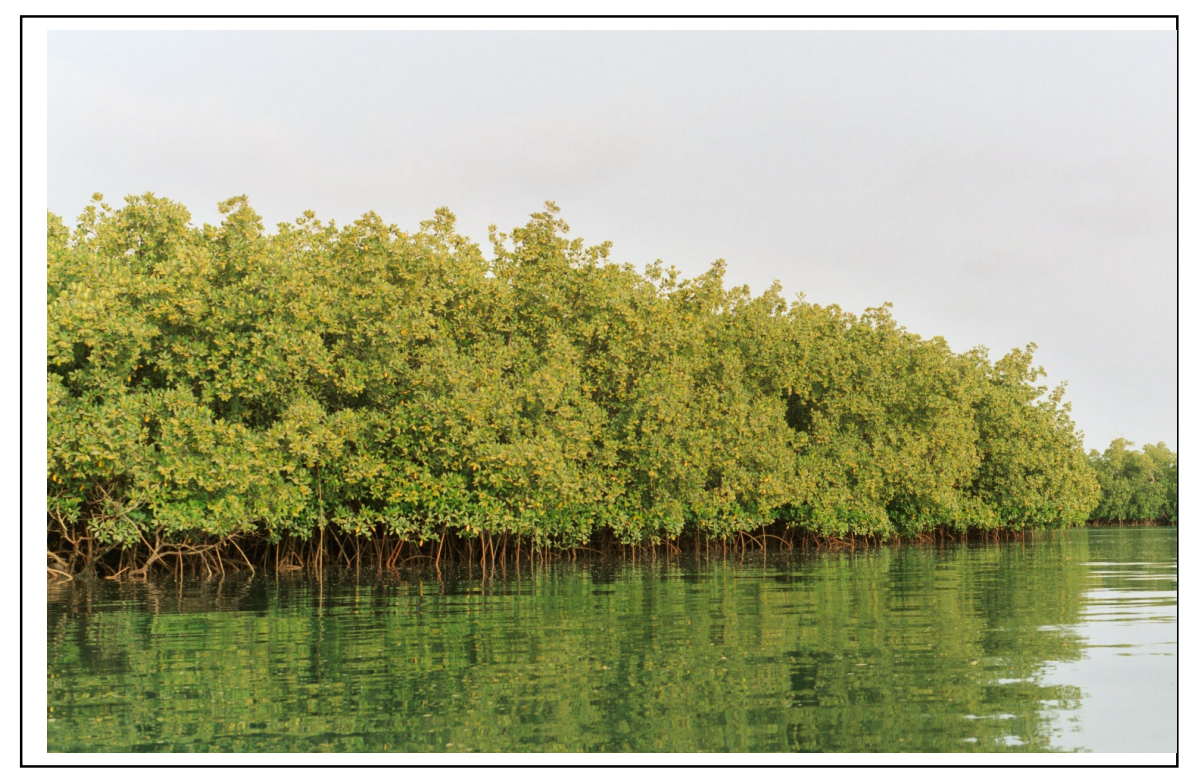

Figure3. Mangrove forests -Formosa (C. Karibuhoye)

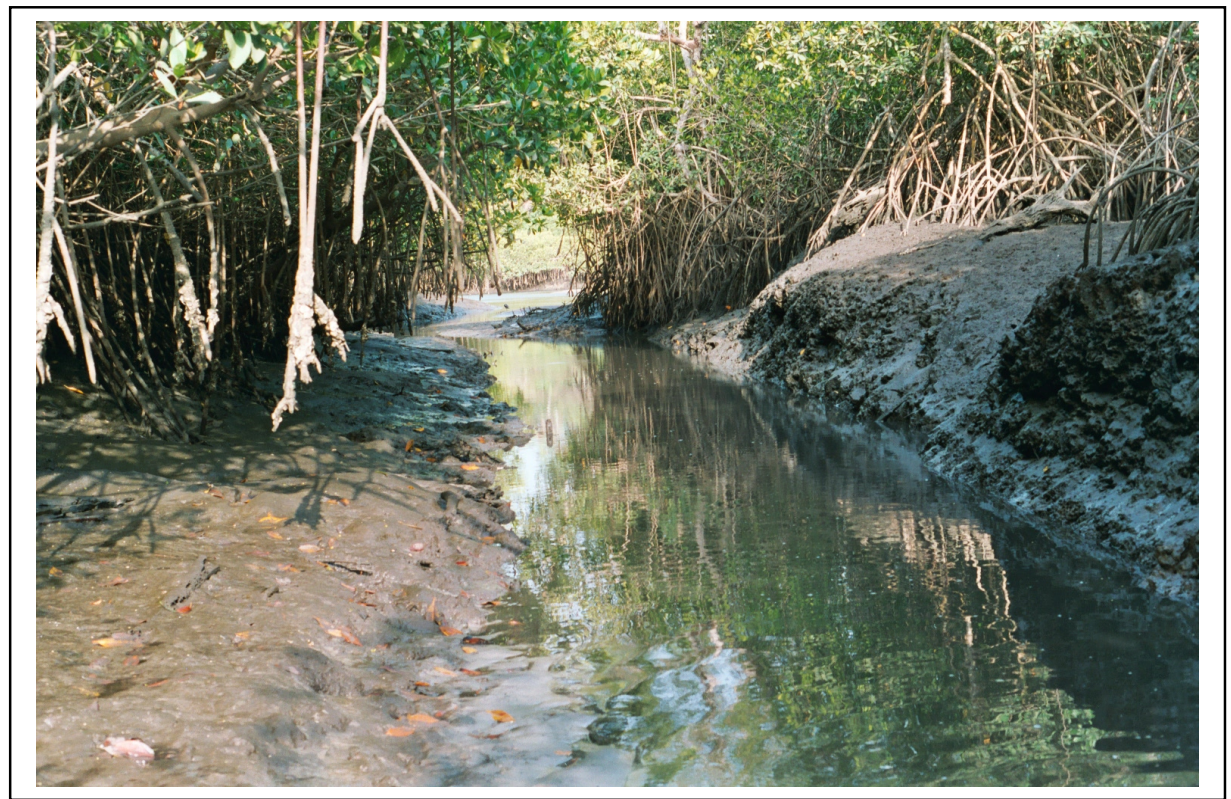

Figure4. Mangrove forests - Ambuduco, Orango (C. Karibuhoye)

In the north-western part of the country and in the Bijagós archipelago, larger areas of palm tree forest are present, mainly dominated by the oil palm Elaeis guineensis with locally restricted massifs of Ron or Borassus palm Borassus aethiopium. Palm groves are also used for agricultural production (rice, other cereals, beans). Pal trees 
are largely exploited for palm oil and wine production, and the trunks are used for house building (particularly Ron palm). The bulk of palm forests are situated in the North-East and in the Bijagós archipelago, covering about $4.4 \%$ of the coastal zone (Géosystèmes 1993, cited by da Silva and Said 1997).

Coastal tree savannahs are adapted to coastal sandy soils and characterised by a dominant grass layer, with sparsely distributed shrub formations. Latter may be sometimes replaced by more homogenous formations dominated by palm trees (IUCN/DGFC-MDRA 1993). The grass areas are also used for rice production ("bolanha"). Tree savannah areas have been considered to increase in GuineaBissau, due to the increasing forest degradation. Their area was estimated at $2.8 \%$ of the coastal zone (Géosystèmes 1993, cited by da Silva and Said 1997).

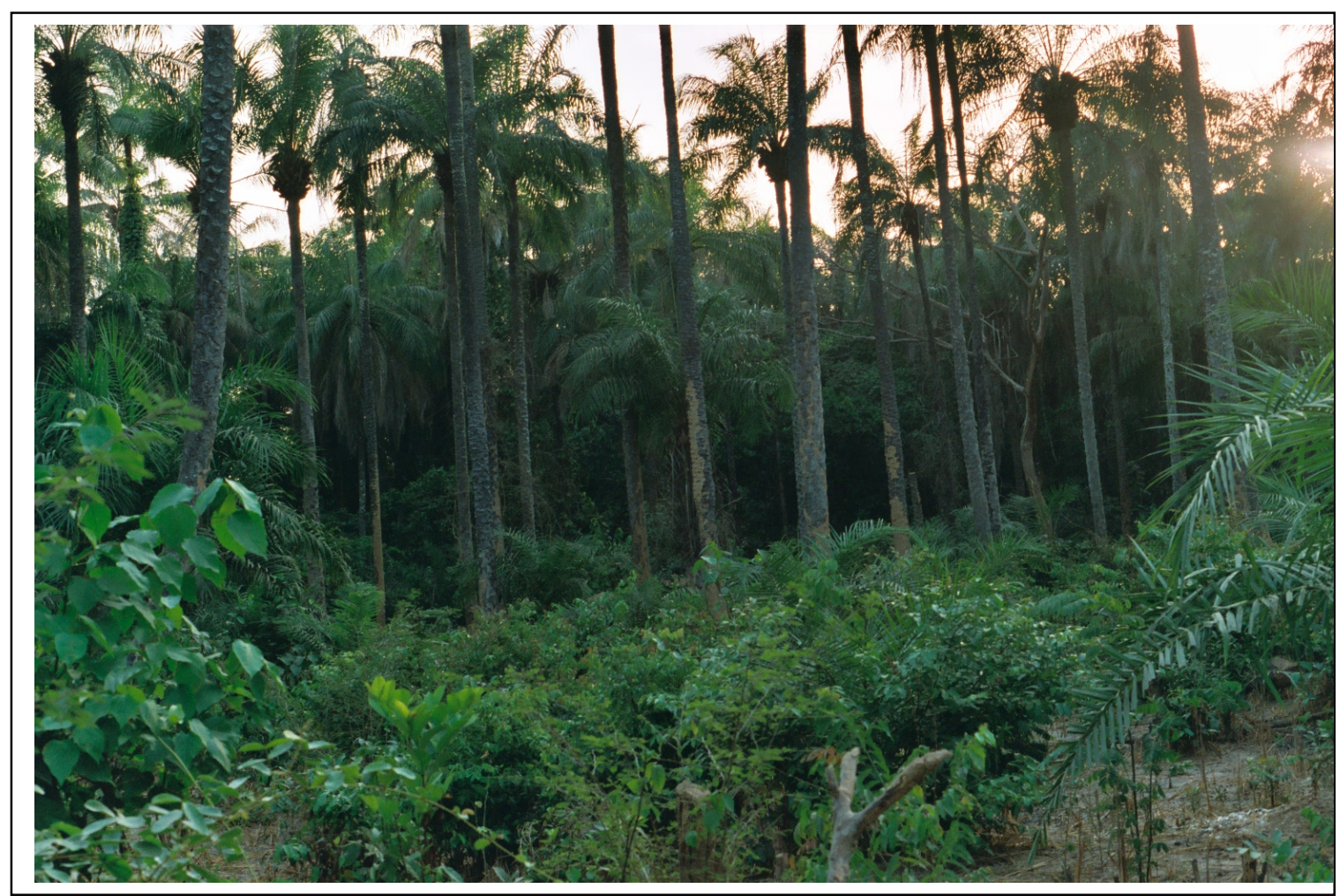

Figure5. Palm forest - Canhabaque Island (C. Karibuhoye)

Humid grass savannahs ("lala") are located in the low humid areas, river or estuarine valleys, which are inundated during the rainy season. These areas, which are almost deprived of trees, are used for rice production ("bolanha de lala") and also as pasture zones after the rainy season (IUCN/DGFC-MDRA 1993). Humid grass savannahs 
are distributed throughout the country and covers about $5 \%$ of the coastal zone (Géosystèmes 1993, cited by da Silva and Said 1997).

\section{III.1.3. Human activities}

According to the last population census in the year 1991, Guinea-Bissau has actually about 1.2 millions inhabitants, who are distributed among about 20 ethnical groups. More than $65 \%$ of the population currently live in the coastal zone where most economic activity is concentrated (IUCN/DGFC-MDRA 1993) (Figure6).

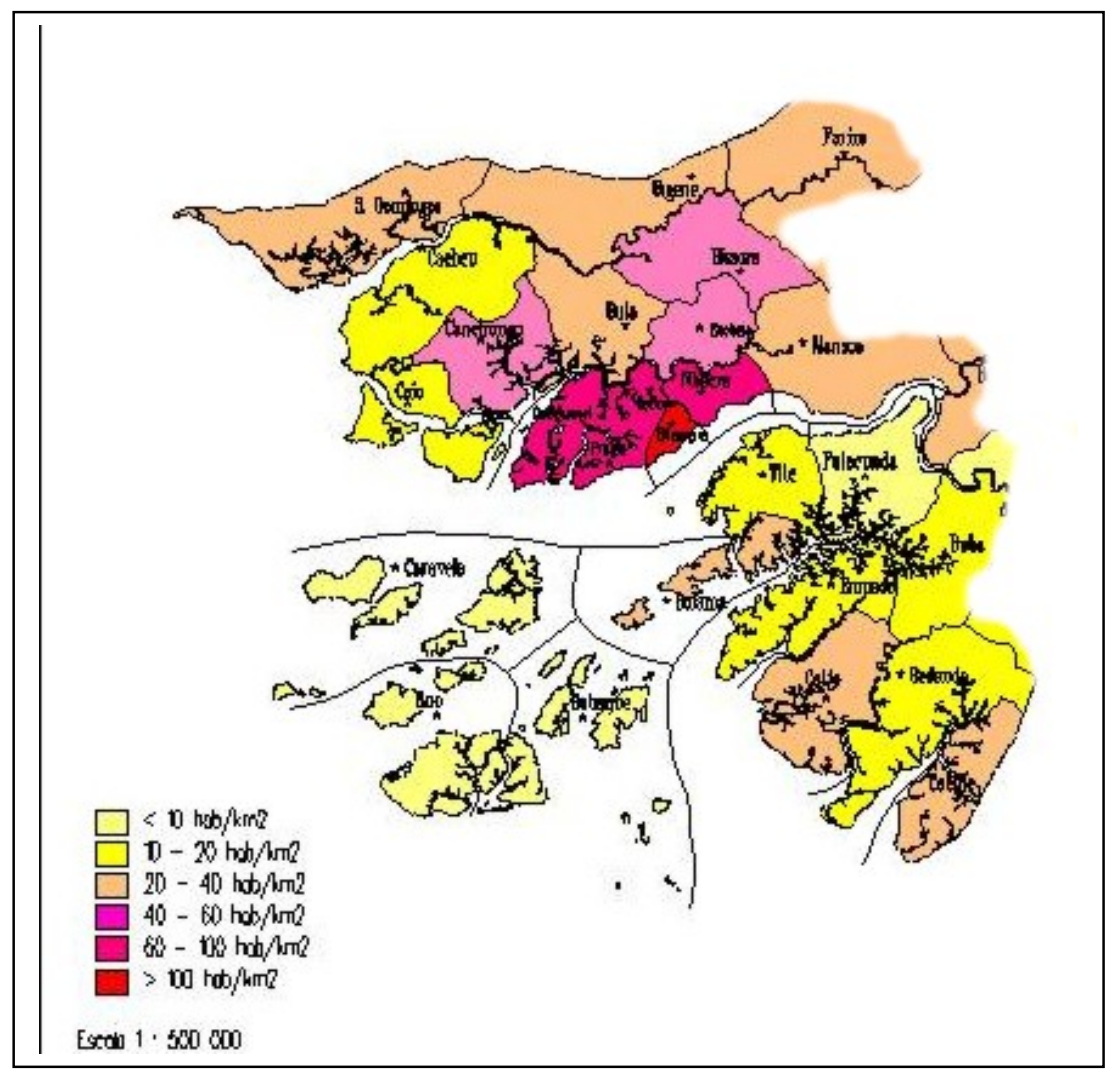

Figure6. Human population density in the coastal zone (Source: Bissasig - Célula SIG INEP/GPC)

Agriculture, forest exploitation and fisheries are the main human economic activities in Guinea-Bissau. Agriculture is the most important economic activity in that country and employs about $75 \%$ of the active population, being essentially oriented towards subsistence production. Mainly rice (the principal aliment) is produced, and to a lesser extent peanuts, beans, sorghum, millet, corn and sweet potatoes. Fruit and vegetables are also cultivated to a smaller scale. Since the eighties, cash crop production has been rapidly increasing, more particularly for cashew nut production. Latter constitutes, along with the licence fees for industrial fishery, the main source of 
foreign currency for the country. Apart from the agriculture, fishery is an important, particularly for the rural coastal population.

\section{III.1.4. Conservation actions}

One of the root causes of biodiversity loss is increasing population pressure on coastal and marine resources. A related cause of biodiversity loss is poverty, and the ensuing lack of economic alternatives. Natural resources currently form the foundation of the livelihood strategies for the majority of the population, for whom few alternatives exist.

Since 1988, Guinea-Bissau has implemented a national conservation programme, which aims at creating a nation-wide protected area network. This coastal zone management programme has been carried out by the government of Guinea-Bissau, with the technical support if the IUCN and international financial support. A number of conservation and development programmes have been carried out by the project, and also by national and international non-government organisations (NGOs).

Most of these programmes have been aiming at supporting sustainable development and poverty alleviation, through the funding of micro-projects focusing on agriculture, fisheries, food security and forestry, in partnership with national NGOs. Environmental education and awareness raising, targeting national decision-makers, technicians, as well as school children and local communities, have been another major component of the programmes.

In order to preserve a representative sample of the natural habitats of GuineaBissau, to protect those where biological diversity is especially high, and to maintain critical ecological and hydrological processes, four priority areas were identified by the coastal zone management programme (IUCN/MDRA-DGFC 1993, Campredon 1993): the Cantanhez forest, the last sub-humid forests of the country; the Cufada Lagoons, the country's first and only Ramsar site; the mangroves of the Rio Cacheu, one of the most extensive and best conserved mangrove areas in the country and the Orango islands group in the Bijagós Archipelago. 


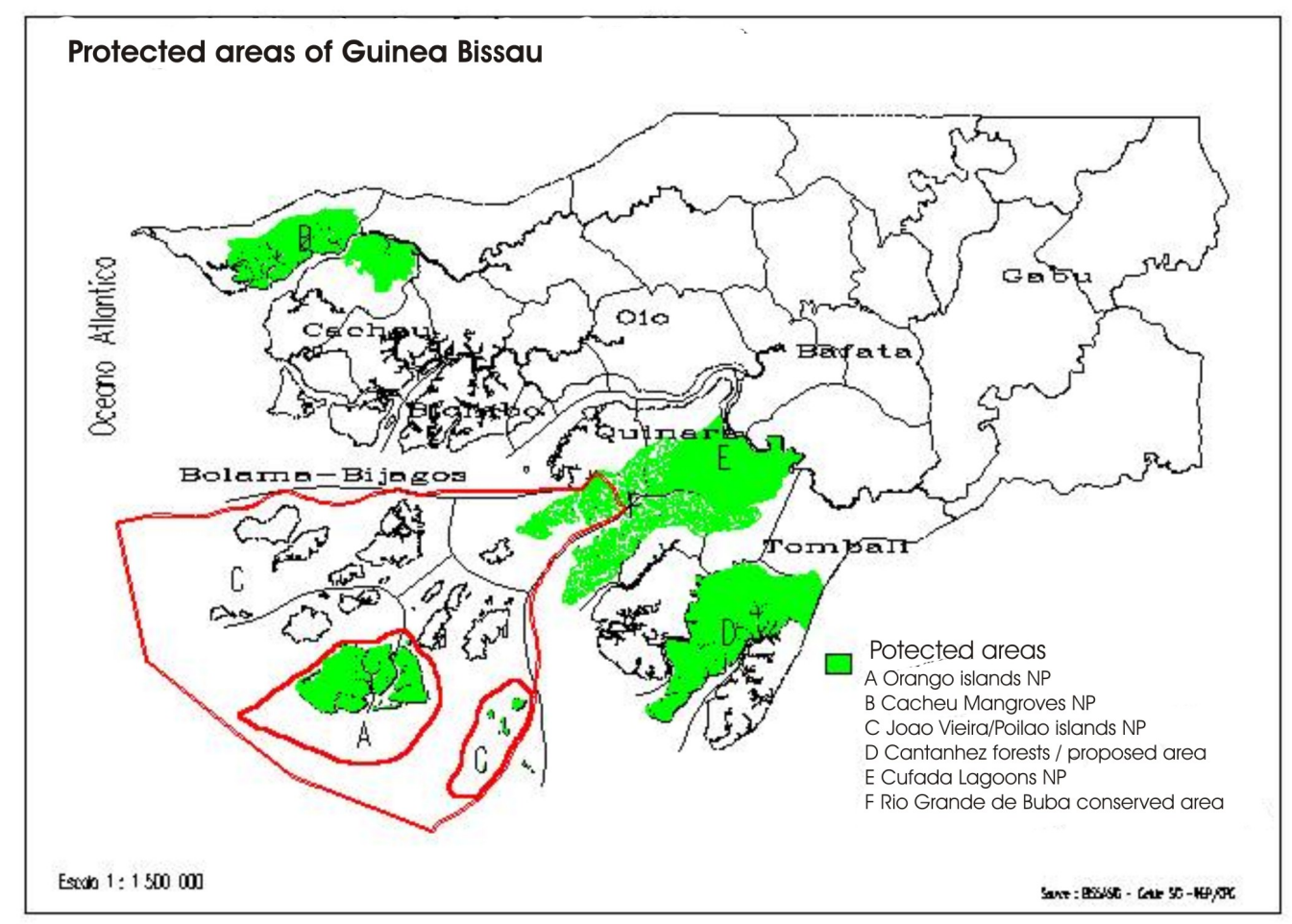

Figure7. Official and proposed PA in coastal Guinea-Bissau (Source: Bissasig - Célula SIG INEP/GPC)

Five protected areas have been officially nominated in Guinea-Bissau's coastal zone (Figure7). The Bolama - Bijagós archipelago biosphere reserve was recognised 1996 by the UNESCO, the mangrove national park of Cacheu and the national park of Orango islands were nominated officially in the year 1997 and the Natural park of Cufada was created ad juri in 1997. In the year 2000, the islands of João-Vieira and Poilão, in the southern part of the Bijagós Archipelago, were classified as a marine national park, for being considered the largest green turtle nesting site on the Atlantic coast of Africa (Fortes et al. 1998, Catry et al. 2002).

Although Guinea-Bissau has succeeded in establishing a network of protected areas, there is little effective management of these areas and management plans must still be finalised and implemented. 


\section{III.2 The selected study sites}

\section{III.2.1. The Bolama-Bijagós Biosphere reserve}

The Bolama-Bijagós archipelago is located in south-west of Guinea-Bissau, between $10^{\circ} 43^{\prime}-11^{\circ} 40^{\prime} \mathrm{N}$ and $15^{\circ} 20^{\prime}-17^{\circ} 00^{\prime} \mathrm{W}$, with a total area of more than $11,000 \mathrm{~km}^{2}$, of which about $1100 \mathrm{~km}^{2}$ (including $350 \mathrm{~km}^{2}$ of mangrove) are mainland and $1600 \mathrm{~km}^{2}$ are intertidal area. The major habitats and land cover types are mangroves; palm forests; mixed dry and semi-dry forests; secondary or degraded forests; coastal savannah; wet savannah; sand banks and rocky aquatic zones. This archipelago consists of more than 80 islands and small islands, of which about 20 are permanently and 20 are temporally inhabited, for agricultural production or religious ceremonies. A population of about 25.000 inhabitants, among which $90 \%$ belong to the local Bijagós ethnic group, live in this region.

The relatively high isolation of this region and the strong cultural identity and tradition, characterised by a parsimonious use of the natural resources, have contributed to the maintenance of a certain equilibrium between the human population and the surrounding ecosystems. However, immigration, market economy, poverty are, among other factors, increasingly threatening this harmonious relationship.

Two different sites were selected in the Bijagós archipelago for this study: the Orango national Park and the Island group of Formosa, and additional short surveys were carried out on the islands of Canhabaque and Bubaque

The Orango National Park has a total area of about $680 \mathrm{~km}^{2}$ (including the marine area) and consists of 5 mains islands (Orango Grande, Imbone, Meneque, Canogo and Orangozinho) and several smaller islands with high cultural importance for the local communities. About 3.000 people live in the region, which is dominated by savannah and mangrove vegetation and is characterised by a high diversity of terrestrial and marine wildlife species (Limoges \& Robillard 1991).

Three main islands (Formosa, Chediã and Ñago) and several small islands form the Formosa group, which occupies a total area of about $545 \mathrm{~km}^{2}$. Dry forests and mangroves are the dominant vegetation forms in this region, which is important for marine vertebrates and Palearctic waders. Mangroves build here one of the largest continued formation in the archipelago, beside the Orango NP. About 2572 
inhabitants live in this region. The greater proximity to the continent led to a higher immigration rate and also to a higher pressure on natural resources.

\section{III.2.2. The Cantanhez forests}

The Cantanhez forests are located in the south of Guinea-Bissau near the border with the Republic of Guinea, between $11^{\circ} 05^{\prime}-11^{\circ} 20^{\prime} \mathrm{N}$ and $14^{\circ} 55^{\prime}-15^{\circ} 15^{\prime} \mathrm{W}$ (Figure7). They are situated between the Rio Cacine and the Rio Cumbidja and represent the most southern peninsulas on the Guinea-Bissau's coast.

The region is considered to be one of the 9 most important natural sites and the biodiversity richest part the country (WCMC 1991). Results of a phytogeographical study of Cantanhez (Malaisse 1996) showed that the region to hosts the last remnants of dense sub-humid forest of Guinea-Bissau. The Cantanhez region covers an area of approximately $1067.67 \mathrm{~km}^{2}$, inhabited by about 20000 people (da Silva \& Cardoso 2001).

Today, the remaining forests only cover about $650 \mathrm{~km}^{2}$ (da Silva 1997). This region hosts forest mammal species of high conservation concern such as chimpanzees, Colobus monkeys, buffaloes, duikers and seasonally elephants (Appendix2) (Limoges 1989, Silva Naga \& Serra 2001, Silva 2003). About fourteen isolated forest blocs are known to remain today in that area (da Silva 1997), which play a crucial role for the conservation of the biodiversity of Guinea-Bissau. However, these forests are rapidly dwindling due to great human pressure, more particularly slash-and-burn agriculture and Borassus palm exploitation (da Silva \& Cardoso 2001).

Although great part of Cantanhez is officially a hunting reserve since 1980 (MDRA/DGFC 1980), this status has not been translated in any protection measure in practice. Various studies have recommended the nomination of this region as a protected area (IUCN-MDRA/DGFC 1993, da Silva 1997, Tiniguena 1997, da Silva \& Cardoso 2001) in order to stop the rapid dwindling of this unique heritage.

\section{III.2.3. The Natural Park of the Cufada lagoons}

The Natural Park of the Cufada lagoons is located in southern Guinea-Bissau, between $11^{\circ} 34^{\prime}-11^{\circ} 51^{\prime} \mathrm{N}$ and $14^{\circ} 49^{\prime}-15^{\circ} 30^{\prime} \mathrm{W}$ (Figure7). The park is limited by the Rio Grande de Buba, the Rio Fulacunda and the Rio Corubal. The Cufada natural 
park covers an area of about $890 \mathrm{~km}^{2}$ with a population density of $3.9 / \mathrm{km}^{2}$; a total of about 3500 people are distributed in 33 villages situated within the park. Cufada is the largest humid area of the country and is since 1990 the first and only recognised Ramsar site of the country. The Natural Park was legally nominated in the year 1997. With its close mosaics of open forests and woodland, this place is an important habitat for large ungulates (Limoges 1989) (Appendix2), and is internationally recognised as an important area for the migrating Palearctic birds. The Cufada Park is located at the intersection of two main roads and between three main local markets (Buba, Quebo and Fulacunda). For this reason, and due to the weak law enforcement capacity by the authorities, this Park has been suffering from heavy hunting pressure, mostly by outside hunters, which supply mainly the neighbouring market of Buba.

As in the Cantanhez region, population migration from the drier northern regions of the country, subsistence agriculture, uncontrolled logging, deforestation either for cash crop production or as an occupation strategy due to property right insecurity are the main causes of forest destruction (Embali \& da Silva 1997, Tiniguena 1997, da Silva \& Cardoso 2001).

\section{III.2.4. The Cacheu Mangroves Natural Park}

Situated in the north-western part of the country along the Rio Cacheu (Figure7), between approximately $12^{\circ}-12^{\circ} 20^{\prime} \mathrm{N}$ and $15^{\circ} 30^{\prime}-16^{\circ} 30^{\prime} \mathrm{W}$, the Cacheu Natural Park is dominated by a complex of estuarine mangroves, swamp and marsh land. About 1500 people live within the park, which occupies a total area of about $700 \mathrm{~km}^{2}$ (including the aquatic area). About $68 \%$ of the Park area are covered by mangroves, which represent $14 \%$ of the country's total mangrove area.

The region is of great importance to Palearctic waders and other aquatic birds and is considered of great importance for the reproduction of shrimps. It also hosts swamp and mangrove dwelling mammal species, such as hippopotamus, manatee and marshbuck (Limoges 1989, IUCN/DGFC-MDRA 1993).

Beside mangroves, dry forests are another important dominating vegetation form. Subsistence agriculture with slash and burn techniques, uncontrolled logging and cash crop production are the main causes for deforestation in that region. 


\section{Methods}

An understanding of the relationship between population biology, economics and rural communities' use of wildlife within and around protected areas is essential to community management plans for sustainable use of the protected area's natural resources (Bodmer 1994).

\section{IV.1. Field data collection on mammal distribution and abundance}

Assessment of distribution and status of mammals was achieved by analysing and combining data from different sources: results from direct observations made during field surveys, data from group interviews in the selected village and from informal discussions with local communities and conservation authorities, identification of trophies and skins from hunted animals encountered in the villages, and bibliographical study on previous censuses and surveys and other existing literature.

\section{IV.1.1. Mammal field survey}

For this study, mainly large and medium-sized mammals were taken into consideration, for being the most threatened animal species and the privileged targets for hunting in Guinea Bissau. Surveys included the following orders: Primates, Artiodactyla, Proboscidea, Sirenia, and also Tubulidentata, Pholidota, and Carnivores. Field surveys of large and medium-sized mammals in the field were carried out between June and September 2002 and between April and Mai 2003. Additional data were collected in the field in May 2001, November-December 2003 and February 2004.

At each survey site, one survey routes was selected locally at random, taking specific characteristics of the site in consideration such as vegetation, the size and the accessibility. In three cases, Imbone, Ancaquia and Acagume, two survey routes were chosen for each site. Depending on the dominant physical conditions, degree of visibility and possibility of walking along straight lines, variable strip-width line transect sampling (Buckland et al. 1993) was combined with reconnaissance surveys (Hall et al. 1998, Walsh and White 1999, Beyers et al. 2001) in four of the five study 
sites and on each of the respective survey routes. Exceptions were the Orango Grande and the Imbone island, where only line transect sampling was used, due to the good visibility conditions guaranteed by the locally dominant savannah vegetation, and also the Canogo island, where only reconnaissance sampling was used.

The most survey units thus consisted of transect segments, interspersed by reconnaissance segments, both of variable length. Accordingly, individual census route lengths varied from 2 to $8 \mathrm{~km}$ and the total survey effort amounted $180.23 \mathrm{~km}$; of these, about $61 \mathrm{~km}$ line transects and $121 \mathrm{~km}$ on reconnaissance segments (Table5). Most starting points and survey routes were recorded using a GPS (Figure8).

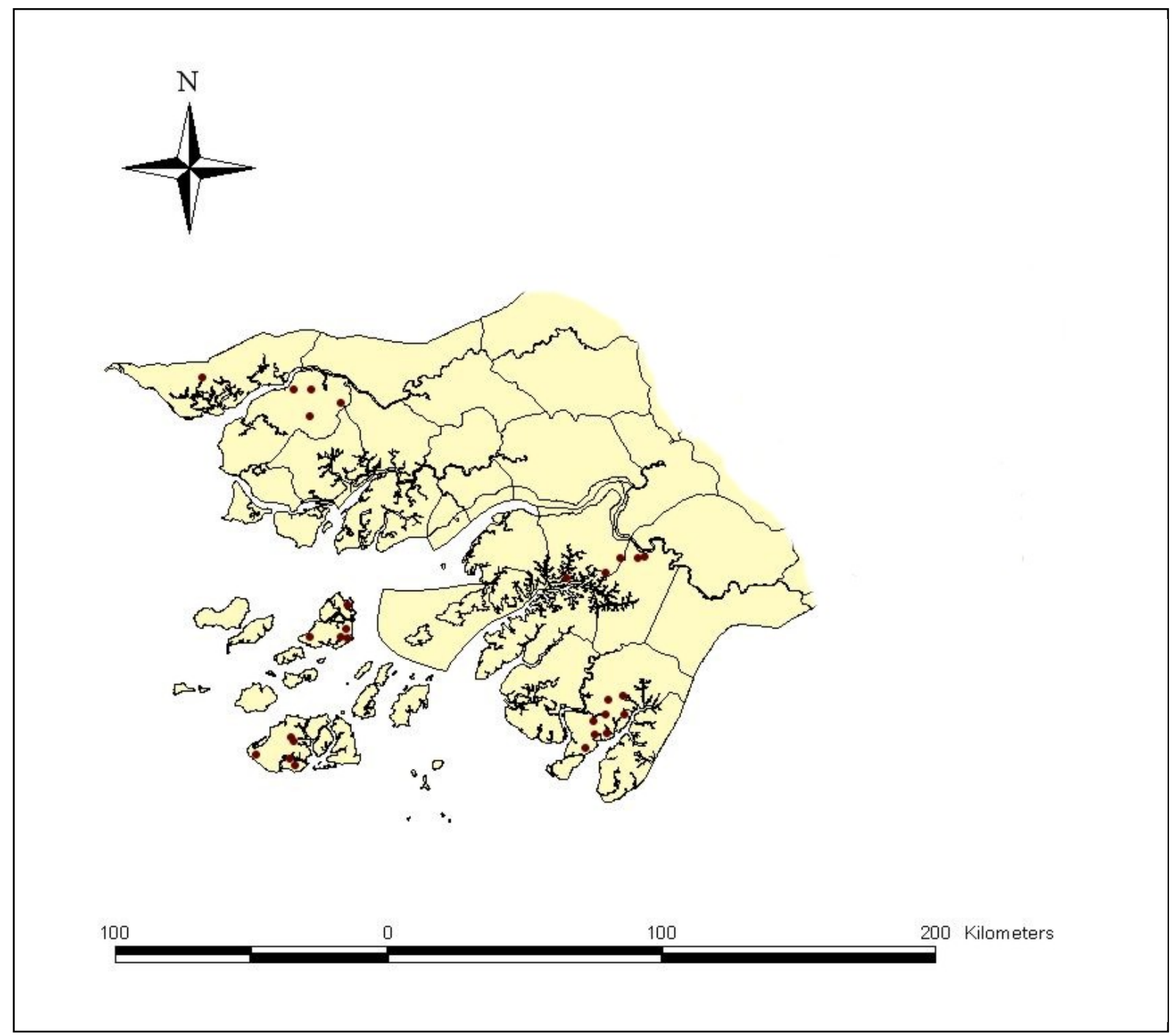

Figure8. Study area showing the location of some census sites (adapted from Bissasig Célula SIG INEP/GPC) 
Routes were generally surveyed in the early morning hours (between 6:00 and 10:00 am) or in the late afternoon (between 4:00 and 7:00 pm). All large and medium-sized mammals seen or heard on transects and on reconnaissance segments were recorded throughout the survey.

Table5. Mammal sampling location and survey effort, with number of Census sites (CS), census routes $(C R)$, Line transect sampling effort $L(t)$, Reconnaissance survey effort $L(r)$ and total survey effort $L(t)$

\begin{tabular}{llllll}
\hline Study site & $\mathrm{CS}$ & $\mathrm{CR}$ & $\mathrm{L}(\mathrm{t})(\mathrm{Km})$ & $\mathrm{L}(\mathrm{r})(\mathrm{Km})$ & $\mathrm{L}(\mathrm{t})$ \\
\hline Orango-Imbone & 6 & 8 & 23 & --- & 23 \\
Canogo & 2 & 2 & --- & 6 & 6 \\
Formosa island & 5 & 5 & 6.23 & 12 & 18.23 \\
Canhabaque island & 2 & 2 & --- & 9 & 9 \\
Bubaque island & 1 & 1 & --- & 2 & 2 \\
Cantanhez & 11 & 12 & 12.2 & 27.7 & 39.9 \\
Cantanhez 2 & 6 & 6 & --- & 20 & 20 \\
Cufada Natural Park & 5 & 5 & 8.3 & 26.7 & 35 \\
Cacheu National Park & 5 & 5 & 9.2 & 17.8 & 27 \\
\hline Total survey effort & 43 & 46 & 61.03 & 121.2 & 180.23
\end{tabular}

For all sighted or heard animals, species and number of observed animals, perpendicular distance to the first observed animal, location, time and when possible animal activity such as feeding, resting or running away were recorded. Unlike Hall et al. (1998), perpendicular distance to the observed group was registered even on reconnaissance segments. Also nest sites of chimpanzees were recorded, and other presence signs of mammals including dung, tracks, and rests of animals were equally identified.

\section{IV.1.2. Survey data analysis}

\section{IV.1.2.1. Relative abundance index}

In order to obtain a crude general overview on mammal abundance, a relative abundance index was calculated for all species encountered, using total direct and indirect observations / surveyed km in each survey sites. 


\section{IV.1.2.2. Density estimates}

a. Due to the small sample sizes for most species observed on transects, density estimate using the computer software Distance 3.5. (Thomas et al. 1998) was made only for primates from Cantanhez and for Callithrix monkeys and Bushbuck from the Orango island group. Due to the very low individual species observation numbers, sightings of all primates in Cantanhez were pooled and a species-specific density was estimated by post stratification (Buckland et al. 1993). The same procedure was applied for Callithrix monkey and Bushbuck in Orango.

Additionally, the following different alternatives for density calculation were tested:

b. Manual density calculation using the formula

$$
D=\frac{n(t)}{2 E S W x L(t)}
$$

with $n(t)$ being the number of observations on line transects, $L(t)$ the total transect length and ESW the effective strip width.

The ESW value used was obtained from analysis with Distance 3.5. Programme. Given that the sample sizes were not large enough to calculate accurately the ESW for each species, as is generally recommended (Buckland et al. 1993), sightings for all transects were combined in order to reduce risk of unrealistic ESW estimates caused by small sample sizes, and a species-specific effective strip was then calculated (Chiarello 2000; de Melo 2001).

c. Density estimate with formula (1) but using the ESW obtained by manual calculation. Two methods were applied:

- the Leopold method, which uses the arithmetic mean of the perpendicular distance between animal and transect line; this method has the advantage of being relatively simple and more suitable where the researcher have little formal education and no access to computer (Steinmetz \& Mather 1996), but leads to overestimates of the density (Struhsaker 2002);

- the Kelker method, which is based on the drop distance or fall-off distance (Whitesides et al. 1988), where

$$
E S W=\frac{N(t)}{N(f) x F D}
$$


with $\mathrm{N}(\mathrm{t})$ being the total observation number, $\mathrm{N}(\mathrm{f})$ the observation number within the FD and FD the fall-off distance, i.e. the first interval at which observation number drops to half or less that of the immediately previous interval.

d. Density calculation, using the calibrated encounter rate $\phi n(r)$ for combined reconnaissance and line transect survey (Walsh \& White 1999, Beyers et al. 2001). Before the data from reconnaissance survey can be used, they must be correct for any difference in encounter rate between reconnaissance and line transect survey. This is done by estimating a correction factor, as the ratio of encounter rate on the line transects with encounter rate on the reconnaissance segments (Walsh \& White 1999), using the formula

$$
\frac{n(t)}{l(t)}=\phi \frac{n(r)}{l(r)}
$$

where $n(r)$ is the observation frequency on reconnaissance survey,

$I(t)$ and $I(r)$ are the lengths of the line transect and of the reconnaissance segments respectively and

$\Phi$ the ratio of encounter rates on line transect to encounters on reconnaissance.

This ratio was then used to calibrate the reconnaissance data (to the expected encounter on a transect with the same length) and to calculate a combined adjusted encounter rate using both the transect data and the calibrated reconnaissance data $(n(I)+\phi n(r)$. From this combined encounter rate, density estimates can be calculated with the formula:

$$
D=\frac{\phi n(r)+n(l)}{2 E S W x L}
$$

However also effective stripe width ESW is variable between reconnaissance and line transects (Struhsaker 2002). For this reason, two alternatives were used here:

d1) an ESW was calculated for the combined line transect and reconnaissance data, following Whitesides et al. (1988) and

d2) the ESW value obtained from line transect data analysis with Distance software was used.

Results from the different density calculation methods using primate field observations data in Cantanhez and partly in the Bijagós archipelago were compared. 


\section{IV.2. Assessment of wildlife use and perception}

\section{IV.2.1. Village interviews}

In order to assess the use patterns and perception of local populations about wildlife in general and wild mammals in particular, interviews were carried out with focus group in villages between June and September 2002 and between April and Mai 2003. In each study zone, four villages were surveyed, with the exception of the Formosa island group where 2 additional village interviews were carried out. A total of 22 villages surveyed on this way, involving 245 persons (Table6).

Table6. Village interviews on wildlife use and perception

\begin{tabular}{llll}
\hline Zone & $\begin{array}{l}\text { Number of } \\
\text { surveyed villages }\end{array}$ & $\begin{array}{l}\text { Name of surveyed } \\
\text { villages }\end{array}$ & $\begin{array}{l}\text { Number of } \\
\text { interviewed people }\end{array}$ \\
\hline Orango NP & 4 & $\begin{array}{l}\text { Ancaquia, Imbone, } \\
\text { Angôr, Eticoga } \\
\text { Abu, } \\
\text { Acuno, Ancadaque, }\end{array}$ & 20 \\
Formosa/Chediã & 6 & $\begin{array}{l}\text { Pandja, Uada, Chedia } \\
\text { lemberem, Cabedu, } \\
\text { Canamine, } \\
\text { Cadique } \\
\text { Buba Tumbo, Ndjassane, }\end{array}$ & 36 \\
Lamane, Bodjol \\
Elia, Guncon, Balimpom, \\
Jopa
\end{tabular}

The selected villages for the interviews were chosen randomly within or around the surveyed protected area/zone, having all some social, cultural or economic relationship (through traditional property right or cultural links) to the surveyed forest . In each village, a semi-structured interview was carried out with a group of persons from the village, mainly influent members of the community, traditional chiefs or leaders, hunters, women, and other members of the village community. During the interview, discussions were made on the basis of prepared and previously formulated questions, whereby succession of the questions remained open (Hopf 1991, Friebertshäuser 1997). 


\section{IV.2.2. Interview data analysis}

The documentation of a semi-structured interview is a very time-consuming and complicated process. It is difficult to code and analyse the data and it requires some interpretation of responses by the person conducting the analysis. For data analysis, it is recommended to use tape recordings of the interviews, and in order to correctly analyse the data gathered from the interviews, it was necessary to entirely transcript the recorded conversations, so that no part of the reality could get lost (Meuser \& Nagel 1991, Schmidt 1997).

Beside general social and ecological information on the region and information on the most important economical human activities, the interview included the different aspects of perception of wildlife use and status by local population, as distributed in the following main categories:

- local extant mammal species

- $\quad$ hunting activities in the village

- population trends of wild mammals

- mammal conservation needs

- conflicts with mammals

- perception on worth/value of wildlife for people

- existing taboos on mammals

- Wildlife in the local mythology

- knowledge on existing hunting regulations

- wild meat trade and

- wildlife monitoring

Only the analysis of all the data allows to identify the most important information and to transmit faithfully the respondents' opinion. The data from each village were analysed with reference to the main theme categories from the interview and a subsequent compilation of the results was made by theme and survey site.

For more accurate identification of mammal species, illustrative material was used such as colour plates and identification manuals. In some cases, trophies, skins and other parts of killed animals were identified. Other additional sources of information in the field were mainly direct observation and informal discussions with individual hunters and villagers, technicians and representatives of projects and NGOs working in the study area and conservation administration officials. 


\section{Results}

\section{V.1. Distribution and conservation status of selected large mammals in the coastal zone}

The occurrence of about 39 large and medium-sized mammal species from 15 families was confirmed in the coastal area of Guinea Bissau. Not included in this study are the following orders: insectivores Insectivora, hares Lagomorpha, rodents Rodentia and bats Chiroptera.

\section{V.1.1. Primates}

\section{V.1.1.1. Species distribution}

The occurrence of eleven primate species from four families was confirmed in the coastal forests (Table7). Forest species were observed mostly in the Cantanhez forests and their presence was referred to by local people also in the southern Cufada region (Table7 and Figure13).

Among these species are two endangered species: the Western Chimpanzee and the Temmincki's red colobus, but also canopy dwelling species endemic to the West African sub-region: Western pied colobus, Campbell's monkey and lesser spot-nosed monkey. Two of these species were observed also in the less humid forests of the Northern Cacheu Natural Park: Temmincki's red colobus and Campbell's monkey.

Two primate species are referred to only in the Cufada Natural Park: lesser spot-nosed Monkey, and Sooty mangabey. Beside of these forest species, three quite ubiquitous savannah species were observed in the study area: Callithrix monkey, Patas monkey and Guinea Baboon, latter only in the South.

Lesser spot-nosed Monkey, Campbell's and Callithrix Monkey are the only three primate species occurring in the Bijagós archipelago: the former was observed on the Canhabaque and Bubaque islands and latest in the Orango NP and on Formosa. Only verbal records on the occurrence of Galagos were obtained in the southern coastal region. 
Table7. Data on primate species distribution in the coastal forests of Guinea Bissau by field observations $(\mathrm{O})$ and verbal records $(\mathrm{V})$

\begin{tabular}{|c|c|c|c|c|c|c|c|c|c|c|c|c|c|c|}
\hline & \multirow[b]{3}{*}{ Scientific name } & \multirow[b]{3}{*}{ Common name } & \multicolumn{4}{|c|}{ Southern region } & \multirow{2}{*}{\multicolumn{2}{|c|}{$\begin{array}{l}\text { North } \\
\text { Cacheu }\end{array}$}} & \multicolumn{4}{|c|}{ Bijagós archipelago } & \multirow{2}{*}{\multicolumn{2}{|c|}{ Canhabaque }} \\
\hline & & & \multicolumn{2}{|c|}{ Cantanhez } & \multicolumn{2}{|c|}{ Cufada } & & & \multicolumn{2}{|c|}{ Orango } & \multicolumn{2}{|c|}{ Formosa } & & \\
\hline & & & $\mathrm{O}$ & V & $\mathrm{O}$ & V & $\mathrm{O}$ & V & $\mathrm{O}$ & V & 0 & V & $\mathrm{O}$ & V \\
\hline & Hominidae & & & & & & & & & & & & & \\
\hline \multirow[t]{2}{*}{1} & P.t. verus & $\begin{array}{l}\text { Western } \\
\text { Chimpanzee }\end{array}$ & $\bullet$ & $\bullet$ & $\bullet$ & $\bullet$ & & & & & & & & \\
\hline & Colobidae & & & & & & & & & & & & & \\
\hline 2 & C. p. polykomos & $\begin{array}{l}\text { Western pied } \\
\text { Colobus }\end{array}$ & $\bullet$ & $\bullet$ & & $\bullet$ & & & & & & & & \\
\hline \multirow[t]{2}{*}{3} & P. b. temmincki & $\begin{array}{l}\text { Temminck's or } \\
\text { Red Colobus }\end{array}$ & $\bullet$ & $\bullet$ & & $\bullet$ & & $\bullet$ & & & & & & \\
\hline & Cercopithecidae & & & & & & & & & & & & & \\
\hline 4 & C. a. atys & $\begin{array}{l}\text { Sooty } \\
\text { Mangabey }\end{array}$ & $\bullet ?$ & $\bullet$ & & $\bullet$ & & & & & & & & \\
\hline 5 & C. m. campbelli & $\begin{array}{l}\text { Campbell } \\
\text { monkey }\end{array}$ & $\bullet$ & $\bullet$ & & $\bullet$ & & $\bullet$ & & & & & & \\
\hline 6 & C. n. stampfii & $\begin{array}{l}\text { Greater Putty- } \\
\text { nosed Monkey }\end{array}$ & & & & $\bullet$ & & & & & & & & \\
\hline 7 & C. p. buettikoferi & $\begin{array}{l}\text { Lesser putty- } \\
\text { nosed monkey }\end{array}$ & & & & $\bullet$ & & & & & & & $\bullet$ & $\bullet$ \\
\hline 8 & C. a. sabaeus & Vervet monkey & $\bullet$ & $\bullet$ & $\bullet$ & $\bullet$ & $\bullet$ & $\bullet$ & $\bullet$ & $\bullet$ & $\bullet$ & $\bullet$ & & \\
\hline 9 & P.p. papio & Guinea Baboon & $\bullet$ & $\bullet$ & & $\bullet$ & & & & & & & & \\
\hline \multirow[t]{2}{*}{10} & E.p.patas & Patas Monkey & & & $\bullet$ & $\bullet$ & $\bullet$ & $\bullet$ & & & & & & \\
\hline & Galagidae & & & & & & & & & & & & & \\
\hline 11 & Galago spp. & Bushbabies & & - & & - & & & & & & & & \\
\hline
\end{tabular}

\section{V.1.1.2. Relative abundance and density estimation methods}

Estimates of relative abundance and of group densities for primates are compiled in Table 8. For the comparison of the results obtained on density calculation, data on the species with most observations, Campbell's monkeys, will be considered as a reference. Analysis with the Distance software (method a) and two manual calculation methods, $b$ and $d(2)$, give comparable results for this species group density values.

The results from these three analysis methods are also quite similar for the species $P$. temminckii, despite the lower observation numbers. The results from method $d(2)$, i.e. the use of the combined encounter rate from line transects and reconnaissance surveys, using the ESW value obtained by the software Distance, are used in the discussions below. 
For the chimpanzees and the Callithrix monkeys, only the most conservative values, which were coincidentally also obtained with method $d(2)$ will be taken into consideration, although with reservation. In Orango, the combined line transects and reconnaissance survey method (d) was not tested (only line transect sampling was applied). But even for this site, the results obtained with Distance 3.5. Software analysis and manual density calculation (using ESW from the former) are quite similar, with the values obtained from manual ESW calculation being slightly higher.

\section{V.1.1.3. Abundance and population trends}

\section{Chimpanzee}

Chimpanzees were observed in the southern part of the country, in the Cantanhez forest and the Cufada regions, where they occupy savannah-forest mosaics, secondary forests and gallery forests. Field observations were made in secondary forests, fallow areas and fruits gardens near settled villages and also near frequented roads, on the way to or from the survey sites. In the surveyed regions, these animals do not seem to be shy or to fear human presence and they would cross through villages. Similarly, humans tolerate the presence of chimpanzees in their vicinity and even in their gardens and fields, because this species is not considered being a significant crop raider.

Nests were seen principally in palm trees (Elaeis guineensis), but also in other tree species (Figure9). In Cantanhez, one group was observed near the village of Camarempo and another was sighted in Madina, in a field under fallow. A third group of at least 6 individuals was observed in the forest of Muna. Nests were observed in Cambeque, Muna, Camarempo and Caiquenem. Chimpanzees were not observed in Cufada on the sampling routes. In Cufada, a large group of about 20 individuals was observed in a fruit garden near the village of Bodjol, and crossing the main road between Quebo and Buba (Figures 10 and 11). Relative abundance figures of 0.1 and 0.05 groups $/ \mathrm{km}$ were estimated respectively in 2002 and 2003. Results of this species density calculation show a conservative estimate of $0.88 \mathrm{groups} / \mathrm{km}^{2}$ (Table8). However, due to the very low observation numbers, these results should be taken with the required reserves. 
Table8. Primates relative abundance (N/L in groups $/ \mathrm{km}$ ) and group density in Cantanhez and Orango, obtained with different calculation methods; N: Total observations, $n(t)$ :Line transect encounter, $n(r)$ :Reconnaissance survey encounters.

\begin{tabular}{|c|c|c|c|c|c|c|c|c|c|c|}
\hline Species & $\mathrm{N}$ & $n(t)$ & $n(r)$ & $N / L$ & \multicolumn{6}{|c|}{ Group density estimates (group $/ \mathrm{km}^{2}$ ) } \\
\hline Cantanhez & 48 & & & & a & $\mathrm{b}$ & $c(1)$ & $c(2)$ & $d(1)$ & $d(2)$ \\
\hline C. c. campbelli & 28 & 17 & 11 & 0.7 & $7.2710(3.8287-13.808)$ & 7.3 & 9.05 & 11.36 & 9.07 & 7.25 \\
\hline P. temminckii & 9 & 6 & 3 & 0.22 & $1.1988(0.29915-4.8041)$ & 1.2 & 1.48 & 2.60 & 2.64 & 1.16 \\
\hline C. polykomos & 6 & 5 & 1 & 0.15 & $0.59086(0.15508-2.2512)$ & 0.59 & 1.23 & 0.82 & 0.79 & 0.32 \\
\hline C. aethiops & 1 & 1 & 0 & 0.02 & $2.2731(0.55303-9.3434)$ & 2.28 & 2.27 & 2.27 & 0.63 & 0.69 \\
\hline
\end{tabular}


People recognise a general negative trend in this species population, as with most mammals (Table15), if compared to the period 30 to 40 years ago. This decrease can be recognised from the comparison of this study's data with those from Limoges (1989) despite the fact that chimpanzees are considered by interviewed local people to be locally more frequently observed in the last years in Cantanhez and in Cufada (Table15).

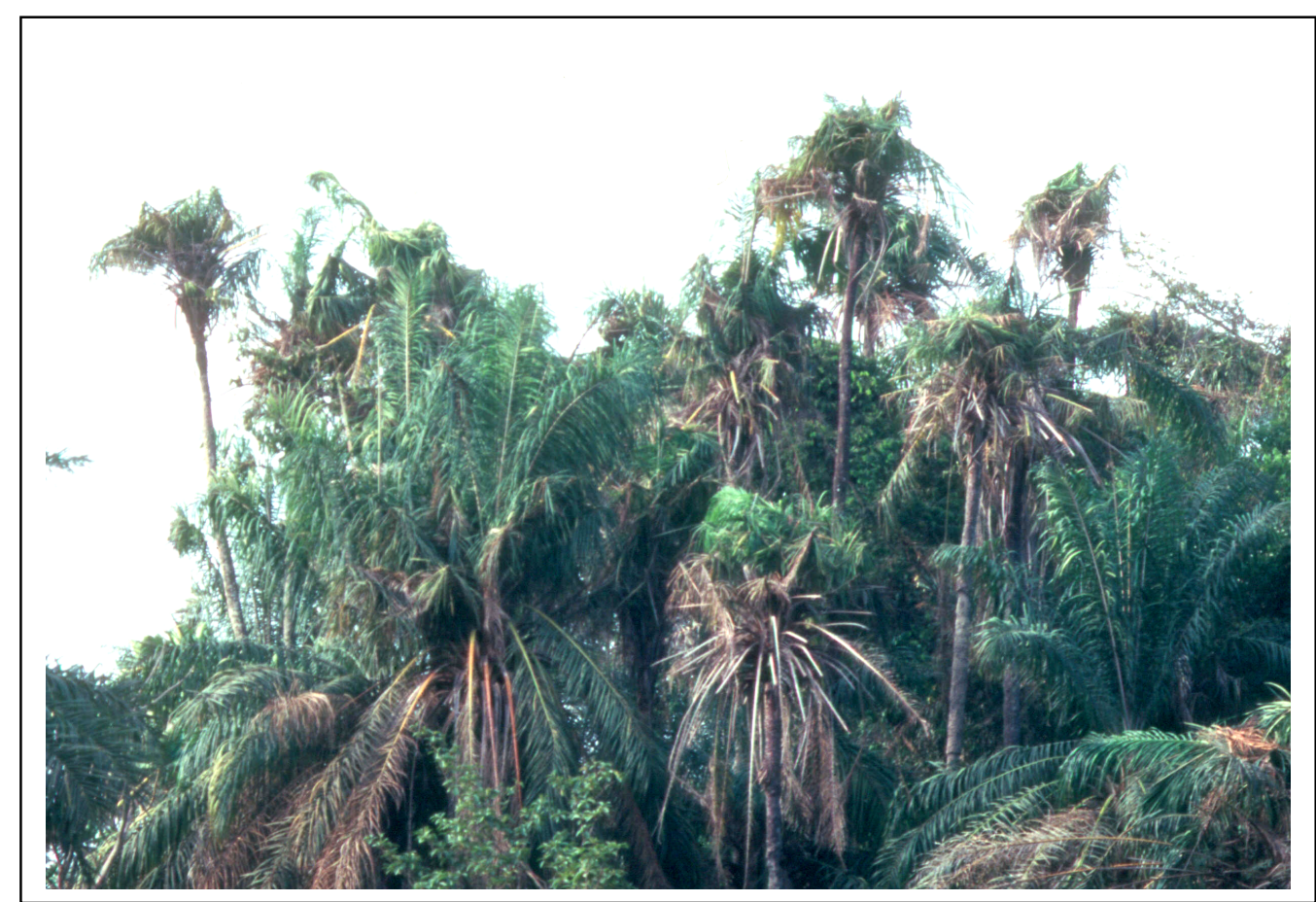

Figure9. Chimpanzees nests in Elaeis guineensis palm trees (J. Dierks)
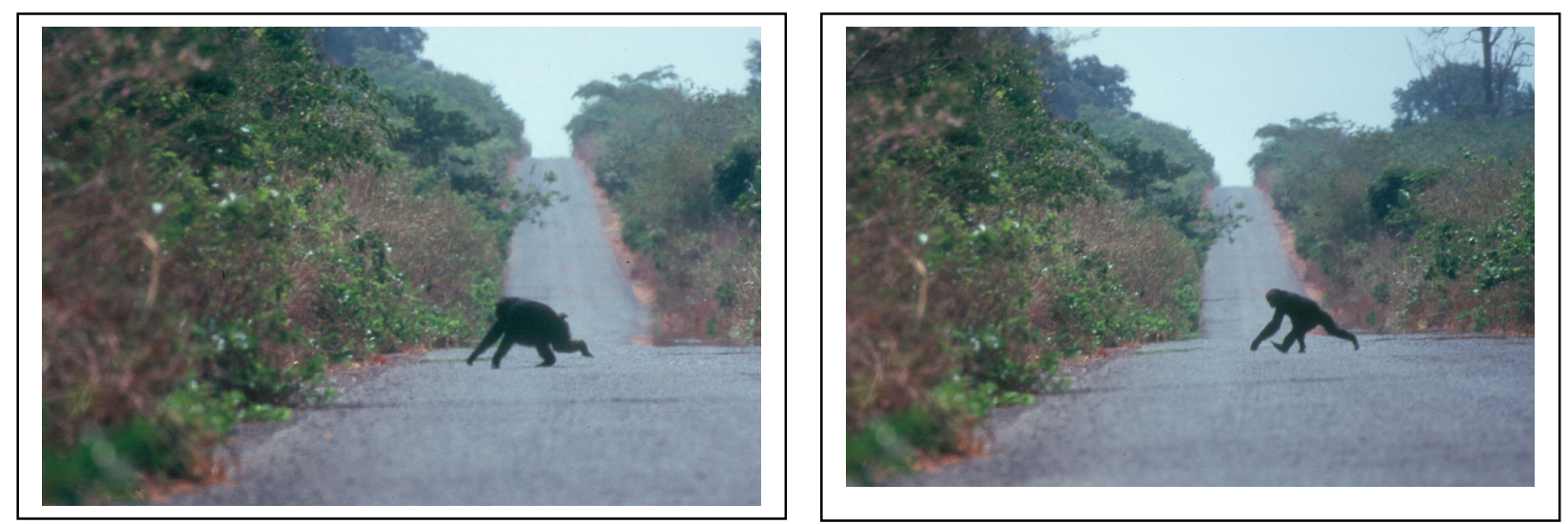

Figure10 and 11. A chimpanzee group crossing the main road between Buba and Quebo (J. Dierks)

\section{Colobus monkeys}

Red and Pied Colobus were observed only in the southern part of the country, namely in Cantanhez, but verbal records of red Colobus were made in Cufada and the Northern Cacheu National Park. These two species were observed very often in association, in 
groups of up to 15 individuals of each species, although Western Pied Colobus were seen often in smaller groups than Red Colobus. Both species were frequently seen feeding in the upper layers of Parinari excelsa (local name: "Mampataz") and Parkia biglobosa (local name: "Faroba") trees (Figure12).

Also Red and pied colobus do coexist peacefully with villagers, particularly in Cantanhez, but Red Colobus are more actively hunted in other parts of the country. In the village of lemberem, a group of about 12 Pied Colobus and one of at least 9 Red Colobus literally live in a group of trees, by the headquarters of a local NGO's project. Numerous groups were observed feeding in trees situated in cultivated fields and not very far from human settlements. The relative group abundance of these species in Cantanhez is estimated at 0.15 and 0.22 groups $/ \mathrm{km}$ for the Pied and for the Red Colobus respectively. A conservative estimation of density showed results amounting about $0.32 \mathrm{groups} / \mathrm{km}^{2}$ for the black and white Colobus and about $1.16 \mathrm{groups} / \mathrm{km}^{2}$ for the Red Colobus.

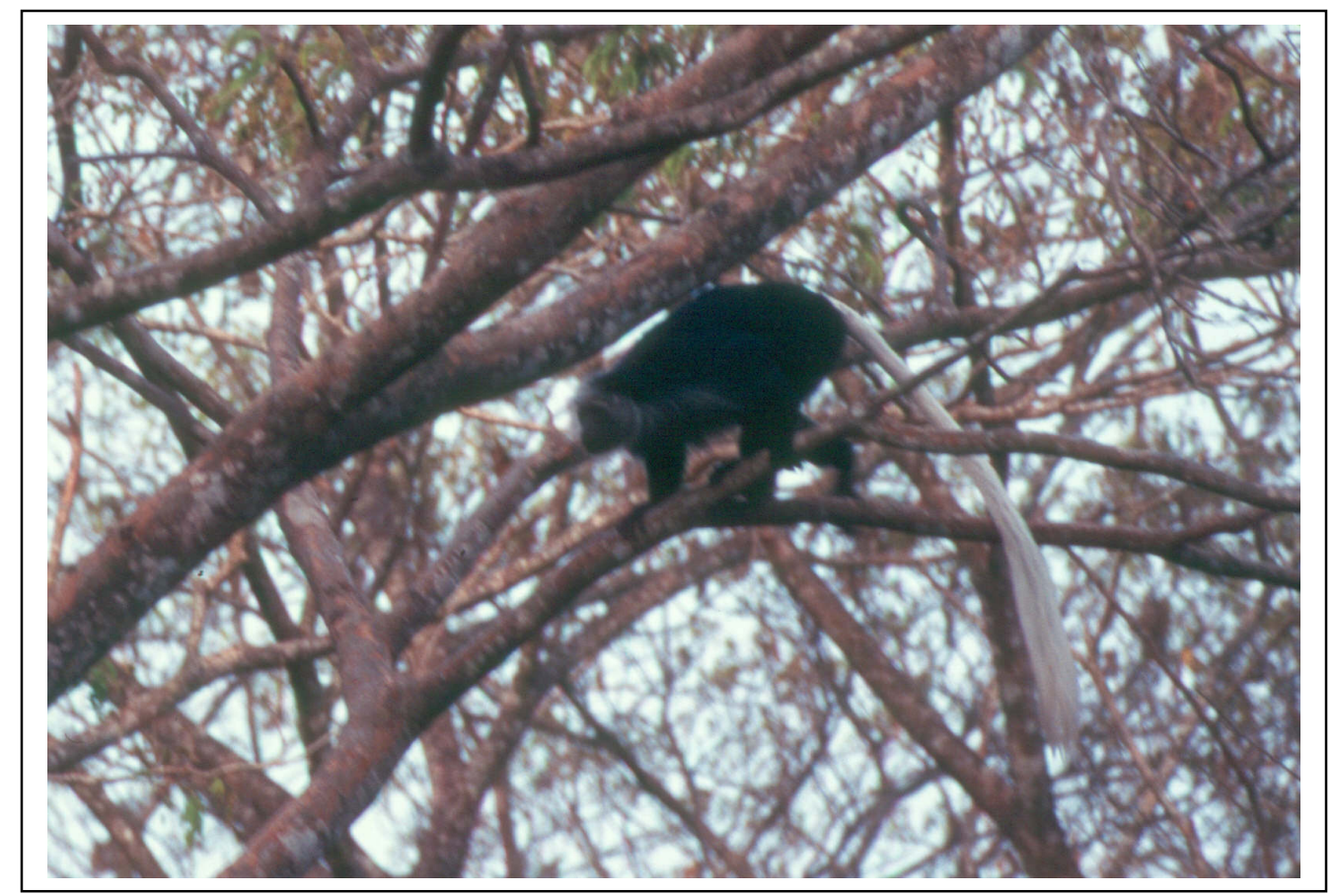

Figure12. Colobus monkeys coexist peacefully with humans in the Cantanhez forest region (J. Dierks) 


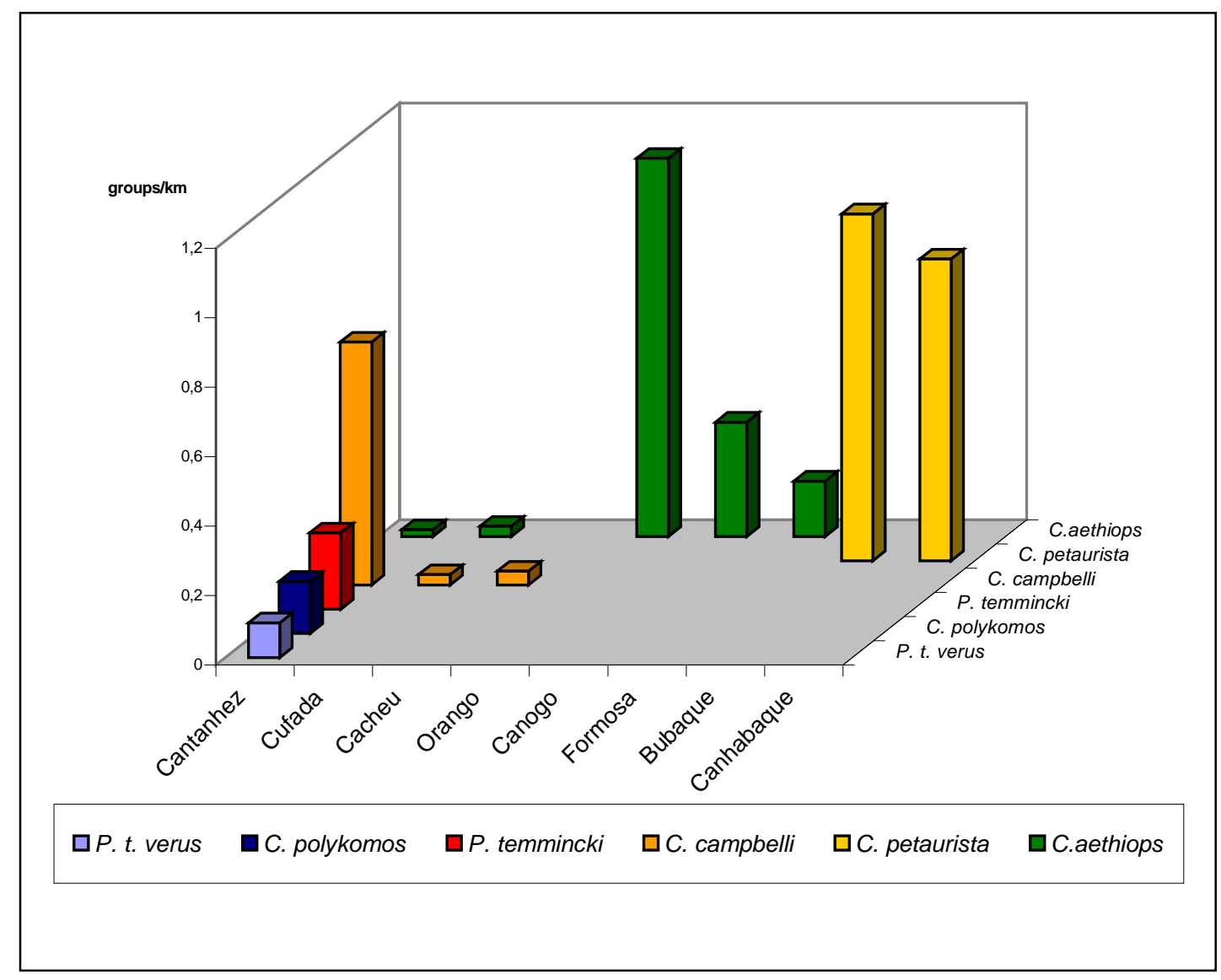

Figure13. Relative abundance (groups/km) of primates species observed in the coastal forests

Interviewed local people consider that Western Black-and-white Colobus and Red Colobus numbers, as for most mammals, have strongly decreased in the last decades, but in Cantanhez, these species have been locally observed more frequently again in the last years (Table15), because they are not hunted for meat by the local Moslem population.

No field observations of these species were made in Cufada and Cacheu during this survey.

\section{Campbell's Monkeys}

Observations of Campbell's monkeys were made mostly in the southern regions of the country. Verbal records were made in the North-Eastern Cacheu National Park also. This species was often observed in Parinari excelsa trees, but also in Parkia biglobosa and in domestic fruit trees (mango) and Borassus palm trees.

It was the most frequently observed species on the country's continental part, and more particularly in Cantanhez (Figures 13 and 14), where a relative abundance index of 0.7 groups $/ \mathrm{km}$ was calculated, with group sizes of up to 17 individuals. In Cufada and in 
Cacheu the estimated abundance index was respectively 0.03 and $0.04 \mathrm{groups} / \mathrm{km}$; a conservative density calculation resulted in $7.25 \mathrm{groups} / \mathrm{km}^{2}$ in Cantanhez (Table8). Interviewed people in all study sites declared that this species is becoming rare, excepting in one village (Jopa) in the Cacheu Natural Park, where Campbell's monkeys were considered to be increasing (Table15).

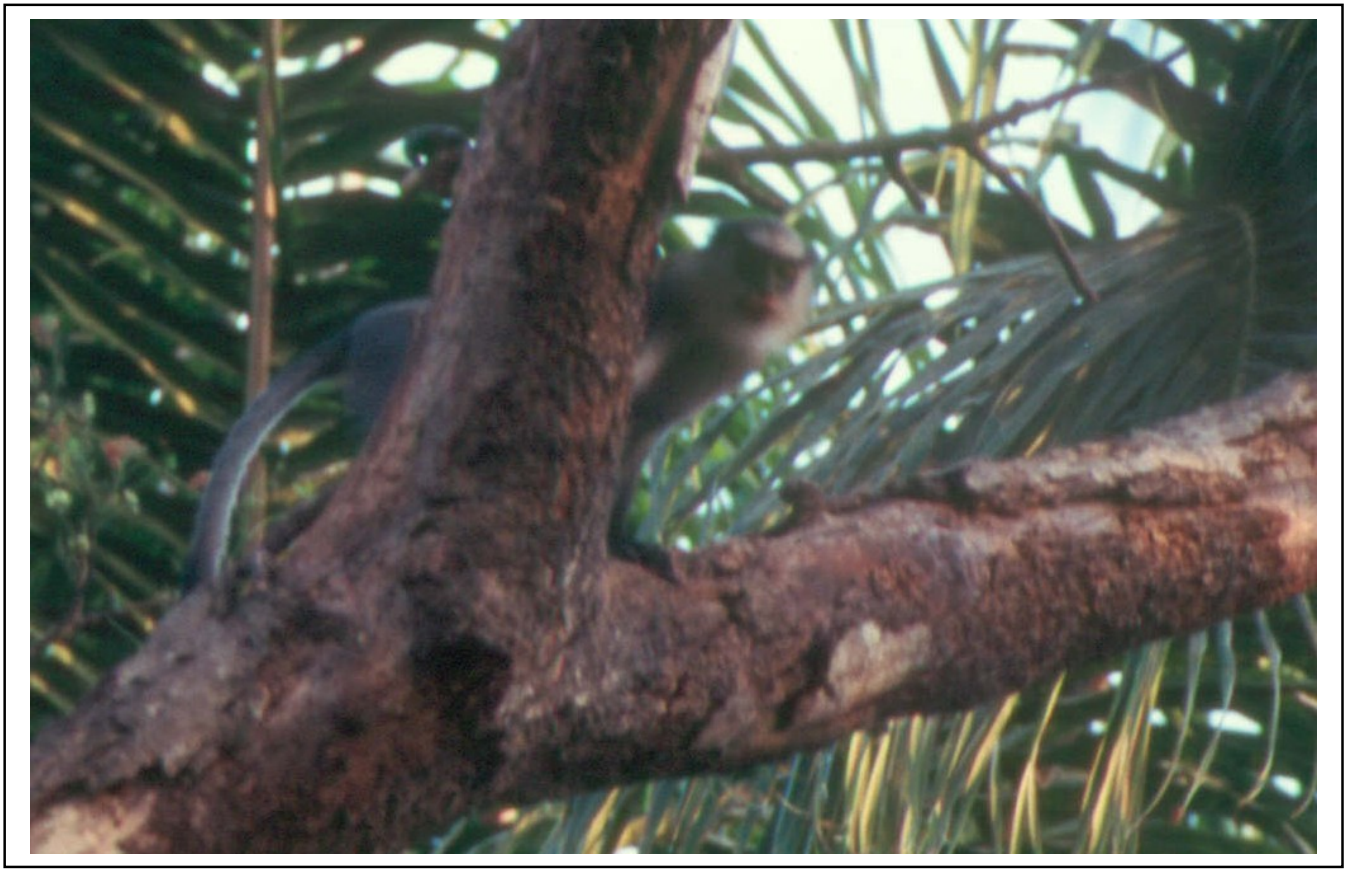

Figure14. Campbell's monkey was the most frequently observed primate species in Cantanhez (J. Dierks)

\section{Greater spot-nosed monkeys}

No field observations of this species were made during the survey. Verbal records were obtained from local people in the Cufada National Park, where this species is considered to be very rare and secretive. This species is known to occupy forested and densely vegetated habitats, rarely venturing beyond forest margins. Groups should have been observed in the forests around the village of Ndjassane and the Bumidi River. The local (Beafada) name given to the greater spot-nosed Monkey is "Djibossa".

Neither older nor younger people from Cantanhez recognised this species. Also local hunters declared this species not to occur in that area.

\section{Lesser-spot-nosed monkeys}

During this survey, lesser white-nosed Monkey was directly observed in the field only in the Bolama-Bijagós archipelago, on the Bubaque and on the Canhabaque islands. 
According to collected verbal records, this species should occur on the continental part, in the Cufada National park, where it is considered to be rare. No records were made in the sub-humid forests of Cantanhez. In the archipelago, this species is facing high hunting pressure.

In Canhabaque, a relative abundance index of $0.87 \mathrm{groups} / \mathrm{km}$ was estimated, which is comparable to that calculated for the palm forest on the Bubaque Island (one group $/ \mathrm{km}$ ) for the same species.

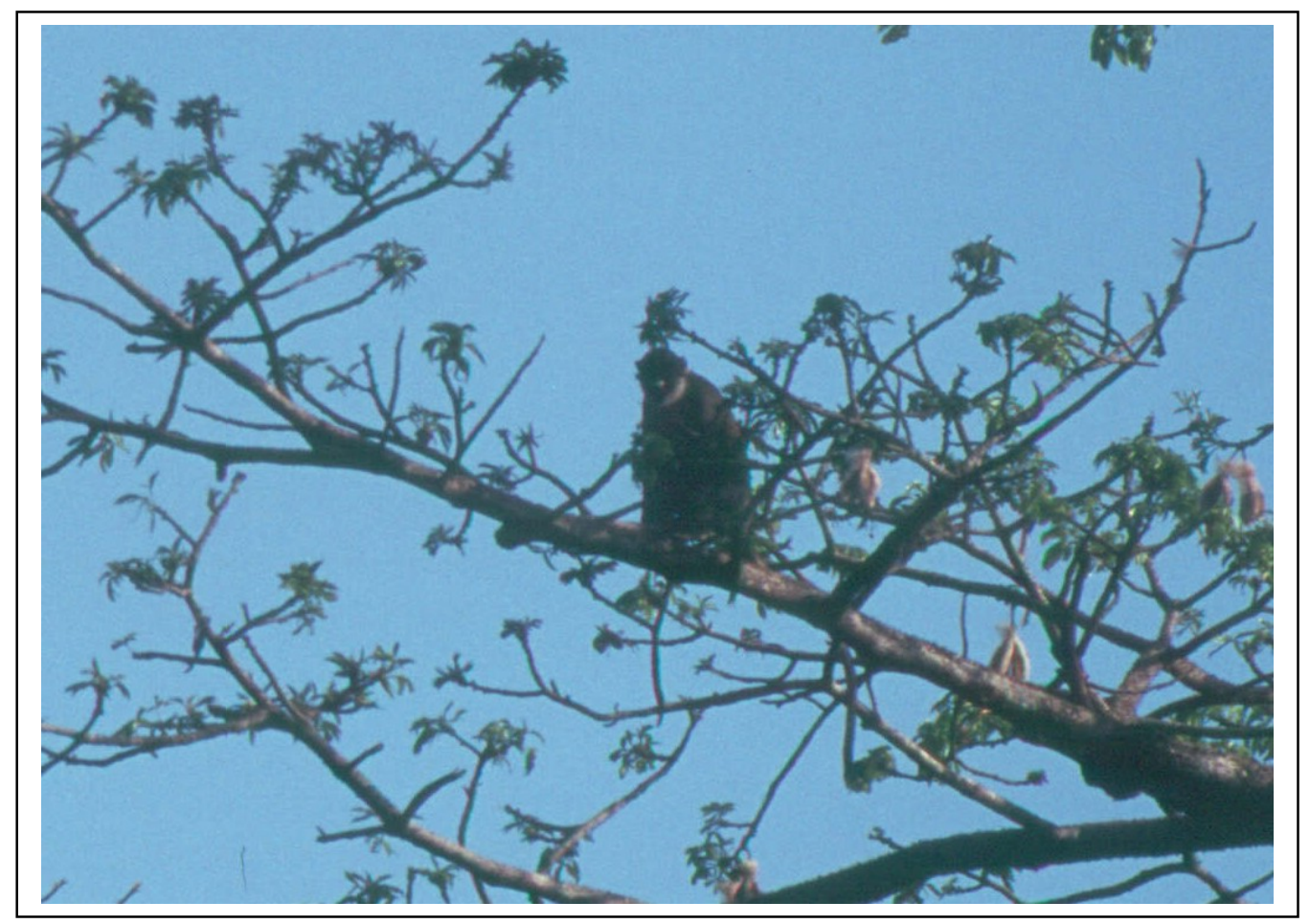

Figure15. Lesser spot-nosed monkeys are frequently observed in Canhabaque (J. Dierks)

Groups were observed mostly on Parinari excelsa and Alstonia trees, but also on Elaeis palm trees (Figure15). The observed groups comprised up to 15 individuals. On the islands of Bubaque and Rubane, this species is becoming rarer, but on the Canhabaque island, local people state that the species is increasing.

\section{Callithrix Monkeys}

Direct field observations of this species were made in all the study sites where it is known to occur and this was one of the most frequently observed primate species during the surveys, more particularly in the Bolama-Bijagós archipelago. The largest groups, with up to 20 individuals, were observed in the Orango National Park, where the highest relative abundance index 1.09groups $/ \mathrm{km}$ was estimated. A conservative density estimate of 
4.74groups $/ \mathrm{km}^{2}$ was calculated in Orango for this species, which was often seen in mangrove forests or in their near proximity, especially in periods of low tide.

Throughout the study area, interviewed people declared that Callithrix Monkeys' population are decreasing. However, in some areas, they are considered to increase, because they are thought to reproduce rapidly and because they are not consumed by the Moslems (Table15).

\section{Guinea Baboon}

Few observations of Guinea Baboons were made in the field, specifically in Cantanhez and in Cufada, although this species was considered until now to be common in the southern part of the country. Despite this species, like other primates, benefiting from consumption taboos in the local mostly Islamic population, it is heavily hunted, being considered one of the most destructive species for crops. There is also a great demand for this species in the important local market of Buba. A relative abundance index based on observed tracks was estimated at $0.08 \mathrm{groups} / \mathrm{km}$.

Results from interviews indicate on one hand an increase in Baboon population in Cantanhez, because they are not hunted by the local people, (majority Moslems). However, interviewed people from Cufada indicated on the other hand, a particularly strong declining trend of this species population in that region. Local people from that region described the increasing numbers of great cane rats and the damage caused by this species in the fields as an indicator of the drastic decrease in Baboons, which are known to kill those rodents. Because this species is becoming rare and difficult to catch for hunters, its meat price is today the highest among primate species.

\section{Patas Monkey}

Field observations of Patas monkey's footprints were made mostly in Cacheu and also in Cufada, but verbal records were also made in Balana, in the north of the Cantanhez region. Direct observations of this species were made in Cufada outside of the survey routes. In Cacheu, the relative abundance index based on encountered tracks was estimated as $0.22 \mathrm{groups} / \mathrm{km}$. The species was often seen crossing roads and near plantations.

Patas monkeys are considered as a pest and are thus pursued throughout their range. Due to their large size, Patas monkeys are an attractive and susceptible prey for hunting, being one of the most hunted species. Interviewed local people consider however, that 
despite this, the species population has increased in Cufada and in Cacheu Natural Park (Table15).

\section{Sooty mangabey}

Verbal records of this species were made in Cantanhez and in the Cufada National Park, where local people undoubtedly recognised this species from pictures and described it as mostly terrestrial, very shy and difficult to observe. Farmers from Cufada Natural Park reported having observed Sooty Mangabey raiding maize fields and even young children (younger than 10 years) claimed to have seen Sooty Mangabey hiding behind maize plants. A hunter declared having killed a Sooty Mangabey, but he could give no detailed information. The local name for this species is "Djigadame" (Beafada language).

A monkey with the characteristics of this species was seen during field surveys in the forest of Cambeque (Cantanhez), but it could not be definitively identified as the Sooty Mangabey. In Guiledje, north of Cantanhez, a hunter declared having observed Sooty Mangabey the last time around the year 2001; the local name for Sooty Mangabey there is Tchalacum (Fula language).

In Cantanhez however, interviewed elder villagers from Cabedu declared that this species has occurred in Cantanhez in the past, but is no longer seen today and younger people did not recognise the species from the pictures. The local name is "Fatack mantchangali" in the Nalu language and "Sakalaka" in the Sosso language. An elder former hunter stated he had seen this species the last time around the year 1967. Although the species is not known to occur or to have occurred in the northern part of the country, there is a local name for this species in the Mandjaco language ("ukalalo"), which is spoken by the majority ethnic group in that region.

\section{Bushbabies}

This species was not observed during the field surveys, and verbal records were obtained only from hunters, who referred to it as being sometimes observed in the night, thus making it very difficult to distinguish the different Galago subspecies occurring. 


\section{V.1.2. Even-toed Ungulates}

About 17 ungulate species from four families were confirmed to occur in the coastal regions of Guinea Bissau (Table9), most observations being made in the Cufada Natural Park, but also in the Cacheu Park.

\section{V.1.2.1. Bovids, horned ungulates}

Eleven horned ungulates were confirmed to occur in the surveyed coastal forests.

\section{African Buffalo}

Direct field observations of Buffalo were made in the Cantanhez forests, where footprints were observed in Amindara and in Lautchande (Figure16). A specimen was seen and a herd was heard while running away during a survey in the same forest. The individual observed was probably a specimen of the forest buffalo or an intermediate form between this species and the African savannah buffalo.

Since Guinea-Bissau is located at the northern most overlap area between the forest and the Western savannah buffaloes (Stuart \& Stuart 1997, East 1999), it appears probable that both subspecies and even intermediate forms between these two subspecies may occur there, especially in the southern part of that country.

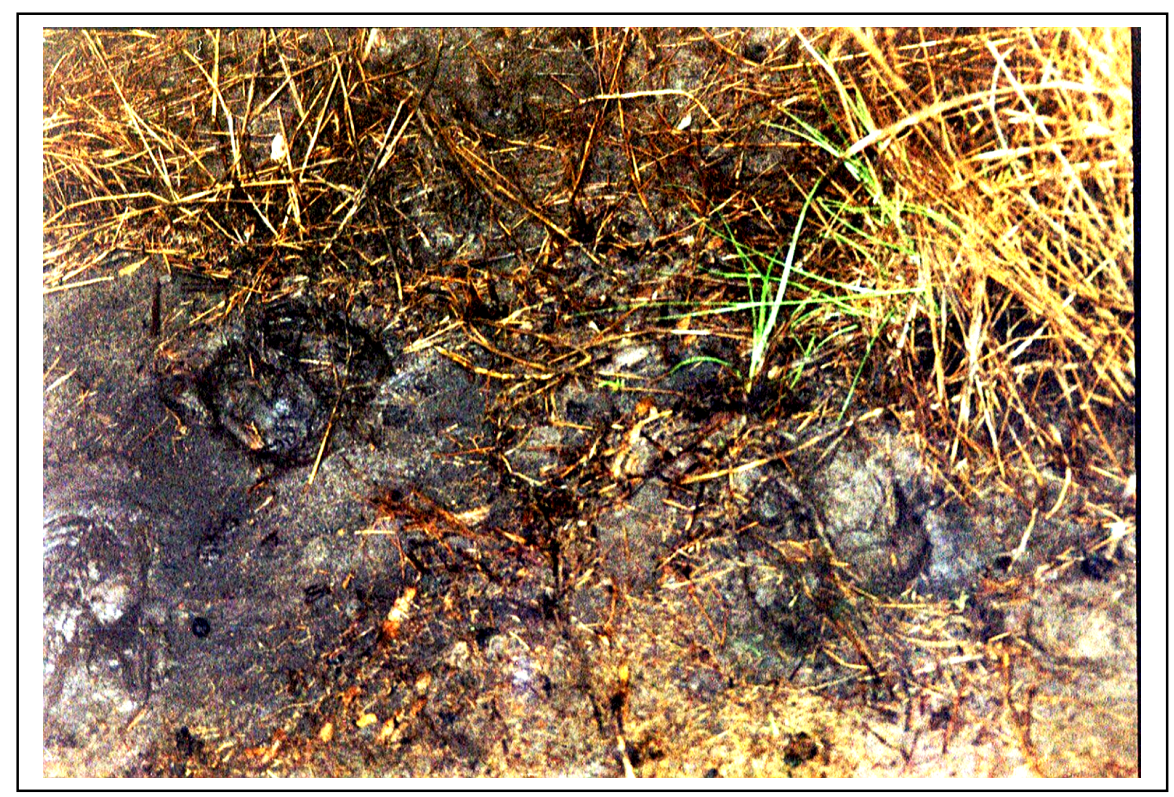

Figure16. Buffalo footprints in the Lautchande forest (Cantanhez) (Photo:C. Karibuhoye) 
Buffaloes occur also in the Cufada Natural Park, where numerous footprints were observed in the woodland savannah around the Bodjol River and in the dry forests around Ndjassane. On the basis of observed tracks, a relative abundance index of 0.11 and 0.02/km was calculated respectively for Cufada and Cantanhez (Figure18). Buffaloes are considered by local villagers to be globally rarer than in the past in all surveyed sites. However, this species has been more frequently observed again in recent years in Cantanhez, since hunting activities for this species have significantly decreased. Interviewed people from the Cacheu Natural Park stated that this species probably has disappeared from that area, since it is no longer observed now.

\section{Spiral-horned antelopes}

Of the 3 "spiral-horned" antelope species known to occur in Guinea Bissau, two were observed during the field surveys and their presence in the coastal forests was referred to by verbal records: the Bushbuck and the Marshbuck or Sitatunga.

\section{Bushbuck}

This was the most frequently seen ungulate species in the whole study area (Figure17), more particularly in the Orango National Park (Orango, Imbone and Canogo islands), where most direct field observations were made. Solitary individuals or females with calves, but also pairs were observed in that region during the day, not seeming to be shy to human presence. This species is considered to be common throughout the study sites where it occurs. However, inhabitants of the Imbone islands declared this species population to be less frequently observed, due to hunting pressure by foreign fishers from a camp on that island.

In other continental regions, more footprints and tracks than animals were observed, suggesting that this species exhibits nocturnal and shyer behaviour than in the island part of the country. The relative abundance was estimated in $0.86 \mathrm{groups} / \mathrm{km}$ in Cufada, $0.17 \mathrm{groups} / \mathrm{km}$ in Cantanhez and $1.48 \mathrm{groups} / \mathrm{km}$ in Cacheu. In Orango, the relative abundance was estimated at $0.48 \mathrm{groups} / \mathrm{km}$ on the basis of direct sightings (Figure17). Results from density estimation with the Distance software analysis and from manual calculation indicate a density of $1.6 \mathrm{groups} / \mathrm{km}^{2}$ for this species in Orango. 


\section{Sitatunga, Marschbuck}

No direct observations of this secretive species were made, however, numerous footprints were observed in the Cacheu Natural Park, more particularly around the Rio Pitchalate, an affluent of the Rio Cacheu (Figure17). The existence of Sitatunga was referred to verbally by local people in Cufada but the alleged footprints could not be clearly identified as those of this species. Marschbuck are locally not clearly distinguished from the bushbuck; both species have the same local names, e.g. "Gazela pintado" (Crioulo), which literally means "painted gazelle", or Djaoré (Fula), or Ndjabuá (Beafada).

However, members of the majority ethnic group in Cacheu (Mandjaco) know that the Marschbuck bucks' range is restricted to mangrove swamps. The local Mandjaco language does have two different names for these two species: "Ubatcha" for the bush buck and "Ucongohu" (or "Ogui") for the Sitatunga. In that region, a relative abundance index of 0.26groups/km was estimated (Figure17).

\section{Kobs}

Records on the existence of two species were made during this study. No direct observations of Defassa Waterbuck were made. Interviewed people stated that this species, which was abundant in the past, has strongly decreased in numbers and even disappeared from certain regions, such as in Cantanhez. Footprints of this rare species were observed only in the Cufada natural park around the Rio Bodjol and the Rio Sibidjan. A relative abundance index of $0.06 / \mathrm{km}$ was calculated for this species in Cufada, based on observed tracks (Figure17). In Cantanhez, the species was not observed in the field during this study.

Buffon's Cobs were also not directly observed during the surveys, but tracks were seen in the Cacheu natural park along the Rio Pitchalate. In all the surveyed sites, local people declared that this species population has strongly diminished. The species has locally disappeared: in Cantanhez, people declared that it is now restricted to the northernwestern part of Cantanhez, around Bedanda. This species is also very rarely observed in Cufada. The relative abundance index estimated for this species on the basis of track observations is $0.11 / \mathrm{km}$ (figure 17). 
No direct or indirect observation of Roan antelopes was made during the surveys. Verbal records were made on the seasonal observation of this species in the Cufada Natural Park. This formerly quite abundant species is considered by interviewed local people to have disappeared from the most regions surveyed.

Table9. Data on ungulate species distribution in the coastal forests of Guinea Bissau by field observations $(\mathrm{O})$ and verbal records $(\mathrm{V})$

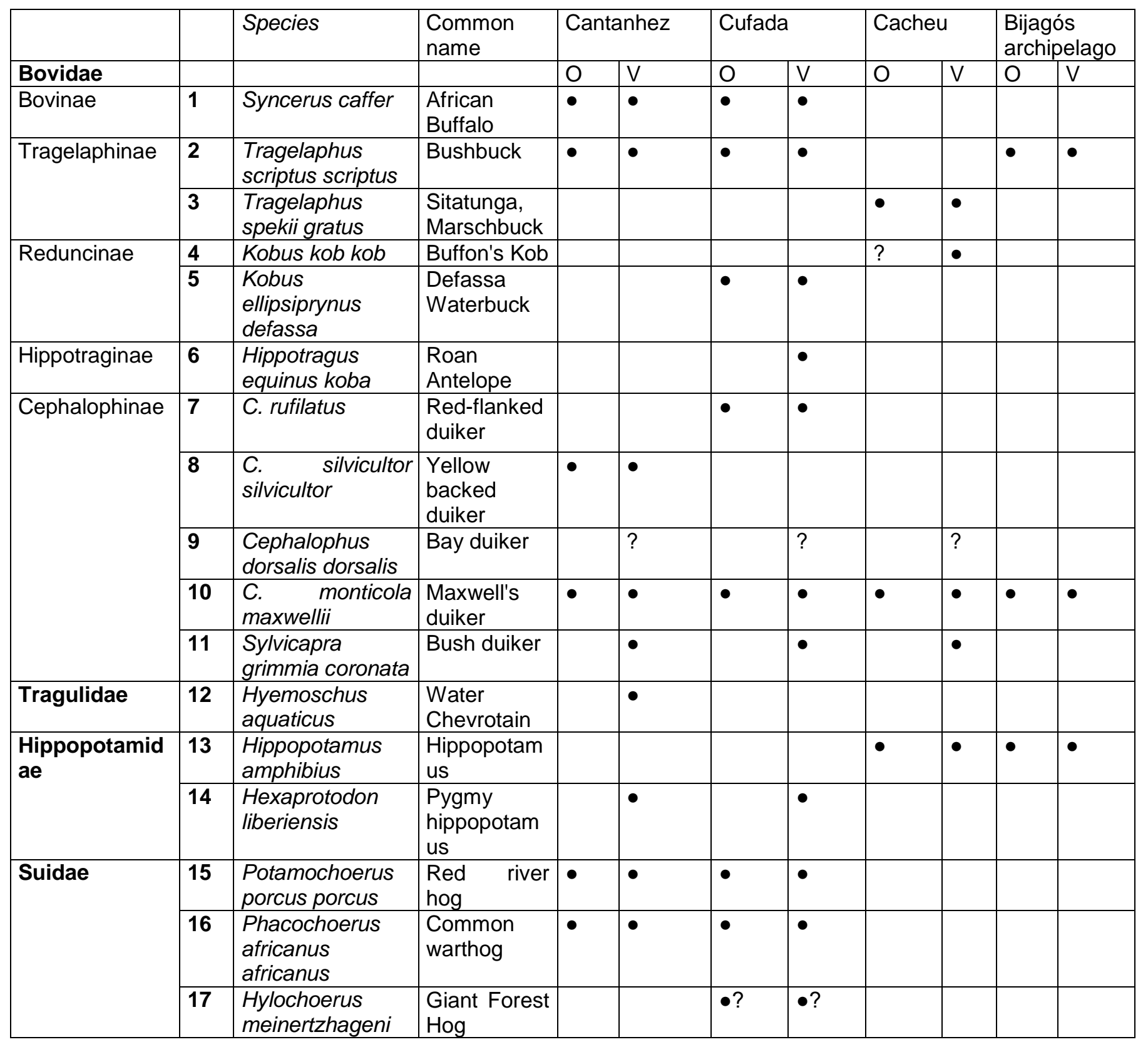




\section{Duikers}

Five duiker species occur in the coastal region of Guinea Bissau.

\section{Yellow backed Duiker}

Footprints of this nocturnal species were observed and its presence was confirmed by local people in the Cantanhez and the Cufada region. Relative abundance indices based on observed tracks amount respectively $0.57 / \mathrm{km}$ and $0.05 / \mathrm{km}$ for Cufada and Cantanhez (Figure17). All interviewed people consider Yellow-backed Duikers as very rare and refer to this species population as dwindling. The actual relative abundance estimates for this species are extremely low, particularly in Cantanhez.

\section{Red-flanked Duiker}

This species was directly observed in the field once in the Cufada Natural Park and outside of the survey routes. Numerous tracks were however observed in the same region, but signs were seen neither in the Cantanhez forest nor in the Cacheu Natural Park, where people consider the species to have disappeared. The relative abundance index based on observed tracks was calculated at about 0.26groups $/ \mathrm{km}$ (Figure18). This species population is considered by all interviewed persons as to be dwindling due to hunting.

Maxwell's Duiker, Bay Duiker and Bush Duiker fall under the local collective name "cabra de mato" (literally bush goat). However, the three species can be easily distinguished on the basis of their differences in physical aspect and habitat preferences.

Maxwell's Duiker footprints were observed in the Cantanhez forest, in the Cufada and the Cacheu Natural parks. These footprint observations were more frequent in Cacheu and Cufada. Direct observations of this species were made in Cantanhez and also on the island of Canhabaque in the Bijagós archipelago. Results of relative abundance index calculation based on tracks observations are of respectively $0.44,0.31,0.17$ and $0.02 / \mathrm{km}$ for Cacheu, Cufada, Canhabaque and Cantanhez (Figure18).

Neither Bay Duiker nor Bush Duiker were observed during the surveys, however verbal records of these two species were made in the three continental study sites (Cacheu, Cufada and Cantanhez), with Bush Duiker being more widely distributed and Bay Duiker being probably restricted to the remaining forest patches. In Cantanhez, a hunter from the village of Cabedu declared having killed a Bay Duiker most recently in the year 1997. These three species are considered by local people to have decreased due to hunting. 


\section{Chevrotains}

The only representative of this family considered to occur in Guinea Bissau is the Water Chevrotain. This species was not observed during the field surveys in any of the study sites. However, interviewed local people in Cufada confirmed the existence of water chevrotain in the past. The local name for Water Chevrotain is "Ndafakedé" in the Beafada language, but the species is no more observed in that region. In the northern part of Cantanhez, people identified the species as occurring in the neighbouring Republic of Guinea, where Water Chevrotain is known under the local name "Mbewa feto" (which means mountain goat in the Fula language).

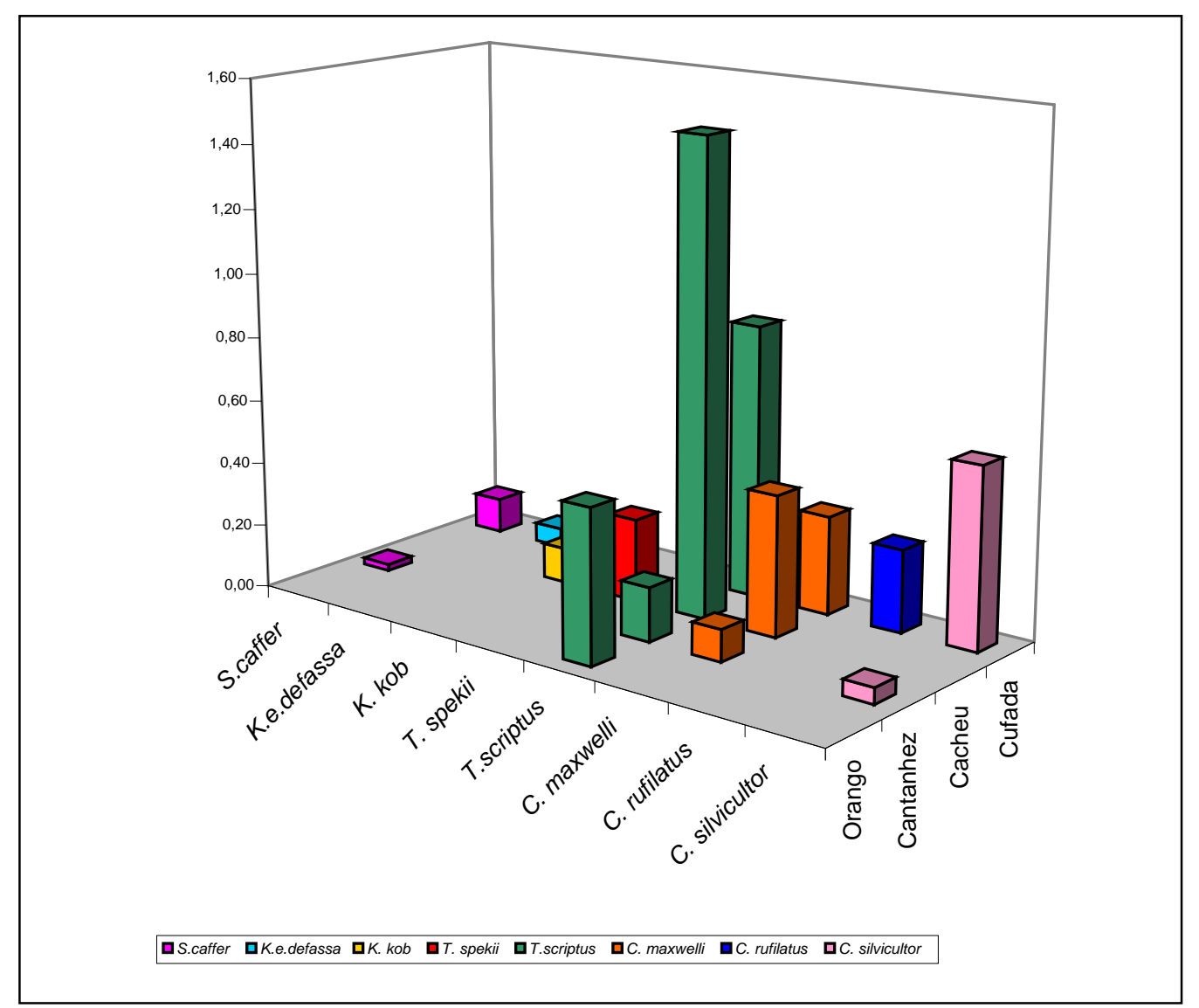

Figure17. Relative abundance of some large- and medium-sized bovids in the coastal forests

\section{V.1.2.2. Hippopotamuses}

Signs of presence of common hippopotamus (tracks, faeces, feeding places) were observed in the Bijagós archipelago (Figures18 and 19), on the islands of Orango, Imbone and Formosa, but also in the Cacheu Natural Park. Signs were observed more frequently in humid grass savannahs and on river margins. On Formosa, this species presence was confirmed only in the south-western part of the island (Uada). Interviewed local people also confirmed that this species is no longer observed in the eastern parts of the island. 
Tracks were comparatively more frequently observed on the Orango/Imbone islands than on Formosa or Cacheu. The relative kilometric abundance index for these three sites is estimated at $0.26,0.16$ and $0.11 / \mathrm{km}$ respectively (Figure20).
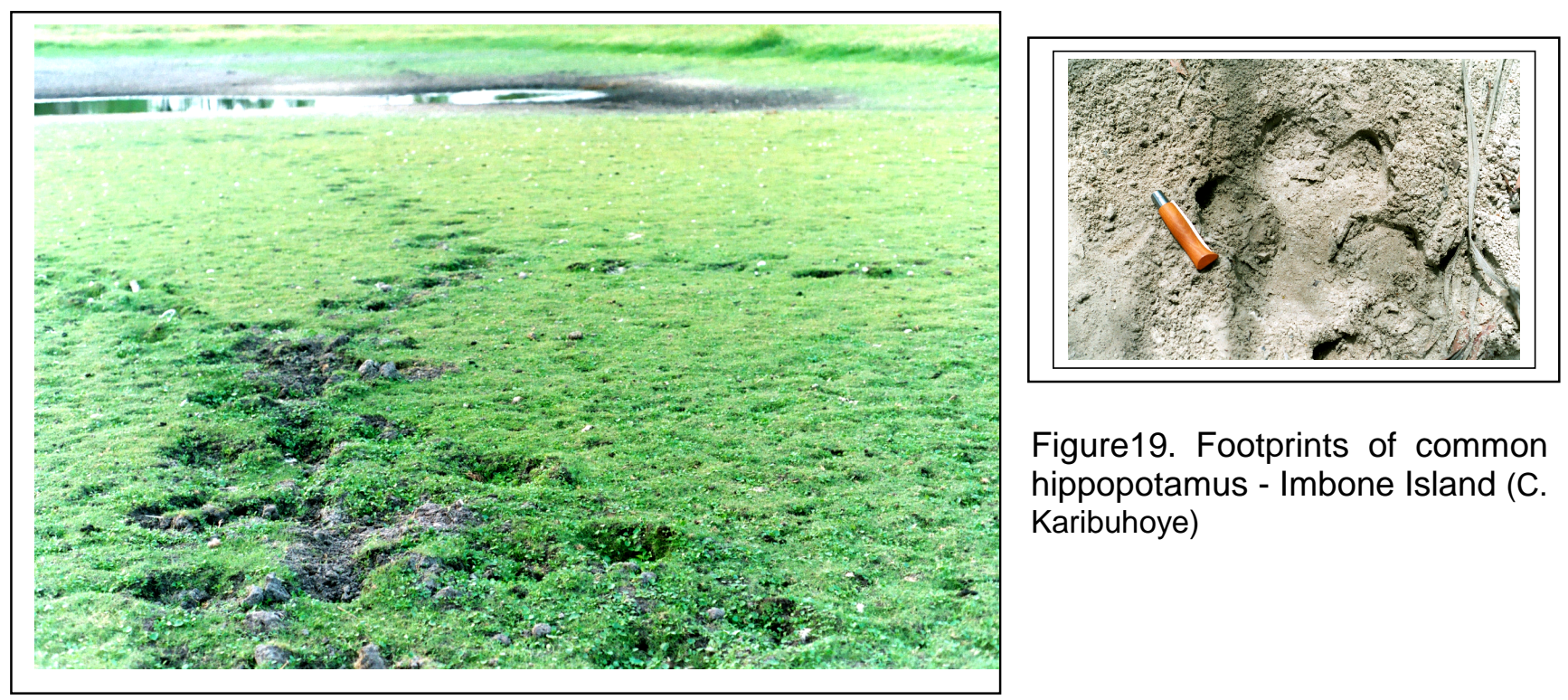

Figure19. Footprints of common hippopotamus - Imbone Island (C. Karibuhoye)

Figure18. The Lagoon of Angôr - an important concentration site for common hippopotamus in the Orango NP (C. Karibuhoye)

Hippopotamuses are considered also by interviewed local people to have been more frequently observed in Orango in recent years, due to the fact that they are no longer hunted. In Formosa, this species is still observed, but local inhabitants consider that hippopotamuses have migrated from the more densely settled eastern parts to the western part of the island (Uada), where this species has been reduced due to intensive hunting during the colonial period. In the village of Acuno, the last specimen was killed more than forty years ago.

According to the interviewed villagers in Cacheu, the population of hippopotami has increased in recent years since the National Park was created. In Cufada, the species is observed in the Cufada lagoons, and more frequently during the rainy season. In Cantanhez, this species is considered to have disappeared from most of the region. According to the local people, hippopotamuses should be still observed in some few rivers, such as the Rio Meldabom, an affluent of the Rio Cacine.

The presence of Pigmy hippopotamus was not confirmed by field observations, but verbal references to the occurrence of this species were obtained in Cantanhez and also from the Boé region more northwards. Hunters from the village of Cabedu in Cantanhez clearly identified this species from illustration material and confirmed its existence: one of 
them claimed to have seen this animal and shot at it in the forest near the village of Cante (Santa Clara) in Cabum (south-western part of Cantanhez). Local people also referred to an animal that occurs in the Boé forests (north-east of Cantanhez) and that could have the same body shape as an hippopotamus or a large pig, with a big head and mouth, but which should be clearly smaller than a hippopotamus. The local name for that species is "Canafabon" in the Fula language, but there is no other local name for this animal in Cantanhez.

\section{V.1.2.3. Suids}

Signs of the Common Warthog were observed in Cufada and Cacheu, but not in Cantanhez. No direct animal observations of this species were made. The most frequent observations were made in the Cufada Natural Park, where a relative abundance index of $1.2 / \mathrm{km}$ was estimated. In Cacheu, signs of the common warthog were less numerous and were observed only in the Jopa forest. For this site, a relative abundance index of 0.22 groups $/ \mathrm{km}$ was calculated. In Cantanhez, no field observations of this species were made during the surveys (Figure20).

Red river hog observations were less frequent than those of the common warthog (Figure20). Signs of this species were seen in different forests of Cantanhez and also in Cufada but not in Cacheu. The calculated relative abundance index for this species was comparable in these two sites, with 0.11 for Cufada and 0.15 for Cantanhez (Figure20).

References to the presence of the Giant forest hog were made by local people in the Cufada National Park and also in Cantanhez, but this species was not directly observed. In both sites, people claimed the existence of a hog, greater than the warthog, but with much more hair, big ears and short legs. In Cufada, footprints were identified by local guides around the Rio Bodjol as pertaining to this species, but which could not be clearly confirmed. In Cantanhez, this animal is known under the local name "Cumbidje" in the local Nalu language and "Bali" in the neighbouring Republic of Guinea. 


\section{V.1.3. Elephants}

\section{African elephant}

Verbal records of seasonal presence of elephants were obtained in the Cufada Natural Park and in the north-eastern part of Cantanhez (Table10).

Table10. Data on the distribution of other large mammal species in the coastal forests of GuineaBissau by field observations $(\mathrm{O})$ and verbal records $(\mathrm{V})$

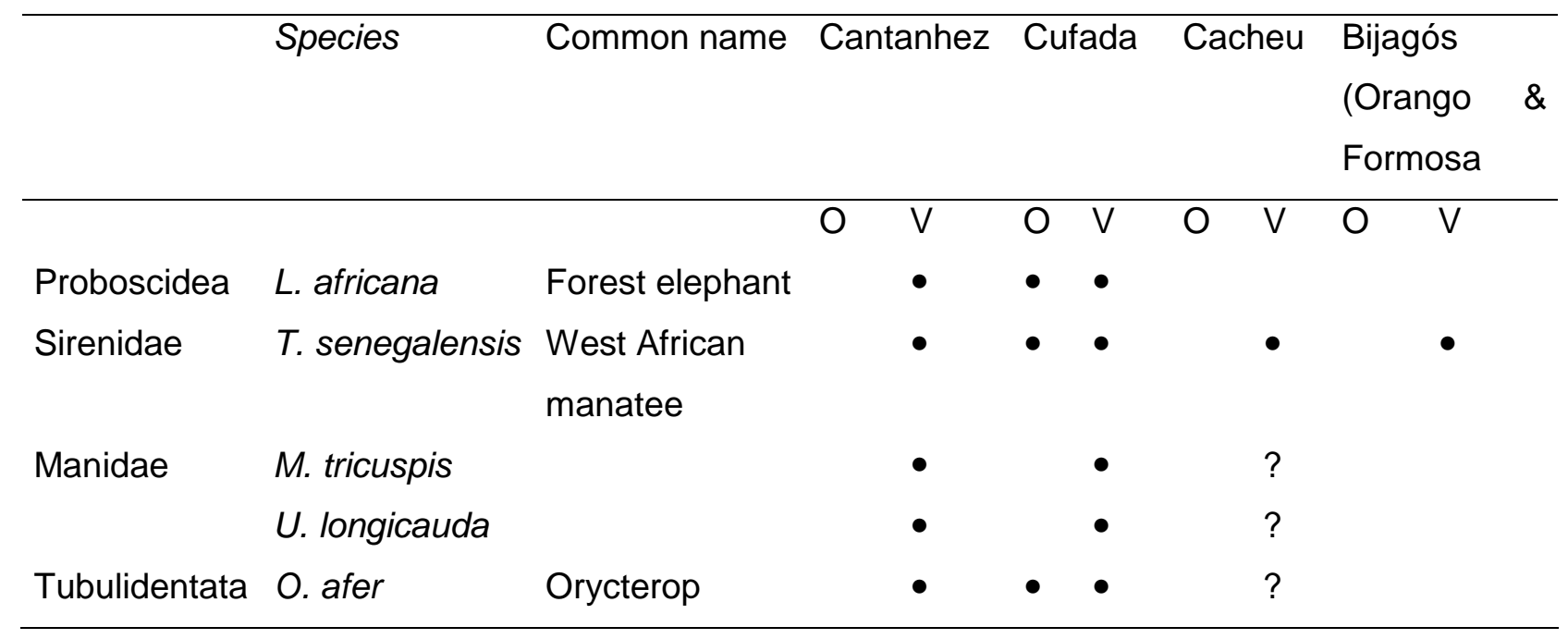

Various sources reported the presence of elephants in Cantanhez and Cufada during the dry season in the last two or three years. Old signs of elephants were observed in the Cufada Natural Park, along the Rio Corubal. In the northern part of Balana, interviewed people declared that a herd had crossed that zone in 2002 and that elephants used to spend the dry season along the Rio Balana.

The local population of Cantanhez consider that elephants, which were more abundant before the independence war (1963-1974), moved away due to intensive bombing, and that they are now localised along the border between Guinea-Bissau and the Republic of Guinea. 


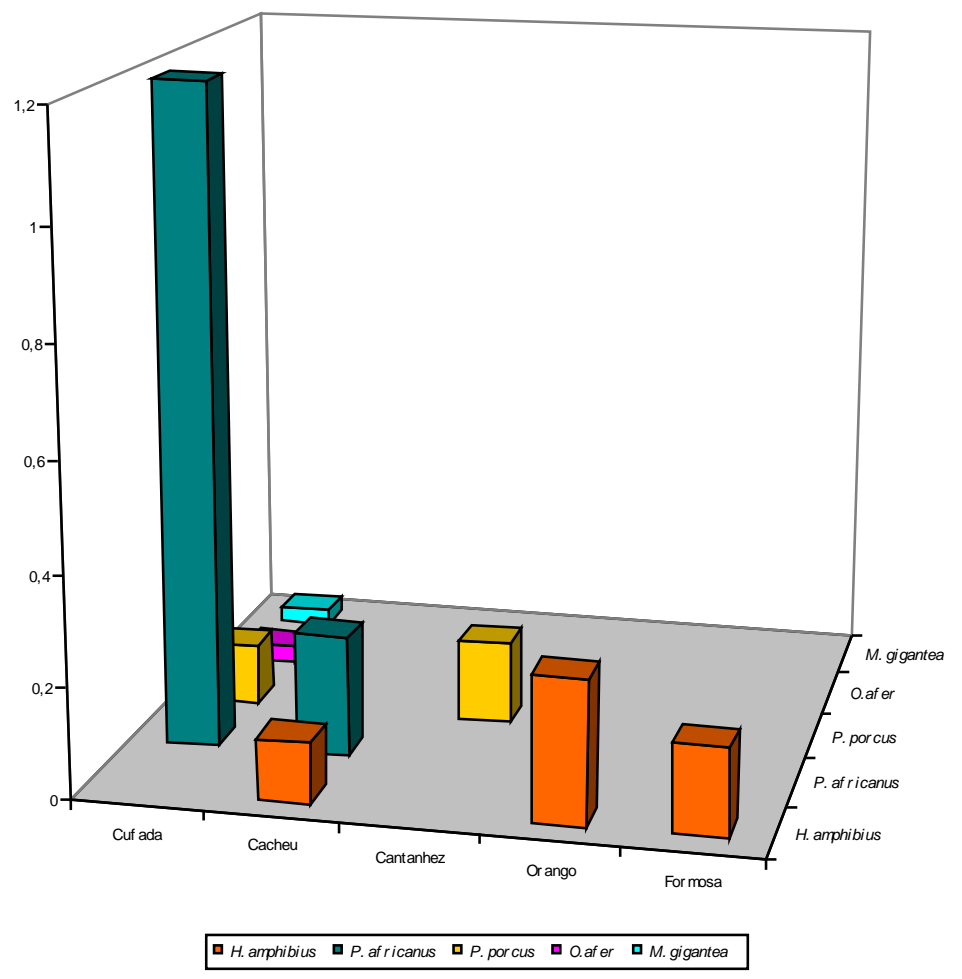

Figure20. Relative abundance of some large- and medium-sized ungulates in the coastal forests

\section{V.1.4. Sirenids}

\section{West African manatee}

The presence of manatees was confirmed by local people in all the study sites, but no active survey of this species was made in the field (Table10). An individual was observed occasionally on the Rio Buba. In Formosa, local women declared that manatees use to feed not only on mangroves, but also on molluscs, e.g. on cockles (Anadara senilis). Previous reports have already been made about feeding on molluscs in this species in Guinea-Bissau (see also Montenegro 1995).

This species benefits locally from a hunting taboo in the Bijagós archipelago and in most parts of the country, since special ceremonies are needed before hunting and also after the killing of a manatee. However, the species has been actively hunted in some areas, for 
example on the Formosa islands group, mostly from the Nhominka, an ethnic group original from Senegal, with a long fishing tradition.

Another major threat factor to manatees remains incidental by-catch in fishing nets. Manatees are considered by interviewed local people to be less frequent in Formosa, whereas people consider that this species is increasing again in Cantanhez, because its hunting is banned.

\section{V.1.5. Carnivores}

Four families were taken into consideration: Felidae, Hyenidae, Mustelidae and Viverridae. Large- and medium-sized carnivores were observed more frequently in Cacheu and to a lesser extend in Cufada.

\section{V.1.5.1.Felids}

In this family, the occurrence of four species was confirmed in the surveyed coastal sites. Verbal records on the presence of Leopards come from Cantanhez, Cufada and Cacheu (Table11). In Cantanhez, hunters declared that this species is now restricted to a few undisturbed forests between Cungha, Catem, Muna and Madina. Very few tracks were observed only in the Cufada and Cacheu Parks, but no direct observation of this animal was made. A tentative relative abundance calculation gives a figure of $0.03 / \mathrm{km}$ for Cufada and $0.07 / \mathrm{km}$ for Cacheu (Figure22). The population of this species, which has been heavily hunted for its skin, should have strongly decreased, although the species is actually protected by law.

Three other cat species also occur in the study area but were not directly observed in the field. The presence of the Serval Cat and the African Wild Cat was confirmed by local interviewed people in the three continental study sites. These two species are also rarely observed; Serval Cat tracks were observed in the field in Cantanhez, Cufada and in Cacheu and for this species, a similar relative abundance index was obtained as for the Leopard (Figure22). Reports on the occurrence of the wild cat were made by local people in Cufada, Cacheu and in Cantanhez, where this species should be observed in grass savannahs near mangrove forests.

The Caracal is considered to occur in Guinea-Bissau, but this species was neither observed in the field, nor was its presence confirmed verbally. 
Although the African Golden Cat until today is not included in the official lists of mammals occurring in Guinea Bissau, its presence was confirmed during this study, but from a forest not included in the mammal surveys. Verbal records of its occurrence were made in Cufada and Cacheu by local people. A Golden Cat skin was clearly identified from the Djalicunda forest in the north, not very far from the Rio Farim (an affluent of the Rio Cacheu), where that animal had been killed by a hunter (Figure21).

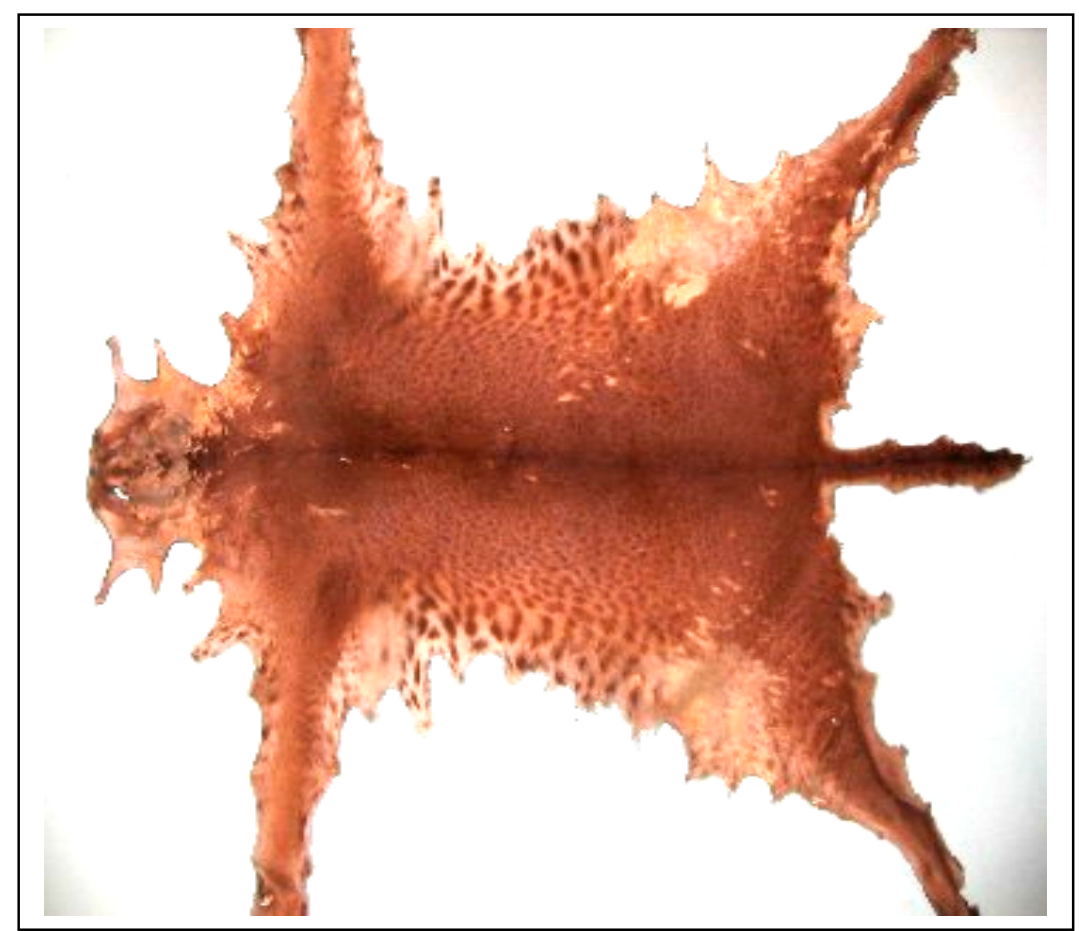

Figure21. Skin of a golden cat from the Djalicunda forest (RADI)

Table11. Data on large- and medium-sized carnivore species observations in the coastal forests of Guinea Bissau

\begin{tabular}{|c|c|c|c|c|c|c|c|c|c|c|c|}
\hline \multirow[t]{2}{*}{ Family } & & \multirow[t]{2}{*}{ Species } & & \multicolumn{2}{|c|}{ Cantanhez } & \multicolumn{2}{|c|}{ Cufada } & \multicolumn{2}{|c|}{ Cacheu } & \multicolumn{2}{|c|}{$\begin{array}{l}\text { Bijagós } \\
\text { Islands }\end{array}$} \\
\hline & & & & 0 & $\mathrm{~V}$ & 0 & $\mathrm{~V}$ & 0 & $\mathrm{~V}$ & 0 & V \\
\hline \multirow[t]{4}{*}{ Felidae } & 1 & P. pardus & Leopard & & $\bullet$ & $\bullet$ & $\bullet$ & $\bullet$ & $\bullet$ & & \\
\hline & 2 & L. serval & Serval cat & & $\bullet$ & $\bullet$ & $\bullet$ & $\bullet$ & $\bullet$ & & \\
\hline & 3 & P. aurata & Golden cat & & & & $\bullet$ & $\bullet$ & $\bullet$ & & \\
\hline & 4 & F. silvestris & African wild cat & & $\bullet$ & & $\bullet$ & & $\bullet$ & & \\
\hline Hyenidae & 5 & C. crocuta & Hyena & & $\bullet$ & $\bullet$ & $\bullet$ & $\bullet$ & $\bullet$ & & \\
\hline \multirow[t]{2}{*}{ Mustelidae } & 6 & A. capensis & Clawless otter & $\bullet$ & $\bullet$ & & $\bullet$ & $\bullet$ & $\bullet$ & $\bullet$ & $\bullet$ \\
\hline & 7 & M. capensis & $\begin{array}{l}\text { Ratel (Honey } \\
\text { badger) }\end{array}$ & & & & $\bullet$ & & $\bullet$ & & \\
\hline \multirow[t]{4}{*}{ Viverridae } & 8 & G. tigrina & Blotched genet & $\bullet$ & $\bullet$ & & $\bullet$ & & $\bullet$ & & $\bullet$ \\
\hline & 9 & G. genetta & Common genet & & $\bullet$ & & $\bullet$ & & $\bullet$ & & \\
\hline & 10. & C. civetta & Civet & & $\bullet$ & & $\bullet$ & & $\bullet$ & & $\bullet$ \\
\hline & 11. & N. binotata & Palm civet & & $\bullet$ & & $\bullet$ & & $\bullet$ & & \\
\hline
\end{tabular}




\section{V.1.5.2. Hyenids}

This family is represented by one species: the Spotted Hyena, whose presence was confirmed during the field surveys in Cufada and in Cacheu. Local people in Cantanhez also referred to its presence in that region. Footprint observations of this crepuscular or nocturnal species were more frequent in Cacheu, where the calculated relative abundance index is $0.11 / \mathrm{km}$, whereas this index is much lower (about a quarter) in Cufada (Figure22).

\section{V.1.5.3. Mustelids}

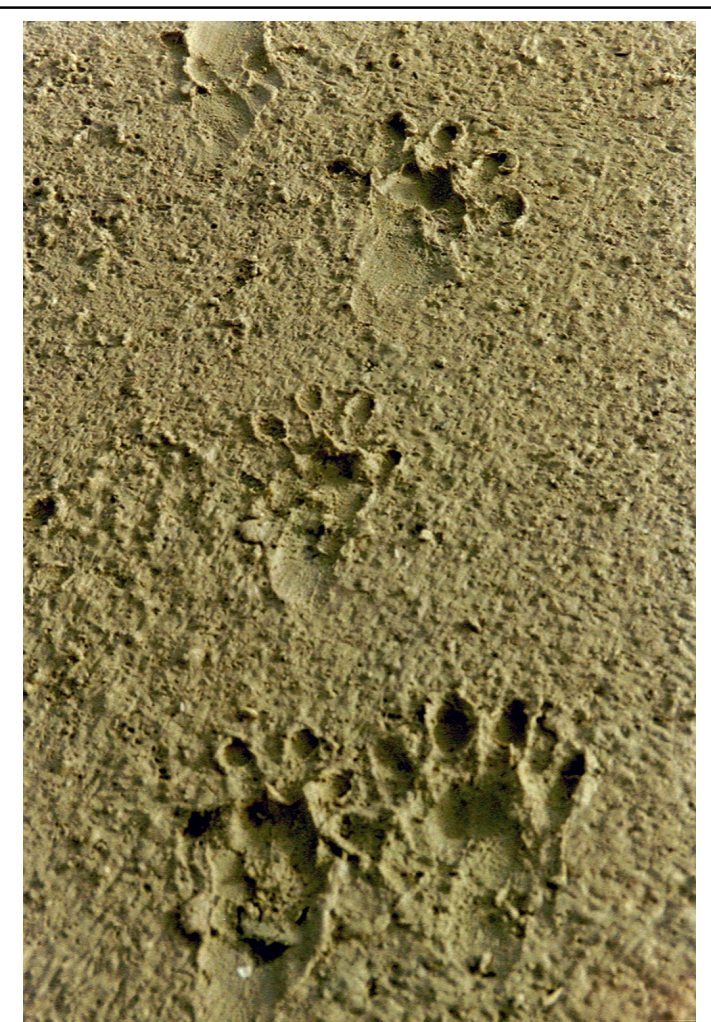

Figure22. Clawless Otter's footprints are observed quite frequently on Formosa Island (C. Karibuhoye)
Two species of this family are known to occur in Guinea Bissau: the Clawless Otter and the Honey Badger. Neither species was observed directly in the field, but interviewed people confirmed the presence of Clawless Otter in all the study sites, where signs (footprints, faeces, sleeping sites) were also observed. In some surveyed sites, such as in Formosa, local people know the ecology of this species. Most of the field observations were made in Cacheu (Belimbom and Rio Bidjop in Guncan) and in the Bijagós islands (Formosa Island) (Figure22). The estimated relative kilometric abundance index of Clawless Otter is 0.18 and $0.27 / \mathrm{km}$ for Cacheu and Formosa respectively and only 0.04 and $0.02 / \mathrm{km}$ for Imbone and Cantanhez respectively (Figure23).

Clawless Otter populations are considered to have increased by local people in Formosa, because this species is not actively hunted. However interviewed villagers in other study sites declared that it is difficult to know whether this species is increasing or not, due to the fact that it is very secretive and difficult to observe.

Although Spot-Necked Otters Lutra maculicollis are considered to be absent from the far West Africa (Kingdon 1997), Crawford (1997) suspected the occurrence of this species in the Cufada Natural Park. However, no signs of this species were observed throughout the study area. 
The presence of the Honey badger was also confirmed by interview in Cufada and Cacheu, but detailed information on its occurrence is difficult to obtain. This nocturnal and crepuscular species is known to occur naturally at low densities. Specimens of this species have been kept in a zoo farm in Xime not far from the capital Bissau.

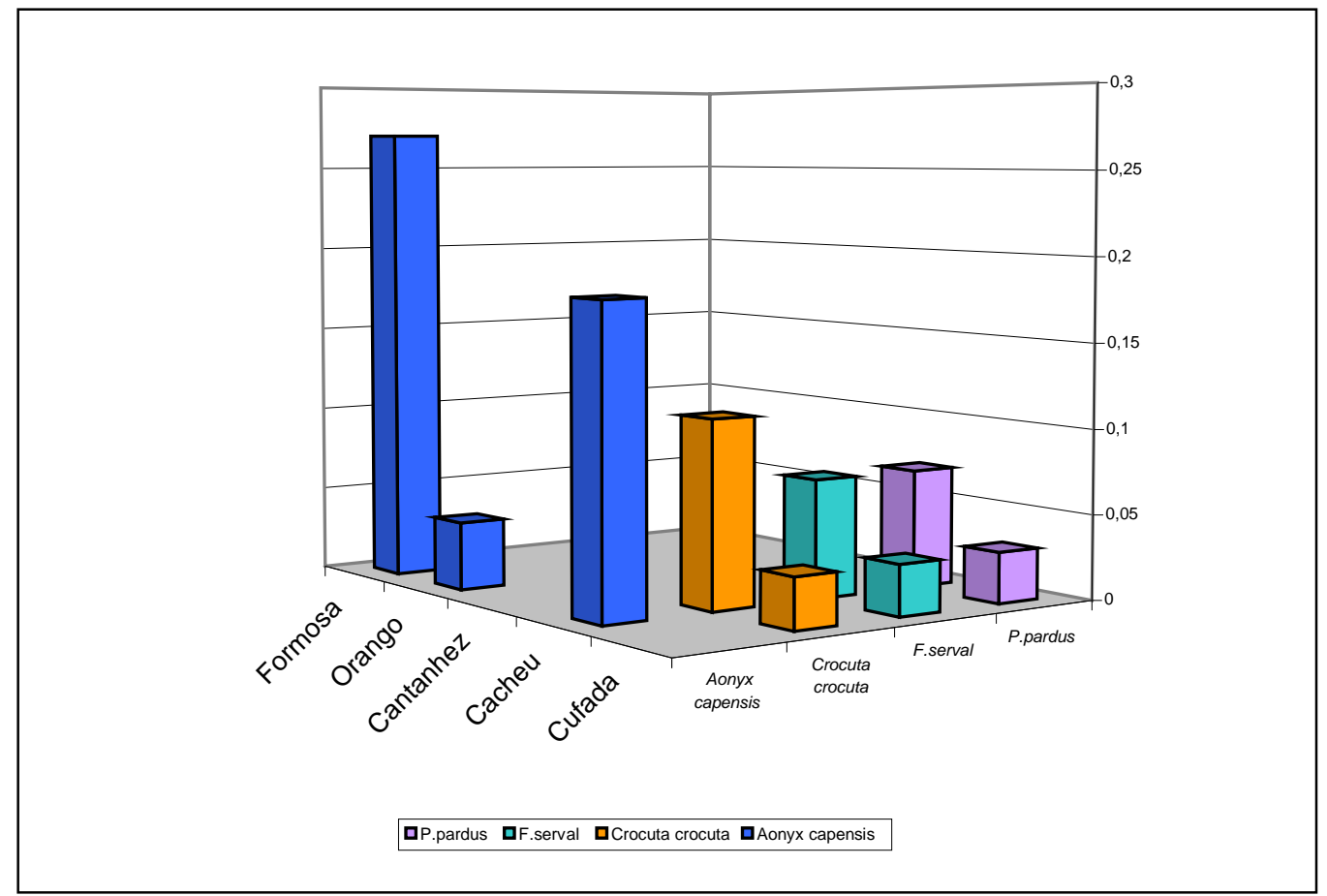

Figure23. Relative abundance of some carnivore species observed in the coastal forests

\section{V.1.5.4.Civets and genets}

Occurrence of Genets was confirmed by field observation of prints and verbal reports throughout the study sites, excepting on the Formosa Island. Genets are commonly known under the name "gato lagaria" or "gato lagar" in the national language Crioulo. Although people are able to recognise the different subspecies, these are not distinguished by different names. Another problem is the fact that even Serval cats are named "gato lagar", which also contributes to more confusion.

The genet species occurring in the Orango NP is probably the Blotched Genet Genetta tigrina (L. Palma, personal communication), which is known as "Bureme" in the Bijagós language of Orango. This species occurs also in the Cacheu Natural Park and in the Cufada Natural Park, where its local name is "gungulgati" in the Beafada language. In Cantanhez, the species is known as "laghabari". The Common Genet Genetta genetta senegalensis was reported by local hunters to occur in Cufada, Cacheu, and also in Cantanhez, where it is known as "bingi" in the local Sosso language. 
Interviewed villagers confirmed the presence of the Civet Civettictis civetta in these three study sites; in Cantanhez this species is known under the name "Soghofutu" in Sosso and is observed in the forest and in savannah areas, having always "a great number of ticks on its body". The Palm Civet should also occur in the continental study sites, according to interviewed people; this species (local name "Sunkulu") is known to steal palm wine from collecting receptacles hanging in the trees. 


\section{V.2. Wildlife conservation and use}

\section{V.2.1. Hunting activities}

\section{V.2.1.1. Categories of hunters}

In each of the surveyed villages, there is an average of two active local hunters: these are people who do regularly hunt, mainly to supply their family with meat, skins or bone. However, even those who do not consider themselves as hunters do occasionally kill animals on their way to or from the fields or to defend their crops from raiding. For subsistence hunters, hunting is one element within the strategy of subsistence, which is based on the use of multiple natural resources, according to the accessibility and availability of those products.

Excess from hunting products can be occasionally sold for cash, which allows the hunter to solve punctually other problems and contributes to the family's household. This category does not depend totally upon hunting to survive and is neither specialised nor professional in this activity, which is practised occasionally and is mostly regulated by traditional laws, taboos and other interdicts. Subsistence hunting is also usually practised with the help of familiar labour or from the hunter's village, using traditional tools and arms, such as traps, harpoons, etc. (Table12)

Some of the local hunters are considered semi-professional, because they are somewhat better equipped and do practise the hunting activity on a more regular and intensive manner throughout the year. These hunters are mostly from the community but not always, and the objective of hunting is clearly selling and self supply. Most of those local subsistence hunters use traps, dogs but also guns (Table12).

Among the professional hunters, one can distinguish between commercial and sport hunters. Commercial hunters are mostly more professional; they are found in somewhat larger rural centres and outside of protected areas. They use to hunt with firearms not only to obtain essential protein, but also for cash income through sale of wild meat. Meat is sold mostly locally, but also in distant markets. In the interviewed villages, "former" professional hunters were encountered in Cantanhez and Cufada, but they declared that they no longer hunted for selling, since commercial hunting within the protected area is forbidden. 
Sport hunters have also mostly professional equipment and hunt almost exclusively in the numerous existing sport hunting camps. Most of them are from the capital city or foreign countries.

The main objective for commercial hunters is the sale of the different hunting products (meat, skins, trophies etc.), where the extent of the activity strongly depends on the value of the hunting products and demand of the market (Table12). Commercial hunters often work with other interest groups such as intermediaries, guides, owners of means of transportation, drivers, etc. They usually hunt with modern firearms and sometimes have professional hunting and weapon licenses.

Because all the study sites are already officially recognised or are to be classified as protected areas, where hunting is legally prohibited, it is difficult to make an accurate estimate of the number of existing hunters in the study area. An exception is the Cufada National Park, where local subsistence hunters are being inventoried. More than 30 hunters have are known to live within the park, but about 16 hunters have already been identified to be in possession of guns, while a significant number of persons actually do hunt with borrowed guns. Another aspect contributing to the difficulty in getting accurate information on existing hunters is that most of the subsistence and semi-professional hunters do not have a hunting licence. In the interviewed villages, "former" professional hunters were encountered throughout the survey area, but they declared no more to hunt for selling, since commercial hunting within the protected area is forbidden.

In most of the hunters, the profession is transmitted in the family, from the fathers to the sons. However, the independence war from 1963 to 1974 and also the politico-military conflict in the year 1998/99 led to a broad distribution of fire guns among the population of Guinea-Bissau and increasingly more people have the possibility to hunt. Older hunters claim that hunting is loosing its mystic dimension, for fire guns are widely distributed and "anybody with a gun considers himself a hunter".

During the colonial period and until recently, hunters from outside the region, mostly Portuguese and members of the Fula ethnic group were known to practice this activity in the different islands of the Bijagós archipelago, mainly to hunt hippopotamus. Today, no hunters from outside are known to enter either the Orango National Park or Formosa island. However it is frequently reported that outsiders from the continental part of the 
country and from neighbouring countries do hunt monkeys on some islands, principally on Rubane, Bubaque and water buck on the island of Galinhas.

Table12. Some characteristics of hunting activities in the study area

\begin{tabular}{|c|c|c|c|}
\hline Characteristics & Subsistence hunter & $\begin{array}{l}\text { Semi-professional } \\
\text { hunter }\end{array}$ & Professional hunter \\
\hline Main objective & $\begin{array}{l}\text { - own consumption } \\
\text { - excess offered } \\
\text { and/or sold }\end{array}$ & $\begin{array}{l}\text { - partly own } \\
\text { consumption and } \\
\text { selling }\end{array}$ & - selling \\
\hline Equipment & $\begin{array}{l}\text {-rudimentary (bows, } \\
\text { traps, harpoon) }\end{array}$ & $\begin{array}{l}\text { - firearms but partly } \\
\text { rudimentary }\end{array}$ & $\begin{array}{l}\text { - sophisticated (mostly } \\
\text { firearms) }\end{array}$ \\
\hline $\begin{array}{r}\text { Integration within the } \\
\text { community }\end{array}$ & - always & $\begin{array}{l}\text { - mostly from the } \\
\text { community but not } \\
\text { always the case }\end{array}$ & $\begin{array}{l}\text { - possible but not the } \\
\text { rule/ mostly from } \\
\text { outside }\end{array}$ \\
\hline Hunting intensity & $\begin{array}{l}\text { - not constant/ by } \\
\text { need or disposition }\end{array}$ & $\begin{array}{l}\text { - regularly/all over the } \\
\text { year }\end{array}$ & $\begin{array}{l}\text { - constant /all over the } \\
\text { year }\end{array}$ \\
\hline Regulations & $\begin{array}{l}\text { - mostly according to } \\
\text { some traditional rules } \\
\text { / local taboos }\end{array}$ & $\begin{array}{l}\text { - Reference to some } \\
\text { traditional rules if } \\
\text { integration within the } \\
\text { community }\end{array}$ & $\begin{array}{l}\text { - No reference to } \\
\text { traditional or local } \\
\text { regulations }\end{array}$ \\
\hline Prey species selection & $\begin{array}{l}\text { - Selection depending } \\
\text { on consumption } \\
\text { habits, availability } \\
\text { and accessibility }\end{array}$ & $\begin{array}{l}\text { - Selection depending } \\
\text { on availability and } \\
\text { accessibility }\end{array}$ & $\begin{array}{l}\text { - Selection depending } \\
\text { on monetary value and } \\
\text { demand of market / } \\
\text { mostly large or medium } \\
\text { sized or rare species }\end{array}$ \\
\hline
\end{tabular}

On the continental part of the coastal zone in Cacheu, Cantanhez and Cufada, local inhabitants report that the number of outsider hunters known to come either from other parts of the country, or from neighbouring Senegal and the Republic of Guinea have been declining in recent years, as a consequence of the creation of the protected areas. However, in Cacheu, members of the Casamance rebellion from southern Senegal and also hunters from Guinea frequently enter the northern and southern part of the park respectively.

In Cufada, outsider and military hunters come principally from the neighbouring towns of Quebo, Buba and Fulacunda. In Cantanhez, hunters, including military, are known to come from the next town of Cacine, although local communities have been increasingly protesting against such actions.

\section{V.2.1.2. Hunting techniques}

Different hunting techniques are used in the study sites. In the Orango NP and in Formosa, animals are mostly hunted with dogs and with the traditional spears ("Canhaco"). Traditional and modern traps are used on Canhabaque and Formosa to 
catch smaller terrestrial animals like Giant Rats and Fish Otters. Even Callithrix monkeys are caught using rat traps. Giant rats are also directly chased out of their holes.

Another technique was used in the past to catch manatees: the "gamboa" is the closing of a river with palm or other branches after the high tide, so that the animals which have entered the river could not escape. This technique is generally no longer used by the Bijagós but some people, particularly from the Nhominkas ethnic groups (original fisher people from Senegal) occasionally practise it. Hunting with guns is common on Formosa, Canhabaque and on the islands of Bubaque and Rubane, principally to kill Callithrix and Lesser white-nosed Monkeys.

In the continental part of the country, most hunters use shotguns, rat traps being mainly used in the crop fields. The most widely distributed and frequently used firearm in GuineaBissau is the twelve bore shotgun. There is a locally produced version of this gun, which is used by a large number of subsistence hunters, although it is considered to be unsafe by many people. The AK gun is a less well distributed model, mostly being used by the military. Most of the munitions are available throughout the country at relatively low cost: most of the interviewed hunters declared to buy munitions for their guns either in their own village or in the neighbouring settlements, or from travelling sellers.

Hunting is practised mostly at night, but animals are also killed during the day, principally diurnal monkeys. Interviewed hunters claimed that, although hunting is today technically easier because of the use of firearms, this activity is more difficult than in the former times, for in the past there were many more animals and of larger size. Today a hunter must walk longer distances to encounter a prey. In the past, large animals were most sought after and smaller animals such as Bushbuck were only killed after one had found a larger species. Today a hunter has to content himself with any species he finds.

\section{V.2.1.3. Most hunted species}

Depending on the locally occurring species and on the socio-cultural characteristics of each region, there are differences in the hunted species among the surveyed sites in the island and the continental region (Table13).

In Formosa, Callithrix Monkeys and the Gambian pouched rat Cricetomys gambianus are the most hunted mammal species. In Orango, bushbuck and Callithrix Monkey are most 
hunted. Other non mammal species frequently hunted on these islands are Spur-winged goose Plectropterus gambensis and the Nile monitor Varanus niloticus.

In Cantanhez, Porcupines, Forest Duiker and Bushbuck suffer the highest hunting pressure; these species are also the preferred species for consumption. Porcupines and Grass cutter Thryonomys swinderianus are most hunted not only because of their good taste, but also because they destroy crops. Monkeys (excepting pied colobus) and pigs are also occasionally killed the former by non Moslem people.

Table13. Most hunted mammal species in the coastal region

\begin{tabular}{|c|c|c|c|c|c|}
\hline \multirow[b]{2}{*}{ Species } & \multicolumn{3}{|c|}{ Continental part } & \multicolumn{2}{|c|}{ Islands } \\
\hline & Cantanhez & Cufada & Cacheu & Orango & Formosa \\
\hline Bushbuck & - & - & - & $\bullet$ & \\
\hline Maxwell's duiker & - & - & - & & \\
\hline $\begin{array}{r}\text { Red-flanked } \\
\text { duiker }\end{array}$ & & $\bullet$ & & & \\
\hline $\begin{array}{r}\text { Yellow-backed } \\
\text { duiker }\end{array}$ & $\bullet$ & & & & \\
\hline Porcupine & $\bullet$ & - & - & & \\
\hline Grater cane rat & $\bullet$ & $\bullet$ & $\bullet$ & & \\
\hline $\begin{array}{r}\text { Gambian } \\
\text { pouched rat }\end{array}$ & & & & & $\bullet$ \\
\hline $\begin{array}{r}\text { Common } \\
\text { warthog }\end{array}$ & & - & - & & \\
\hline Red river hog & - & - & & & \\
\hline Callithrix monkey & & & - & - & - \\
\hline Red Colobus & $\bullet$ & $\bullet$ & $\bullet$ & & \\
\hline $\begin{array}{r}\text { Campbell's } \\
\text { monkeys } \\
\text { Baboons }\end{array}$ & & - & $\bullet$ & & \\
\hline Patas monkeys & & & - & & \\
\hline
\end{tabular}

In Cufada, bushbuck and duikers are the preferred species of the mostly Moslem population of that area. Porcupines and Greater cane rats are also regularly consumed. Guinea Baboon and common warthogs are killed only for commercial purposes, as there is a high demand for these species, especially in the markets of the neighbouring towns of Buba and Bissau (Table14). 
In Cacheu, monkeys, duikers and bushbuck are the most hunted species as they are consumed by preference. Hogs, giant cane rats and porcupines are also heavily hunted in Cacheu.

\section{VII.2.2. Wild meat trade}

In the interviewed villages of the Orango NP, meat from killed wild animals is generally for family consumption and is not sold. In Formosa and on other islands such as Canhabaque, Bubaque and Rubane, wild meat is for the hunter's own consumption and the excess is sold either directly in the same village or outside. This is the same case in Cantanhez, in Cufada and in Cacheu.

Table14. Wild meat trading prices (in Francs CFA; $1 €=$ about 650 CFA) of wild meat in different regions of the country (in Francs CFA), as practised by hunters in the villages and by intermediaries on local town markets.

\begin{tabular}{|c|c|c|c|c|c|c|c|}
\hline \multirow[t]{3}{*}{ Animal species (local name) } & \multicolumn{7}{|c|}{ Price $/ \mathrm{Kg}$ in different regions } \\
\hline & \multirow[t]{2}{*}{ Bissau } & \multicolumn{2}{|c|}{ North } & \multicolumn{2}{|c|}{ East } & \multicolumn{2}{|c|}{ South } \\
\hline & & Town & Village & Town & Village & Town & Village \\
\hline Antelopes(a) (Gazela) & 1500 & 1000 & 500 & 750 & 350 & 500 & 300 \\
\hline Duikers (b) (Cabra do mato) & 1250 & 1000 & 500 & 750 & 350 & 500 & 300 \\
\hline Porcupine (Porco espinho) & 1500 & 1000 & 500 & 750 & 500 & 500 & 300 \\
\hline $\begin{array}{r}\text { Common warthog (Porco do } \\
\text { mato) }\end{array}$ & 1000 & 500 & 500 & 500 & 250 & 500 & 250 \\
\hline $\begin{array}{r}\text { Red river hog (Porco } \\
\text { vermelho) }\end{array}$ & 1250 & 1000 & 500 & 500 & 250 & 500 & 250 \\
\hline Patas monkeys (Santcho fula) & 1250 & & & & & & \\
\hline Red Colobus (Fatango)(c) & 5000 & 2500 & 1500 & 1500 & 1000 & 1000 & 500 \\
\hline Campbell's monkey (Mona)(c) & 5000 & 2000 & 1000 & 1000 & 550 & 750 & 500 \\
\hline Baboon (“Con”)(c) & 15000 & & & 5000 & 2500 & 3500 & 1500 \\
\hline Domestic pig & 2500 & 1000 & & 1000 & & 1000 & \\
\hline Cow & 1750 & $1000-$ & & $1000-$ & & $1000-$ & \\
\hline & & 1500 & & 1500 & & 1500 & \\
\hline Chicken & $\begin{array}{l}2000- \\
2500\end{array}$ & & & & & & \\
\hline Fish (d) & $1000-$ & & & & & & \\
\hline & 1500 & & & & & & \\
\hline
\end{tabular}

(a) Include bushbuck, marshbuck and cob antelope

(b) Include Maxwell's, Bay's and common duiker

(c) Most monkeys are sold by unity and not by weight

(d)Depending on the category (fish species)

Wild meat selling in the villages within protected areas (Orango, Cufada, and Cacheu) is made informally and in secret. Even in Cantanhez, hunters said that they hide themselves from the official forest guard, in order to sell the meat of killed animals. In urban and peri- 
urban centres, wild meat is sold in public markets, even if it is from officially protected species. Hunters generally bring the meat to the markets or to other selling places such as car and bus stations in the capital city, or even directly to restaurants, bars and to individual consumers. However, there are increasingly intermediates who buy the meat from hunters and sell it on at higher prices.

\section{V.2.3. Perception of general population trends of wild mammals}

Most mammal species are considered to have decreased or to have locally disappeared in the surveyed coastal sites, and more particularly in the continental part. Local people consider heavy hunting pressure and to a lesser extend forest destruction, as the main reason for this population decline. However, according to the interviewed people, a few species are more frequently observed in recent years, due to reduced hunting pressure as a consequence of the official creation of protected areas, or as a result of local conservation efforts and awareness building (Table15).

\section{V.2.3.1. Species considered showing increasing population trends}

Chimpanzees, black-and-white Colobus, red Colobus and Guinea Baboons are considered to have increased in Cantanhez in recent years. Inhabitants of Cantanhez consider that red river hogs and common warthogs have also become more numerous, as these species are not hunted by the local (majority Islamic) people.

Chimpanzees are also increasing in Cufada according to interviewed local communities, as are Patas Monkeys and great cane rats. The latter are normally killed by Baboons which are now rarer in the Cufada region. Common warthogs and red river hog are considered to increase both in Cantanhez and Cufada, where they are not consumed by the majority of the local people.

In most interviewed villages of the Cacheu Natural Park, people declared that only Patas Monkeys and spotted hyenas have increased. An exception is the Jopa forests, where local people consider that also Red Colobus, Mona and Callithrix Monkeys have increased. According to the interviewed villages in Cacheu, the population of hippopotamuses has increased in the last years since the National Park was created, because these animals are no longer hunted. 
Hippopotamus populations are considered to have increased by local people in the Orango National Park (where they are not actively hunted). Also Bushbucks and Callithrix monkey are thought to have generally increased, excepting in the island of Imbone, where Bushbucks have decreased. According to local people in the central and western part of Formosa (Ancadaque, Uada), the Gambian pouched rat and Callithrix monkey populations are increasing, because they are considered to have a high reproduction rate. Also Fish Otters and marsh mongoose are considered to be more numerous in that zone.

Table15. Local perception on population trends of some mammal species in the coastal forests, with $\uparrow$ : increasing and $\downarrow$ decreasing population trends.

\begin{tabular}{|c|c|c|c|c|c|}
\hline & Continental part & & & \multicolumn{2}{|c|}{ Bijagós archipelago } \\
\hline Species & Cantanhez & Cufada & Cacheu & Orango & Formosa \\
\hline Chimpanzee & $\uparrow$ & $\uparrow$ & & & \\
\hline Pied Colobus & $\uparrow$ & & & & \\
\hline Red colobus & $\uparrow$ & $\downarrow$ & $\downarrow$ & & \\
\hline $\begin{array}{r}\text { Campbell's } \\
\text { monkey }\end{array}$ & $\downarrow$ & $\downarrow$ & $\downarrow(2)$ & & \\
\hline Callithrix monkey & $\downarrow$ & $\downarrow$ & $\downarrow(2)$ & $\uparrow$ & $\downarrow(1)$ \\
\hline Patas monkey & & $\uparrow$ & $\uparrow$ & & \\
\hline Baboon & $\uparrow$ & $\downarrow$ & & & \\
\hline Sooty mangabey & $\downarrow$ No longer observed & $\downarrow$ Very rare & & & \\
\hline Buffalo & $\downarrow(3)$ & $\downarrow(3)$ & No longer observed & & \\
\hline Roan antelope & $\downarrow$ rare & $\downarrow$ rare & $\downarrow$ No longer observed & & \\
\hline Waterbuck & Rare & $\downarrow$ Rare & & & \\
\hline Buffon Kob & $\downarrow$ No longer observed & $\downarrow$ Rare & $\downarrow$ & & \\
\hline Bushbuck & $\downarrow$ & $\downarrow$ & $\downarrow$ & $\uparrow(4)$ & \\
\hline $\begin{array}{r}\text { Yellow-backed } \\
\text { duiker }\end{array}$ & $\downarrow$ & $\downarrow$ & & & \\
\hline $\begin{array}{r}\text { Red-flanked } \\
\text { duiker }\end{array}$ & $\downarrow$ No longer observed & $\downarrow$ & & & \\
\hline Maxwell's duiker & $\downarrow$ & $\downarrow$ & $\downarrow$ & & \\
\hline African manatee & & & & $\downarrow$ & \\
\hline Hippopotamus & $\downarrow$ No longer observed & $\downarrow$ & $\downarrow(3)$ & $\uparrow$ & $\downarrow(5)$ \\
\hline Elephant & $\downarrow$ seasonal & $\downarrow$ seasonal & & & \\
\hline $\begin{array}{r}\text { Common } \\
\text { Warthog }\end{array}$ & $\uparrow$ & $\uparrow$ & $\downarrow$ rare & & \\
\hline Red river hog & $\uparrow$ & $\uparrow$ & $\downarrow$ rare & & \\
\hline Leopard & $\downarrow$ & $\downarrow$ rare & $\downarrow$ rare & & \\
\hline Spotted hyena & $\downarrow$ & $\downarrow$ & $\uparrow$ & & \\
\hline $\begin{array}{l}\text { African giant } \\
\text { pouched rat }\end{array}$ & & & & & $\downarrow(1)$ \\
\hline
\end{tabular}

(1)Decreasing in densely settled eastern part of the island (heavy hunting)

(2) Increasing in Jopa

(3) Locally more frequently observed in the last years

(4)Decrease in Imbone (hunting pressure from a fisher camp)

(5)No longer observed in the eastern part of the island

(6)Decreasing locally due to hunting pressure 


\section{V.2.3.2. Species with negative population trends}

In the Orango NP, Bushbucks have become rarer on the Imbone Island, according to the local inhabitants, because they are hunted by fishers from an illegal camp on that island. Also Manatee populations are considered to have declined in the Orango NP and also in Formosa. In latter, hippopotamuses are now observed only in Uada. Still in Formosa, most animal species are becoming rarer, particularly in some more densely settled parts, where hunting activities are more intensive. Villagers from Abu declared that Vervet monkeys are now more abundant in a sacred grove which is exclusively used for women's ceremonies, a site where no man (and hence no hunter) can enter.

Most mammal species, including primates, large antelopes, forest duikers, hippopotamuses, leopards and spotted hyenas are considered to have decreased in Cantanhez, Cufada and Cacheu, in spite of the fact that some species such as buffaloes and elephants have been observed more frequently in the last few years (Table15). Especially primates, Bushbuck and duikers (the most consumed species) have strongly decreased.

\section{V.2.3.3. Locally no longer observed species}

Some species are considered by the interviewed communities to have disappeared locally: this is the case for the hippopotamus in the eastern part of the island Formosa and in Cantanhez. Red-flanked duikers are no longer observed in Cantanhez and in Cacheu and Waterbuck no longer exists in Cantanhez. Still in some areas of Cacheu, some animals such as roan antelopes, buffaloes, red river hog and even common warthogs are locally no longer observed (Table15).

The sooty mangabey is no longer observed in Cantanhez: the last direct observations were made at the end of the sixties, still during the independence war.

\section{V.2.4. Perception of mammal conservation needs}

Throughout the study area, local people are aware of the need to implement conservation measures in benefit of certain overexploited or rare species (Table16).

In most of the interviewed villages in Orango and in Formosa, people consider that hippopotamuses and manatees should not be hunted for being rare. However, most respondents in Formosa and also in Orango also consider that hunting should not be prohibited in general to villagers for their own consumption. 
Table16. Mammal species considered as most threatened

\begin{tabular}{|c|c|c|c|c|c|}
\hline \multirow[t]{2}{*}{ Species } & \multicolumn{3}{|c|}{ Continental part } & \multicolumn{2}{|c|}{ Islands } \\
\hline & Cantanhez & Cufada & Cacheu & Orango & Formosa \\
\hline Chimpanzee & - & - & & & \\
\hline Pied Colobus & - & & & & \\
\hline Red Colobus & - & & - & & \\
\hline Hippopotamus & & & - & - & - \\
\hline Manatee & - & & - & - & - \\
\hline Buffalo & - & - & & & \\
\hline Kob antelope & - & - & - & & \\
\hline Waterbuck & - & - & - & & \\
\hline Roan antelope & & - & & & \\
\hline Bushbuck & - & & & & \\
\hline Red-flanked duiker & - & & & & \\
\hline Maxwell's duiker & - & & & & \\
\hline Yellow-backed duiker & - & & & & \\
\hline Red river hog & & & - & & \\
\hline Leopard & - & & - & & \\
\hline
\end{tabular}

In Cantanhez, overexploited species such as duikers and antelopes are considered to be threatened. Rare species which are not hunted such as chimpanzees, buffaloes and leopards are also considered to be threatened and to deserve conservation measures. Also in Cufada, very rare species such as Chimpanzee, waterbuck, Roan antelopes and buffaloes are considered to be the species of most concern for conservation.

Interviewed communities of Cacheu consider exploited species such as common warthogs, water buck and red Colobus to be most threatened. They also consider that rare species such as hippopotami, and leopards should be protected.

\section{V.2.5. Conflicts with mammals}

Potential and real conflicts between human population and mammal species in coastal regions and in Guinea-Bissau in general derive principally from crop destruction by wild animals (Table17).

Monkeys, wild pigs and great cane rats are the most feared crop raiding species in the whole country. Monkeys (especially Callithrix, Mona, Patas monkeys, and Baboons) destroy rice fields and other grain cultures. In some cases, entire harvests are destroyed if 
not permanently guarded. Great cane rats and wild pigs are known to cause huge damage in the rice fields. Unlike diurnal primates, they attack particularly rice fields during the night, which make it difficult to protect the fields.

Hippopotamuses are known to be generally peaceful and not aggressive, excepting females with young infants, which are known to hide their new born in mud and to be very aggressive against anyone who approaches the hiding place. However this species also destroys crops and causes damage on the Bijagós islands and also in Cacheu and in other parts of the country. In the past, when hippopotamuses were encountered destroying fields, Bijagós people used fire, machetes or traditional spears to put them flee. Today, those practices have been abandoned. In the Orango national Park, people believe that now hippopotamuses "have become daring" because they know that nobody will attack them. However, people also consider that hippopotami in that region have become more peaceful towards humans, since people are no longer aggressive to them.

Buffaloes regularly cause damage in rice fields; in recent years, buffaloes have been reported as causing increasing damage in rice fields in Cantanhez and Cufada (Bodjol), and local people consider this to be a consequence of the increasing number of this species. Other species such as Bushbuck are known to feed in fields, especially in beans, maize and melon cultures, but they are considered to be less destructive than monkeys and wild pigs.

Table17. Main crop raiding mammal species

\begin{tabular}{|c|c|c|c|c|c|}
\hline \multirow[t]{2}{*}{ Species } & \multicolumn{2}{|c|}{ Islands } & \multicolumn{3}{|c|}{ Continental part } \\
\hline & Orango & Formosa & Cantanhez & Cufada & Cacheu \\
\hline Callithrix Monkey & $\bullet$ & $\bullet$ & $\bullet$ & $\bullet$ & $\bullet$ \\
\hline Campbell's Monkey & & & $\bullet$ & $\bullet$ & $\bullet$ \\
\hline Baboon & & & $\bullet$ & $\bullet$ & \\
\hline Wild pigs & & & $\bullet$ & $\bullet$ & $\bullet$ \\
\hline Greater cane rat & & & $\bullet$ & $\bullet$ & $\bullet$ \\
\hline Bushbuck & $\bullet$ & & & $\bullet$ & $\bullet$ \\
\hline Hippopotamus & $\bullet$ & & & $\bullet$ & $\bullet$ \\
\hline Buffalo & & & $\bullet$ & $\bullet$ & \\
\hline
\end{tabular}




\section{V.2.6. Perception on wildlife value}

\section{V.2.6.1. Consumptive value}

The most valued wildlife assets are their importance as source of food, as an additional source of income, religious and cultural importance and as a heritage from ancestors to be transmitted to the own descendants (Table18). In all the surveyed sites, wild animals are important first of all as source of food. However, there are some interesting differences between the sites in the further valuation of wildlife

The second most cited value of wildlife is as an additional source of income for interviewees in Cantanhez, Cufada and Formosa, but for people in Cacheu the second value is the importance as heritage from ancestors, whereas the second most important value of wildlife for people in the Orango NP is their role for cosmogony/ religious life.

The third most cited value is as an heritage from ancestors for people in Orango and Cantanhez, religious and cultural importance in Formosa whereas for interviewees in Cacheu it is additional source of income.

The results also show that the importance of wildlife for traditional medicine and the potential for ecotourism income generation are also present, latter mostly in the continental part. The value of wild animals for their ecological role is often among the last listed, together with other indirect benefits such as social relationships from hunting activities or other utilitarian values (Table18).

Table18. Perceived value of wildlife in coastal forests, with ranking by naming sequence

\begin{tabular}{rrrccc}
\hline Value & \multicolumn{3}{c}{ Continental part } & \multicolumn{2}{c}{ Islands } \\
& Cantanhez & Cufada & Cacheu & Orango & Formosa \\
\hline Food & 1 & 1 & 1 & 1 & 1 \\
Additional source of income & 2 & 2 & 3 & & 2 \\
Heritage from ancestors & 3 & & 2 & 3 & 5 \\
Ecotourism income & 4 & 5 & 4 & 6 & 9 \\
Medicine & 5 & 3 & 5 & 4 & 4 \\
Ecological role & 6 & 4 & 7 & & 6 \\
Religious ceremonies/culture & 7 & 6 & & 2 & 3 \\
Reputation of the region & 8 & & 6 & 5 & 7 \\
Social relationship & & & & & 8 \\
Other utilitarian value & & 7 & & & 10 \\
\hline
\end{tabular}




\section{V.6.2. Social, medicinal and ecological value}

Mammals and wildlife in general are valued for a high number of important cultural, medicinal/protective and ecological assets (Table19).

The ecological role of some species is well known. Monkeys are known to disperse seeds of forest tree species, and also domestic fruits such as cashew, mango, oil palm and other fruits from the plantations in the forests. Monkeys are considered to be very useful, because they kill snakes. This is particularly important in regions known to have high snake densities as in some parts of the Bijagós archipelago. People consider for instance that the existence of an important snake population on the island of Soga is due to the fact that that island hosts no monkeys.

Guinea Baboons are considered to be very useful as they are known to kill the giant cane rat (Grass cutter) which is a very harmful crop raider. People in the region of Quinara around the Cufada region are confronted with significantly greater destruction of crop fields by giant cane rats, since the population of Baboons has been drastically reduced due to intensive hunting pressure. The tail of monkeys is considered very important for the production of a powerful talisman for the protection of pregnant women and their new-born babies.

Horns of large antelopes such as Roan antelopes and Defassa cob are used to produce musical instruments, but more importantly they were traditionally used for important rituals by the ethnic group of the Beafada ("Fanado beafada: Sakala"). Today this ceremony is no longer conducted, since these animals have become very rare. In Imbone/Orango for example, blood from Bushbuck is used during ceremonies for the protector spirit of the village ("irã de tabanca").

The horn and the crest of duikers and especially of the red-flanked duiker and of the yellow-backed duiker are considered to be very effective talismans for the protection of pregnant women and of new-born babies. The skin of the red-flanked duiker is also used in a traditional medicine against pain, whereas bones of duikers are used for the treatment of chronic wounds. Although meat from the spotted is considered poisonous, the skin is thought to be very effective against measles and to confer protection. Wild pigs are believed to be able to show water locations to humans in the forest. 
Table19. Examples of medicinal and protective use of some wildlife species

\begin{tabular}{lll}
\hline Species & Use & Part used \\
\hline Monkeys & $\begin{array}{l}\text { Talisman confection for } \\
\text { pregnant women and babies }\end{array}$ & tail \\
Duikers & $\begin{array}{l}\text { Talisman confection for } \\
\text { pregnant women and babies }\end{array}$ & horn and the crest \\
& $\begin{array}{l}\text { against pain } \\
\text { treatment of chronic wounds }\end{array}$ & $\begin{array}{l}\text { skin } \\
\text { bones }\end{array}$ \\
& Measles & skin \\
Spotted & Protection & skin \\
& Confers courage to new-borns & lever \\
Fish otter & Protection & Skin \\
& Abdominal pains & Intestines \\
Porcupines & Protection & bones \\
Crocodile & heal haemorrhoids & Skin \\
Savannah Monitor & chest inflammation & Teeth \\
Python & Pain & Fat \\
& skin tears & shed skin \\
Snakes & Protection & \\
Chameleons & &
\end{tabular}

Fish otters are believed to have special powers and even to be able to resist machetes. Because of this alleged bravery and for being so strong, fish otters have got a special "initiation name" from the Beafada ethnic group ("Dame Dabo"). If one wishes his son to be very courageous, it is recommended to give him the lever or heart from a fresh killed fish otter to eat. Another method is to wash the child in the same bath with the skin from an otter. Such children are believed to become very strong and to be good fighters, but no woman should see that skin before using it, otherwise it is believed that it will not have the desired effect. The Fish otter's skin has a very high value since it is believed to give a special protection and is used as a protective talisman. It is sold at very high prices. This has led to heavy hunting pressure on this species in the past.

Even giant cane rats have a positive role as they are known to kill snakes, and porcupine intestines are used to heal abdominal pains. The Gambian pouched rat (local name: "Djiquindor") is particularly important for the local communities of the Canhabaque Island, where this species is not only a highly appreciated for its meat, but has also an important 
cultural role. Gambian pouched rats are used not only for traditional ceremonies, but are also a required special gift when recruiting a bride.

Other wild animals, including non mammals, are considered to be important for different purposes. Shields of marine turtles are used as pots and bones of crocodile are used in traditional medicine. The skin of the Savannah Monitor Varanus exanthematicus (local name: "Kuto") is used to heal haemorrhoids. Teeth from the Python are used to heal chest inflammation and its fat is effective against body pain. The shed skin of snakes is used together with palm oil to heal skin tears, while chameleons are also used to produce talisman.

\section{V.2.7. Wildlife in mythology and culture/Existing taboos on mammals}

Wildlife and more specifically wild mammals play an important role in the popular mythology and cosmogony in Guinea-Bissau, but their role in the religious life is stronger in the Bijagós archipelago than in the continental part of the country. Hunting and consumption taboos do exist in the different ethnic groups for a number of species, for cultural, religious, or other reasons (Table20).

The results of the interviews show that certain mammal species, e.g. Manatee, Hippopotamus, Chimpanzee and Spotted have been partially protected, due to their cultural and religious importance. These species are considered by interviewed local people to deserve most conservation efforts. However, there is a general evidence of changes in consumption habits and species formerly under taboo are increasingly being consumed by young people or persons who have lived in the capital or in other urban centres or/and have had contact with people from other communities or other countries.

Special ceremonies before hunting are known in certain ethnic groups with a tradition of hunting such as the Fulas and Mandingos. Those ceremonies are particularly important when larger animal species are to be hunted, as for instance hippopotamuses, large antelopes, buffaloes, manatees, leopards and yellow backed duiker. The rituals and carried talismans are thought to protect the hunter from malefic spirits of the forest. If these ceremonies are not conducted, some misfortune is expected to happen to the hunter. A very famous hunter from the Cufada Natural Park is believed to have shot an animal which 
was in reality the son of a spirit and since then he has been forced to hide himself from that spirit by disguising himself permanently as a woman.

\section{Chimpanzee}

Chimpanzees are not actively hunted by local villagers in their area of occurrence (around the Cufada Natural Park and the Cantanhez forest zone). They are considered sacred for their strong resemblance with humans and for their high intelligence. This is illustrated by numerous existing stories on this species. One famous story is about a baby who was lost in the forest during the independence war and was saved by chimpanzees. It is told that this child was found and raised by a family of chimpanzees and found again several years later after the war. Chimpanzees are also considered to be less destructive than the other crop raiding animals. Although they do consume villager's fruits (Cashew, Mango, Banana, etc.), they do not destroy the field as do Baboons or Callithrix monkeys for example.

\section{Black-and-white Colobus monkeys}

Black-and-white Colobus monkeys are also feared and respected and are generally not hunted, even by non-Moslem people. This respect is shown by their local name "Fidalgo", which means "noble", due to their very calm and mysterious behaviour and also due to the fact that they don't destroy the fields as much as other smaller monkey species. In Cantanhez, where this species is restricted to today, it is told that a hunter who had shouted at a black and white Colobus died on the same day after he shot himself. Since then, nobody would kill this species intentionally. In the past some persons should have eaten this Colobus meat, but today it is not consumed.

Monkeys and wild pigs are not hunted for consumption by Moslem people; however, even in the mostly Islamic regions, Baboons and wild pigs are killed "on command" or when destroying fields and are sold in the neighbouring areas where there is a high demand for these animals meat.

On the Bijagós islands, water dwelling animals such as hippopotami, manatees, crocodiles and marine turtles are considered to be sacred and were traditionally used only for special ceremonies. In the past, a turtle or hippopotamus had a high value for certain initiation ceremonies, but today those animals are replaced by fish or in some cases by shark or even palm wine. However there are still some very special ceremonies which take place every five years and for which a marine turtle should be used. Only a few people are 
thought to be able to hunt these species, because of the mystic power that is attributed to them. But also in other regions Hippopotami, manatees and fish otters are respected by the majority of the local population.

\section{Hippopotami}

Hippopotami are feared by most people in Guinea-Bissau and are considered to have very strong mystic power. Although these animals are considered to be in principle peaceful, some people are believed to turn into or to assign a hippopotamus for malefic purposes, for example to destroy a field or to injure or even eliminate an enemy. This species was killed in the past, only when it had attacked or killed a person. Intentional killing of this species is considered to have consequences for the hunter. That is why a hunter must make very special purification ceremonies after he has killed a hippopotamus, in order to avoid such negative consequences. It is told for example that a villager from an island in the Bijagós archipelago was born with a cleft lip (harelip), because his father fought with a hippopotamus and wounded it in the mouth, while his mother was pregnant. Another village fisherman from another island was wounded by a hippopotamus on his left leg and is still handicapped now; it is believed that due to that incident, all his children were born with a malformation on their left leg.

Hippopotamuses are said to have several spirits and are believed to be able to hypnotise hunters using mirages. Even dead, a hippopotamus remains dangerous: inadvertently touching its eyes would bring misfortune, a reason why the hunter will cover them carefully with mud to avoid such an accident. After a hippopotamus is killed, the hunter must inform the eldest members of the village and also the neighbouring villages. Before the meat can be consumed, a special ceremony needs to take place in order to purify the hunter. Otherwise, the hunter and the person who will cut up the animal will die or have some misfortune. The meat will then be distributed to all the villagers from the neighbourhood. Distribution of the killed animal's meat must take place silently, without previous discussion and more especially without calling the name of the persons present; otherwise the called person will die also.

\section{Manatee}

Manatees play an important role in the mythology all over the country, and only a few hunters with special abilities can kill this species. Even then, there are different restrictions on the number of manatees one can kill during his life, because frequent repetitions could 
bring misfortune. If a manatee is killed, no pregnant woman should approach the place where the animal is, otherwise, the baby could die. If an animal is accidentally caught in the fishing net, it will be necessary to make a purifying ceremony, for example in the "Baloba" (the hut of the ancestors spirit) before the meat can be consumed.

Table20. Examples of taboos on wildlife species

\begin{tabular}{|c|c|c|c|c|c|}
\hline & \multirow{2}{*}{$\begin{array}{l}\text { Totem } \\
\text { species }\end{array}$} & \multicolumn{3}{|c|}{ Taboo species } & \multirow{2}{*}{$\begin{array}{l}\text { Sacrificial and/or } \\
\text { ceremonial species }\end{array}$} \\
\hline & & Sacred & Unclean & Religion & \\
\hline Monkeys & & & & $\bullet(\mathrm{f})(1)$ & \\
\hline Chimps & & $\bullet$ & & & \\
\hline Pied Colobus & & $\bullet$ & & & \\
\hline Hippopotamus & & $\bullet$ & & & $\bullet(a)$ \\
\hline Manatee & & $\bullet$ & & & $\bullet(a)$ \\
\hline Wild pigs & & & & $\bullet(f)(1)$ & \\
\hline Leopard & & $\bullet(d)$ & & & \\
\hline Spotted & $\bullet(b, c)$ & & $\bullet$ & & $\bullet(d)$ \\
\hline Fish otter & & $\bullet$ & & & \\
\hline Genets & & & $\bullet$ & & \\
\hline Mongooses & & & $\bullet$ & & \\
\hline Crocodile & & $\bullet(e)$ & & & $\bullet(a, d)$ \\
\hline $\begin{array}{r}\text { Leatherback } \\
\text { Sea Turtle }\end{array}$ & & & & & $\bullet(a)$ \\
\hline Nile monitor & & $\bullet(b)$ & & & \\
\hline
\end{tabular}

(a) Bijagós, (b) Beafada, (c) Mandjaco, (d) Nalu, (e) Balanta, (f) Moslem, (1) killed for sale

\section{Other mammals}

The Fish otter is considered to be very intelligent but very aggressive. It is also believed that these animals have special powers and are very resistant. They are said to be very difficult to observe or even to catch. Meat of fish otter is consumed, but killings are more or less coincidentally.

Spotted hyenas are not hunted by the Mandjaco people from the Cacheu region; members of this ethnic group are believed to turn themselves into spotted hyenas. Spotted hyenas are also not hunted by the first inhabitants of the Cufada Lagoon ("Djagra de lagoa de Cufada"), as being considered a totem for this group. It is said that this animal showed that group the territory where they could establish themselves. This species is thus considered as a parent by the Beafada ethnic group and a killed spotted must be correctly 
buried like a human being. Spotted hyenas are believed to send different messages to people, depending on the frequency of howling, e.g. the death of a member of that group or the need to carry out a special ceremony. It is said that people in the southern forests received warning messages from spotted hyenas during the colonial war.

Hyenas were used for very special initiation ceremonies in the past, and on those rare occasions, spotted hyena's meat was consumed. Even other ethnic groups don't consume spotted hyena's meat, whose intestines are considered to be poisonous. For this reason, a killed spotted hyena must be buried or completely burned, in order to avoid the unintentional consumption or the premeditated use of those poisonous parts.

Hunting of Roan antelope, and of other large mammal species always requires special rules to be followed. If a Roan antelope is killed, some details such as the position in which the animal falls while dying is also important, because they can led to unexpected consequences such as the death of trees or some misfortune or disease for the hunter.

Red-flanked duikers are considered as the fortune-teller for all forest animals and to have some magic power. Through the observation of a red-flanked duiker walking on grass, one could predict periods of high animal mortality. It is also said that this animal can set fire to the forest, in order to promote new grass growing.

Leopards are also not hunted for consumption, but mostly for their skin. They are feared and also considered as sacred by some people, especially in the southern regions. Some people are believed to turn themselves into leopards and a hunter who kills a leopard is believed not to live much longer afterwards.

Consumption taboos exist in general for most small carnivores such as genets and mongooses, the former especially as being considered to be very similar to cats and their hairs to be extremely dangerous if inadvertently consumed. These species are not hunted for meat.

\section{Non mammal species}

Meat from non mammals, especially water dwelling species like crocodiles and marine turtles are used only for very special ceremonies, more particularly in the Bijagós islands. 


\section{Crocodiles}

This species has played a special role for the Nalu ethnic group in the South. In this group, only the women used to make a ceremony in the past, after which they could never consume meat from the crocodile. Today, this ceremony has been abandoned, but such persons may still not eat crocodile meat, otherwise it is believed that they could still be punished, for example by getting a skin disease. Crocodiles still play an important role in some special traditional ceremonies in the Bijagós archipelago, especially in the age initiation rituals.

\section{Nile Monitor}

This species is sacred for the Beafada in the south: they cannot be killed, otherwise, it is believed that the hunter will get ill (mainly with skin diseases). Members of the Beafada ethnic group are believed to be able to turn themselves into monitors.

\section{Leatherback Sea Turtle Dermochelys coriacea}

Marine turtles and especially the Leatherback Sea Turtle are very important in the Bijagós culture. Their aspect is reminiscent of the form of the deceased during funeral ceremonies ("Djongago"). If such a turtle is killed, a purifying ceremony is required before the meat can be eaten. The ceremony must be carried out only by initiated people; children and non initiated persons cannot take part.

\section{V.2.8. Knowledge on existing hunting regulations}

In the surveyed protected areas, most park wardens are originally from those regions; this has made information and sensitisation work easier. Most inhabitants of the Orango, Cufada and Cantanhez know about the existence and to some extend about the content of the law on hunting. In these regions, information was provided by the park wardens, by local forest guards, or by environmental education programs from community radios.

In the interviewed villages of Formosa however, people declared not to be informed about the content of the law on hunting.

In the village of Imbone, people claimed that the law on hunting should also include regulations and measures against outside fishermen who are destroying the island. In all the surveyed sites, people stated that the official law should not prohibit hunting for own (local) consumption, but should prohibit this activity to hunters from outside the area. In 
Cantanhez for example, people claimed that military corps used to enter the forest of Canamina to kill monkeys.

\section{VII.2.9. Knowledge and perceptions of existing protected areas}

Most of the interviewed people in the three protected areas (Orango, Cufada and Cacheu) knew of the existence of protected areas and consider that these protected areas were created to protect animals and the forest or landscape.

In the Orango National Park, people consider that the main benefit they have had from the existence of the park are the VHF communication radios, the water wells and the fact that no outside hunters enter their area any longer. In the Cufada natural park, the village shops, the solar light and the schools and also the improvement of the roads in some areas are the main benefits the inhabitants have received. In Cacheu, a number of development projects were implemented, with the installation of wells, village shops, and support for horticulture and apiculture.

In Orango, people consider crop raiding by animals, especially by hippopotamuses as the main constraint proceeding from the existence of the park. In general, people claimed that the major constraints they are experiencing since the establishment of the protected areas (or of the new regulations) are the restrictions on the use of natural resources such as hunting, exploitation of other forest products such as Ron palm and restrictions to deforestation for agricultural activities.

\section{VII.2.10. Perception of the importance of wildlife monitoring}

Monitoring of hunting activities is seen as necessary and feasible in all the villages visited. Most people interviewed said that hunting activities should be controlled by the local hunters themselves, as they are present and know best their environment, the forests, animal species and local people's habits. According to the villagers, official forest guards could support local hunters for general supervision of the villages, for explanation of and sensitisation on existing laws and for the application of penalties.

According to the inhabitants of Orango, monitoring and control would help to keep outside hunters from entering the villages. In that National Park, villagers state that they would be 
able to carry out the monitoring activities with the help of their park wardens (who are mostly natives from the villages) and the official legal support of the government.

In Cufada and Cantanhez, people consider that monitoring would help to protect endangered species, since there are too many hunters and it is difficult now to know which species are endangered and how much they are hunted.

In Cantanhez, a local initiative was launched since 2002, with the help of a local NGO, and a forest management committee was created with representative groups and forest guides from different villages. A law was approved by the community to control the exploitation of the remaining forest and wild animals (see below). In the Cufada and Cacheu natural parks, there exist similar local structures (Park management committees) with representatives from different villages, one of whose functions is to control exploitation activities. Interviewed villagers consider that those management committees would monitor hunting activities, with the forest warden supporting them as the government representative for law enforcement awareness building and activities.

\section{V.3. Examples of community-based conservation initiatives in Guinea- Bissau}

There is little experience with specific Community-based wildlife management activities in Guinea Bissau. However, there are numerous examples of traditional community natural resources conservation initiatives among the different ethnic groups throughout the country, in the absence of external intervention. Community conserved areas are widespread in the form of sacred forests and groves, which are considered to host spirits.

Although some sacred forests have already disappeared, a number of those sites remain almost intact, even when the surrounding areas are exploited for agriculture, being used exclusively for traditional ceremonies and rituals. Some sacred forests are still well conserved in the south-east region and Cufada area (Robillard 1989) and in Cantanhez (Tiniguena 1997, da Silva 1997). However, it is more particularly in the Bijagós archipelago Biosphere Reserve that community conserved areas are still quite widespread (Figure16) and embedded in the local traditional culture (Limoges \& Robillard 1991, Marreti 2003). As already stated elsewhere, many such community-conserved areas are based largely on 
customary rules and agreements, with no intervention of government or non governmental agencies and remain basically informal (Borrini-Feyerabend 2003).

Some existing CBWM actions have been initiated by the State institutions (Table21), with international donors support (Zeba 1998, Dias 2000), however those initiatives have focused their actions mainly on the management of timber and non-timber forest resources. Several community forestry activities were initiated in the year 1994, mostly in the eastern part of the country, in the context of a governmental agroforestry project, the PASP ("Projecto Agro-silvo-pastoril"), with a funding and the technical support of a Netherlands development agency, the SNV.

In the light of the new legislative context, there have also increasingly been examples of community-based conservation actions initiated by local populations with the support of non-governmental local or international organisations (Table21). Three of those community-based conservation initiatives are presented below: the participatory coastal resource management in the Formosa islands group, the community forest conservation in Cantanhez and the Green space management programme in Oio.

Table21. Examples of community-based conservation initiatives in Guinea Bissau

\begin{tabular}{lll}
\hline Site & Administrative region & Initiator \\
\hline Madina Djalocunda/ Pitche & Gabu (east) & $\begin{array}{l}\text { Governmental } \\
\text { institution } \\
\text { Governmental } \\
\text { institution }\end{array}$ \\
Sibidjan Fula/Contuboel & Bafata (east) & $\begin{array}{l}\text { Governmental } \\
\text { institution }\end{array}$ \\
Munini/Cossé & Bafata (east) & Community and NGO \\
Formosa islands group & Bolama-Bijagós archipelago & Community and NGO \\
Cantanhez Forests & Quinara/Tombali (south) & Community and NGO \\
Farim & Oio (north) & Comm \\
\hline
\end{tabular}

Details of the main opportunities and constraints to the implementation of communitybased wildlife management schemes in Guinea-Bissau, including issues related to these three examples, are discussed later (see chapter discussion on CBWM). 


\section{V.3.1. Participatory coastal resources management in the Formosa island group}

The Bijagós traditional society is characterised by a gerontocratic system and the organisation in age groups. The natural resource management is collectively ensured by the oldest age group and this control by one group over the others has repercussions on the access and the use of natural resources, which are regulated by a set of rules and prohibitions carefully observed by the local communities (Said et al. 1996, BorriniFeyerabend 2003). The Bijagós specific culture and way of life and the relatively low external influences have for a long time contributed to the maintenance of a harmonic coexistence between the Bijagós society and the local natural environment.

In recent decades however, numerous factors have significantly affected this traditional resource management system in that region, including on the Formosa islands group. Immigration from other parts of the country (particularly by the Pepel ethnic group) and from neighbouring states (mostly from Senegal), and increasing commercial exchanges are leading to a rapid degradation of natural resources and to conflicts with local communities in that region (Biai et al. 2004). In Formosa meanwhile, the members of the resident large community of the Pepel are known to exploit shells, palm trees and grass. There is also a community of resident immigrant Nhominka fishers, but the temporary fishermen's camps are particularly contributing to the overexploitation of coastal resources. Since this exploitation has mainly commercial purposes, take off has sometimes been excessive; according to Tiniguena (2003), certain shells (e.g. Melongena) and fish species (e.g. sawfish) have been almost driven to extinction. Beside the degradation of natural resources, other observed constraints are the progressive weakening of traditional regulations and an increasing trend for income generating activities among younger generations.

The initiative for the participatory coastal resource management was formally launched in the year 2003, as an initiative of local communities with the support of a national NGO (Tiniguena) and with the technical and financial support from an international foundation (FIBA: Fondation Internationale du Banc d'Arguin). A long process of collaboration for sustainable development had, however, already started in 1993. The aim is to "reinforce the process of appropriation and sustainable participatory management of the natural resources and the biological diversity on the Formosa island group, to the benefit of the local populations and of the country" (Tiniguena 2003). 
In the first phase, this programme has focused on marine resources, i.e. fish and shells, but the process is a plausible example of creating and developing the local capacity for successful CBWM. Several steps were made for the implementation of this programme. The first one was the identification and description of the activities related to fishery, fish product processing and trade. A specific survey was carried out on the exploitation of shells by women and on the economic and socio-cultural importance of these resources. Fish capture monitoring allowed to assess the spatial and temporal distribution of the different species and also to evaluate the fishing effort. Village fishing territories were also identified and mapped. Information was collected on traditional use regulations, conflict sources and in general on local knowledge of ecosystems and wildlife.

Along with these resource use assessment activities, information and sensitization actions and deliberations were carried out on new use regulations to be recommended. This work led to the creation of representative village fishermen and (shell exploiting) women committees. Visits to other communities with similar experiences and cultural activities related to conservation issues also supported the awareness building process. Local fishermen were provided with technical training in the use of some new fishing engines and with organizational capacity-building. Additionally, a loan scheme has been established in order to allow those fishers to access the new fishing material.

In order to ensure the effective involvement of local communities, participatory consultation mechanisms have been developed, which involve different stakeholders groups from the three islands of Formosa, Chediã and Ñago, and also integrate traditional structures. Local authorities and technical structures linked to conservation are integrated in the consultation structure. This mechanism foresees annual general assemblies on the respective islands and also an annual meeting of all representatives from the three islands. The dialogue process has led to the design of a general resource use scheme, which represents the core of the management plan for that group of islands, and which has integrated local and traditional use and conservation mechanisms.

The management plan defines the agreed rules on access and use of the coastal and marine resources (including defined zoning areas, conservation measures for certain threatened fish, terrestrial and marine animal species); the mechanisms envisaged for the resource management and monitoring; and other complementary measures required for the successful implementation of the management plan. The latter include, for example, 
measures for the improvement of the living conditions of the local communities, capacitybuilding and empowering actions for negotiation and monitoring, and also cultural education and communication activities (Biai et al. 2004). The locally negotiated and designed coastal ecosystem and resource management plan has been submitted to the government approval, for its official recognition. The long-term objective of this initiative is the creation of a community protected area.

\section{V.3.2. Community-based conservation of the Cantanhez Forests}

The existence of traditional mechanisms of nature conservation, in form of sacred forests and groves, rituals and ceremonies, local knowledge and practices of sustainable resource use in Cantanhez has suffered significant alterations due to numerous factors, but mainly from increasing demographic pressure, particularly through migration from the north and from neighbouring countries, decreased rainfall, augmenting crash crop agriculture, and insecurity over land tenure (IUCN/DGFC-MDRA 1993, Tiniguena 1997, da Silva and Cardoso 2001). Furthermore, the Cantanhez forests are particularly vulnerable to external pressure, since this area has no actual official protected status.

Already in the year 1993, the "Iniciativa de Cantanhez", a joint initiative was launched by three national NGO (AD - Acção para o Desenvolvimento, Alternag and Tiniguena), in order to support local communities in the conservation of the last forest remnants, with the technical and financial support of different international organisations and donors. Alternative actions aiming at the reduction of the human pressure on forests, income generating activities, community development, environmental education and capacity building of the grassroots organisations, and support to local forest guards were the main components of this initiative.

Since 2002, a stronger emphasis has been given to the reinforcement of the local management structures. With the support of the NGO AD, a local forest management structure has been created, including several village forest management committees. These management structures include not only traditional authorities, but also representatives of different stakeholders from the different villages and ethnic groups from that area. Forest surveillance is of the responsibility of the village committees. 
A bylaw was elaborated and locally agreed by the members of the community, which specifies concrete regulations and measures on access and use of the forest resource, including the conservation of endangered wildlife species (primates -more particularly chimpanzees and colobus monkeys, buffaloes, manatees, elephants, large antelopes, etc). The measures aim at protecting the remaining forests and their resources from overexploitation through deforestation, commercial hunting, to the benefit of the local communities. Information activities have been carried out, in order to inform the population of this local law, which was also submitted to and approved by the local administration but was not yet approved by the central government.

A project supported technically and financially by the IUCN (World Union for Nature) for that area aims to support the local communities in the conservation of the forests, ensuring at the same time the wellbeing of local populations. The aim is the creation of a protected area, managed by local committees based in the four traditional kingdoms throughout the zone, reinforcing at the same time the process of decentralisation (IUCN 2002, 2004).

\section{V.3.3. Experience of Community forests: the Green space management programme in Oio}

Since the colonial period, logging activities and sawmills have been mainly situated in the northern and eastern part of the country, with an intensive selective exploitation of a few valuable species. With the economic liberalisation in the middle of the nineteen eighties, numerous logging companies surged, with a heavy concentration on the clear forests in the eastern and northern parts of the country (Dias 2000). Beside uncontrolled logging and sawmill activities, a range of other factors have further accelerated the degradation of forest areas in the northern regions of Guinea Bissau, e.g. decreased rainfall in the last three decades, slash-and-burn agriculture, charcoal production, cash crop production etc. (Swissaid 2000).

Following the above presented community forests model developed in the eastern part of the country, a number of community forestry experiences have been launched in other regions by local communities, with the support of NGOs, in order to protect their respective forests and wildlife resources. One of these experiences, the Green space management programme in the northern region of Oio, involves about 45 forests managed by the local communities from about 22 villages (Swissaid 2003). This programme has been 
implemented since the year 2000 by a national NGO (RADI- rede africana de desenvolvimento integrado), with the financial support of a Swiss development agency (Swissaid). This programmes objectives are capacity-building through training and equipment of the involved local communities in the forest restoration and management areas, and the reinforcement of the communities organisational structures for obtaining the legal recognition of the collective property rights on their villages forests (Swissaid 2000, RADI 2001).

A management plan was locally elaborated and agreed, and as stipulated by the legislation on community forests, a first memorandum of agreement was signed for instance between the local communities of the Djalicunda village and the official forestry authorities. This agreement cedes to the local communities the right to manage the designed forest for a three-year period and according to an approved management plan. After this period, the agreement and the communities use rights will become permanent if the community has demonstrated its capacity to protect and to manage the forest as agreed (APGFC Djalicunda 2003).

The agreement regulates the mechanisms of access and use of the resources from the referred forest, the operating mode of the management committees and the roles of the different partners. The former also manage the funds deriving from the forest management, which have to be invested in environment and social development activities such as forest conservation, community infrastructures and training. The State keeps the right to monitor the use of the funds any time, e.g. by unannounced audits. 


\section{Discussion}

\section{VI.1. Survey methods}

\section{VI.1.1. Line transects}

For relatively small animals (including primates), and in woodland and forest area where visibility is limited, walking surveys are often the only feasible method (Whitesides et al. 1988). The line transect technique is considered to be the most suited for animal surveys in large tropical forest areas (Tutin \& Fernandes 1984, Buckland et al. 1993). Robust data on population densities can be obtained with this method (Buckland et al.1993), which are not only comparable between sites, but also between species. This method has been used to estimate the density of primate groups (Whitesides et al. 1988, Oates et al. 1990, Mitani 1991, White 1994, Plumptre \& Reynolds 1994, Plumptre 2000) and for surveys of other mammal species in forests (Koster \& Hart 1988, Waitkuwait 1994, Steinmetz \& Mather 1996, Carrillo et al. 2000, de Thoisy 2000, Lannoy et al. 2003) and in woodlands (Mackanga 1997, Sinsin et al. 1998, 2002, Caro 1999a/b, Fischer \& Linsenmair 2001). In African tropical rainforests, line transect census have been shown to give reasonable density estimates for primates (Whitesides et al.1988) and ungulates (Koster \& Hart 1988, Lannoy et al. 2003). For apes, line transect methods have been also used for density estimates, using nest counting (Hall et al. 1998).

For some species or groups, over- or underestimation has been demonstrated (National Research Council 1981, Defler \& Pintor 1985). Failure of the technique can result when a study species does not conform to various fundamental assumptions, for line transect censusing (Burnham et al. 1980, Buckland et al. 1993). Also will the accuracy and resolution of the sample depend upon the sampling intensity; the degree of variability between censuses and resolution of differences less than 25$50 \%$ will often not be possible without a large number of repeat censuses (National Research Council 1981, Skorupa 1988 cited in White 1994). Also according to Plumptre (2000), differences of less than 10-30\% change in the population, when using visual sightings of animals, and differences of $30-50 \%$, when using indirect methods, are unlikely to be detected between two surveys. 
For some species which occur at very low densities, this method may underestimate their population estimates (Chiarello 2000). According to Mitani et al. (2000), linetransect census methods may not be particularly appropriate for estimating the abundance of species with low population densities, large home range and diffuse social systems like chimpanzees. Densities determined from line-transect counts, conducted over a relatively short period, may be considered as an index; this index will remain closely dependent on calculation methods (de Thoisy 2000). To calculate densities with line transect data, it is thus recommended to undertake long-term studies (National Research Council 1981, Butynski 1990 cited by White 1994).

Determining the distance at which animals are observed during censuses is critical to making accurate assessments of the area surveyed and, correspondingly, estimating absolute primate densities. The results of this study illustrate well importance of the observation distance and thus of the effective strip width ESW for accurate density estimation. Comparing the density estimates obtained in this study with different calculation methods (on the basis of Campbell's monkey data), we observe that the density estimates from analysis with the Distance software are quite similar to those obtained with manual calculation (using line transect data or the combined encounters from reconnaissance and line transect survey) when the same ESW value as calculated by distance is used. Also density estimates obtained with manual calculation using line transect data only are comparable with those obtained using the combined encounters from line and reconnaissance surveys, when the considered ESW was calculated with the same method (i.e. fall-off method). Data obtained using the mean value of the perpendicular observation distance, appear to be overestimated, if compared to other methods. Furthermore estimates of sighting distances may vary significantly between observers (Plumptre 2000).

Furthermore, a minimum of 40 observations are needed for statistically reliable density estimates with line transect data (Burnham et al.1980), and ideally 60 to 80 observations for estimation using the computer software Distance, whereas at least ten transects are recommended to ensure adequate sample sizes (Buckland et al. 1993). For species occurring at very low densities however, this is usually an important constraint for the estimation of densities and abundance with this programme (Carrillo et al. 2000, Karibuhoye 2001). According to Carrillo et al. (2000), 
for some tropical mammal species, considerable sampling efforts of hundreds or even thousands of $\mathrm{km}$ might be necessary to obtain the minimal 20 sighting events required. Sample sizes in surveys should reach at least 100 groups if the objective of the study is to monitor the population changes in future. For rare species, obtaining 100 sightings is likely to require many hundreds of kilometres of transects, and consequently line transects may not be appropriate, reconnaissance walks may be a better method (Plumptre 2000). This is also the case for Chimpanzees, red colobus and pied colobus in Cantanhez, for which $300 \mathrm{~km}, 200 \mathrm{~km}$ and $240 \mathrm{~km}$ of transect would need to be surveyed respectively in order to obtain 100 sightings (see chapter VI.9. and table31).

An additional disadvantage of line transect sampling in rain forest vegetation is that it is a slow and labour intensive process (Walsh \& White 1999, Hall et al. 1998). For some forest mammal species, mostly indirect estimation techniques are a valuable alternative, because visibility is often poor and direct observation frequencies are low, especially in secret, solitary and nocturnal species. It is also not always possible to get precise measurements and observation distances. A number of conservation scientists have thus been looking for alternative methods to these standard line transect survey methods.

Struhsaker (2002) considers that data on mobile animals from line-transect censuses are most useful as indices of relative abundance, i.e. number of groups or animals detected per $\mathrm{km}$ walked, and that their utility in estimating absolute population densities (number per unit area) is often highly questionable and problematic at best. The use of relative abundance indices can be used to detect changes in populations over time and between different places in similar habitats (Conroy 1996, Mitani et al. . 2000, Struhsaker 2002). According to Mitani et al. (2000), if one is interested in gaining a first approximation of numerical changes, for instance in a primate community over time, then the measure of relative abundance, the number of groups seen per kilometre censused, is satisfactory and inter-observer differences in estimating sighting distances are not a problem.

Noss (1999) has used encounter rates to calculate abundance indices and density estimates for rainforest game species. The kilometric index has been used to monitor 
forest roe deer populations in France (Vincent et al. 1991 cited in Maillard et al. 2001) and large terrestrial animals in Central African savannah regions (Maillard 2001). De Thoisy (2000) used this abundance index for mammals in Neotropical forests of French Guyana. The kilometric index (or encounter rate/sampled km) can be calculated for total abundance (total number of observations/sampled $\mathrm{km}$ ), for species number (number of species observed / sampled $\mathrm{km}$ ) or for each species (number of observation per species/ sampled km) (Maillard et al. 2001). In a study carried out in Chad, Maillard (2001) has shown that the kilometric index method, carried out under standardised conditions, is suitable for detecting trends in animal populations in the Sudano-sahelian savannah areas. According to De Thoisy (2000), the abundance method has a poor ecological significance, but has the important advantage of not requiring any further calculation, which leads to limited biases and makes comparison with other data more reliable (Emmons 1984, cited in De Thoisy 2000). This method is also suitable for limited data sets.

Carrillo et al. (2000) have monitored mammal populations in Costa Rican forest areas using pre-established trails and calculating a kilometric abundance index of direct sighting of primates or of indirect tracks observations of other mammal species. Because detectability of tracks of different species may vary, Carrillo et al. (2000) recommend the use of abundance index based on tracks for comparisons of mammal abundance over time, only within species.

The use of tracks of tropical mammals has some advantages: they can be used to document the presence of species which are shy, inconspicuous or nocturnal and observations can be made independently of the main activity period of the animals (Carrillo et al. 2000). The same authors point out the low cost and the rapid way of obtaining data as a further advantage of this method: a substantially less sampling effort is needed to document population differences between sites or trends between different sampling periods than by using line-transect methods.

Odendaal et al. (1980) have analysed the use of track counts for estimating population densities on bushbuck, and they found a relationship between the number of tracks on a transect or road and the number of animals. These authors also point out the simplicity of this method as an advantage. In a study of duikers in Kibale, 
Uganda, McCoy's (1995, cited in Struhsaker 2002) observed that there was greater consistency in measures of duiker abundance between direct detections and track counts than between either of these methods and dung counts.

However, the most obvious disadvantage of the using tracks for mammal survey is the fact that some species such as arboreal and very small animals are not registered by means of their tracks. Furthermore, the obtained relative abundance indices convey rather indices of relative abundance and no accurate information on the actual size of wildlife population (Odendaal et al. 1980, Carrillo et al. 2000, Struhsaker 2002). A further disadvantage is the very large sample units required to detect changes in population density with reliable probability of success (Seydack 1977, cited in Odendaal et al. 1980). Carrillo et al. (2000) recommend combining the use of relative abundance indices using tracks and sightings with line-transect sampling of the most common species. As this author states, comparison of relative abundance indices and abundance data from line-transect sampling or from other methods could permit to know about their relationship, which would help to optimise fieldwork and expand usefulness of mammal survey information.

\section{VI.1.2. Reconnaissance surveys}

Reconnaissance or general survey walks have been used mainly in Central African forest (Hall et al. 1998, Walsh \& White 1999, Mitani et al. 2000) and in East Africa regions (Dinesen et al. 2001) to assess elephant and other mammals' populations. Survey walks are commonly employed during the initial stages of more detailed studies and when the objective is to gain a general and qualitative impression of the fauna of an area. For reconnaissance sampling, a path of least resistance is followed along game trails and natural features such as watercourses and ridges, cutting only enough vegetation to maintain a general compass bearing (Walsh \& White 1999). Existing and abandoned human tracks, trails and footpaths linking villages are also used, while particularly difficult topography and exceedingly dense vegetation are avoided (Walsh \& White 1999).

According to Walsh \& White 1999, the reconnaissance method requires roughly three times less effort per unit distance than transect sampling and allows researchers to cover about four times more ground than transect sampling. This point of view is 
shared by Beyers et al. (2001), who also consider the method to be simpler and less strenuous. Moreover, this method results in less damage to vegetation than transect sampling (Walsh \& White 1999). Hall et al. (1998) argue that using the reconnaissance method is an economical and relatively accurate method to assess ape distribution and abundance in large blocks of forest. To detect a change of $20 \%$ in elephant population for instance, a reconnaissance-transect combination should require about $70 \%$ less time effort than transect sampling alone (Walsh \& White 1999).

The reconnaissance walks can provide information on the relative abundance of animals, but, by definition, they are expected to be biased and not necessarily representative of the larger area being surveyed (Hall et al. 1998, Struhsaker 2002). Two problems arise with reconnaissance surveys that can bias the density estimation (Beyers et al. 2001): certain types of vegetation are avoided and a sample based on reconnaissance transects is not representative for the area. The path of least resistance is often an animal or human trail and signs of animals or humans will therefore be overestimated. Reconnaissance walks do not follow the ideal line (the line where the transect would be in case of random or systematic placement of transects). Moreover, observers move faster on reconnaissance walks and so may not be able to observe carefully.

The obvious disadvantage of reconnaissance survey comes with interpreting the data and understanding the nature and extent of the biases inherent in this method and related for example to such problems like sample width estimation or temporal variation (Struhsaker 2002). However, a strong correlation was found between data from transect line and reconnaissance survey of elephant dung piles in southwestern Gabon, suggesting that reconnaissance walks have potential for density estimates (Walsh and White 1999).

According to Hall et al. (1998), forest reconnaissance survey can be used to assess gorilla densities accurately within well-defined strata where it is reasonable to assume similar nest site group sizes and decay functions within the areas. In a study on the feasibility of using forest reconnaissance as a cost-effective alternative to the labour intensive transect sampling, these authors compared gorilla nest site 
encounter rates on transects with those observed on nearby forest reconnaissance trajectories. The mean encounter rate on forest reconnaissance segments within a region was found to correlated well with the transect encounter rate for that region, suggesting that nest site encounter rates on forest reconnaissance provide a good estimate of encounter rates from transect sampling. Forest reconnaissance may also work for chimpanzees in similar situations (Hall et al.1998).

A statistically rigorous estimate of density can be made from reconnaissance survey data if some effort is made to calibrate the functional relationship between reconnaissance and line transect encounter rates and thereby correct the bias (Walsh and White 1999, Beyers et al. 2001). A combination of reconnaissance and transect counts was proven to provide a more precise estimate of density than line transect sampling alone, and the sensitivity difference should be most pronounced at low to moderate effort levels.

\section{VI.1.3. Semi-structured focal group interviews}

An interview centred in beliefs and in the imaginary has little to do with the mechanism of question-reply and the quantification element which is present, for example, in a socio-economic inquiry, but is rather depending on the favourable circumstances, the place, the hour of the day, the people present, the relationship and confidence between the person who tells and that who hears (Montenegro 1995).

The choice of semi-directive group interview method was justified by a number of considerations. One underlying hypothesis for the execution of group interviews is that the discussion is better suitable in the group due to its own dynamic, to bring "deeper" consciousness layers and emotional connections to light, which can not be made visible by a frontal personal interview (Mangold 1973). This method is thus particularly suitable for the research of motives and attitudes. Focus group interviews involve a selected group of informants who share a common background or knowledge (e.g. use patterns, language, organisation membership) (Bunce et al. 2000). The distinguishing features of the focus group are generally agreed, namely 
that the discussion is focused on a particular topic and that group dynamics assist in data generation (Catterall \& Maclaran 1997).

Through the open questions, participants are enabled to a detailed expression of their opinion, so that the group discussions supply more information than single interviews with the same number of respondents. The created situation corresponds more to everyday communication situations with more opportunities to opinion building and exchanges than the usual single interview (Mangold, 1973, Carpaneto \& Fusari 2000, Robillard \& Limoges 1994). The discussion atmosphere, the presence of other members of the group stimulates and turns the respondents more confident, in such a way that inhibitions to express themselves on certain topics are diminished.

The semi-structured interview is a powerful method, allowing the facilitator flexibility to probe for answers, follow-up the original questions and pursue new lines of questions. Topics resulting from the answers and from the discussion itself can be taken up and further pursued (Atteslander 1995 pp.173ff., Schnell R. 1999 pp 300, Bohnsack 1999 pp492ff, Kromrey 1998, pp363ff.). Therefore, the interview and information evolve allowing the facilitator to cover a range of topics. This method differs from surveys, which have specific questions with limited answers (e.g. multiple choice, true/false). This flexible and open approach encourages two-way interactions, including exchanges of information between the facilitator and the informant and is suitable particularly to get in-depth, qualitative and descriptive information on specific issues such as stakeholder perceptions and traditional knowledge (Schnell et al. 1995, Bunce et al. 2000).

Additional advantages of this method are that it encourages informants to raise relevant issues that the facilitator may not know about and allows them to discuss issues of importance and at length. Moreover, informants can discuss sensitive issues and emotions, tailoring the answers to their situation, experience and knowledge. Finally, this method identifies local terminology, language and priorities Bunce et al. 2000).

A cordial atmosphere between the interviewer and the respondents during the interviews is an important factor for the motivation of the group to answer the 
questions (Friedrichs, 1990). This was guaranteed in most of the villages by previous contacts between the interviewer and the communities for many years. In those villages where no previous contact had taken place, a local agent, mostly a national park warden from the village did prepare and organise the meeting prior to the interview. In every village, at least one local contact person and/or one national park warden were present. In the visited protected areas, wardens are in their majority from the villages within or around the protected area.

All the interviews were carried out in the national language Crioulo, but respondents who did not feel comfortable with this language could speak their own dialect and the contact person would translate. All the interviews were recorded on tape with the permission of the interviewed group. Tape recording allows the interviewer to concentrate on the discussion and not to be distracted while taking notices.

However semi-structured group interviews have a number of constraints, which should be taken into consideration (Mangold 1973, Friedrichs 1990, Schnell et al. 1995, Atteslander 1995, Friebertshäuser 1997, Kromrey 1998, Bunce et al. 2000). This method can generate a large volume of extraneous data that usually cannot be analysed statistically with confidence. It is time consuming for both the assessment team and informants and requires an experienced facilitator: varying responses can be obtained, depending on the facilitators and how they ask the questions. Another problem linked to this semi-structured group interviews is the difficulty to determine whether informants are providing information they think the interviewer wants to hear and the risk for the interview to be side-tracked by hidden agendas. 


\section{VI.2. Mammal distribution and conservation status}

\section{VI.2.1. Status of primates}

Primates are known to persist reasonably well in modified habitats, when no hunting or low hunting pressure is observed (Cowlishaw and Dunbar 2000). The Cantanhez forest region, where some primate species are still abundant could be said to be representative of this situation. The absence of a well developed road network, and more particularly of regular and reliable transport to and from that region have limited the development of an intensive local bush meat market. Isolation, but combined with lower human population density, may also explain the limited hunting pressure and the abundance of most mammal species in the Bijagós archipelago. This is not the case in the Cufada Natural Park, which is located between three important regional markets (Quebo, Buba and Fulacunda) that are connected by well frequented main roads. However, despite the locally existing consumption taboos and the recognition today of some endangered species, all primate species should be considered as threatened in Guinea-Bissau, even those considered to be common, mostly due to increasing hunting pressure and to rapid habitat loss.

The estimated group density of Chimpanzees in southern Guinea-Bissau (Cantanhez) is lower than that on Tiwai island and in the Tai National Park in Côte d'Ivoire, but it is still higher than in some central African lowland forests such as the Lopé reserve in Gabon or the Korup support zone in Cameroon (Table22 and 23). The higher figures in Tiwai and in the Tai NP could be linked to better habitat conditions in those two areas. However, the estimates obtained from this study should be taken with caution and additional, long term surveys, also using nest count sampling, will be necessary in order to obtain more reliable density estimates. Inversely to many other West and Central and West African countries, where apes are known to be intensively killed for meat, Chimpanzees are subject to consumption taboo in most of Guinea-Bissau, so that this species can still be quite frequently observed. Peaceful cohabitation with human and an almost habituated behaviour are characteristics of this species in the southern coastal forest. Chimpanzees now enter villages in search of food, invading gardens and plantations, and this is still tolerated by local people. This species was not always protected from hunting; chimps have been heavily hunted in the past, mostly for live animal trade. Hunting pressure has considerably decreased in the last five to ten years. In Cantanhez, this could be a 
result of environmental education activities, which have been carried out by some NGOs since 1993, and in Cufada this could be a consequence of the official recognition of the Natural Park in 1997 and the awareness building activities by the Park authorities. However, this species remains threatened, for suitable habitat areas are rapidly shrinking and the existence of feeding and sleeping trees and access to water are key factors for this species (Stuart \& Stuart 1997). The observation frequency of chimpanzee nests in Cantanhez shows a drastic decrease from about 0.43 groups $/ \mathrm{km}$ in the year 1989 to 0.1 group $/ \mathrm{km}$ in 2002/2003 (Table26). This species is not totally protected from killing, due to some latent hunting pressure for live animal trade, and also because of new consumption habits which are being introduced by migration from the neighbouring areas and other West African countries. In the absence of a legal protected status for the Cantanhez forest and of law enforcement capacity by state authorities in the Cufada Park, it is difficult to assess how long chimpanzees will benefit from this informal "protected" status.

Table22. Density estimates of Chimpanzees in different West and Central African forests

\begin{tabular}{|l|l|l|l|}
\hline Country & Vegetation & $\begin{array}{l}\text { Individual } \\
\text { Density/km²) }\end{array}$ & Source \\
\hline Odzala (Congo) & Lowland moist forest & 2.2 & Bermejo 1999 \\
\hline $\begin{array}{l}\text { Azagny NP (Côte } \\
\text { d'Ivoire) }\end{array}$ & Coastal forest & 1.64 & Marchesi et al. 1995 \\
\hline $\begin{array}{l}\text { Marahoué NP (Côte } \\
\text { d'Ivoire) }\end{array}$ & Semi-deciduous forest & 1.64 & Marchesi et al. 1995 \\
\hline $\begin{array}{l}\text { Mt Nimba } \\
\text { (Guinea/Liberia/Côte } \\
\text { d'Ivoire) }\end{array}$ & Lowland moist forest & 1.31 & Marchesi et al. 1995 \\
\hline $\begin{array}{l}\text { Cantanhez(Guinea- } \\
\text { Bissau) }\end{array}$ & Semi-deciduous forest & 1.15 & This study( ${ }^{*}$ ) \\
\hline $\begin{array}{l}\text { Tai NP (Côte } \\
\text { d'Ivoire) }\end{array}$ & Lowland moist forest & $0.4-1.4$ & Marchesi et al. 1995 \\
\hline Lopé (Gabon) & Lowland moist forest & $0.2-1.1$ & White 1994 \\
\hline Haut Niger (Guinea) & Semi-deciduous forest & 0.5 & Kormos et al. 2003 \\
\hline $\begin{array}{l}\text { N'Zo fauna Reserve } \\
\text { (Côte d'lvoire) }\end{array}$ & Lowland moist forest & 0.4 & Marchesi et al. 1995 \\
\hline Kilimi (Sierra Leone) & Lowland moist forest & 0.3 & Harding 1983 \\
\hline $\begin{array}{l}\text { Bossematié (Côte } \\
\text { d'Ivoire) }\end{array}$ & Semi-deciduous forest & 0.3 & $\begin{array}{l}\text { Mühlenberg \& Slowik } \\
1996\end{array}$ \\
\hline Bafing (Mali) & Woodland & Pavy 1993 \\
\hline Mt Assirik (Senegal) & Woodland & Baldwin et al. 1982 \\
\hline
\end{tabular}

$\left(^{*}\right)$ Individual density lower limit as calculated with Distance 3.5. 
Colobus monkeys are threatened in Guinea-Bissau; although Western pied colobus benefit from hunting and consumption taboo by local people, this highly arboreal species is increasingly suffering from rapid deforestation. This species is now restricted to the strongly fragmented Cantanhez forests, where they are clearly less abundant than the red colobus. Verbal reference on the existence of this species within the Cufada Natural Park could not be confirmed by field observation. This species may be restricted to the forest patches on the northern side of the Corubal River, which is not included within the park area, but is part of the Xitole. That region is known to still have some undisturbed closed, sacred forest areas, with an adequate habitat for this species. However the region is also known to be intensively exploited for logging, charcoal production and sport hunting.

Temmincki colobus are also threatened in Guinea-Bissau, not only due to rapid habitat loss, but also because this species is actively hunted by non-Moslem people, being increasingly consumed such as other small monkeys. A comparison of red colobus relative abundance between 1989 and 2002/2003 shows in Cufada a decrease to about half the value of 14 years ago (from 0.4 to 0.22 groups $/ \mathrm{km}$ ) (Table26). For the Western pied colobus, no relative abundance data are available from the 1989 survey for comparison. The density estimates for the red colobus species in southern Guinea-Bissau are comparable to those from the Tiwai island in Sierra Leone, whereas pied colobus are much more abundant on latter. Both species have much lower densities than in the Tai National Park, Côte-d'lvoire (Table23). Although the Tiwai Island is much smaller than the Cantanhez forests, these species may find there and in the larger and better conserved Tai NP a less disturbed habitat. Better habitat combined with year long protection from hunting (Fimbel 1994a) could explain those higher densities on the Tiwai Island.

Campbell's monkeys are known to raid more particularly on fruit gardens and face high hunting pressure. This species is considered to be one of the most common primates in farming communities in unprotected areas of Sierra Leone, despite the hunting pressure (Davies \& Richards 1991, cited by Fimbel 1994b). A comparison of actual data gained from observation of this species with the reported situation in the year 1989 (Table26) shows a drastic decrease in the relative abundance by $94 \%$ in Cufada (from 0.5 in 1989 to 0.03 groups/km in 2002/03) and a significant reduction to about half (from 0.6 to 0.37 groups $/ \mathrm{km}$ ) in Cacheu. Only in Cantanhez are the 
estimated values for this species relative abundance quite similar for these two periods (0.8 and 0.7 groups $/ \mathrm{km}$ ). Comparison with data from different African forest sites indicate that density values for this species in southern Guinea-Bissau are higher than in the compared sites (Table23), where they are probably more intensively hunted than in Cantanhez. Despite the fact of this species being still considered quite abundant in Guinea-Bissau, it is threatened since it now represents one of the most killed and consumed primate species and also suffers from rapid habitat loss.

The presence of the greater spot-nosed monkey needs to be clearly assessed and confirmed by long-term surveys, since there is still some confusion between this species and the lesser spot-nosed monkey. Throughout its distribution range in West Africa, the status of this species is highly fragile, due to high hunting pressure and a rapid deforestation rate. Considering the critically endangered status of this subspecies in West Africa, research on the occurrence and status of this species in Guinea-Bissau is urgently needed. In that country, the species might be eventually restricted to the Cufada and more probably to the Corubal region. This species is known to be excluded in many areas by the presence of other competing primate species, which may be a limiting factor to its distribution (Kingdon 1997). This could explain why this species probably does not occur in the Cantanhez forest region, which hosts the highest primate abundance. In the forest patches and galleries of the Cufada and Corubal region, this species could find the required habitat and little competition.

Lesser spot-nosed monkeys are rare in the continental part of coastal GuineaBissau, but they are quite common in their occurrence range on the Bijagós islands. This species is threatened by deforestation and is also actively hunted, not only on the continental part of the country, but also in the Bijagós archipelago. The species occurs there on a few islands, among which is the most urbanised Island of Bubaque, where demographic and also hunting pressure is stronger. On the close island of Canhabaque, this species is also subjected to active hunting. However, on that island, the relative abundance estimates obtained are comparable to those from an early survey (0.9groups $/ \mathrm{km})$ (Table26). In all cases, if commercial hunting 
increases in its distribution range, this species will be seriously threatened, because of its limited range.

The Callithrix monkey is considered by local people to be one of the most serious field crop raiders and is heavily hunted throughout its range. But this species is also actively hunted for commercial purposes and its meat is considered to be very tasty. In most of its continental range, it also suffers from habitat destruction (mangrove destruction and woodland and forest conversion) through agricultural activities. All these factors are contributing to the degradation of Callithrix monkey's status all over the country, but more particularly on the continental coastal part. Data from an early survey by Limoges (1991) indicated a much lower relative abundance for Orango $(0.1 / \mathrm{km})$ compared to the present study $(1.09 / \mathrm{km})$, while comparable values were obtained for the island of Formosa with $0.2 \mathrm{groups} / \mathrm{km}$ in 1991 and $0.16 \mathrm{groups} / \mathrm{km}$ in this study (Table26). This could partly support the presumption of a lower hunting pressure on the Orango than on Formosa Island, mostly due to a lower human population density. A comparison with data from East African sites indicates higher figures of the density estimates in Cantanhez forests than in Katavi woodland area, but lower figures than in the Pemba islands forests, the latest showing similar Callithrix monkey density estimates to those on the Orango islands (Table25).

There is evidence of the degradation of Baboon conservation status in GuineaBissau: the large troops which were usually observed until some 6-7 years ago, crossing the roads of the southern region of Guinea-Bissau, were absent during this survey. This least abundant form of the savannah baboon is threatened, mainly due to heavy hunting pressure. Available data on the abundance of this species illustrate this negative trend, since estimated relative abundance in Cufada decreased by almost $60 \%$, i.e. from $1.9 / \mathrm{km}$ in the year 1989 to 0.8 during this study (Table26).

Patas monkeys are observed throughout the study site, but they are rarer in Cantanhez. This mostly savannah dwelling species is suffering from habitat modification and tree cutting in its distribution range and is actively pursued, being considered a vermin. Its large body makes it a preferred prey for the hunter and its meat is also one of the most expensive at bush meat markets (Table14), which is an additional motivating factor for its hunting. 
The Sooty mangabey was considered by some authors (Limoges 1989) to be extinct; however it may still occur in Guinea-Bissau, according to the verbal references obtained during this study. The species is known to occur in neighbouring Senegal and in the Republic of Guinea (Struhsaker 1971, Kingdon 1997, IUCN 2003). Rarely observed, it might be restricted to the southern forest regions, more particularly in the Cufada Natural Park, Corubal and eventually in the northern parts of the Cantanhez forests. This species is known to occupy valleys within forests and also gallery and mosaic forests, with preference to swamp and palm forests. These requirements could be met in those three areas. High terrestrial activity and crop raiding constitute risk factors for active pursuit of this species, despite its secretive behaviour. According to the IUCN Redlist Categories and Criteria (version 2001 version 3.1), a taxon should be considered as extinct when there is no reasonable doubt that the last individual has died, and when exhaustive surveys in known and/or expected habitat, at appropriate times (diurnal, seasonal, annual), throughout its historic range have failed to record an individual. Long-term surveys in Cufada, the Corubal region and the Cantanhez forests are necessary to clarify the status of sooty mangabey in Guinea-Bissau.

Bushbabies are not actively hunted; their small size, their arboreal and nocturnal behaviour make them to difficult prey for possible hunting, and unfortunately also to observation and abundance estimation. It is necessary to clarify their status and the occurrence of Galagoides demidoff, since there is no reliable information on this species.

\section{VI.2.2. Comparison of the primate community with other African forests}

The sites most similar to Cantanhez are the Tiwai Island in Sierra Leone and the Tai National Park in Côte-d'Ivoire, which host comparable sets of primates species. A comparison of the primate community of Cantanhez and of Cufada with the Tiwai island and the Tai NP shows that Tiwai and Tai host a higher number of forest species (Table24), which derive from the occurrence of one more Colobine species (Olive colobus $P$. verus) and of one more arboreal Cercopithecine (Diana monkey $C$. diana) in these two sites. Colobus monkeys are known to prefer more undisturbed forests than other arboreal primate species (Fimbel 1994b). On the other hand, Cantanhez and Cufada host two more terrestrial cercopithecine species: the Baboon 
$P$. papio and the vervet monkey $C$. aethiops, the latter being considered rare in Tiwai (Oates et al. 1990, Fimbel 1994a). The estimated forest primate densities in Cantanhez are also lower than in Tiwai and Tai, excepting the Campbell's monkeys (Table23). Much of the variation in primate biomass in African forests is considered to be produced by variation in the density of red colobus (Oates et al. 1990).

Species lists however do not illustrate necessarily the forest quality in the tropics (Mühlenberg et al. 1995). On the other hand, low biomass of folivore primates is associated with ecosystems showing synchrony in the deciduous behaviour of trees (Ripley 1979, cited by Oates et al. 1990), as is the case in regions with relatively long dry seasons during which leaf shedding by canopy trees is concentrated. This could hold for the forests in southern Guinea-Bissau, although Oates et al. (1990) consider that this is not always true, suggesting that numerous other factors influence variation in primate biomass, including feeding habits, soil quality, tree-species composition, climate, habitat disturbance, but also historical, zoogeographical factors, competition, predation and disease.

Table23. Comparison of group density of some primate species between coastal Guinea-Bissau and some African forests

\begin{tabular}{|c|c|c|c|c|c|c|c|}
\hline Species & Tiwai (a) & $\begin{array}{l}\text { Tai NP } \\
\text { (b) }\end{array}$ & $\begin{array}{l}\text { Cantanhez } \\
\text { (Guinea- } \\
\text { Bissau) (c) }\end{array}$ & $\begin{array}{l}\text { Orango } \\
\text { NP } \\
\text { (Guinea- } \\
\text { Bissau) } \\
\text { (d) }\end{array}$ & $\begin{array}{l}\text { Lopé } \\
\text { (Gabon) } \\
\text { (e) }\end{array}$ & $\begin{array}{l}\text { Korup } \\
\text { support zone } \\
\text { (Cameroon) } \\
\text { (f) }\end{array}$ & $\begin{array}{l}\text { Bossematié } \\
\text { (Côte } \\
\text { d'Ivoire)(g) }\end{array}$ \\
\hline $\begin{array}{l}\text { Pan } \\
\text { troglodytes } \\
\text { verus }\end{array}$ & 1.3 & 1.7 & 0.88 & & $0.07-0.46$ & 0.16 & \\
\hline P. badius & 1.4 & 3.8-7.5 & 1.16 & & & & \\
\hline C. polykomos & 5.0 & $3-4.5$ & 0.32 & & & & \\
\hline C. campbelli & 2.7 & $2-4$ & 7.25 & & & $1.3-1.4$ & 0.34 \\
\hline C. aethiops & rare & & 0.69 & 4.7 & & & \\
\hline
\end{tabular}

(a)Oates et al. 1990

(b)Calculated from individual densities from Boesch 1984, using group size data from Oates et al .1990

(c) (d) This study

(e)White 1994

(f) Waltert et al. 2002

(g) Karibuhoye 2001

This underlines the need to conduct more extensive studies on the Cantanhez and Cufada primate communities, in order to understand their ecology. However the existence of this relatively high primate species diversity in that region confirms the 
importance of Guinea-Bissau forest remnants for the conservation of the endangered West African primates endemic to Upper Guinea. In the short-term however, this is one more argument, if needed, for the urgent classification of the Cantanhez as a protected area.

\section{VI.2.3. Status of ungulates}

Buffaloes have been heavily hunted in the past, mostly by professional sport hunters from tourist camps in the southern part of the country. These activities have persisted to a lesser degree in that region until today, particularly around the Rio Corubal, which borders to the Cufada Natural Park, and where several tourist camps have been active. This species could be hunted with a professional licence according to the previous law on hunting.

Although local people have claimed that this species is observed more frequently again in recent years, buffaloes are not safe from the combined pressures of hunting and rapid habitat loss. In spite of Buffaloes being included in the year 2004 in the new list of integrally protected species, for which hunting is totally banned, the still weak capacity of law enforcement, especially regarding sports hunting, remains a weak point for this species conservation.

The three larger antelope species known to occur in the coastal region, Waterbuck, Buffon's Cob and Roan antelope are very rare in coastal Guinea-Bissau. Observations are rarely made (Waterbuck) or only seasonally (roan) and these species already are no longer observed in most of the surveyed areas. Of these three species, Buffon's Cob appears to be still more threatened in Guinea-Bissau, due to its more restricted range (see also Limoges 1989). Also on the Bijagós archipelago, this species is known to occur only on the island of Galinhas, which was not included in the study sites. In the coastal forests, it is restricted to the Cacheu Natural Park and probably also in the Cufada Natural Park. 
Table24. Comparison of forest primate communities of southern Guinea-Bissau with other similar sites (adapted from Chapman et al. 1999)

\begin{tabular}{|c|c|c|c|c|c|c|c|c|c|c|c|}
\hline Site & Vegetation & $\begin{array}{l}\text { Total forest } \\
\text { species }\end{array}$ & Galagos & $\begin{array}{l}\text { Terrestrial } \\
\text { cercopithe } \\
\text { cines }\end{array}$ & $\begin{array}{l}\text { Arboreal } \\
\text { cercopith } \\
\text { ecines }\end{array}$ & $\begin{array}{l}\text { Colobi } \\
\text { nes }\end{array}$ & Apes & $\begin{array}{l}\text { Rainfall } \\
\text { (mm/ } \\
\text { year) }\end{array}$ & $\begin{array}{l}\text { Elevation } \\
\text { (m) }\end{array}$ & $\begin{array}{l}\text { Coordina } \\
\text { tes }\end{array}$ & Source \\
\hline Tiwai & $\begin{array}{l}\text { Lowland moist } \\
\text { forest }\end{array}$ & $10(11)$ & 1 & $1(-2)$ & 3 & 3 & 1 & 2708 & $82-112$ & $\begin{array}{l}7^{\circ} 31^{\prime} \mathrm{N} \\
11^{\circ} 20^{\prime} \mathrm{W}\end{array}$ & $\begin{array}{l}\text { Oates et al. 1990, } \\
\text { Oates 1994, Fimbel } \\
\text { 1994a }\end{array}$ \\
\hline Tai NP & $\begin{array}{l}\text { Lowland moist } \\
\text { forest }\end{array}$ & $10(11)$ & 1 & 1 & $3(-4)$ & 3 & 1 & 1800 & 90 & $\begin{array}{l}6^{\circ} 10^{\prime} \mathrm{N} \\
4^{\circ} 20^{\prime} \mathrm{W}\end{array}$ & $\begin{array}{l}\text { Boesch \& Boesch } \\
\text { 1993, Merz } 1986\end{array}$ \\
\hline Cantanhez & $\begin{array}{l}\text { Lowland semi- } \\
\text { deciduous } \\
\text { forest }\end{array}$ & $7(9)$ & $1(2 ?)$ & $2(3 ?)$ & 1 & 2 & 1 & $\begin{array}{l}>2200 \\
(-2400)\end{array}$ & W30 & $\begin{array}{l}11^{\circ} 05^{\prime} \mathrm{N} \\
15^{\circ} \mathrm{W}\end{array}$ & $\begin{array}{l}\text { Da Silva 1997, } \\
\text { Malaisse } 1996\end{array}$ \\
\hline Cufada & $\begin{array}{l}\text { Lowland dry } \\
\text { forest }\end{array}$ & $7(10)$ & $1(2 ?)$ & $2(3 ?)$ & $2(3 ?)$ & 1 & 1 & $\begin{array}{l}>2000 \\
(-2200)\end{array}$ & W45 & $\begin{array}{l}11^{\circ} 5 \mathrm{~N} \\
15^{\circ} \mathrm{W}\end{array}$ & MTAA/INEP 1997 \\
\hline
\end{tabular}


Although Waterbuck and Roan antelope are also distributed in non coastal woodland throughout the country, these two species are no less fragile. Cob and Roan antelope are integrally protected, whereas Defassa Waterbuck is listed as partially protected. These three species are at the same time among the preferred prey for professional sport and commercial hunters and have become very rare throughout the study site. The classification of Defassa buck as "partially" protected is not justified and this species should be urgently listed on the "integrally" protected species list, as being now both very rare and confined to a few areas.

Bushbucks suffer from heavy hunting pressure throughout the country, as this species is valued by all population groups, independently of religious and other cultural interdicts. Bushbucks are also caught for sale in the urban centres as pet animals. Negative population trends are observed for this species by interviewed local people in almost all the surveyed regions, excepting on Orango Island, where villagers consider this species to have increased.

In fact, Bushbucks are much less abundant than they were some years ago, as a result of overexploitation of this species: bushbucks are the preferred wild meat for most population groups. However, habitat degradation throughout their range may also play a role. Bushbucks suffer very low hunting pressure on the sparsely settled Orango NP, for which a density estimate of $1.6 \mathrm{groups} / \mathrm{km}$ ) was obtained.

Results from other studies in different African sites indicates comparable figures for the Orango NP as for the Lopé Reserve in Gabon and higher figures than in woodlands of Tanzania and Côte d'Ivoire (Table25). However, density estimates might be lower in continental areas, due to overexploitation.

Table25. Comparison of Bushbuck density in different African forests

\begin{tabular}{|c|c|c|c|}
\hline Country & Vegetation & Density & Source \\
\hline Tanzania (Katavi) & Woodland & 0.04 groups $/ \mathrm{km}^{2}$ & Caro 1999a)b) \\
\hline Côte d'Ivoire & Woodland & $0.08 \mathrm{ind} / \mathrm{km}^{2}$ & Fischer \\
\hline (Comoé) & & & Linsenmair 2001 \\
\hline Gabon (Lopé) & $\begin{array}{l}\text { Savannah-forest } \\
\text { mosaic }\end{array}$ & 1.4 ind. $/ \mathrm{km}^{2}$ & Tutin et al. 1997 \\
\hline $\begin{array}{l}\text { Guinea-Bissau } \\
\text { (Orango//mbone) }\end{array}$ & $\begin{array}{l}\text { Savannah-palm } \\
\text { forest mosaic }\end{array}$ & 1.6 groups $/ \mathrm{km}^{2}$ & This study \\
\hline
\end{tabular}


The fragile status of Sitatunga is not very well known, even by local people in its distribution range, and this species is commonly confused with the Bushbuck. Like the latter, this species is also subject to hunting, although it may be more difficult to observe. Marshbucks are very rare and restricted to a small territory with suitable habitat within the Mangrove Natural Park of Cacheu. The official nomination of this park was an important contribution to this species conservation.

However, hunting pressure is still high in that region, which is located close to the international boundary with the Republic of Senegal, and where dislocated refugees and armed groups have increased pressure on the natural resources, including wildlife (Vasconcelos et al. 2002). References to the occurrence of this species in the Cufada Natural Park do not appear to be consistent enough and need to be assessed. Although this species is known to reach high densities in exceptional small home ranges if a year-round food supply is guaranteed (Kingdon 1997), they are vulnerable to persistent hunting and to habitat destruction.

Sitatungas are included in the red list of threatened species of Guinea-Bissau and are integrally protected. This justified status needs to be complemented by effective law enforcement and by environmental education actions, in order to raise awareness of local people in the Cacheu region regarding this vulnerable species. The potential of this species to play a role as a local flagship species for the northern Cacheu mangrove Natural Park should be assessed (Table28).

Observation data and information collected on all duiker species suggest that these species have drastically decreased in the surveyed areas. A comparison of the results from this study with the values presented by Limoges in 1989 is not possible, because different methods were used for this species group. These negative trends are a direct result of combined habitat conversion for agriculture and overexploitation: these species are subject to heavy hunting and are among the preferred hunter's prey. They are considered very tasty and represent one of the most consumed wild meat types, being eaten by most people, independently of religion and cultural group.

All duikers are now officially protected and all but the grey duiker are included in the red list. However, only the bay duiker is integrally protected, which means that the others might be hunted. Particularly the red-flanked and the yellow-backed duikers 
should urgently be listed as integrally protected, because they are already rare, having disappeared locally.

Water chevrotain is one of the lesser known species in Guinea-Bissau; its secretive behaviour and its naturally sparse distribution make its observation and thus the assessment of its status difficult. The few references obtained on the former occurrence of this species in the Cufada Natural Park could indicate that this species is either very rare or already extinct. As this species is also data deficient in most of its range, an extensive assessment of its occurrence and distribution in GuineaBissau is urgently needed.

Although observation frequencies of Hippopotamuses are reported to have increased locally in the last years, evidence suggests that this species has declined throughout most of its range in Guinea-Bissau. Despite the considerable decrease in hunting pressure on this species, they remain under threat from habitat destruction due to mangrove destruction and conversion of grazing areas for agricultural activities.

As the bulk of the hippopotamus population is distributed in the Bijagós archipelago, and more particularly in the Orango NP, the recognition of the Bijagós Biosphere reserve and the creation of that protected area was an important step towards the conservation of hippopotamuses in Guinea-Bissau. However, the presence of various fishermen camps within the core zones of the Biosphere reserve has not only contributed to the destruction of important mangrove areas but have also restricted the movements of local populations of hippopotamus, which have in some cases moved out to less frequented areas.

The important place this species occupies in the culture of the Bijagós ethnic group and in the mythological world of most people along with the increasing awareness of local communities about the conservation needs of this species, constitute a valuable potential for the development of community-based conservation actions in favour of this species. 
The presence of the pigmy hippopotamus was not confirmed by the field surveys, but rather by verbal references. It remains to be proven, whether those verbal references are effectively related to that species. Pigmy hippopotamuses are present at low densities throughout their range, and are known to be very difficult to observe. On the other hand, this species could find ideal range conditions more particularly in the sub-humid and gallery forests in southern and south-eastern Guinea-Bissau. There is an urgent need for detailed and targeted investigation of this species, in order to definitely clarify its status in that country.

Wild pigs are generally considered to be still abundant in Guinea-Bissau. These species are not very popular, as they raid crop fields, but warthogs are considered to be more destructive than red river hogs. The two species are subject to consumption taboo in a part of the population (mostly the Moslems), however they are killed when destroying crops and are then sold.

Warthogs are considered to be quite ubiquitous and abundant, whereas red river hogs are less abundant, with a more restricted distribution range, due to the rapidly shrinking forest habitats. The combined effect of habitat loss and hunting pressure makes the status of red river hogs more vulnerable.

Giant forest hogs might occur in Guinea-Bissau but in very low densities and they may be restricted to the southern forest regions. Their distribution needs urgently to be assessed. The observation of this species in the neighbouring republic of Guinea, in a dense savannah-dominated region makes the hypothesis of this species occurrence in Guinea-Bissau plausible. The naturally low densities of this species and its dependence on forest and on dense thickets and woodlands make it vulnerable, due to the rapid deforestation. Moreover, as suids are not popular, there will be a need of intensive information and sensitisation actions in favour of this species.

\section{VI.2.4. Status of the African Elephant}

Since the nineteen nineties, the need for elephant conservation actions has been identified by the official authorities of Guinea-Bissau (MDRA/DGFC 1991). Although this species is not actively hunted in Guinea-Bissau, its occurrence in that country is 
threatened mainly due to habitat loss. Important human migration waves from the northern drier parts of the country have led to the rapid development of new settlements in the south of the country.

An important step towards elephant conservation was the identification of the main corridors seasonally used by this species. It seems from the different observations, that two migration routes are used from the frontier zone between Guinea-Bissau and the Republic of Guinea: southwards to the Cantanhez zone and westwards the valley along the Corubal river to the Cufada Natural Park. The first one was assessed thoroughly and is better known (da Silva Naga and Serra 2001), but the detailed course of the second one also needs to be studied (see also Frade et al. 1946).

However, it is already evident that the areas used by migrating elephants are crossed by important main roads, along which most new settlements are placed: these are for the first corridor the road between Mampata and Guiledge, and for the second corridor, the road between Quebo and Buba. Sensitisation actions are being carried out by Natural Park authorities in Cufada and conservation organisations in Cantanhez, in order to reduce the establishment of new settlements and new agricultural fields along the identified corridor zone. This requires a number of complementary measures, since agriculture is the main economic activity in that region. For effective results, it will be necessary to elaborate, together with the local population, a negotiated integrated management plan of that region, identifying clearly the corridor areas to be preserved.

The most critical area for elephants in Guinea-Bissau is the triangle situated between the Dulombi region, the Cantanhez forests and the Cufada Natural Park. For the conservation of elephants in Guinea-Bissau, the implementation of a protected area in Cantanhez and of a transboundary protected area between Guinea-Bissau and the Republic of Guinea are essential.

\section{VI.2.5. Status of West African Manatee}

The existence of an extensive suitable habitat, the perception and place of this species in the local culture and consequently the low hunting pressure are favourable factors for the conservation of this species in coastal Guinea-Bissau. In local 
communities, this positive attitude does not seem to be affected by the damage occasionally caused by manatees to fishing nets or in the fields.

However, manatees incidentally caught are not freed and this remains the major threat factor to this species. Moreover, large mangrove areas have been locally converted mostly for agricultural activities or destroyed for fish smoking. In some regions, where large fishermen camps are located, mangrove destruction has been combined with active manatee hunting, leading to depletion of this species population.

Considering the place this species occupy in people's culture, more particularly in the Bijagós archipelago, its conservation status and ecological characteristics, Manatees are a valuable potential flagship species which could be used to support local conservation efforts (Table28). Existing local conservation initiatives have also identified this species as one of the potential flagship species which should be promoted in the future (Biai et al. 2003).

\section{VI.2.6. Status of some carnivore species}

Leopards and felids in general have been heavily hunted for their skin, and are now very rare. Leopards still occur at low densities in the coastal forests, where they are rarely observed. They are integrally protected but are still pursued for their skins, particularly by illegal hunters from outside.

This study has confirmed the occurrence of the African golden cat in the coastal forests of Guinea-Bissau, by verbal references and an identified skin. This species is very rare and has not always been included in the official lists of mammals of Guinea-Bissau. Apart from a mention by Stuart et al. (1990), Crawford Cabral (1997) considered its presence as possible but doubtful, on the basis of verbal information.

The African Golden Cat is listed as a vulnerable species (IUCN 2003); its distribution and status need to be urgently assessed but in the short time, this species should be classified as integrally protected and should be included in the red list of threatened animals of Guinea-Bissau. 
Although hyenas are not popular, they benefit from a consumption taboo and do not suffer from hunting. Despite this low hunting pressure, this species population has decreased in recent years, probably because of reduced availability of most of its prey species. Spotted hyenas are in fact known to feed mostly on large and mediumsized ungulates (Di Silvestre et al. 2000). This might be the reason for hyenas to increasingly attack domestic animals, and to be killed by animal keepers. Hyenas' inclusion in the red list of threatened species of animals of Guinea-Bissau reflects this decreasing incidence.

Information on the status of the clawless otter and honey badger is very scarce. Clawless otters' habitats have been either drastically changed or lost, following bush clearing, deforestation, overgrazing, draining of wetlands or water extraction or denudation of riparian vegetation (Rowe-Rowe 1995, Nel and Somers 1998). However the two species are not actively hunted in Guinea-Bissau, although the skin of the clawless otter is highly valued for the manufacture of traditional medicine.

However, the mystique involving this species has limited the pressure on it, and the species seems to be still quite abundant in the Bijagós archipelago. On the continental part of the country, clawless otter populations may have suffered from habitat loss, mostly through mangrove destruction. Clawless otter and honey badger are internationally listed as of least concern (IUCN 2003), but in Guinea-Bissau these two species are integrally protected; there is a need for an accurate assessment of their distribution and status in that country.

\section{VI.3. Trends in relative abundance of some large mammals}

Some species are locally considered by interviewed villagers, to have increased in the last few years, e.g. primates and buffaloes in Cantanhez, hippopotamuses in the Bijagós archipelago and in the Cacheu Natural Park, wild pigs in the continental part and Callithrix monkeys throughout the study area.

However, on a more global scale, results of interviews (Table15) indicate negative trends in most large and medium-sized mammal species. Limoges (1989) and Limoges \& Robillard (1990) used faeces counting for most surveyed species, which makes impracticable a comparison with our data, excepting data on arboreal 
primates, for which direct group counting was used, and data on chimpanzees, for which nests were the measuring unit. For this group, most species show decreasing trends, but the negative trends appear to be much stronger on the continental part of the country than on the Bijagós islands. The negative trends appear to be much stronger on the continental part of the country than on the Bijagós islands (Table26).

Some species are considered by the interviewed communities to be locally extinct: Red-flanked duikers are no longer observed in Cantanhez and in Cacheu and Buffon's Kob no longer occurs in Cantanhez. In some areas of Cacheu, species such as roan antelopes, buffaloes, red river hog and even wild pigs are locally no longer observed. The sooty mangabey Cercocebus atys is probably extinct from Cantanhez: although verbal records exist regarding observations a few years ago in the northern part of this region, the last direct observations in the southern part were made at the end of the nineteen sixties, during the independence war. In the eastern part of the Formosa island group and in Cantanhez, hippopotamuses are no longer observed.

Table 26. Comparison of relative abundance of some primate species between 1989 and 2002 (in group observations $/ \mathrm{km}$ ); with n.d.: no observations along the survey routes and n.o.: species does not occur in the area

\begin{tabular}{|c|c|c|c|c|c|c|}
\hline \multicolumn{3}{|c|}{ Cufada } & \multicolumn{2}{|c|}{ Cantanhez } & \multicolumn{2}{|l|}{ Cacheu } \\
\hline Species & $\begin{array}{l}\text { Limoges } \\
\text { (1989) }\end{array}$ & This study & $\begin{array}{l}\text { Limoges } \\
(1989)\end{array}$ & This study & $\begin{array}{l}\text { Limoges } \\
(1989)\end{array}$ & This study \\
\hline P.t. verus & 2.3 & n.d. & 0,43 & 0.1 & & n.o. \\
\hline P. temminckii & 0.6 & n.d. & 0.4 & 0.22 & & n.d. \\
\hline \multirow[t]{2}{*}{ C. campbelli } & 0.5 & 0.03 & 0.8 & 0.7 & 0.6 & 0.37 \\
\hline & Orango & & Formosa & & Canhaba & ue \\
\hline Species & $\begin{array}{l}\text { Limoges } \\
(1991)\end{array}$ & This study & $\begin{array}{l}\text { Limoges } \\
\text { (1991) }\end{array}$ & This study & $\begin{array}{l}\text { Limoges } \\
(1991)\end{array}$ & This study \\
\hline C. petaurista & & n.o. & & n.o. & 0.9 & 0.87 \\
\hline C. aethiops & 0.1 & 1.09 & 0.2 & 0.16 & & \\
\hline
\end{tabular}

The fact that some species are no longer observed however does not mean automatically that those species are really locally extinct: it could be a result of high 
rarity or simply of modification in the behaviour of the animals facing heavy hunting pressure. Equally, the fact that in some areas, some species such as primates, buffaloes, and hippopotamuses are observed more frequently does not necessarily mean, that these species are more abundant. This could be a consequence of a less shy behaviour of the animals (also as a result of decreasing persecution), or of the fact that animals feed more frequently in crop fields or fruit gardens due to decreasing feeding trees in the forest.

It is difficult to compare the estimated abundance values obtained for the coastal sites with those from non coastal regions, due to lack of recent data and to the use of different survey methods. The only available data obtained using similar methods to this study are ten (10) years old and were obtained from a mammal monitoring experience by Thibault (1993) in the south-eastern Dulombi woodland region (Table 27).

Table27. Comparison of relative abundance (group observations $/ \mathrm{km}$ ) of some large and medium sized mammals between the coastal and non-coastal regions; with n.d.: No observations along survey routes; n.o.: Species does not occur in the area

\begin{tabular}{cllll}
\hline Species & Thibault (1993) & & This study (2002/2003) \\
& Dulombi & Cufada & Cantanhez & Cacheu \\
\hline T. scriptus & $\sim 0.15$ & 0.86 & 0.17 & 1.48 \\
S. c. nanus & $\sim 0.2$ & 0.11 & 0.02 & n.d. \\
K. e. defassa & $\sim 0.2$ & 0.06 & n.d. & n.o. \\
C. silvicultor & $\sim 0.26$ & 0.57 & 0.05 & n.o. \\
C. maxwellii & $\sim 0.9$ & 0.31 & 0.02 & 0.44 \\
C. rufilatus & $\sim 0.21$ & 0.26 & n.d. & n.d. \\
P. pardus & $\sim 0.01$ & 0.03 & n.d. & 0.07 \\
P. porcus & $\sim 0.05$ & 0.11 & 0.15 & n.d. \\
P. africanus & $\sim 0.7$ & 1.2 & n.d. & 0.22 \\
\hline
\end{tabular}


The comparison of these data with our results shows that:

- Buffaloes, Waterbuck and Maxwell's duikers were observed more frequently in the non coastal woodlands of Dulombi, than in the three coastal study sites.

- Bushbuck observations were lower in Dulombi than in Cufada and Cacheu, but quite similar to Cantanhez.

- Yellow-backed duikers' relative abundance are higher in Cufada than in Dulombi, but much lower in Cantanhez

- Data on red-flanked duikers are comparable for Dulombi and Cufada

- The relative abundance of the forest dwelling red river hog and leopard is higher in the coastal forests than in the Dulombi savannahs

- Wild pigs' observations were lower in Dulombi than in Cufada and much higher than in Cufada.

This comparison, in spite of being incomplete, confirms the high importance of the Dulombi woodland region for larger mammals and the role of the Cufada Natural Park particularly for medium-sized mammals.

\section{VI.4. Perceived versus real trends in animal abundance - Attitudes towards wildlife}

Excepting small monkeys, wild pigs, red hogs and great cane rats, interviewed local inhabitants consider that most animal species have decreased. It is interesting to note that those animals considered to have increased are at the same time those considered to be the most damaging crop raiding species. On the other hand, most of the rare or most threatened mammal species, including the most hunted antelopes and duikers, are considered by local people from their respective occurrence range, to need special conservation measures, e.g. hunting ban.

The perceived increasing population trends of certain species suggest a negative attitude towards those species, due to their existing or potential conflicts with local people. Even when negative population trends are recognised, crop raiding species, e.g. monkeys, pigs and rodents are not considered by interviewed local people as deserving particular conservation measures, as they are considered very destructive. 
A more positive attitude was generally observed for mammal species which do not cause damage, such as great antelopes, or which play some role in the culture or religion, such as chimpanzees, hippopotamuses and manatees, despite the occasional damage which these animals can cause in crops or fruit gardens.

In villages where environmental education activities have taken place and where the potential for ecotourism has been discussed, those charismatic species such elephants, chimpanzees, hippopotamuses and buffaloes were considered to deserve special conservation measures. Some active and former hunters declare that certain species should be protected now to allow them reproduce themselves and become more abundant in order that they could be hunted again in the future.

\section{VI.5. Which are the main threat factors for mammals in coastal Guinea-Bissau?}

\section{Hunting}

Hunting is presented by local people as the main reason for decreasing wildlife populations in Guinea-Bissau. Hunters have noticed that fewer large-bodied mammals are being caught; more time is needed and longer distances have to be walked than in the past, in order to catch animals formerly quite abundant.

The number of existing village hunters in the surveyed coastal villages has not increased, if compared to data from former surveys: Robillard (1989) identified 3 hunters per village in Cacheu, Cufada and Cantanhez respectively, whereas in this study an average of two hunters per village was named during the village interviews. However, it is important to consider, that in 1989, no protected area was officially nominated in the survey coastal sites, and the willingness to talk about hunting activities was probably greater than now.

It is actually thus more difficult to obtain reliable information on hunters existing within and around the protected areas, where commercial hunting is banned. Most known local professional hunters claim to have abandoned their commercial activities. Most people are willing to declare that they hunt only for their own family consumption. This may be actually the case for most interviewed people in the most isolated areas 
of the study sites, such as some remote villages of the Orango NP or on Formosa. Due to the increasing commercialisation of bush meat however, it is more and more difficult to make the distinction between hunting for personal consumption and for sale. As in other regions (Hart and Hart 1986, Wilkie et al. 1992, 2000; Fa et al. 1995, Vanwijnsberghe 1996), money rather than food is now increasingly the prime motivation for hunters, and in many areas even hunters who are primarily interested in bushmeat for their own consumption will sell part of the meat they catch.

Although the stated most important value of wildlife is as source of food, interviewed hunters declared that hunting is also an important source of income, in order to solve other problems requiring cash money, e.g. to buy rice, or pay for school or medical treatment. In a study on hunting activities in the Dja reserve in Cameroon, Muchaal and Ngandjui (1999) observed that two thirds of the animals killed were sold, indicating that commercial gain was a more important motivation for hunting in areas farther from villages.

The increasing demand for animal protein in both rural and urban areas of GuineaBissau has encouraged the number of professional and commercial hunters and the wild meat trade is increasing. There are several wild meat public markets in the capital city and in other urban centres. Wild meat can also be purchased in several restaurants. In Guinea-Bissau, the role of livestock as a wealth and social asset also leads to high wild meat consumption, as is the case in some other West African rural societies (Chardonnet et al. 1995). This is aggravated by the virtual absence of a national animal production programme. Moreover domestic animal meat is in general more expensive than wild meat, even in the capital city and other urban centres, and thus not affordable for the majority of the population.

In Guinea-Bissau, wild meat thus does not represent principally a luxury product for the urban population as in some other central African countries (Bowen-Jones 2003); it is above all an affordable source of protein for large parts of the population in general. According to Chardonnet et al. (1995), agriculturists in Africa were found to eat wildlife products to improve their ordinary diet and to prevent starvation during food shortage or between crops. However, it is evident that a luxury wild meat market is in fact developing, more particularly in the capital city Bissau, with some local 
restaurants offering meat of some wild species at high prices to a small elite and tourists.

Additionally, the existence of more or less well frequented roads around the Cufada and the Cacheu Natural Parks has contributed to the development of important local markets, which are also used for wild meat trade. This is an important difference with the Cantanhez region, which is still quite isolated, since the road system does not allow regular transportation. In a study on the effects of roads on wildlife conservation in Northern Congo, Wilkie et al. (2000) found out, that although residents of more isolated settlements ate about as much bush meat, they traded and hunted much less than those of other settlements with more access to roads and markets.

The local population from coastal Guinea-Bissau have no professional fishing tradition: the great majority are primary farmers, fishing and mollusc collection being in most cases a secondary activity to cover protein needs. Particularly in the Bijagós archipelago, young Guineans are slowly learning to fish, in most cases from the more professional and better equipped fishermen from the neighbouring countries. The lack of a well organised commercial chain and irregular and unreliable supply of national markets with fish makes this product a rare and expensive commodity in various regions of this country, which also contributes to the increase of pressure on wild animals.

Another important fact is the wide distribution of fire-arms and the easy opportunities to acquire munitions at low prices throughout the country. This is particularly the case in the continental part and this has greatly contributed to augmentation of hunting pressure. There has been several actions to try to collect those arms, but with limited success.

As in other tropical African countries, the most hunted mammal species in GuineaBissau are antelopes (Bushbuck, duikers), rodents (porcupines, grass cutter), and to a lesser extend also wild pigs and monkeys. In a country where most people are Moslems, meat from antelopes and rodents is not subjected to any religious consumption taboo, representing thus the bulk of the hunting prey. Antelopes are usually not killed for subsistence, but for commercial purposes. However, because 
antelopes and duikers are becoming rarer; there is a shift towards rodents, more particularly porcupines for meat. The latter are one of the preferred wild meat types in the three study site villages in the continental part of the country and people consider that they are very tasty. Small monkeys are also increasingly hunted and consumed (see below). However, as Brashares (2003) states, estimates of human preference based on the economic and subsistence value do not account for the degree to which species are targeted as a result of the threat they pose as crop raiders or predators. Species such as monkeys, wild pigs, porcupines and grass cutters are thus also killed, not primarily for meat, but to prevent crop destruction.

The laws of economics are also applying to wild meat: differences in trading prices between the villages and the towns, and between the different regions of the country are linked to the availability and demand of the different species, and to the purchasing power of the local clients. Meat of antelopes for example, which is the most expensive (calculated per kilo), is cheaper in the local markets in the south, maybe due to this species being somewhat more abundant than in the north of the country. Wild meat is in general more expensive in the urban centres than in the villages. In the capital city Bissau, the prices are three to five times higher than in the rural areas. The higher prices in the capital and in other cities are another encouraging factor for commercial hunting.

Estimating wildlife trade is generally difficult, since most small species and locally produced shotgun arms require no permits, and there is poor control by the official authorities. Furthermore, market surveys data remain also incomplete, because a proportion of captured animals never reach the markets.

\section{Habitat disturbance}

The link between shrinking forest areas and dwindling mammal populations was made by the interviewees, but agriculture is seldom pointed out as contributing to habitat loss. This however is a commonly observed attitude, which could illustrate the fear of having to change some practices related to agricultural production, once one recognises their negative effects (see also Robillard 1989). No intensive logging activities are registered within the four study sites, aside from some small-scale tree felling for canoe construction. Selective logging activities in the region around and 
partly within the Cufada Natural Park were stopped with the beginning of the Natural Park activities but local communities reported about some persisting illegal logging in the region northern of the Cantanhez forest. Forest areas are being rapidly converted for agricultural activities in all the study sites. Major land cover changes have resulted from agriculture and other land use forms, combined with reduction in rain fall (Malaisse 1996, MTAA/INEP 1997, Vasconcelos et al. 2002), with changes being more important on the continental part of the country than in the archipelago (Vasconcelos et al. 2002).

Permanent agriculture is more likely to lead to habitat loss than shifting cultivation; where taller trees are left in place to provide shadow to the planted crops, some arboreal primates will continue to use these areas (Cowlishaw and Dunbar 2000). In shifting cultivation systems, such as those used in Guinea-Bissau, primary and regenerating secondary forest mosaics usually dominate the landscape. If only a relative small percentage of the land cover is actively cultivated at any one time, then the primate population has a greater chance of persistence (Cowlishaw and Dunbar 2000). Food availability seems to play a key role here (Fimbel 1994a); some fruits are produced by secondary forest species, such as the Musanga tree, which are eaten by a variety of primates (Weisenseel et al. 1993; Hashimoto 1995 both cited by Cowlishaw and Dunbar 2000).

C. aethiops, E. patas and $P$. papio are considered nondependent on closed forest (Cowlishaw 1999), but some primate forest species such as red colobus, black-andwhite colobus and chimpanzees are known to use degraded forests (Chapman and Lambert 2000). In a study on Tiwai Island (Sierra Leone), Fimbel (1994b) found Campbell's monkey, lesser-spot nosed monkey, sooty mangabey and Chimpanzees to be more abundant in secondary forest than in old forest, where black-and-white and red colobus were more abundant. In the same study, the Maxwell's duiker $C$. monticola was found to use both habitats equally.

In a study on mammal extinction correlates in West Africa, Brashares (2003) also found that habitat-restricted species such as Colobids persisted poorly compared with habitat generalists such as baboons, Patas and green monkeys. Persistence was also related negatively to population isolation (Brashares 2003). The average 
mammal density was found to be significantly lower in smaller Neotropical forest fragments than in larger ones, whereas lack of food is believed to be important (Chiarello 2000).

Habitat disturbance and forest fragmentation are known to lead to more hunting activities (Grieser Johns and Grieser Johns 1995, Cowlishaw and Dunbar 2000, Peres 2001): cultivated mosaics are more accessible for hunters, and in those areas, hunting is regularly practised to protect crop fields. In fragmented areas, the size of remaining natural forest patches and thus food availability are crucial factors affecting the mammal community (Chiarello 2000, Laidlaw 2000). Cowlishaw and Dunbar (2000) also consider that apart from food availability, other factors related to habitat disturbance considered to be important include the extent of cultivation, the distance to large undisturbed forest areas and the rate of field turn over. In Cantanhez, the remaining forest patches have become smaller and smaller and more and more isolated (da Silva 1997). Today, the remaining 14 forest patches cover only an area of less than 9000 ha, i.e. less than $9 \%$ of the total area of Cantanhez, with the larger patch (Amindara) being about 2,507 ha and the smallest (Capicada) being about 47.5 ha (da Silva 1997). These forest fragments are isolated from each other by human settlements and/or roads; they are surrounded by agricultural land, which is used by the mammal species, and more particularly by primates. These use to feed on trees left within field crops and to cross the villages and fields between the forest patches in search of food. In the Lope Reserve of Central Gabon, most large and medium-sized forest mammal species were found to also use the savannah dominated habitat, and to cross open grassland to visit forest fragments, and few lived permanently in a single forest fragment (Tutin et al. 1997). Some primate species have showed high resistance to habitat fragmentation, being able to survive in small sacred forest patches, e.g. chimpanzees in the Republic of Guinea and Sclater's guenon in Nigeria (Sugiyama 1989, Oates et al. 1992 cited by Tutin et al. 1997).

In Guinea-Bissau, numerous sacred groves still exist throughout the surveyed sites and the coastal area in general. Primates and other mammals have benefited from the existence of those sacred groves, which are protected by local people. However, these forest remnants need urgently to be officially gazetted as protected areas, in order to confer more legal power to the local traditional measures (see below). Only 
under these conditions and provided hunting pressure on primates of Cantanhez does not increase, will these species possibly be able to survive in some of the remaining less disturbed forest patches. This is likely to be also the case for less heavily hunted species such as red river hogs and medium-sized carnivores in that area. Whether this will be the case for other species such as antelopes and forest duikers in that region and in the other continental sites is questionable, since they actually suffer more hunting pressure than primates, and have already registered dramatic declines in their populations. In fact, preferred prey species have been brought to extinction in small forest patches, even where hunting pressure is light (Wright et al. 2000). The persistence of large species such as elephants, buffaloes, roan and waterbuck will depend not only on protection from hunting, but also strongly on further availability of more or less undisturbed migration corridors within their range of occurrence.

\section{VI.6. Do traditional cultural practices contribute to wildlife conservation?}

The importance of culture for providing incentives for communities to conserve wildlife has been confirmed by different studies (Infield 2001, Jones 1999, Kangwana \& Ole Mako 1998). A number of hunting and consumption taboos are still respected by a part of local people in the coastal Guinea-Bissau, due to religious, ceremonial or other reasons.

Although primates and wild pigs in general benefit from consumption taboos by the mostly Moslem population, two primate species additionally benefit from an eating taboo by most people, independently from religion: these are the chimpanzee and the black-and-white colobus. These two species also benefit from local taboos in various countries (Colding and Folke 2001). This may be the main reason why these two species still occur in Cantanhez and other restricted parts of Guinea-Bissau.

Other mammal species also benefit today from hunting and/or consumption taboos, which contribute to limit their exploitation in Guinea-Bissau. Most ceremonial species have suffered minimal hunting pressure from the local ethnic groups: this is the case for hippopotamuses and manatees in the Bijagós archipelago. However, as with other taboo species, hunters and fishermen from outside do not always follow those 
local regulations, especially for manatees, and this has resulted in intensive exploitation of this species in some areas. Hyenas are also normally not consumed, either for being a totem species or for being considered unclean, but they are known to catch domestic animals, and are occasionally killed for this reason.

Taboos may offer local protection to some species and habitats, if they are adhered to since their enforcement is based on local beliefs in sanctions by spiritual forces (Colding and Folke 2001). However, where animals benefit from existing local taboos or traditional regulations, they may be threatened by hunters from outside. Moreover, immigrants from other cultural groups usually do not follow local customs and rules (Olsen et al. 2001, Garcia \& Goodman 2003). In Madagascar for example, various taboos and restriction are being abandoned and this process is accelerated by economic difficulties (Sautter 1980, cited by Garcia \& Goodman 2003). In the Fouta Djalon central highlands of the Republic of Guinea, chimpanzees are locally not eaten, however, they are killed by hunters from the southern parts of the country, where this species is consumed (Ham 1998). As in other parts, new consumption habits are being introduced in Guinea-Bissau by immigrants from neighbouring countries, and these new habits do not always correspond to local traditional customs. Furthermore, the adoption and abandonment of taboos is flexible within and between different groups, and even in the same persons at different times (see also Colding and Folke 2001), thus some species which are currently protected by taboos could be hunted in the future (Cowlishaw and Dunbar 2000).

Another aspect is the need for hunters to make special ceremonies before hunting certain species such as hippopotamuses, large antelopes, buffaloes, manatees, leopards and the rare yellow backed duiker. In the past, not any hunter could kill those species, since special power was considered to be required for this. This might have limited pressure on certain species. Although those ceremonies are still practised in some cases today, older interviewees claimed that younger people already do not respect those rules, because they feel more confident through the use of firearms.

These traditional interdicts are locally disappearing, because the new generations do not always follow them: older generations claim, that today the youth does not 
respect the customs. This is particularly the case in areas which have suffered strong external influence, be it through immigration from different culture areas or through intensive contacts with the capital city or with foreign countries. The most noticeable change is consumption of species formerly under taboo most by young people. Monkey meat is for example increasingly consumed, even by those from Moslem families who consider it to be a delicious snack. Small arboreal guenons, specially Campbell's and lesser spot-nosed monkeys, and also terrestrial monkeys, i.e. baboons, Patas and vervet monkeys, are the most affected by this change, which is absolutely not conditioned by the lack of alternative protein sources. It is noticeable that variation in consumer preference also occurred as a consequence of war (the independence war in the sixties and the civil war of 1998/99), as harsh living conditions "led people to eat anything", as older villagers stated.

Culture- or religion-based interdicts and beliefs are however still present and practised in some areas of the surveyed coastal forests and beyond, which host species with high conservation values, and more particularly in the Bijagós archipelago and to a lesser extend in other parts of the country. These cultural values, combined with the extant awareness on the conservation needs of some endangered species, have a strong potential for enhancing the communities support for local conservation actions. A number of criteria must be fulfilled, for the selection of local appropriate flagship species (Bowen-Jones \& Entwistle 2002). Since a number of local community-based conservation initiatives are being implemented, the potential of some mammals for acting as flagship species and supporting those local initiatives should be further assessed and valued (see Table28). 
Table28. Potential local flagship species in coastal Guinea-Bissau (adapted from Bowen-Jones \& Entwistle 2002)

\begin{tabular}{|c|c|c|c|c|}
\hline & Criteria & Chimpanzee & Hippopotamus & African Manatee \\
\hline $\begin{array}{l}\text { Geographical } \\
\text { distribution }\end{array}$ & $\begin{array}{l}\text { Local occurrence; typical of local } \\
\text { important habitats; endemism or } \\
\text { restricted distribution }\end{array}$ & $\begin{array}{l}\text { - Highest frequency in the } \\
\text { South and South-East } \\
\text { - Mostly humid forests/ } \\
\text { woodland savannahs }\end{array}$ & $\begin{array}{l}\text { - Highest densities in the } \\
\text { Bijagós archipelago } \\
\text { - Mangrove and grass } \\
\text { savannahs } \\
\text { - coastal area }\end{array}$ & $\begin{array}{l}\text { - Highest densities in the } \\
\text { Bijagós and coastal rivers } \\
\text { - Mangroves, estuaries } \\
\text { - Coastal area }\end{array}$ \\
\hline Existence usage & $\begin{array}{l}\text { species not already in use by } \\
\text { other organisations or products } \\
\text { (no potential conflicts) }\end{array}$ & $\begin{array}{l}\text { Not used for other } \\
\text { purposes }\end{array}$ & Not used for other purposes & Not used for other purposes \\
\hline Recognition & $\begin{array}{l}\text { Species known, distinctive and } \\
\text { not readily confused with others }\end{array}$ & $\begin{array}{l}\text { Well known, no confusion } \\
\text { with other species }\end{array}$ & $\begin{array}{l}\text { Well known, no confusion } \\
\text { with other species }\end{array}$ & $\begin{array}{l}\text { Well known, no confusion } \\
\text { with other species }\end{array}$ \\
\hline
\end{tabular}


Table28 (continued). Potential local flagship species in coastal Guinea-Bissau (adapted from Bowen-Jones \& Entwistle 2002)

\begin{tabular}{|l|l|l|l|l|}
\hline \multicolumn{2}{|c|}{ Criteria } & Chimpanzee & Hippopotamus & African Manatee \\
\hline Charisma & $\begin{array}{l}\text { Traditional charismatic large } \\
\text { mammals or birds, but NOT } \\
\text { necessary }\end{array}$ & $\begin{array}{l}\text { Yes, locally and } \\
\text { internationally }\end{array}$ & $\begin{array}{l}\text { Yes, locally and } \\
\text { internationally }\end{array}$ & $\begin{array}{l}\text { Yes, locally and } \\
\text { internationally }\end{array}$ \\
\hline $\begin{array}{l}\text { Common } \\
\text { name }\end{array}$ & $\begin{array}{l}\text { Local meaning without negative } \\
\text { connotation }\end{array}$ & "Dari" : No negative & $\begin{array}{l}\text { "Pis cabalo" (cr.: literally } \\
\text { horse fish)/; Egomor } \\
\text { (Bijagós) }\end{array}$ & $\begin{array}{l}\text { "Pis bus"/ (cr.: literally cattle } \\
\text { fish); Ekitan (Bijagós) }\end{array}$ \\
\hline $\begin{array}{l}\text { Cultural } \\
\text { significance }\end{array}$ & $\begin{array}{l}\text { Cultural association, } \\
\text { Relationship to folklore or art, } \\
\text { use for food or handicraft }\end{array}$ & $\begin{array}{l}\text {-High: tabooed sacred, } \\
\text { regarded as relatives of } \\
\text { humans } \\
\text {-mystic power }\end{array}$ & $\begin{array}{l}\text { High: tabooed ceremonial } \\
\text { species for the Bijagós ethnic } \\
\text { group; otherwise strong } \\
\text { association in mythology }\end{array}$ & $\begin{array}{l}\text { High: tabooed ceremonial, } \\
\text { used in very special Bijagós } \\
\text { ceremonies, strong } \\
\text { association in mythology }\end{array}$ \\
\hline $\begin{array}{l}\text { Positive } \\
\text { associations }\end{array}$ & $\begin{array}{l}\text { not only strong but positive } \\
\text { reputation }\end{array}$ & $\begin{array}{l}\text { - Positive association } \\
\text { - Assistance to humans } \\
\text {-Well tolerated, because } \\
\text { no massive crop raiding }\end{array}$ & $\begin{array}{l}\text {-Increasingly positive } \\
\text { association, related to } \\
\text { potential for ecotourism } \\
\text {-Also respected and feared } \\
\text { (malign spirits) }\end{array}$ & $\begin{array}{l}\text {-Positive association } \\
\text {-Not fierce, no massive crop } \\
\text { raiding, } \\
\text {-respected for its special } \\
\text { power }\end{array}$ \\
\hline $\begin{array}{l}\text { Traditional } \\
\text { knowledge }\end{array}$ & $\begin{array}{l}\text { Existence of local knowledge of } \\
\text { species (e.g. on ecology, } \\
\text { subspecies,...) }\end{array}$ & $\begin{array}{l}\text { - Ecology behaviour, } \\
\text { feeding.. well known } \\
\text { feeding,...well known }\end{array}$ & $\begin{array}{l}\text { Ecology, behaviour, } \\
\text { feeding,...well known }\end{array}$ & \\
\hline
\end{tabular}




\section{VI.7. What about the non tabooed, non charismatic or even destructive species?}

One could argue that culture and religion might eventually contribute to the conservation of sacred, tabooed, charismatic and other species with mythic characteristics. But what about those species which are not? This is a difficult and important question; since a number of species may cause great damage and have at first sight little or no value for local people. In fact, the first and most important value interviewed people give to wildlife is as source of food, and the second most cited value of wildlife is as additional source of income.

However people are aware of the other non consumptive value wildlife has for them, and which might mitigate the negative perception they could develop towards such non tabooed, non charismatic or even destructive species. Interviewed people stated the importance of wildlife as a heritage from their ancestors, and which we should pass on to our descendants. Another important aspect is the value attributed to numerous animal species for traditional healing in a country where a significant part of the population does not have access to modern medical services and where traditional medicine is the only alternative existing. Parts of numerous species are thus used in the confection of curative products or of protective talismans.

Although the ecological role of wildlife, as predators or seed dispersers, was not stated as the most important value, this is one of the main reasons why some destructive species are tolerated. Monkeys for instance are known to kill snakes: this is a particularly valuable characteristic in the Bijagós islands, where snakes are known to be abundant, but also elsewhere in the country. Farmers from the Cufada Natural Park claim that rice field raiding by the Giant rats has increased in the last years, because their predators, the Baboons, have become rarer. The seed disperser role of primates and some forest ungulates is also recognised and is presented to explain why forest tree species but also domestic fruit trees are able to grow on remote places within the forests, without the active intervention of the villagers. Knowledge about the ecological role of wildlife is however not valued and there is a need for extensive environmental education actions on the conservation value and needs of wildlife in general and of non charismatic and destructive species. 


\section{VI.8. Specific legal measures for wildlife conservation}

Most interviewed people from the three parks (Orango, Cufada and Cacheu) know about the protected areas within or around which they are living. Most of them also know about the existence and to a much lesser extend about the main content of the law on hunting which was in force at the moment, and especially about the restriction on the hunting periods and the need of hunting license. This is easily explained by the information activities on this law and other topics, which have been carried out by park authorities within the protected areas (Orango, Cufada, and Cacheu) and in Cantanhez and Formosa by conservation NGOs.

However, most hunters declare that they hunt during the night and also during the rainy season, although it is prohibited. Most interviewed hunters had neither a license for their arms, nor for hunting. An important proportion of local hunters use locally produced shotguns, which require no license. Detailed information on the content of the law on hunting and on further important conservation measures included in the law, such as the species which are protected, the existing hunting reserves etc. need to be divulged. This is particularly crucial, since a new law on hunting was approved early this year, which has introduced some important changes.

In this study non coastal regions were not included, which are known to host mostly woodland dwelling species (most large ungulates, Vervet monkey, Patas monkey and Baboon), but also forest species such as elephants, buffaloes, chimpanzees and red colobus in the Southeast. As the results of this study show, the status of most large and medium-sized mammal species in the coastal forests is alarming. Important steps have been taken, since some species which were not protected by the former decree were recently listed as protected in the new approved decree.

However, the actual conservation status of some species needs to be taken more strongly into consideration and their protection status updated (Table29). Until the status of all in Guinea-Bissau primates at the national level has been clearly determined by results of a nation-wide survey, all primates should be included in the Redlist of endangered species and listed as integrally protected. 
Table29. Actual and proposed protected status of some endangered large- and medium-sized mammals with IP: integrally protected, PP: partially protected, RL: Redlist, NL: not include in the mammal list and (1): presence to be confirmed/eventually recent extinction

\begin{tabular}{|c|c|c|c|c|}
\hline & Species & $\begin{array}{l}\text { Actual } \\
\text { status }\end{array}$ & $\begin{array}{l}\text { Proposed } \\
\text { status }\end{array}$ & Observations \\
\hline \multirow[t]{6}{*}{ Primates } & C. petaurista & IP & RL-IP & $\begin{array}{l}\text { Restricted distribution, } \\
\text { dependent o forests, high } \\
\text { hunting pressure }\end{array}$ \\
\hline & C. nictitans & $\mathrm{IP}(1)$ & RL-IP & $\begin{array}{l}\text { Distribution unclear/very rare, } \\
\text { dependent on forests }\end{array}$ \\
\hline & C. campbelli & RL-PP & RL-IP & $\begin{array}{l}\text { Heavily hunted, strongly } \\
\text { negative trends }\end{array}$ \\
\hline & P. papio & RL-PP & RL-IP & $\begin{array}{l}\text { Heavily hunted, strongly } \\
\text { negative trends }\end{array}$ \\
\hline & E. patas & PP & RL-IP & $\begin{array}{l}\text { Heavily hunted, strongly } \\
\text { negative trends }\end{array}$ \\
\hline & C. sabaeus & PP & RL-IP & Heavily hunted \\
\hline \multirow[t]{8}{*}{ Artiodactyls } & K. ellipsiprymnus & RL-PP & RL-IP & $\begin{array}{l}\text { Very rare, seasonal and } \\
\text { restricted observations, } \\
\text { negative population trend }\end{array}$ \\
\hline & R. redunca & RL-PP & RL-IP & Rare, restricted distribution \\
\hline & K. kob & $\mathrm{PP}$ & RL-IP & $\begin{array}{l}\text { Rare, restricted distribution, } \\
\text { should be included in the } \\
\text { Redlist }\end{array}$ \\
\hline & H. equinus & IP & RL-IP & $\begin{array}{l}\text { Very rare, seasonal and } \\
\text { restricted observations, } \\
\text { negative population trend, } \\
\text { should be included in the } \\
\text { Redlist }\end{array}$ \\
\hline & C. maxwellii & RL-PP & RL-IP & $\begin{array}{l}\text { Rare, dependent on forests, } \\
\text { heavily hunted, negative } \\
\text { trends }\end{array}$ \\
\hline & C. rufilatus & RL-PP & RL-IP & $\begin{array}{l}\text { Very rare, dependent on } \\
\text { forests, heavily hunted, } \\
\text { negative trends, }\end{array}$ \\
\hline & C. silvicultor & RL-PP & RL-IP & $\begin{array}{l}\text { Very rare, dependent on } \\
\text { forests, heavily hunted, } \\
\text { negative trends, }\end{array}$ \\
\hline & P. porcus & PP & RL-PP & $\begin{array}{l}\text { Rare, dependent on forests, } \\
\text { negative trends, should be } \\
\text { included in the Redlist }\end{array}$ \\
\hline \multirow[t]{3}{*}{ Carnivores } & P. pardus & IP & RL-IP & $\begin{array}{l}\text { Rare, dependent on forests, } \\
\text { negative population trends, } \\
\text { should be included in the } \\
\text { Redlist }\end{array}$ \\
\hline & C. crocuta & RL-PP & RL-IP & $\begin{array}{l}\text { Rare, negative population } \\
\text { trends }\end{array}$ \\
\hline & P. aureus & $\mathrm{NL}$ & RL-IP & $\begin{array}{l}\text { Very rare, dependent on } \\
\text { forests, should be included in } \\
\text { the Redlist }\end{array}$ \\
\hline
\end{tabular}


Mammal species which are already listed in the official Redlist of endangered species should be integrally protected. Species listed as partially protected, but which show drastic negative trends in their abundance and/or are already confined to restricted areas, e.g. Buffon Kob and red river hog, should be included in the integrally protected species. The golden cat should be included in the Redlist and be listed as integrally protected, unless its distribution and status has not been reliably determined.

\section{VI.9. Development and implementation of Community-based wildlife monitoring schemes in the study sites}

The information gained from this pilot study represents a basis which should facilitate the development and implementation of specific monitoring programmes for mammals in the surveyed sites and in other regions of the country with high conservation value.

\section{V1.9.1. Monitoring objectives and objects}

The objectives of long-term community-based monitoring programmes in the coastal forests of Guinea-Bissau should be to gather information on selected wildlife species and also to collect information on population trends over time. Thus it will be necessary to obtain information on presence-absence and abundance estimates. On the other side, data from long-term monitoring will deliver information on the state of the habitats used by the monitored species.

Community-based monitoring should allow local protected areas managers and communities to assess the impact of human activities on wildlife in their own region. The importance of effectively involving local people not only in data collection, but also in data analysis has already been by different authors (Mühlenberg et al. 1993, 1995, Little 1994, Waitkuwait 1994, Marks 1994, 1996; Steinmetz \& Mather 1996, Abbot \& Guijt 1998, Gibson 1999, Ramsar Convention 2002, Steinmetz 2000); this will allow the wider community to understand how the monitoring results are linked to management measures of the wildlife resource. 
As stated by Abbot and Guijt (1998), "community-based monitoring will only work if it contributes to local understanding and empowerment and not simply to the satisfaction of the researcher". The attempt to actively involve local managers and communities in the monitoring of wildlife will have an impact on the choice of methods to be used, taking into consideration the need for reliable and high quality data.

Different criteria are considered for the selection of indicator species for monitoring programmes (Noss 1990, Kremen et al. 1994, Mühlenberg et al. 1995, Waitkuwait 1999; 2001, Steinmetz 2000, Struhsaker 2002):

- ecological indicators, e.g. red colobus monkey and chimpanzee;

- keystone species, e.g. ; elephant, hippopotamus;

- umbrella species such as elephant, leopard and chimpanzee;

- flagship species, e.g. elephant, hippopotami and chimpanzees

- vulnerable species, which are rare and/or prone to extinction, e.g. elephant and chimpanzees; and

- popular species of direct economic or cultural interest, for example duiker and antelopes on one hand, hippopotamus and manatee on the other hand.

An additional important criterion to be included is also data deficiency on occurrence and distribution of species in the country. This will allow collection of information in order to clarify the status of species such as greater putty-nosed monkey and sooty mangabey, pigmy hippopotamus, and giant forest hog among others. It will be necessary to determine local-specific monitoring species lists in each study site, taking into consideration the distribution patterns and the criteria presented above (see Appendice 4).

\section{VI.9.2. Monitoring programme design}

In African forests, line transects surveys have been successfully used mainly to obtain density estimates of large mammals, but there are few examples of long-term monitoring programmes (Thibault 1993, Mühlenberg \& Slowik 1996, Plumptre 2000, Thomas et al. 2001, Waitkuwait 2001, Waltert 2002). If changes in population are to be detected, then the survey must be intensive.

The collection and analysis of distance sampling data has however been proven to be complicated and difficult to implement within community-based wildlife 
management schemes in poor countries with limited financial and human resources (see chapter on methods). Beside the high encounter rate required, estimates of precision indicate that a high number of censuses may be required to reach asymptotic precision (Mitani et al. 2000). Carrying out regular surveys or using the same transects for the various surveys can thus help to improve resolution in detecting changes in the population but this implies high costs (Struhsaker 2002).

The results from our pilot field surveys give indications of the technical possibility of developing local-specific long-term monitoring programmes in the different sites surveyed. On this basis, it is theoretically possible to determine the survey effort which will need to be made, in order to collect statistically reliable mammal density estimates. Following Buckland et al. (1993), the overall transect length needed to satisfy a known level of precision can be calculated with the formula

$$
L=\left(\frac{b}{[C V(D)]^{2}}\right)\left(\frac{L o}{\mathrm{no}}\right)
$$

Where $\quad$ CV (D) is the intended coefficient of variation for the estimated density, $\mathrm{b}$ is called the dispersion parameter, associated with the variation of sighting number and sighting distances;

Lo the pilot transect length and no the number of sighting from the pilot survey.

Burnham et al. (1980) recommend the use of the value $b=3$ for planning purposes, in order to avoid underestimating the required line length. Examples of the estimates of the survey effort required to satisfy different levels of precision, as calculated for some species in Cantanhez and Orango, are presented in Table30.

Yet according to Buckland et al. (1993), after obtaining the required transect length, one could theoretically also estimate the expected encounter rate to be achieved on the calculated transect length, using the formula

$$
\frac{\text { Lo }}{\text { no }}=\frac{L}{n}
$$

Where Lo is the pilot transect length, no the number of sightings from the pilot survey and

$L$ the estimated required transect length. 
If we take into consideration the calculated required transect length $L$ for the three different precision levels, this would correspond to a theoretically expected encounter of 300, 150 and 100 observations for each of the species listed in Table30.

The obtained estimates of the total survey effort for the different species are quite high and difficult to achieve where resources are limited. It is however possible to consider a period of one year as the reference, and thus to distribute the total effort among various surveys, whose frequency should be determined locally (see below).

Table30. Example of required survey effort for line transect sampling in Cantanhez and Imbone/Orango for different levels of precision, with CV(D): Density estimate coefficient of variation

\begin{tabular}{|c|c|c|c|c|c|}
\hline Species & Lo & no & $\begin{array}{l}\text { Required survey } \\
\text { effort } L(k m) \text { for } \\
C V(D) \text { of } 10 \%\end{array}$ & $\begin{array}{l}\text { Required survey } \\
\text { effort } L(\mathrm{~km}) \text { for } \\
\text { CV(D) of } 20 \%\end{array}$ & $\begin{array}{l}\text { Required survey } \\
\text { effort } L(\mathrm{~km}) \text { for } \\
\mathrm{CV}(\mathrm{D}) \text { of } 30 \%\end{array}$ \\
\hline \multicolumn{6}{|l|}{ Cantanhez } \\
\hline P.t. verus & 12 & 4 & 900 & 450 & 300 \\
\hline C. campbelli & 12 & 17 & 212 & 106 & 70.6 \\
\hline P. badius & 12 & 6 & 600 & 300 & 200 \\
\hline C. polykomos & 12 & 5 & 720 & 360 & 240 \\
\hline C. aethiops & 12 & 1 & 3600 & 1800 & 1200 \\
\hline \multicolumn{6}{|l|}{ Orango-Imbone } \\
\hline C. aethiops & 25 & 25 & 300 & 150 & 100 \\
\hline T. scriptus & 25 & 23 & 326 & 163 & 109 \\
\hline
\end{tabular}

Another alternative would be to estimate, on the basis of the encounter rates obtained from this pilot survey, the line transect survey effort required for obtaining the recommended minimum encounter rate of 60 to 80 observations for line transect sampling (Buckland et al. 1993) (see Table31), using the same formula

$$
\frac{\text { Lo }}{\text { no }}=\frac{L}{n}
$$

Where Lo is the pilot transect length, no the number of sightings from the pilot survey and $\mathrm{n}$ the intended observation number (60 or 80 ). 
The obtained values for the required survey effort are lower (Table31), but there is no indication as to the level of precision which will be attained. This will depend on the real number and the quality of the data collected.

According to the second survey effort calculation alternative, a total survey effort of 42-56km would be sufficient to obtain $60-80$ observations for the most common primate species, the Campbell's monkey, in Cantanhez. This is however not the case for the less abundant species such as chimpanzees for which a minimum of 180 to $240 \mathrm{~km}$ of line transects, and slightly lower distances for both colobus species, would be necessary to obtain statistically reliable data in the same region. Vervet monkeys are rare in Cantanhez, which explains the very high distance necessary to obtain reliable data for this species.

According to the resources available in each region, the most appropriate formula should be applied. However, under the real conditions of a community-based monitoring in coastal Guinea-Bissau with poor financial and human resources, a survey effort of 180 to $240 \mathrm{~km}$ would allow collection of good data for all primate species occurring in Cantanhez. These figures might hold also for line transect sampling in the other study sites, the Cufada and Cacheu parks and on the Formosa Island.

Table31. Required total survey effort for 60 to 100 observations of some species

\begin{tabular}{rrrr}
\hline Species & $\begin{array}{r}\text { Required survey } \\
\text { effort for } 60 \\
\text { observations }(\mathrm{km})\end{array}$ & $\begin{array}{r}\text { Required survey } \\
\text { effort for } 80 \\
\text { observations }(\mathrm{km})\end{array}$ & $\begin{array}{r}\text { Required survey } \\
\text { effort for } 100 \\
\text { observations (km) }\end{array}$ \\
\hline Cantanhez & 180 & 240 & 300 \\
\hline P. t. verus & 42 & 56 & 70 \\
C. campbelli & 120 & 160 & 200 \\
P. badius & 140 & 192 & 240 \\
C. polykomos & 720 & 960 & 1200 \\
C. aethiops & & & 100 \\
\hline Orango-Imbone & 60 & 80 & 109 \\
\hline C. aethiops/ & 65 & 87 & \\
T. scriptus & & & \\
\hline
\end{tabular}

It should be noted that, these numbers derive essentially from primate observations, and not from other species, which are also rare, such as forest antelopes and 
buffaloes. It will be necessary to test the suitability of such a scheme in each site; the system will need to be permanently adapted and improved, taking into consideration the data, the precision requirements and the resources available.

In Orango, shorter distances appear to be sufficient, since 80 and $87 \mathrm{~km}$, or ideally $90 \mathrm{~km}$, would be sufficient to obtain an encounter rate of 80 for Vervet monkeys and bushbuck respectively. The use of the distance sampling method was easier on the two islands of Orango and Imbone, than in the other study sites, mostly due to the dominant vegetation: extensive grass and tree savannah areas which made it easy to walk in straight lines, with good visibility, which was not the case in all the other sites. The two islands of Orangozinho and Menegue, which were not included in this pilot study, should be integrated into a possible monitoring programme in the Orango NP. In the Formosa group, the islands of Chediã and Nago should also be included in a monitoring programme.

The need to develop financially, technically and socially more sustainable monitoring systems is increasingly recognised, and various authors have presented the reconnaissance surveys (or "recce" walk) as a less costly and easier alternative to line transect sampling (Barnes and Jensen 1987, Hall et al. 1998, Walsh \& White 1999, Mitani et al. 2000, Beyers et al. 2001, Olsen et al. 2001, Struhsaker 2002). In the context of the limited human and financial resources in community-based wildlife management programmes in coastal forests of Guinea-Bissau, and considering the constraints related to the use of distance sampling methods data, reconnaissance surveys appear clearly as an easier and more effective method for collecting data on wildlife species on a regular basis.

Results from these reconnaissance surveys can provide important information on trends of species within determined areas, and they are easier for analysis and interpretation by local communities. However line transect sampling remains crucial for obtaining quantitative data on abundance and densities and for comparing the abundance of animals between habitats that afford radically different visibility (Struhsaker 2002). 
Combining reconnaissance walks and transect sampling provided comparable density results to those obtained only with line transect data for our reference species with the highest observation frequency, the Campbell's monkey. A compromise solution could be a combined formula where for example monthly reconnaissance surveys are carried out routinely by local village teams and are complemented through regular but much less frequent line transect sampling by trained technicians (Table32).

Regular joint workshops with the different monitoring groups and other community's members, for data presentation and discussion, would allow different stakeholders to be integrated into a participatory monitoring exercise. For chimpanzees, nest counting is known to be a relatively quick and inexpensive means to assess chimpanzee numbers (National Research Council, 1981; Plumptre and Reynolds, 1997). Chimpanzee nest counting should be carried out not only during the routine reconnaissance surveys, but also during line transect sampling.

Line transect sampling will allow estimation of the density of most mammals, but other methods will need to be implemented for specific species. Because of the low resolution of changes that can be detected by line transect sampling, monitoring of animal populations in African forests must rely on information from various sources in order to adapt management practices in time to assist declining populations (Plumptre 2000).

Considering the lack of information on most mammal species of Guinea-Bissau, monitoring activities should be complemented by other detailed studies of specific species or species groups. Detailed, long-term studies of several specific groups that include group counts and home range estimates appear to be the most indicated method in terms of accurately estimating absolute population and biomass densities of primates (Mitani et al. 2000). This method will need to be used also for specific resident groups of hippopotamuses for instance. For this species and for manatee, canoe surveys from the river will be necessary to collect complementary data.

Dung and track counts have been particularly well developed for estimating population densities of elephants (see Walsh and White 1999, White and Edwards 
2000) and to a much lesser extent and less successfully for duikers (e.g. Koster and Hart 1988, Payne 1992, McCoy 1995, Struhsaker 1997), but Barnes and Jensen (1987) consider that the use of dung and track counts for other medium and large sized mammals than elephants is useful only in giving indices of relative abundance. Plumptre (2000) stresses the need to use various complementary methods, such as collecting records of carcasses and conducting surveys of meat in markets, so that additional data are available from other sources, and a clearer picture of changes in mammal abundance is obtained.

\section{VI.9.3. Capacity-building of monitoring teams}

The quality of collected monitoring data is crucial; according to Struhsaker (2002), and establishing professional integrity among the monitors is often a difficult task and one that does not necessarily depend on the level of education of the observers. Building trust and training of local people involved in the monitoring is one of the first steps.

The constraints of the limited literacy rate have already been presented; however, there are a few people with the minimum required level in the surveyed sites. Some of those people have already been taking part in environmental and adult education activities, for instance in Cantanhez and in Formosa, thus their integration should not be a major problem. Also local hunters who are already participating in some local conservation actions can be easily part of the monitoring groups. Struhsaker (2002) underlines that training of those responsible for monitoring is thus of highest importance, whereas "the objective in training personnel for use of the sampling method should be to emphasise that honest data is more important than data that indicate large numbers of animals".

Besides general training on simple sampling methods, knowledge of the biology of mammal species occurring in each study site will need to be transmitted to the local monitoring groups responsible of routine reconnaissance surveys. Training should also include aspects of simple data analysis and interpreting methods, if local people are to really understand the importance and the management implications of the monitoring programme. The number of people to be trained and of teams to be built in each of our study sites will depend on the size of the area to be surveyed and on 
the number of the sampling locations. Ideally, each village "owning" the area with one or more sampling location should have a monitoring group formed.

At least one group of persons with a higher level of literacy should be constituted and progressively trained in each study site, in order to carry out in the future more complicated sampling activities such line and point transect. These groups, which could also include people from the reconnaissance survey groups or even local employees from the forestry and/or environment department, must receive accordingly adequate and more advanced training.

Bringing back the main monitoring results to the local communities in a simple and adequate manner, interpreting and discussing the most important aspects and implications collectively in an understandable way can be a powerful tool for enhancing local environmental awareness and commitment with the communitybased management programme.

\section{VI.9.4. Data collection}

If line transect sampling is to be carried out, respectively about 30 and $60-80$ sampling units (i.e. surveys on individual transects) will need to be carried out each year for the density estimate in Orango and in the other surveyed sites respectively, if we consider a maximal individual foot transect length of $3 \mathrm{~km}$. The transects' total number, distribution and the survey frequency will need to be determined specifically for each region.

Table32. Example of data collection schedule for a community-based monitoring programme

\begin{tabular}{|l|l|l|l|l|l|l|l|l|l|l|l|l|}
\hline & J & F & M & A & M & J & J & A & S & O & N & D \\
\hline & \multicolumn{2}{|l|}{ Dry season } & & - & -3 & \multicolumn{3}{|l|}{ Rainy season } & & \multicolumn{2}{l|}{ Dry season } \\
\hline $\begin{array}{l}\text { Reconnaissance } \\
\text { survey }\end{array}$ & $\bullet$ & $\bullet$ & $\bullet$ & $\bullet$ & $\bullet$ & $\bullet$ & & & $\bullet$ & $\bullet$ & $\bullet$ & $\bullet$ \\
\hline $\begin{array}{l}\text { Line transect } \\
\text { sampling }\end{array}$ & & & $\bullet$ & & & $\bullet$ & & & $\bullet$ & & & $\bullet$ \\
\hline
\end{tabular}

Limoges \& Robillard (1989) consider the period between the late dry season and the early rainy season to be the most suitable for annual observations in Guinea-Bissau. 
Thibault (1993) also recommends the period from March to June, due to the difficulties of animal surveying in the rainy season. In order to include possible seasonal fluctuations and depending on the available means, the line transect sampling activities could take place for instance two (to four) times per year, i.e. to the beginning (and to the end) of the dry and of the rainy season respectively. For more effectiveness, monitoring activities should be avoided during the months of July and August (Table32), since more than half of the rainfall is registered during that period.

In each region, it will be necessary to define the most adequate monitoring schedule, taking into consideration these climatic characteristics, but also the available human and financial resources, and the biological characteristics of the species to be monitored, e.g. the migration patterns.

\section{VI.10. Towards community-based monitoring and management? Opportunities and constraints for successful implementation of long-term community-based wildlife management}

The implementation of community-based conservation schemes is a lengthy, complex and expensive process. The number and diversity of factors that can influence success or failure of community-based wildlife management, and the interplay between them make it impossible to prescribe specific conditions under which CBWM will or will not work (Roe et al. 2000). Collaborative management processes and agreements have to be tailored in order to fit the specific needs and opportunities of each context (Borrini-Feyerabend 1996). However, some specific attributes and conditions may influence the success of implementing and developing community-based conservation schemes in the short and the long-term (BorriniFeyerabend 1996, Wells and Brandon 1993, Ramsar Convention 2002, Roe et al. 2000). These attributes may be related to the biological resources to be managed, the effective legal framework, the technical capacity, the communities and existing institutions and the available resources.

Starting from the results of this study, from the examples presented above of some existing community-based conservation initiatives, and from the ecological, social, 
cultural and political characteristics of the country, there appear to be numerous opportunities for the development of CBWM in Coastal Guinea-Bissau. However, some important constraints will need to be addressed for its successful implementation (Tables 33-37). This chapter presents some of the most important opportunities and constraints, as well as respective strategies for the successful implementation of CBWM schemes in coastal Guinea-Bissau.

\section{VI.10.1. Biological resources}

The existence of rich and diverse natural resources with high national and international conservation value in the coastal forest sites included in this study, combined with the important role these resources play for the cultural and religious life of local communities are a valuable opportunity for the implementation of a CBWM scheme. Furthermore, local communities are increasingly aware of the conservation value and needs of threatened wildlife species (Table 33).

The links between culture and wildlife conservation are particularly strong in the Bijagós people and also in some ethnic groups of the Cantanhez forest region (Nalu /Tanda), but also to a lesser extent in the other ethnic groups. This relationship should be enhanced and valued in the conservation activities, for instance through the identification and promotion of local flagship species with high cultural value (Bowen-Jones \& Entwistle 2002; see also Table37) and the promotion of collective cultural activities related to conservation issues (Borrini-Feyerabend 2003).

The implementation of CWM is favoured by the existence of wildlife assets which are clearly demarcated and agreed by users; but the mobility of most animal species makes this difficult (Roe et al. 2000). This clear demarcation would appear to be easier for sedentary species such as primates and other forest ungulates. This issue thus will need to be tackled more particularly for mammal species such as Manatees, large ungulates, elephants etc., which are known to migrate over long distances. Environmental information and education on the ecology of those species will need to be carried out, in order to improve people's understanding. The definition of and agreements on the species and the respective areas to be managed amongst the different users are crucial for the success of $\mathrm{CBC}$ initiatives. 
Table33. Important aspects of the biological resources for the implementation of community wildlife management in Guinea-Bissau

\begin{tabular}{|c|c|c|}
\hline Opportunities & Constraints & Strategies \\
\hline 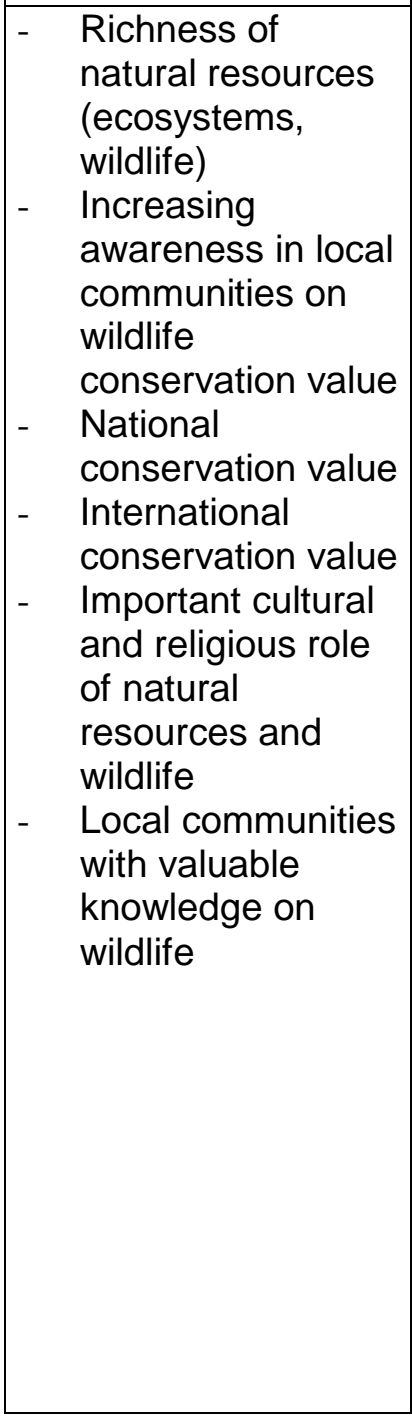 & $\begin{array}{ll}- & \text { Highly mobile resources } \\
\text { - } & \text { Rapid degradation, } \\
\text { fragmentation and destruction } \\
\text { of forest areas } \\
\text { - } \\
\text { Increasing exploitation } \\
\text { pressure } \\
\text { - } \quad \text { Declining wildlife resources } \\
\text { - Some threatened species are } \\
\text { not officially protected; } \\
\text { - Existing and potential } \\
\text { human/wildlife conflicts } \\
\text { Lack of local wildlife } \\
\text { monitoring and management } \\
\text { capacity } \\
\text { Some areas (e.g. Islands) } \\
\text { area very costly to manage } \\
\text { (high communication and } \\
\text { transport costs) } \\
\text { Lack of financial capacity for } \\
\text { the implementation of } \\
\text { autonomous conservation } \\
\text { programmes }\end{array}$ & $\begin{array}{ll}- & \text { information and education } \\
\text { activities on species and their } & \text { habitats } \\
\text { - } & \text { Clear definition and } \\
\text { agreements on the species } \\
\text { and areas to be managed } \\
\text { - } & \text { Identification and promotion } \\
\text { of local flagship species with } \\
\text { high conservation and } \\
\text { cultural value } \\
\text { - } \quad \text { collective cultural activities } \\
\text { related to conservation issues } \\
\text { Development and active } \\
\text { involvement of local } \\
\text { communities in monitoring } \\
\text { activities } \\
\text { - Promote research and } \\
\text { targeted public and decisions } \\
\text { makers' information on status } \\
\text { of endangered species } \\
\text { Improvement of } \\
\text { communication and } \\
\text { transportation in the } \\
\text { managed area for monitoring } \\
\text { purposes } \\
\text { Organisational capacity- } \\
\text { building of local communities } \\
\text { and users' groups } \\
\text { Identification and } \\
\text { implementation of acceptable } \\
\text { and viable alternatives to } \\
\text { hunting }\end{array}$ \\
\hline
\end{tabular}

A manageable scale is another important asset, as the area considered should not be too large and costly to manage (Roe et al. 2000). This could be an important constraint in some areas surveyed, more especially in the Bijagós islands, where the monitoring and management capacity is strongly affected by communication and transportation capacity. This constraint has already been identified for example in Formosa, where the proposed management plan has established the improvement of communication and transportation as one of the most important measures to be implemented (Biai et al. 2003). This is a critical issue in such a sensitive area, which is being increasingly invaded by migrating populations with mostly short-term benefit concerns. Once agreements on the conservation of specific species and habitats are 
met, local communities are highly interested in being involved in well functioning controlling mechanisms.

Organisational capacity-building of local communities and users' groups is also essential for the successful implementation of the agreements. Without having the required technical and organisational capacity for their effective involvement, local users groups might develop mistrust or even to negative perceptions towards the agreements.

Roe et al. (2000) and Olsen et al. (2001) consider that increasing scarcity or significant negative trends in the wildlife resource and impending ecological degradation appear to be major catalysts of CWM. There would thus seem theoretically to be little advantage to try to implement CBWM in situations where wildlife species are not overexploited and abundant, as it is the case in some isolated parts of the Bijagós archipelago for instance. However, the rapid degradation of wildlife species and their habitat throughout the country, along with the lack of longterm and reliable data on evolution of wildlife populations, could lead to the situation in which the wildlife resources to be managed are too scarce to improve, which clearly constitute a major constraint. Even in the Bijagós archipelago, some species of high conservation value, such as Manatees, lesser spot-nosed monkeys and cob antelopes are suffering increasing pressure from hunting and habitat loss; also other non mammal species are known to have strongly decreased. Some threatened species are officially not adequately protected, due to lack of up-dated information on their distribution and abundance.

Community-based wildlife management initiatives should include in their programmes research and targeted information of public and decisions makers on status of locally endangered species. This would contribute not only to arise awareness on these species, but also to influence decision making related to official conservation measures. However, environmental education alone will not reduce the pressure on wildlife; the development of adequate and local-specific strategies will have to follow the characteristics of each region and each group. In each area, it is necessary to identify, together with the local communities, the species and habitats for which concrete conservation measures are needed. Concrete agreements on the use of those resources need to be then met and complied with, and realistic controlling 
mechanisms must be developed. In this perspective, it is helpful to start with those species and habitats of high actual or potential value to the local communities, for which the need to conserve them is easier linked to the benefits from them.

The development of a participatory monitoring system would allow collection of reliable data and documentation of the declining population trends that are seen for most wildlife species. The active involvement of local communities in monitoring activities would enhance understanding and awareness on key species and habitats. The collected data would also deliver more scientifically grounded arguments for justifying necessary management measures to be taken.

Another constraint could derive from the existing and potential human/wildlife conflicts, which are mostly due to damage caused by crop raiding species. This is the case especially for (non arboreal) primates and wild pigs throughout the country, and hippopotamus mainly in the Bijagós archipelago and in the northern Cacheu Natural Park. Different techniques are locally used with more or less success to keep wild pigs and cane rats away from crop fields, for instance through the establishment of hedges, dams and canals around the field, but these techniques require high initial work and financial investments. It will be necessary to negotiate with the involved communities, and to support them, in order to identify locally adapted and viable alternative ways to minimise those conflicts.

\section{VI.10.2. Legal framework}

In West Africa, the implementation of national decentralisation programmes has favoured the shift towards greater community involvement in wildlife management, although the degree of decentralisation is variable. Guinea-Bissau does not constitute an exception; the decentralisation process was initiated in 1994 as a complement to the process of privatisation which was launched in 1986, however, the decentralisation law only came into effect in 1997 (Bonnal, undated). In the of rural development area, the decentralisation process proved to be purely formal, since neither the intermediate nor the local level received any new resources to carry out the new functions that were assigned them under decentralisation. The hesitation of the government of Guinea-Bissau about going ahead with decentralisation could 
be explained also as a lack of political will to take into account the aspirations of the local communities and to allow them to manage their own affairs (Bonnal, undated).

Table34. Legal aspects related to the implementation of community wildlife management in Guinea-Bissau

\begin{tabular}{|c|c|c|}
\hline Opportunities & Constraints & Strategies \\
\hline $\begin{array}{l}\text { Provision of support for } \\
\text { the concept of } \\
\text { community forestry by } \\
\text { the official law on } \\
\text { forestry } \\
\text { Support for the concept } \\
\text { of community hunting } \\
\text { area by the official law } \\
\text { on hunting } \\
\text { Law on protected areas } \\
\text { supports involvement of } \\
\text { local communities in PA } \\
\text { management structures } \\
\text { Legal Community } \\
\text { organisation possible } \\
\text { (GIE, hunters } \\
\text { associations) } \\
\text { Recognition of } \\
\text { customary property right } \\
\text { in official legislation } \\
\text { Legal recognition and } \\
\text { inclusion of sacred areas } \\
\text { as a protected areas } \\
\text { category }\end{array}$ & 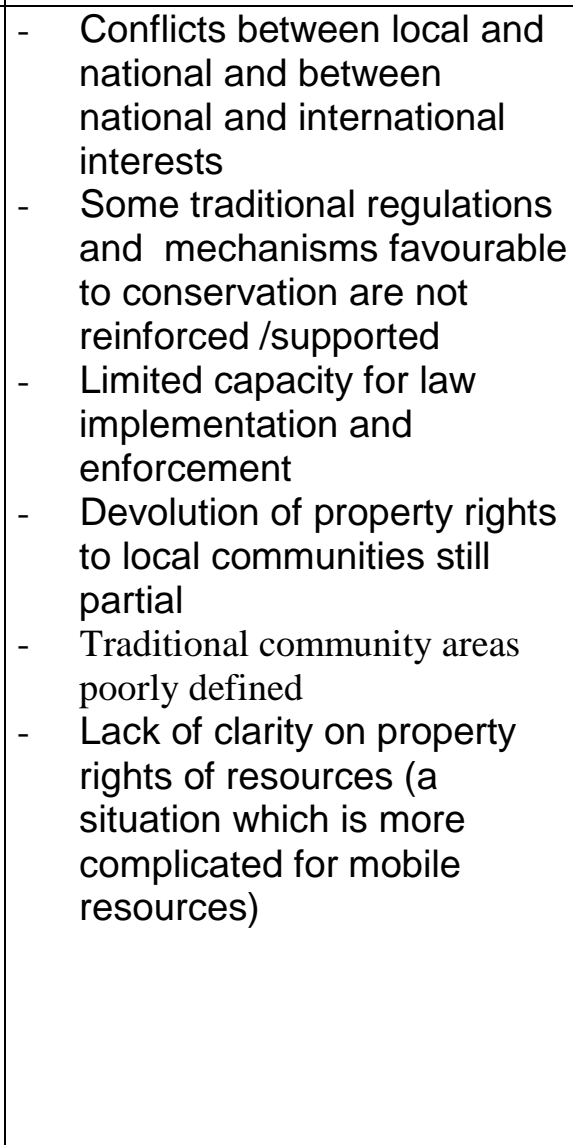 & 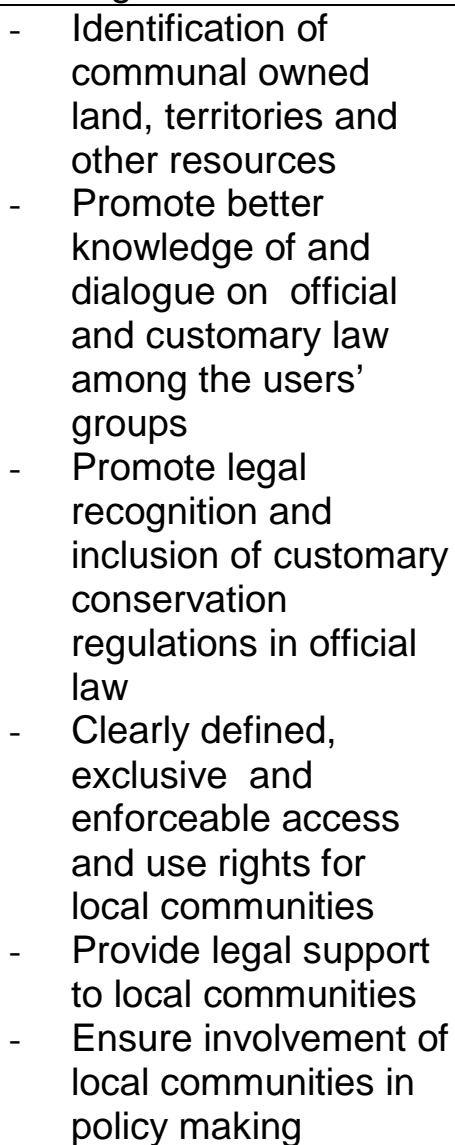 \\
\hline
\end{tabular}

Land tenure and Forestry laws are considered to be among the most important nonwildlife laws which impact on wildlife policy (McHenry 1993, Borrini-Feyerabend 2003, Nelson \& Gami 2003). In Guinea-Bissau, an important legal basis is the official law on land tenure (Decreto-lei da terra 1998), which officially recognises the customary property rights on land (art.6/ §4) and allows for the management of community land (including settlements, agriculturally exploited and fallow areas, pasture and other communal areas, forests and water resources) by the local community according to customary laws (art.17/\$1-4 and art.44). An important aspect of this law is also that it stipulates that local regulations aiming at the conservation of natural resources are applicable to residents and non residents (art.20/§3) (Table 34). 
It is however evident, that secure tenure is not achieved simply through the allocation of rights by the State or traditional leaders. Although the recognition of tenure rights is crucial, the ability to claim and put them into practice is the deciding factor (Little 1994, Roe et al. 2000, Glaser and da Silva Oliveira 2004). In fact, despite the theoretical equivalence between the customary and the modern law on land tenure in Guinea-Bissau, the still existing lack of clarity and security about property rights of land is one of the most crucial constraints to the development of community-based conservation actions.

Property rights on resources remain centralised as land is the property of the State. Furthermore, local community often ignore the contents, or even the existence of official laws. Community-based conservation initiatives should seek to promote better knowledge of and dialogue on official and customary law among the users' groups. Local communities are in general not involved in central decision making. Community-based conservation initiatives should try to ensure involvement of local users in policy making, particularly in matters related to natural resources. Information and discussion sessions on these topics could improve knowledge on theses issues and could facilitate the identification of important points of convergence or divergence, which need to be addressed.

The opening up of agriculture to foreign investment has led to the distribution of land concessions to private producers ('Ponteiros') who, in general, seek maximum shortterm economic return from the land, rather than sustainable long-term management Campredon 1993). Already in the year 1993, this new form of land ownership was covering some $45 \%$ of the national territory, leading to conflicts with local communities. The limits of traditional community areas, which are managed according to customary laws, remain poorly defined. This insecurity over land tenure and the increasing number of private owned properties in the rural areas have been leading to increased pressure on forest.

Also ownership of wildlife lies in the hands of the state, and the conservation of wildlife is considered to be the public domain of State (Law on hunting, art.3/§1) (MAFCP/DGFC 2004). "The forests are considered as a vacant good under the administration of the State, and individual trees, even within the forest, are State 
property, and may be cut only with the respective permission; thus their conservation generally does not interest the rural inhabitants" (Djombera 1999).

It is essential for community-based conservation initiatives to support local communities, in order to identify communal owned land, territories and other resources and to ensure legal recognition of communal land rights and security of tenure. Agreed access and use rights for local communities should be clearly defined, exclusive and enforceable. An example of such exclusive access and use right for local communities was achieved for local small-scale fisher groups on the Rio Grande de Buba in the nineties.

The "Plano director florestal nacional" (1992) defines the national policy on forestry, and considers that the transfer of responsibility to rural populations in the management of forest resources on their territories is a priority. The forest act (Lei florestal 1991, art.22) and the regulation on community forests represent actually other important opportunities at legal level, for the implementation of CBWM. These regulations provide legal support for the creation and management of community forests, managed by the communities around the forest. For this purpose, experimental three-year contracts are signed between the local communities and with the State forestry departments, after which period the contracts may turn definitive, if the State considers the conditions to be fulfilled.

Community forests have been found to have some success in a few sites in GuineaBissau, where positive effects were observed, such as the drastic reduction of bush fires, forest regeneration, and increase in wildlife numbers, contributing at the same time to the local development (PASP 2001, Swissaid 2003). However, the process of creating community forests is complex; preliminary agreements are signed between the local communities and the State for a three-years period, during which the community forest management remains under the State control, the latter having the possibility to unilaterally put an end to the management contract if it is judged to be justified. This situation of insecurity about the future of the community managed areas is a major constraint for the local communities to engage deeply and to develop long-term conservation strategies in those areas. Some villages have expressed their reservations to creating such official community forests, alleging this risk of the state "taking back" the forest (PASP 2001). 
In fact, there must be long-term security for institutional arrangements to alter the high discount rate of the future which characterises the culture of poverty (Murphree 2000), and thus to motivate community-based management. Dias (2000) recommends, among other measures, the definition of a clear status and delimitation and the promotion of the existing community forests management, in order to improve the situation of the forest conservation and management in Guinea-Bissau. Furthermore, the official law on community forests does prescribe a functioning mode for community forests, which does not always take into consideration the existing traditional regulation institutions, which may create a potential conflict situation.

A new hunting act was recently approved, which enables the creation of community hunting areas on the initiative of local hunters and in collaboration with local communities (MAFCP/DGFC 2004: Lei da Caça art.26/ §1-3 and Regulamento da Caça, art.43/ §1-4). According to these two legal regulations, community hunting areas are managed by local comities, according to management plans elaborated by the local communities with the support of the responsible State department.

However, community hunting areas are subjected to the same regulations as community forests, and as such are also gazetted for a limited period, under the control of the State.

Another very important legal opportunity for CBWM is that the Law on Protected Area provides support for the participation of local communities in their management (Lei Quadro das áreas protegidas 1997, art.18 and art.21). Furthermore, traditionally community conserved areas (sacred forests), which are used for religious and traditional ceremonies, are recognised by the same law as a PA category in GuineaBissau (art.3/1e and art 38). The legal framework also allows local communities to organise into associations and other groups with common interests, in order to implement activities to the benefit of their communities.

However, traditional regulations and other community driven mechanisms favourable to conservation have not always been supported, in spite of the recognition of sacred forests within the protected area legislation. Conflicts between local and national and between national and international interests have however often arisen, and have resulted for example in unsustainable agreements and permits for the exploitation of 
natural resources or in open conflict situations between government institutions and the local communities. Licences for commercial exploitation have been for instance granted in community-conserved or in core zones of protected areas. This conflict has been aggravated by the weak institutional capacity and the limited capacity for law implementation and enforcement of local institutions.

Community-based conservation initiatives should seek to promote not only legal recognition and inclusion of customary conservation regulations in official law, but also to monitor locally for the effective enforcement of the law. If necessary, legal support should be provided to local communities for this purpose.

Sense of responsibility, ownership, or proprietorship devolution at the community and resource user level has been identified as key factors for successful community conservation (Robinson \& Redford 1994, Western \& Wright 1994, Murphree 1998, Hackel 1999, Roe et al. 2000, Borrini-Feyerabend 2003). Legal frameworks should focus on the granting of rights, access and security of tenure to local resource users; this is essential for the poor to take the long term view (Pimbert \& Pretty 1997). Otherwise, hostility to conservation initiatives, increasing intolerance of wildlife and a continued lack of communal environmental control will be the results (Murphree 1996, Tchamie 1994).

\section{VI.10.3.Institutional level}

At the institutional level, various characteristics can be observed, which support the implementation of community-based wildlife management schemes. One of them is the existence of traditional institutions with a high cultural value of wildlife and forests in the religious and spiritual life of some communities. Cultural integration of local groups with wildlife is considered to be a possible key ingredient of CWM, particularly for indigenous forms of CWM which are often accompanied by a range of cultural practices that are valued for their meaningfulness (Roe et al. 2000, BorriniFeyerabend 2003).

Community-conserved areas are known in most cultural groups of Guinea-Bissau, but they have been documented in more details from the Bolama-Bijagós archipelago (Limoges \& Robillard 1991, Mendes Fernandes et al. 1991, Said et al. 1996, BorriniFeyerabend 2003, Maretti 2003). In that region, for instance, a complex system of indications at the entrance of a forests, river affluent or whole islands ("mandjidura": 
access restriction or prohibition) signal a set of rules and prohibitions, which are carefully observed by the local residents but not always by outsiders. The Nalu ethnic groups in the south of the country have also developed and implemented traditional regulations and other mechanisms aiming at the conservation of some forest resources (Tiniguena 1997, da Silva and Cardoso 2001). This group has had in the past a much stronger mystic relationship to the forests, with the existence of "dono do mato" (literally "owner of the forest", an "intermediary" personage between the humans and spiritual forest forces); today, this important cultural aspect still survives only in a few sites (da Silva and Cardoso 2001).

The existence of those local wildlife regulations is related to the existence of very informal but highly effective organisations, based on traditional and regularised practices of these particular groups. However, traditional culture and regulation mechanisms are weakening as a result of immigration and increasing modernisation of the society. Although the local regulations on wildlife are officially recognised in certain legal texts (see above), they have in practice no legal strength and outside users thus do not always comply with them, which can lead to conflicts between traditional and modern institutions. Whereas the local people can manage to enforce individual migrant residents to agree to some form of resource use regulation, it is more difficult for them to control poaching or illegal fishing by outsiders, who enter their territories with official permits.

It is thus important to disseminate information on existing legal provisions in the laws on protected areas and on land tenure, which are related to community conservation. Actions aiming at strengthening local communities' identity and culture would play an important role (Kleymeyer 1994, Borrini-Feyerabend 2003), for instance through the promotion of cultural activities. Also promoting (collecting, disseminating, valuing) traditional ecological knowledge is another aspect essential to the transmission of knowledge and values about natural resources and for minimising the weakening of traditional culture.

The successful implementation of community-based conservation schemes will depend on strengthening existing local resource management systems and on capacity-building of local management structures (see below). An important tool in 
order to reinforce the sense of ownership and knowledge of the own resources is participatory community territory assessment, which at the same time represents a solid base for collective reflection and wise resource use planning. In order to optimise conservation efforts at regional level, community conservation mechanisms should be best integrated into local or regional landscape management.

Table35. Institutional characteristics related to the implementation of community wildlife management in Guinea-Bissau

\begin{tabular}{|c|c|c|}
\hline Opportunities & Constraints & Strategies \\
\hline $\begin{array}{l}\text { Traditional institutions with } \\
\text { cultural values of wildlife and } \\
\text { forests } \\
\text { Existence of local } \\
\text { regulations on wildlife } \\
\text { Existence of local } \\
\text { forest/Park management } \\
\text { comities/councils } \\
\text { Local communities } \\
\text { increasingly claiming more } \\
\text { responsibilities in the } \\
\text { management of natural } \\
\text { resources and wildlife } \\
\text { Village development } \\
\text { groups/associations } \\
\text { Intervening conservation } \\
\text { and development NGOs and } \\
\text { projects } \\
\text { Local administration } \\
\text { involved and willing to co- } \\
\text { operate in local initiatives } \\
\text { Governmental instances } \\
\text { represented in most local } \\
\text { community conservation } \\
\text { initiatives } \\
\text { Existence of networking } \\
\text { opportunities on } \\
\text { participatory management in } \\
\text { the West African region } \\
\text { (community protected areas, } \\
\text { RAMAO) }\end{array}$ & 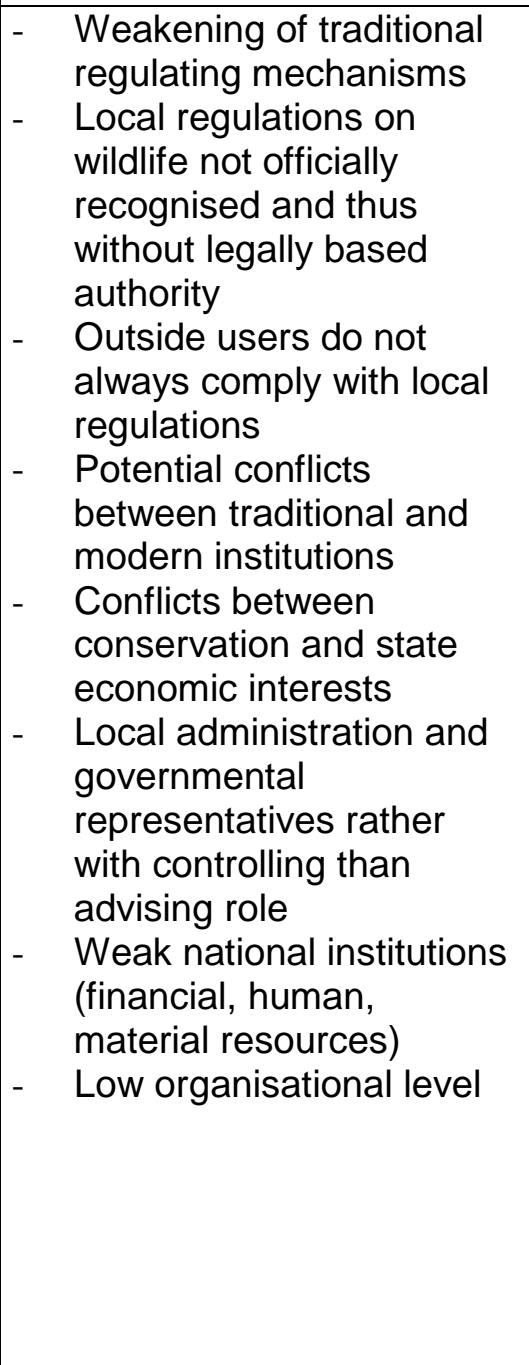 & $\begin{array}{ll}- & \text { Promoting and } \\
\text { strengthening local } \\
\text { communities' identity } \\
\text { and culture } \\
\text { - } \\
\text { Promoting traditional } \\
\text { ecological knowledge } \\
\text { - } \\
\text { Participatory community } \\
\text { territory assessment } \\
\text { and resource use } \\
\text { planning } \\
\text { - } \text { Integrating community } \\
\text { conservation } \\
\text { mechanisms into } \\
\text { landscape management } \\
\text { - Capacity-building of } \\
\text { local resource } \\
\text { management structures } \\
\text { Strengthening existing } \\
\text { local resource } \\
\text { management systems } \\
\text { Promoting devolution of } \\
\text { responsibility and } \\
\text { authority to local } \\
\text { communities } \\
\text { Promotion of own or } \\
\text { adapted organisational } \\
\text { models } \\
\text { Disseminate information } \\
\text { on existing legal } \\
\text { provisions on } \\
\text { community conservation }\end{array}$ \\
\hline
\end{tabular}

For the implementation of CBWM, effective rules, mutual obligations and sanctions will need to be negotiated and applied, which ideally integrate these traditional conservation mechanisms and reinforce them. A balance between customary and statutory law thus will be needed, because people in rural areas tend to be more familiar with customary rules, regulations and boundaries than with statutory law (Roe et al. 2000), whereas the conservation objectives should be kept in mind. 
In Orango, Cufada and Cacheu, park management committees were created, in order to allow local communities to take part in the management of the respective PA. In the forests of Cantanhez and on the Formosa Island, local management councils also exist, which include representatives of the traditional authorities and of different groups in the communities. Those committees/councils constitute potentially important forums for negotiating goals and actions and information exchange processes, which contribute to reducing potential conflicts between neighbouring groups or communities and to take into consideration the needs and interests of the different stakeholders. Negotiation with and involvement of the different stakeholders are of particular importance in all surveyed sites, and especially in the Bijagós islands, in Cantanhez and in Cacheu, where important immigrating communities lack this traditional knowledge and understanding of the local ecosystems.

In all sites included in this study, local people place particular non-monetary values on some wild species or habitats. If the community-based conservation initiatives are to survive in these areas, other types of benefits need to be made accessible, if neighbouring or migrant communities do not benefit directly from CWM (Roe et al. 2000). A balance needs to be found between the need of reinforcing the traditional conservation practices of local groups and the needs of the resident communities from the migration, if latter are to endorse them or to participate effectively in their implementation.

Transparent, negotiated and well-understood benefit-sharing schemes, which take into consideration the different sacrifices and contributions made or the damages incurred, will thus be a key to the long-term success of these initiatives (Western 1994, Murphree 1998, Roe et al. 2000, Borrini-Feyerabend 1997, 2003, Adams \& Infield 2003). In all cases, the conception of local incentives purely in terms of community economic benefits is "too narrow, too simplistic, and potentially counterproductive"; various kinds of social and political benefits are also likely to be important, and key considerations include equity fairness in the distribution of benefits and empowerment (Berkes 2004). In this perspective, the promotion of an effective devolution of responsibility and authority to local communities is essential, with a clear distribution of concrete functions and tasks. At the same time, own (or at least quite adapted) and not imposed organisational models should be privileged. In 
this perspective, the promotion of an effective devolution of responsibility and authority to local communities is essential, with a clear distribution of concrete functions and tasks. At the same time, own (or at least quite adapted) and not imposed organisational models should be privileged.

In some of the surveyed areas (mostly Cantanhez and Formosa and to a much lesser extend Orango, Cacheu and Cufada), there has been a strong rural development dynamics, with the creation of numerous village development groups/associations and other common interest groups. These existing dynamics represent an opportunity to strengthen the communities identity and for capacitybuilding. Conservation issues have been also increasingly addressed in those areas and need to be more strongly integrated: the legitimate aspiration to better living conditions has to be linked in a stronger manner with the need to conserve the natural resources. Conservation and development NGOs and projects have been intervening in the surveyed areas for a long time. This intervention has led to the already referred to dynamics and to an increasing awareness of conservation issues among local communities. The NGOs have also been involved with the origin of the few community-based conservation initiatives existing in Guinea-Bissau, with the support of international conservation institutions. These organisations do thus further represent strategic allies for community-based wildlife management actions.

However, most of the local NGOs rely greatly upon external financial support and often lack some specific technical tools and abilities. Capacity-building is thus necessary for both the local communities and the agents of these organisations. The three Parks of Orango, Cacheu and Cufada have been struggling with financial problems in the last years, and this has strongly affected their effective management.

The existing conservation initiatives show that local administration and state representatives present in the surveyed areas have been strongly involved and are in general willing to co-operate with and to support local initiatives, provided this does not imply additional costs and that their authority is not threatened. However, their competencies and means of intervention are often limited.

Local administration and governmental representatives have had more of a controlling than an advising role, which has greatly affected their relations with the local communities. In more isolated regions, forest guards are poorly motivated as they often face difficult problems such as lack of or irregularities in the payment of 
salaries, erratic supply with basic products due to isolation, lack of transportation to cover all the areas under their responsibilities, insufficient contacts with the central administration. Moreover, the role of forest guards is often perceived as a repressive one, and not a sensitising one, which does not contribute to a good relationship between them and local people. This is particularly the case, as most of forest guards do not originally come from the region they are assigned to and do not speak the local language. It is however worth noting that positive experiences of collaboration between local initiatives and local authorities or forest department officials for instance have been registered, for instance, in Formosa and in Cantanhez.

A critical role of the state remains among others its intervention in the resolution of disputes which cannot be solved at the local level, legal and administrative support for community conservation efforts; and protection against exploitative outsiders (Roe et al. 2000).

Apart from the local representatives of governmental institutions, there are an increasing number of government and non governmental agencies dealing with conservation issues, and there are increasingly networking opportunities on specific conservation issues. However, they have limited necessary knowledge and technical and human resources. The institutional framework of environmental policy is also not very clear, with gaps (lack of structures) and conflicts (limits of competence not clear, superposition, or non existent...) among different levels, the co-ordination between the different departments within the governmental structures with responsibilities for environment issues being rather weak.

A West African network (RAMAO) was created within the Regional Programme for the Conservation of coastal and marine resources (PRCM), an initiatives of different international and national conservation organisations. The network RAMAO aims at strengthening the local capacity for participatory management in the marine protected areas of that region (PRCM 2004). This represents a valuable opportunity for capacity-building and exchange for CBWM initiatives in coastal Guinea-Bissau. Some West African countries such as Senegal have specifically integrated in their legal framework, the category of Community Protected Areas (Larivière \& Sylla 1998); this could be an interesting example for promoting CBWM actions. This is also 
the long-term goal of the participatory coastal resource management initiative in the Formosa island group.

\section{VI.10.4. Technical aspects}

Local communities generally have valuable knowledge on wildlife occurring in their area. The daily coexistence with and observation of the processes taking place in their ecosystem, constitute a precious basis for collecting this empirical knowledge, which is maintained and enriched by incorporating new information throughout the generations (Steinmetz 2000).

Such knowledge is based on an oral tradition, with strong cultural influences, and incorporates information, attitudes, values, which are embedded in the culture of the community. Recently, traditional knowledge has been increasingly recognised as a valid component of resource management (Agrawa \& Gibson 1999, Ramsar Convention 2002, Roe et al. 2000, Colding \& Folke 2001, Berkes 2004). Communitybased conservation initiatives that build on a combination of traditional knowledge and 'scientific' knowledge can result in increased acceptance by both communities and conservationists and mutual understanding (Ramsar Convention 2002, Roe et al. 2000). Furthermore, there is an increasing awareness on conservation issues in local communities, particularly in the areas where conservation and development actions are being implemented by either governmental or non governmental institutions.

However, there appears to be a lack of knowledge and a need for strong environmental education on important issues such as the ecological value and on the conservation status of wildlife. Furthermore, the local knowledge is rapidly weakening and getting lost, due to the increasing influences from outside. Community-based initiatives should therefore promote local and traditional ecological knowledge, through collecting and divulging information on community conservation institutions and experiences. Promoting participatory research on traditional ecological knowledge and land use systems, collecting and disseminating local names of animal and plant species, and developing communication activities on traditional and local ecological values are important means of reinforce the sense of identity and ownership, but will also contribute to reinforce community-based conservation institutions. 
Table36. Technical aspects related to the implementation of community wildlife management in Guinea-Bissau

\begin{tabular}{|c|c|c|}
\hline Opportunities & Constraints & Strategies \\
\hline $\begin{array}{l}\text { Local communities with } \\
\text { valuable knowledge on } \\
\text { wildlife } \\
\text { Conservation related } \\
\text { attitudes and values } \\
\text { embedded in the culture } \\
\text { of the community } \\
\text { Increasing awareness on } \\
\text { conservation issues in } \\
\text { local communities } \\
\text { Increasing recognition } \\
\text { and valuation of local } \\
\text { knowledge by } \\
\text { conservation initiatives }\end{array}$ & 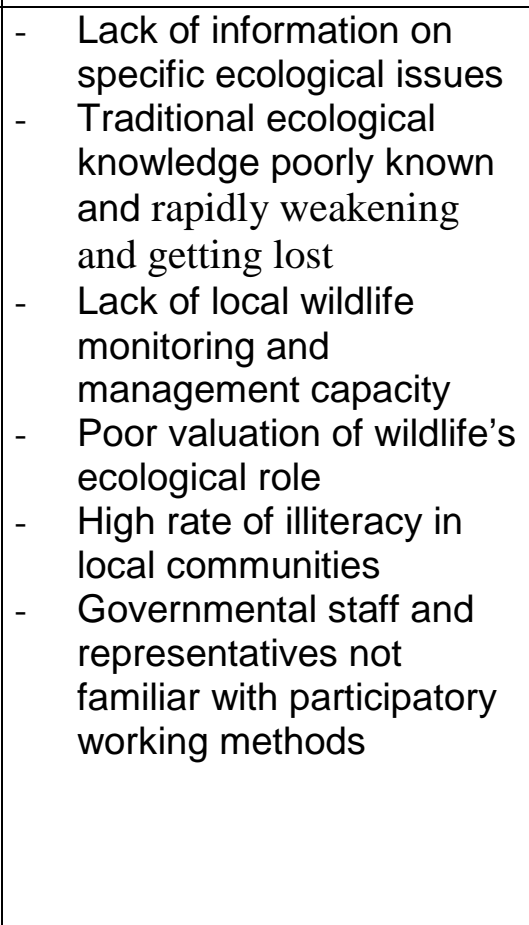 & $\begin{array}{ll}- & \text { Restoring and divulging } \\
\text { local names of animal } \\
\text { and plant species } \\
\text { - } \quad \text { Promoting participatory } \\
\text { research on traditional } \\
\text { ecological knowledge } \\
\text { and land use systems } \\
\text { - } \quad \text { Participatory } \\
\text { assessment of local- } \\
\text { specific capacity- } \\
\text { building needs } \\
\text { Developing information } \\
\text { and communication } \\
\text { activities on community } \\
\text { conservation } \\
\text { institutions and } \\
\text { experiences } \\
\text { Involvement of } \\
\text { governmental and PA } \\
\text { staff in capacity- } \\
\text { building activities }\end{array}$ \\
\hline
\end{tabular}

Another constraint is the lack of local wildlife monitoring and management capacity in the country. There are only a few monitoring programmes running with international donors' support on migratory bird (in the Cufada Natural Park and in Bolama/Bijagós archipelago) and on marine turtles respectively (also in the Bolama/Bijagós archipelago). Fisheries capture is also being monitored in Formosa. The rapid degradation of wildlife species and their habitat, along with the lack of long-term and reliable data on evolution of wildlife populations, could lead to the situation in which the wildlife resources to be managed are too scarce to improve, which clearly constitute a major constraint. Beside wildlife monitoring, it is also necessary to implement nationwide a wild meat market and consumption survey, in order to assess more clearly the importance of wildlife as a diet component and its contribution to household livelihoods.

The high rate of illiteracy in the rural areas constitutes a major constraint and reinforces the need to develop simple and adapted monitoring models, which can be understood and implemented with and by local communities (see recommendations on monitoring). Different programmes are running in order to reduce the illiteracy rate 
in some of the surveyed areas, but in general, there is a need for capacity-building, both for local communities' members and protected areas technical staff, if the necessary long-term wildlife management schemes are to be implemented.

Technical, organisational and managerial skills of both groups need to be improved for successful community-based conservation initiatives. The technical skills to be developed could include for instance biodiversity monitoring and survey methods, species and landscape conservation. Organisational training could address issues related to group building and communication, and conflict resolution. Managerial training would include material and financial management, small project planning and management, and participatory monitoring and evaluation. Capacity building for community-based conservation will however need to be local-specific and to take into account the skills that are required for communities and individuals to be successfully. Participatory assessment of local-specific capacity-building needs is thus essential for that purpose.

Collaborators from local communities have been found to be a more "sustainable" human resource than governmental and non-governmental agents after capacitybuilding (Thibault 2002). It is however important to involve local Governmental staff and representatives, because they are in general not familiar with participatory working methods. Their role has mainly been of a repressive and at best of controlling nature. For a successful devolution of responsibility and authority to local communities, the role and attitude of governmental staff and representatives will need to shift towards more partnership-based interaction with the communities. Involving official and PA staff in capacity-building activities will therefore contribute to enhance their understanding of community-conservation initiatives and to improve their communication skills with local communities (Borrini-Feyerabend 1997, 2003). It should be noted, that capacity-building methods should involve the more diverse forms of building and disseminating the knowledge, including the most classic and formal forms of workshops and training session, informal sessions, experimenting, exchange visits to successful experiences in $\mathrm{CBC}$ and other forms. 


\section{VI.10.5. Financial resources}

Until now, national policies have considered conservation not to be of priority, since other issues perceived as more crucial and urgent had to be addressed. The costs for implementation of long-term monitoring and other conservation activities are high and the funding issue remains a critical one for $\mathrm{CBC}$ initiatives. For the implementation of community-based wildlife monitoring and conservation initiatives, which are viable in the long-term, financial resources are required for training, equipment, monitoring, information and communication, promoting alternative income generating activities, etc. Conservation activities closely linked to production and income gains, those which build on existing production systems and programmes which rely on a valuable natural resource (e.g. a high-value marine or forest product) have the greater potential to generate economic benefits (Little 1994).

Due to widespread poverty, there is almost no local private financial capacity in the surveyed sites and in Guinea-Bissau in general. In the surveyed areas however, there is some limited local capacity for mobilising resources by the existing village groups and associations and also through traditional saving and local solidarity mechanisms. This local capacity for resource mobilisation, though, is far from sufficient for the implementation of autonomous conservation programmes, even if participatory, community-based schemes have the advantage of being considerably less costly than schemes relying on external technical assistance by foreign experts. Further funding opportunities arise from the increasing awareness of the international community about conservation issues, from the intervention of national and international conservation and development NGOs, and also from different international convention funding mechanisms.

Numerous conservation initiatives have, for instance, experienced the conversion of local hunters and villagers into monitoring teams (Mühlenberg et al. 1993, 1995; Marks 1994, 1996; Waitkuwait 1994; Gibson 1999; Waltert 1999). This approach has the advantage of being less costly, and more importantly, of valuing the knowledge of local communities, allowing them at the same time to effectively be involved in the conservation programme and to develop a sense of ownership. 
Table37. Financial aspects related to the implementation of community wildlife management in Guinea-Bissau

\begin{tabular}{|c|c|c|}
\hline Opportunities & Constraints & Strategies \\
\hline $\begin{array}{l}\text { Mobilisation of own } \\
\text { resources by associations } \\
\text { and traditional } \\
\text { mechanisms } \\
\text { - Potential for small-scale } \\
\text { ecotourism } \\
\text { - Local experience with } \\
\text { successful small loan } \\
\text { programmes } \\
\text { - Increasing awareness of } \\
\text { the international } \\
\text { community about } \\
\text { conservation issues } \\
\text { Financial support from } \\
\text { national and international } \\
\text { conservation and } \\
\text { development NGOs } \\
\text { International conventions } \\
\text { funding mechanisms }\end{array}$ & $\begin{array}{ll}\text { - } & \text { Limited local private } \\
\text { financial capacity due to } \\
\text { widespread poverty } \\
\text { - } \quad \text { Limited self-financing } \\
\text { capacity through } \\
\text { ecotourism } \\
\text { - } \quad \text { High costs for long-term } \\
\text { monitoring and other } \\
\text { conservation activities } \\
\text { - } \text { Funds needed for } \\
\text { supporting alternative } \\
\text { income generating } \\
\text { activities }\end{array}$ & 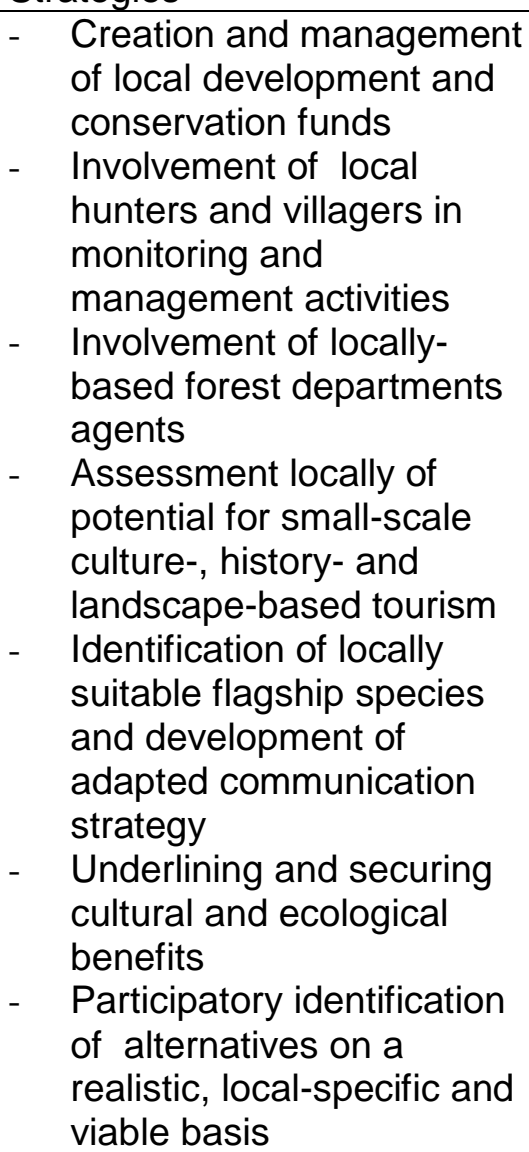 \\
\hline
\end{tabular}

Most such experiences have relied on external funding and have provided monetary compensation for these wildlife monitors and local communities. Regular monetary compensation or salary schemes are problematic in cases such as Guinea-Bissau, where financial resources are very limited, unless the conservation programme has developed self financing mechanisms. In such cases, monitoring activities and conservation benefits in general are likely to be maintained as long as funding or financial support is available to cover the costs (Adams and Hulme 2001).

On the other hand, direct monetary compensation of local monitors on a regular basis runs the risk of isolating them from the rest of the community and giving them the status of project employees, with all the implied side effects. This is particularly the case, when the community members do not have or feel any benefit from the conservation initiative. Such situations are critical and may lead to lack of motivation, indifference and in the worst cases to hostility from the community to that conservation initiative (Murphree 1998, Gibson 1999). Studies in Zambia also 
suggest that if benefits are limited to a small part of residents, those who are not involved may resent the programme and conspire to frustrate the success of those who are employed (Lewis et al. 1990).It could also be interesting to test the possibility of integrating locally-based official agents of the forest departments in those monitoring teams, particularly in cases where those agents come from the area involved. These usually have a somewhat higher level of education and monitoring could be an integral part of their duties, which would imply no additional costs with their salaries. However, in most cases, official forest agents are known to be poorly motivated, as their salaries are not only quite low, but are also irregularly received.

Punctual premiums, loan facilities, training opportunities, and other alternative, non monetary and non obligatory incentives are examples of schemes that could be tested. Other, non monetary incentive options include the providing of services and goods, concession of exclusive rights, and the promotion of alternative sources of income for local communities. Latter include employment opportunities for local communities' members, e.g. as wardens, wildlife monitors or guides, the promotion of small enterprises, new skills training and capacity-building and low-interest loans. In some of the surveyed sites (Cantanhez, Formosa), and in other regions of GuineaBissau, there is already long experience with successful small loan schemes. This constitutes a valuable opportunity for the creation and management of local funds for the supporting local development and conservation initiatives.

According to Kiss (1990), conservation projects, which provide local communities with development assistance in return for their co-operation in respecting the boundaries of the protected area or restrictions on hunting, work as long as benefits continue to flow to the people directly and as long as they are clearly linked to the conservation objectives. Compensatory payments for traditional uses foregone may provide a valid alternative in certain circumstances, but are not a realistic option, because funding is seldom available to fully cover the costs (Brown 1998). Still following Brown (1998), "many protected areas have little funds, and very large investments would be needed to bring them up to basic standards of management, even before any consideration is given to compensating for livelihoods foregone" in areas with little tourist potential. Spergel (1997) also considers that cash 
compensation payments in general could lead to the creation of a sense of welfare dependency.

For successful implementation of community-base conservation schemes, funds are needed for supporting alternative income generating activities, more particularly in areas where hunting is increasingly becoming commercial. Brown (1998) has analysed some key factors the development of income generating activities (IGA) in low-population density areas. For this author, the fact that local interest in hunting for instance usually lies in the high returns which it offers to labour, has limited the success of game animal domestication activities in West and Central Africa.

Alternative IGA are often implemented without any analysis of the market opportunities and, most importantly, lack any association with the goal of conservation (Brown 1998). Promotion of apiculture and of exploitation of other non timber forest products, poultry and small animal breeding, small scale fisheries, village tourism,...have been implemented in several countries with more or less success. Apiculture and fisheries have been supported in most of protected areas with some success, but they have not been specifically targeted at hunters. In all cases, there is a need to analyse the different alternatives on a realistic, local-specific and viable basis, taking into consideration the available resources, the market, the concrete benefits and the conservation goals.

Many authors have also underlined the fact that many community-based conservation initiatives are non-utilitarian (Roe et al. 2000, Kothari 2001, BorriniFeyerabend 2003), being generated by cultural and ecological benefits, in which cases there need for monetary compensation schemes is at least reduced.

In the surveyed areas, there is also some limited capacity for developing small-scale ecotourism; it is however clear that this represents a very limited revenue-generating potential, which means insufficient financial outcomes (Kiss 1990, Hackel 1999). The constraints to the development of tourism activities in forest areas have been presented elsewhere (see chapter on state of current research on CBWM). In contrast to savannah regions, tourism in forested areas is more strongly focused on history and culture, and also on birds and vegetation (Entwistle and Stephenson 
2000). A high potential for culture-based small-scale tourism can be found more particularly in the Bijagós archipelago. This could be combined with landscape and bird watching (Orango and Formosa), but also with wildlife watching (e.g. hippopotamus in Orango, marine turtles in Joao Vieira/Poilão). In the forested region of Cantanhez and in Cufada, Chimpanzee and primate watching could be combined with culture-based tourism. Some of the forests have played an important role in the anti-colonial history of Guinea-Bissau and could be integrated in a history-based tourism programme. The Cufada lagoons are additionally a valuable asset for landscape and bird watching tourism, which could be also combined with a history component in some of the forest areas. The Cacheu Park has great potential for mangrove landscape watching, but also for history-and culture-based tourism in some of the famous forests located within the park. Moreover, it should be assessed the possibility of developing local animal and vegetal flagship species in these sites, as part of the strategy of mobilising national and international support for local conservation efforts. Small-scale tourism income could be increased through the socio-cultural and ecological certification of local products.

"As with any management regime, participatory management may never be fully selffinancing" (Ramsar Convention 2002). It appears, that in the near future, communitybased and other conservation actions will further rely on their capacity to mobilise external support. Supporting capacity for community conservation and comanagement at all levels, including technical capacities for conservation and economic needs for conservation are a major challenge for community-based conservation (Borrini-Feyerabend 1997, 2003). In all cases, there is a need to analyse the different alternatives on a realistic and viable basis, so that financial resources do not constitute a major blockage. Agreed and local-specific schemes will need to be negotiated. 


\section{Conclusions and implications for conservation}

\section{VII.1. Conservation status of mammals}

This study has confirmed the existence of endangered primates and other mammal species with high local and international conservation value in Guinea-Bissau. A comparison with other forest sites in Upper Guinea have shown that the estimated group density of Chimpanzees in southern Guinea-Bissau (Cantanhez) are lower than that on Tiwai Island and in the Tai National Park in Côte-d'Ivoire, but they are yet higher than in some Central African lowland forests such as the Lopé reserve in Gabon or the Korup support zone in Cameroon. Although obtained density estimates are statistically not highly reliable, the results of this survey give a general overview on actual primate abundance and will serve as a valuable basis for needed future investigations.

There is still a lack of reliable information on the occurrence and distribution of some species endemic to West Africa, such as spot-nosed monkeys, sooty mangabey, pigmy hippopotamus, but also on water chevrotain, giant forest hog and the African golden cat. More detailed long-term biological research is needed in order to clarify the distribution and status of these and other species. As Bodmer (2000) states, CBC is likely to fail, if the biology of natural resources is not adequately taken into account; biological studies are thus needed to help communities manage wildlife populations according to the biological needs.

The results of this study show that negative trends have been observed in most large and medium-sized mammals; however, some species of high conservation value still occur in restricted areas within and outside of existing protected areas. This calls for specific measures in order to reduce pressure on more threatened species. Some species are locally endangered and not adequately protected in the law on hunting. The first step should be to update the legal framework, according to the conservation needs of those species. Campbell's monkey, Guinea Baboon and Callithrix monkey should also be integrally protected and be included in the Red list of threatened species. The rare large antelopes such as Defassa waterbuck, Buffon's Kob and Bohor Redunca and the forest duikers, as well as the red river hog should also be, at 
least temporarily integrally protected. Also species such as the African golden cat or water chevrotain, for which distribution data are lacking or whose occurrence is still to be documented, should be listed as protected.

Commercial hunting is increasingly becoming an important source of income for rural and urban populations. Only by taking an integrated and interdisciplinary approach can sustainable and viable solutions for the bushmeat trade be found (Bowen-Jones 2003). The bushmeat market is still in development, driven by the growing bushmeat demand in urban areas and increasing poverty in both rural and urban areas. Besides conservation education and active involvement of local communities in management efforts, economic measures are urgently needed, not only to improve access to different conventional sources of proteins, such as fish or domestic meat, but also to develop, together with the stakeholders, other realistic and locally adapted sources of income for rural people.

If the forest primate community of Guinea-Bissau is to be protected from extinction, it is urgent to improve the protected status and to promote connectivity between of the remaining forest areas, which are also of high importance for the conservation of other threatened forest dwelling mammal species. This is especially the case for the Cantanhez forests and the Cufada National Park, which host the bulk of the forest primate community of Guinea-Bissau.

Different proposals have been made as to the adequate protected status to be given to the Cantanhez forests, including that of a National Park, Natural Park or a biosphere reserve. Considering human population density in Cantanhez, the high fragmentation of the forests and the importance of agricultural and other human activities, the complete protection of the forest zone will not be possible. Rather a formula ensuring the implementation of sanctuary (ies), that is (are) strictly protected against any exploitation, both to act as refuge or reservoirs of animal (and plant) species and as reference area (Oates 1997) appears to be more realistic. Those sanctuaries should be best selected from sites having the least amount of destruction and their size should guarantee a minimum area for viability of selected species (Mühlenberg et al. 1995). In Cantanhez, these sanctuaries should correspond to some of the remaining, already traditionally protected forest patches, among which 
are important sacred groves. An official protected status would support the efforts of local organisations in order to ban incursion into the forests by poachers from outside, allowing them to implement punitive measures with the institutional backstopping of the law.

\section{VII.2. Development of community-based wildlife management schemes}

Our results show that some mammal species such as chimpanzee, black-and-white colobus, hippopotamus, and manatee have benefited from hunting and/or consumption taboos, because of their cultural or religious value; this has contributed to reduce pressure on these species. However, immigration, poverty, crop raiding and limited access to other sources of protein are leading to increasing pressure on other mammal species. The potential of those species with cultural or religious value as locally suitable flagship species with a strong potential to support environmental education and conservation actions, should be further assessed and valued. The different values placed on mammals by different groups should be reflected in the conservation approaches and priorities set for mammals; this is a key factor, if conservation is to be participatory and, in the long-term, successful (Entwistle \& Dunstone 2000).

Local community-based conservation initiatives are reinforcing community awareness about wildlife conservation and traditional conservation mechanisms, in order to protect local ecosystems and species with high conservation and cultural value. Some success has been reported by these initiatives, with the increased awareness of local communities on conservation needs of some species and reported increasing trends in some animals' populations. However, no correlation exists between the observation frequency of a species and its absolute abundance/density. Community awareness building activities must be complemented with simple, long-term community-based wildlife monitoring programmes, in order to complete those empirical observations with scientifically grounded data.

The development of long-term detailed studies and cost-effective monitoring activities is necessary, in order to provide conservation authorities, protected areas managers 
and local communities with reliable information on the conservation status of endangered species and to justify concrete management and conservation measures. To launch a truly community-based monitoring programme, it will be necessary for the local people and the state forest or protected areas agents to be involved in the planning process, in its implementation and in the data analysing process, in order to understand and to effectively assume the implications. The active Involvement of local communities in wildlife monitoring will thus facilitate effective implementation of management measures (as for instance hunting restrictions on some species, or restrictions on the opening up of new crop fields along elephant corridors). Through this research study, a starting point was made for the potential such a process.

There are examples of community conservation mechanisms in Guinea-Bissau, which have managed it to locally conserve valuable resources, with no intervention of official authorities. However, those community conservation institutions are increasingly weakening due to several external factors related to immigration, market economy, poverty and land tenure insecurity. Those traditional regulations have no official legal basis to enforce the laws approved by the communities and to tackle with encroachment from outside.

Apart from technical requirements, institutional, political and economic measures are thus necessary for the effective implementation of wildlife community-based management in Guinea-Bissau. Political support and effective participation of all stakeholders are the key to success of large mammal conservation (Muruthi et al. 2000). Legal measures are urgently needed, which support and reinforce the ongoing community-based conservation efforts through the official recognition of locally established conservation measures and bylaws, and the effective reinforcement of local communities' responsibility and authority.

Also long-term financial and technical support is critical for the effective and adequate management of the most coastal protected areas. Effective comanagement is essential also in the Orango, Cufada and Cacheu Parks and should be more strongly promoted, in order to reduce pressure from outside on these areas. In any case, the presence of illegal poachers (e.g. fishermen camps, hunters, etc.) 
within protected areas should not be tolerated by official authorities, because this may lead to the weakening of local conservation efforts and, more importantly, to increasing insecurity in local communities and their reduced commitment with agreed management schemes.

There is a need for a multidisciplinary approach, with an overall focus on habitat conservation and on the overall threats facing the species in each area (Feistner \& Mallison 2000, Muruthi et al. 2000). "An effective overall strategy for mobilising political and economic support for conserving mammals will give management responsibility and tenure rights to people most directly involved, provide economic incentives to long-term benefit individual behaviour, provide best available science to support decision making and seek a diversity of local solutions to local problems" (MC Neely 2000).

The implementation of community-based conservation schemes is a complex and lengthy process, which needs to be tailored to each specific situation. A number of steps are necessary (Borrini-Feyerabend 1997, Olsen et al. 2001, Chatelain et al. 2003), which include: the identification of all the stakeholders involved in the use of the wildlife resource; a participatory analysis of the situation which allows for exploring relevant knowledge and perceptions of issues related to the resource; the analysis of different options for action, in order to ensure the sustainability of the resource; the development and implementation of a management structure, with clear agreements on the sharing of functions, rights, responsibilities and benefits among the different parties and the legitimating of agreements or other local by-laws at the local community level and at the official legal level.

“....we have two broad choices. We can promote a policy shift toward authoritarian protectionism that would most likely alienate key allies at local, regional and national levels and thus precipitate resistance and conflict. Alternatively, we can build on past experience and constructively negotiate ecologically sound, politically feasible and socially just programs in specific contexts that can be legitimately enforced based on strong agreements with all affected parties" (Wilshusen et al. 2001). 


\section{References}

Adams, W.M. and Hulme, D. 1998. Conservation and communities: changing narratives, policies and practices in African conservation. Community conservation research in Africa - principles and comparative practice. Working paper no 4. Institute for Development Policy and Management, University of Manchester. Manchester, United Kingdom.

Adams, W. M. and Infield, M. 2003. Who is on the Gorilla's Payroll? Claims on tourist revenue from a Ugandan National Park. World Development, Vol. 31 (1), 177-190.

African Convention on the Conservation of Nature and Natural Resources, 1968. Algiers, Algeria 15 September 1968

African Elephant Specialist Group (AESG), 1999. Strategy for the conservation of West African elephants. Nairobi. IUCN/SSC, African Elephant Specialist Group.

Agrawa, A. \& Gibson C.C. 1999. Enchantment and disenchantment: The Role of community in natural resource conservation. World Development 1999, Volume 27 (4), 629-771 (April 1999)

Almeida e Silva, M. 1998. West African manatee conservation plan in Guinea-Bissau. Sirenews 30: 10-12.

Altenburg, W. \& van der Kamp, J. 1985: Oiseaux d'eau dans les rizières de la Guinée Bissau, Résultats préliminaires d'un recensement entre Mi-novembre et Mi-décembre 1983. UICN/WWF project 3096. IUCN/WWF, Gland, Switzerland.

Andresen, E. 2000. Ecological roles of mammals: the case of seed dispersal. In: Priorities for the conservation of Mammalian Biodiversity - Has the Panda had its day? Entwistle A. and N. Dunstone (eds.). Cambridge University Press.

Anon. 2004. Scientist: Extinct monkey may be alive. Science and Space - CNN 2004, February 6, 2004. The Associated Press 2004. 
Anónimo 1998. Lei da Terra. Lei No 5/98 de 23 de Abril. Suplemento ao Boletim oficial da Republica da Guiné Bissau No17 de 28.04.1998.

Araújo, A. 1994. A importância ornitológica da região da Cufada na Guiné-Bissau. Estudos de Biologia e Conservação da Natureza 13. ICN - CEMPA. Lisboa. 71 p.

Asibey, E.O.A. 1974. Wildlife as a source of protein south of the Sahara, Biological Conservation, 6: 32-9.

Atteslander P. 1995. Methoden der empirischen Sozialforschung. Walter de Gruyter Berlin, New York.

Bailey, R.C., Bahuchet S., and Hewlett B. 1992. Development in the Central African rainforest: concern for forest peoples. In : World Bank Environment Paper No1Conservation of West and Central African Rainforests (Cleaver K., Munasinghe M., Dyson M., Egli N., Peuker A., Wencelius F. (eds.).

Bakarr, M.I., da Fonseca, G.A.B., Mittermeier, R., Rylands, A.B. and K. Walker Painemilla. 2001. Hunting and bush meat utilization in the African rain forest. Perspectives towards a blueprint for conservation action. Advances in Applied Biodiversity Science, Number 2. Conservation International, Washington DC.

Baldwin, P.J., Sabatier, P.J., McGrew, W.C. and Tutin, C.E.G. 1981. Comparisons of nests made by different populations of chimpanzees (Pan Troglodytes). Primates 22: 474-486.

Baldwin, P.J., McGrew, W.C. and Tutin, C.E.G. 1982. Wide-ranging chimpanzees at Mt. Assirik, Senegal. International Journal of Primatology. 3:367-385

Barnes, R.F.W. 2002. The bushmeat boom and bust in West and Central Africa. Oryx, 36(3), 236-242

Barnett, A. A., Prangley, M., Hayman, P. V., Diawara, D. \& Koman, J. 1996. A survey of the mammals of the Kounounkan Massif, south-western Guinea, West Africa. Journal of African Zoology, 110, 235-240. 
Barnett, A.A and Prangley, M.L. 1997: Mammalogy in the Republic of Guinea: An overview of research from 1946 to 1996, a preliminary check-list and a summary of research recommendations for the future. Mammal Revue 27(3) :115-164.

Barnett, A., Prangley M., Hayman P., Diawara D. and Koman J. 1994. A preliminary survey of Kounounkan Forest, Guinea, West Africa. Oryx 28: 474-486.

Barrow E., Bergin P., Infield M., and Lembuya P. 1995a. Community conservation Lessons from benefit sharing in East Africa. In Bissonette \& Krausman (eds.). Integrating people and wildlife for a sustainable future. The Wildlife Society Maryland.

Barrow E., Bergin P., Infield M., and Lembuya P. 1995b. The Peoples' Voice: Partnership and community conservation. In Bissonette \& Krausman (eds.). Integrating people and wildlife for a sustainable future. The Wildlife Society Maryland.

Barrow, E.G.C. and Murphree, M.W. 1998. Community Conservation from Concept to Practice. A Practical Framework. Machester, Institute for Development Policy and Management, University of Manchester: 33.

Bassi, M. 2003. Enhancing equity in the relationship between protected areas and local communities in the context of global change - Horn of Africa and Kenya. TILCEPA report. IUCN//CEESP.

Beier, P. and Noss R.F. 1998. Do habitat corridors provide connectivity? Conservation Biology Vol.12 (6) 1241-1252.

Bennett, E. L. and Robinson, J.G. 2000. Hunting for sustainability: the start of a synthesis. In: Hunting for sustainability in tropical forests. Robinson J.G. \& L. Elisabeth (eds.). Columbia University Press, New York.

Bennett, E.L. and Robinson, J.G. 2000. Hunting of Wildlife in Tropical Forests: Implications for Biodiversity and Forest Peoples. The World Bank, Washington D.C. 
Beyers, R., Thomas, L., Hart, J. and Buckland, S. 2001. Recommendations for groundbased survey methods for elephants in the central African forest region. Technical report no 2. Monitoring Illegal Killing of elephants (MIKE) - Central African Pilot Project

Berkes, F. 2004. Rethinking Community-Based Conservation. Conservation Biology. Volume 18 Issue 3 Page 621 - June 2004

Bermejo, M. 1999. Status and conservation of primates in Odzala National Park, Republic of the Congo. Oryx 33:323.

Biai, J., Campredon, P., Ducroq, M., Henriques, A. and da Silva, A. O. 2004. Plano de gestao da zona costeira das ilhas Urok (Formosa, Nago \& Chediã) 2004-2008. Reserva da biosfera do Arquipelago Bolama/Bijagós. Guiné Bissau. Tiniguena, Bissau.

Bissonette, J.A, Krausman, P.R. (eds.) Integrating people and wildife for a sustainable future. Proceedings of the First International Wildlife Management Congress. The Wildlife Society, Bethesda, USA. 697 pp.

Bodmer, R. E. 1994. Managing wildlife with local communities in the Peruvian Amazon: the case of the Reserva Communal Tamshiyacu-Tahuayo. In: Western, D., Wright, M., Strum, S. (eds). Natural connections: perspectives in community-based conservation. Island Press, Washington, D.C.

Bodmer, R.E. 1995. Susceptibility of mammals to overhunting in Amazonian. In: Bissonette and P. Krausman (eds.) Integrating People and Wildlife for a Sustainable Future. The Wildlife Society, Bethesda, Maryland, pp. 292-295.

Bodmer, R. E. 2000. Integrating hunting and protected areas in the Amazon. In Entwistle A.C. \& N. Dunstone 2000 (eds.): Priorities for the conservation of Mammalian Diversity. Has the Panda had its day? Cambridge University press.

Bohnsack, R. 1991. Rekonstruktive Sozialforschung. Einführung in Methodologie und Praxis qualitativer Forschung. Leske \& Budrich Verlag, Opladen. 
Bohnsack Ralf 1997. Gruppendiskussionsverfahren und Milieuforschung. In: Friebertshäuser B. and Prengel A. (Hrsg.) 1997. Handbuch Qualitative Forschungsmethoden in der Erziehungswissenschaft. Juventa Verlag. Weinheim zu München. S. 492-502.

Bonnal, J. Undated. Guinea-Bissau. The Online Sourcebook on Decentralization and Local Development. FAO. Available online at http://www.ciesin.org/decentralization/English/CaseStudies/guinea e.html

Borrini-Feyerabend, G. 1996. Collaborative management of protected areas: Tailoring the approach to the context. - Gland, Switzerland (IUCN) 67pp.

Borrini-Feyerabend, G. (ed.) 1997. Beyond Fences: Seeking Social Sustainability in Conservation. Gland, Switzerland: IUCN.

Borrini-Feyerabend, G. 2003. Community conserved areas (CCAs) and co-managed protected areas (CMPAs) - towards equitable and effective conservation in the context of global change. TILCEPA report for the Ecosystem, Protected Areas and People (EPP) project, Online available at :

http://www.iucn.org/themes/ceesp/Wkg grp/TILCEPA/community.htm\#synthesis

Bortz, J., Döring, N. 1995. Forschungsmethoden und Evaluation für Sozialwissenschaftler. Springer Verlag.

Bowen-Jones, E. 1998. A review of the commercial bush meat trade with emphasis on the Central/West Africa and the great apes. African Primates 3 (Suppl.) S1-S37.

Bowen-Jones, E. and Entwistle, A. 2002. Identifying appropriate flagship species: the importance of local knowledge. Oryx, 36, 189-195.

Bowen-Jones, E. and Pendry, S. 1999. The threat to primates and other mammals from the bushmeat trade in Africa and how this threat could be diminished. Oryx, 33(3), 233246. 
Bowen-Jones, E., Brown, D. and Robinson, E. J. Z. 2003. Economic commodity or environmental crisis? An interdisciplinary approach to analysing the bushmeat trade in central and West Africa. Area, Vol. 35 (4), 390.

Brashares, J.S. 2003. Ecological, Behavioural and Life-History correlates of mammal extinction in West Africa. Conservation Biology, Vol. 17(3), June 2003.

Brown, D. 1998. Participatory biodiversity conservation. Rethinking the strategy in the low tourist potential areas of tropical Africa. Natural resource perspectives. London, Overseas Development Institute.

Brugière, D. and Magasouba, B. 2003. Mammalian diversity in the National Park of Upper Niger, Republic of Guinea - an update. Oryx, Vol. 37(1), 19

Buckland, S. T., Anderson, D. R., Burnham, K. P. and Laake, J. L. 1993. Distance Sampling: estimating abundance of biologica I populations. Chapman \& Hall, London , $446 \mathrm{pp}$

Buckland, S. T., Anderson, D. R., Burnham, K. P., Laake, J. L., Borchers, D. L. and Thomas, L. 2001. Introduction to distance sampling: estimating abundance of biological populations. Oxford University Press, 432 pp.

Bunce L., Townsley, P., Pomeroy, R., Pollnac, R. 2000. Socioeconomic manual for coral reef management. Australian Institute of Marine Science.

Burnham, K.P., Anderson, D.R. and Laake, J.L. 1980. Estimation of density from line transect sampling of biological populations. Wildlife monographs No.72. 202pp.

Butynski, T. and Members of the Primate Specialist Group 2000. Pan troglodytes. In: IUCN 2003. 2003 IUCN Red List of Threatened Species. <www.redlist.org>. Downloaded on 08 September 2004

Campredon, P. 1993. Coastal wetland planning and management in Guinea-Bissau. In : Davis T. J. 1993 (ed.) Towards the wise Use of Wetlands. Wise Use Project, Ramsar Convention Bureau, Gland, Switzerland. 
Carrillo, E., Wong, G., and Cuarón, A. D. 2000. Monitoring Mammal Populations in Costa Rican Protected Areas under Different Hunting Restrictions. Conservation Biology 14:6, 1580-1591.

Caro, T.M. 1999a. Conservation monitoring; estimating mammal densities in woodland habitats. Animal Conservation 1999 (2), 305-315. London, U.K.

Caro, T.M. 1999b. Abundance and distribution of mammals in Katavi national Park, Tanzania. African Journal of Ecology 1999 (37), 305-313.

Carpaneto, G. M. and Fusari, A. 2000. Subsistence hunting and bushmeat exploitation in central-western Tanzania. Biodiversity and Conservation, 9 (11): 1571-1585.

Caspary, H.U. 1999 Utilisation de la faune sauvage en Côte d'Ivoire et Afrique de l'Ouest: potentiel et contraintes pour la coopération au développement. GTZ. Eschborn, Germany.

Catry, P., Barbosa, C., Indjai, B., Almeida, A., Godley, B.J. and Vie, J.C. 2002. First census of the green turtle at Poilão, Bijagós Archipelago, Guinea-Bissau: the most important nesting colony on the Atlantic coast of Africa. Oryx 36: 400-403.

Catterall, M. and Maclaran, P. 1997. 'Focus Group Data and Qualitative Analysis Programs: Coding the Moving Picture as Well as the Snapshots'. Sociological Research Online, vol. 2, no. $1 \mathrm{http}: / / \mathrm{www}$. socresonline.org.uk/socresonline/2/1/6.html

Chapman, C. A., Balcomb, S. R., Gillespie, T. R., Skorupa, J. P. and Struhsaker, T.T. 2000. Long-term effects of logging on African primate communities: a 28-year comparison from Kibale National Park, Uganda.

Chapman, C. A., Gauthier-Hion, A., Oates, J.F. and Onderdonk, D.A. 1999. African Primate communities: determinants of structure and threats to survival. In : Primate Communities. J.G. Fleagle, C.H. Janson \& K.E. Reed (eds).Cambridge University Press 1999. 
Chapman, C. A. and Lambert J. E. 2000. Habitat alteration and the conservation of African primates: Case study of Kibale National Park, Uganda. American-Journal-ofPrimatology. March, 2000; 50 (3): 169-185.

Chardonnet, B. 1983. Gestion de la Faune sauvage africaine; proposition d'un projet en Guinée-Bissau. Thèse pour le doctorat vétérinaire à la Faculté de médecine de Créteil. $143 p$.

Chardonnet, P. 1995. Faune sauvage africaine. La ressource oubliée. Fondation Internationale pour la Sauvegarde de la Faune - CIRAD-EMVT. 2 Tomes- Luxembourg.

Chardonnet, P., Fritz, H., Zorzi, N. and Féron, E. 1995. Current importance of traditional hunting and major contrasts in wild meat consumption in sub-Sahara Africa. In Bissonette \& Krausman (eds.). Integrating people and wildlife for a sustainable future. The Wildlife Society Maryland.

Chiarello, A.G. 2000. Density and population size of mammals in remnants of Brazilian Atlantic Forest. Conservation Biology, Pages 1649-1657. Vol.14, No.6, December 2000.

Chiarello, A.G., and de Melo, F.R. 2001. Primate population densities and sizes in Atlantic forest remnants of northern Espirito Santo, Brazil. International. J. Primatol. 22(3):379-396.

Colding, J. and Folke C. 1997. The relations among threatened species, their protection and taboos. Conservation Ecology [online]1(1): 6. Available from the Internet. URL: http://www.consecol.org/vol1/iss1/art6

Colding J. and Folke C. 2001. Social Taboos: "Invisible" System of local resource management and biological conservation. Ecological applications 11 (2), 584-600.

Conroy, M. J. 1996. Abundance indices. In Wilson, D.E., Cole, F.R., Nicholson, J.D., Rudran R. and Foster M.S., eds. Measuring and monitoring biological diversity: standard methods for mammals. Smithsonian Institution Press, Washington D.C.

Conservation Biology, Vol.14, Nº1, 2000 
Conselho do Estado 1991. Decreto-Lei no 4-A/91 : Lei Florestal. Boletim oficial No 43 de 29 de Outubro 1991. Suplemento. Republica da Guiné-Bissau

Conselho dos comissários de Estado 1980. Decreto-Lei no 21/80 : Regulamento da caca. Boletim oficial No 20 de 17 de Maio 1980. Suplemento. Republica da GuinéBissau.

Conservation International 2001. Upper Guinean Forest Ecosystem of the Guinean Forest Biodiversity Hotspot West Africa. Critical Ecosystem Partnership fund Ecosystem Profile. Revised version.

Cowlishaw, G. 1999. Predicting the Pattern of Decline of African Primate Diversity: an Extinction Debt from Historical Deforestation. Conservation Biology 13 (5), 1183-1193.

Cowlishaw G. and Dunbar R. 2000. Primate conservation Biology. The University of Chicago Press. Chicago and London.

Crawford Cabral, J. 1990. Relatório da deslocação do investigador principal do IICT à Guiné-Bissau. Centro de Zoologia do IICT. 388pp. Lisboa.

Crawford Cabral, J. and Veríssimo, L.M. 1997. Relatório específico sobre a fauna de mamíferos. 1a missão zoológica - Projecto "Estudo do Parque natural da Cufada (Guiné-Bissau)". IICT- Centro de Zoologia.

Cristino, J. J. de SA E. Melo. 1958. Statut des ongulés en Guinée Portugaise. Mammalia, 22: 387-389.

Cullen, L. Jr., Bodmer, E.R. and Valladares-Padua, C. 2001. Ecological consequences of hunting in Atlantic forest patches, Sao Paulo, Brazil. Oryx, 35(2), 137-144.

Cuq, F. (ed.) 2001. Un système d'information géographique pour l'aide à la gestion intégrée de l'archipel des Bijagós (Guinée-Bissau) - Notices de la carte, constitution et exploitation du SIG. Géosystèmes, Brest, France. 88p. 56ill. 
Da Silva, A. S. 1997. Identificação e delimitação cartográfica dos grandes maciços florestais de Cantanhez. Acção para o Desenvolvimento, Bissau.

Da Silva, A. O. and Cardoso, L. 2001. Um tipo de área protegida para Cantanhez. GPC/UICN. Bissau

Da Silva Naga, H. and Sera, B. 2001. Identificação, delimitação e cartografia dos corredores e zonas de pastagem da fauna grossa. Relatório preliminar. UICN/GPC/AD. Bissau.

Defler, T.R. and Pintor, D. 1985. Censusing primates by transects in a forest of known primate density. International Journal of primatology, 6, 243-259

De Thoisy, B. 2000. Line-transects: sampling application to a French Guyana rainforest. Mammalia 64: 101-112.

D'Huart, J.-P. 1993. Forest Hog, Hylochoerus meinertzhageni. In: William R. L. Oliver (ed.). Status survey and Conservation Action Plan - Pigs, Peccaries and Hippos. IUCN/SSC-PPSG.

Dinesen, L., Lehmberg, T., Rahner, M.C. and Fjeldsa J. 2001. Conservation priorities for the forests of the Udzungwa Mountains, Tanzania, based on primates, duikers and birds. Biological Conservation 99, 223-236.

Di Silvestre, I., Novelli, O. and Bogliani, G. 2000. Feeding habits of the spotted hyena in the Niokolo Koba National Park, Senegal. East African Wild Life Society, Afr. J. Ecol., $38,102-107$

Djombera, K. 1999. Programme d'évaluation des Ressources Forestières Mondiales en Guinée-Bissau. Programme de partenariat CE - FAO (1998-2002).

Douglas-Hamilton, I. 1988. African Elephant Population Study. EEC/WWF/Global Environment Monitoring Centre. Nairobi, Kenya 
East, R. (compiler). 1999. African Antelope Database 1998. IUCN/SSC Antelope Specialist Group. Gland, Switzerland and Cambridge, UK. IUCN.

Eltringham, S. K. 1993. The Common Hippopotamus Hippopotamus amphibius. In: Status survey and Conservation Action Plan - Pigs, Peccaries and Hippos. William R. L. Oliver (ed.). IUCN/SSC-PPSG

Emerton, L. 1998. Why Wildlife Conservation has not economically benefited Communities in Africa. Manchester, Institute of Development Policy and Management, University of Manchester, England.

Entwistle, A.C. and Dunstone, N. 2000. Future priorities for mammal conservation. In Entwistle A.C. \& N. Dunstone 2000 (eds.): Priorities for the conservation of Mammalian Diversity. Has the Panda had its day? Cambridge University press.

Entwistle A.C. \& P.J. Stephenson 2000. Small mammals and the conservation agenda. In Entwistle A. \& N. Dunstone 2000 (eds.): Priorities for the conservation of Mammalian Diversity. Has the Panda had its day? Cambridge University press.

Estes, R.D. 1991. The Behaviour Guide to African Mammals. University of California Press.

Eves, H.E. and Bakarr, M.I. 2001. Impacts of Bushmeat Hunting on Wildlife Populations in West Africa's Upper Guinea forest ecosystem. In Bakarr M.I. et al (eds.) Hunting and Bushmeat Utilisation in the African Rain Forest - Perspectives toward a Blueprint for conservation Action. Cl. Washington D.C.

Eves, H.E. and Ruggiero G. 2002. Antelopes in Africa: bushmeat, game meat and wild meat - a question of sustainability. In: Sue Mainka and Mandar Trived (eds). Links between Biodiversity Conservation, Livelihoods and Food Security. The sustainable use of wild species for meat. IUCN/SSC Occasional paper No 24. Gland, Switzerland and Cambridge, UK. 135pp.

Fa E. J., Juste, J., Perez Del Val, J. and Castroviviejo, J. 1995. Impact of market hunting on mammal species in Equatorial Guinea. Conservation Biology 9: 1107-1115. 
Fa, E.J., Yuste, J.E.G. and Castelo, R. 2000. Bushmeat Market on Bioko Island as a measure of hunting pressure. Conservation Biology, 14 (6): 1602-1613.

Feistner, A. T. and Mallison, J. J. C. 2000. A recipe for species conservation: multidisciplinary ingredients. In Entwistle A.C. \& N. Dunstone 2000 (eds.): Priorities for the conservation of Mammalian Diversity. Has the Panda had its day? Cambridge University press.

Ferreira, J. D.A. 1973. Bichos da Guiné. Caça, fauna, natureza. 227pp., Lisboa.

Ferreira, J. A. 1948. Fauna da reserva de Cufada. Boletim Cultural da Guiné Portuguesa, Vol. III, No 11. Junta de Investigações cientificas do Ultramar. Lisboa

Fimbel, C. 1994a. Ecological Correlates of species success in modified habitats may be disturbance- and site-specific: the primates of Tiwai Island. Conservation Biology, Volume 8, No1. $106-113$.

Fimbel, C. 1994b. The relative use of abandoned farm clearings and old forest habitats by primates and a forest antelope at Tiwai, Sierra Leone, West Africa. Biological Conservation 70(3) 1994: 277-286.

Fischer, F. and Linsenmair, K. E. 2001. Decreases in ungulate population densities. Examples from the Comoé National Park, Ivory Coast. Biological Conservation 101 (2001) 131-135

Fitzgibbon, C. D, Mogaka, H. and Fanshawe, J.H. 1995. Subsistence hunting in the Arabuko-Sokoke forest, Kenya, and its effects on mammal populations. Conservation Biology, Vol.9 No 5, 1995.

Flick, U. 1995. Stationen des Qualitativen Forschungsprozesses. In: Flick, U., von Kardorff, E., Keupp, H., von Rosenstiel, L. und Wolff, S. (Hrsg.). Handbuch qualitative Sozialforschung. Grundlagen, Konzepte, Methoden und Anwendungen. München:

Psychologie Verlags-Union. 2. Auflage 1995. S. 148-173. 
Fortes, O., Pires, A.J. and Bellini, C. 1998. Green turtle, Chelonia mydas, on the island of Poilão, Bolama-Bijagós Archipelago, Guinea-Bissau, West Africa. Marine Turtle Newsletter, 80, 8-10.

Fotso, R.C. and Ngnegueu, P.R.1997. Commercial hunting and its consequences on the dynamic of duiker population. Proceedings of the Limbe conference: African rainforests and conservation of biodiversity. Cameroon. Online at: http://www.earthwatch.org/europe/limbe/upcom.html

Frade, F. 1949. Algumas novidades para a fauna da Guiné Portuguesa (Aves e Mamíferos). Relatório da missão zoológica e contribuições para o conhecimento da fauna da Guiné Portuguesa. Anais da junta de investigações coloniais XXII: 167-207. Lisboa.

Frade, F. 1949. Considerações acerca da distribuição da fauna na Guiné Portuguesa. Anais da junta de investigações coloniais XIII:11-16. Lisboa.

Frade, F. 1950. Notas de zoogeografia e de história das explorações faunísticas da Guiné Portuguesa. Ministério das colónias, Lisboa. 32p.

Frade F., Bacelar, A. and Gonçalves, B. 1946. Trabalho da missão zoológica da Guiné I-V. Relatório da missão zoológica e contribuições para o conhecimento da fauna da Guiné Portuguesa. Anais da junta de investigações coloniais I:261-415.

Frade, F. and Silva, J.A. 1980. Mamíferos da Guiné (colecção do Centro de Zoologia). Boletim Cultural da Guiné Portuguesa, Vol. 9, No1+2). Junta de Investigações cientificas do Ultramar. Lisboa

Freese, C. H., Heltne, P. G., Castro, N. and Whitesides, J. 1982. Patterns and determinants of monkey densities in Peru and Bolivia, with notes on distributions. International Journal of Primatology 3:53-90.

Friebertshäuser, B. and Prengel A. (Hrsg.) 1997. Handbuch Qualitative Forschungsmethoden in der Erziehungswissenschaft.. Juventa Verlag, Weinheim zu München. 
Friebertshäuser, B. 1997. Interviewtechniken - ein Überblick. In : Friebertshäuser Barbara, Annelore Prengel (Hrsg.) 1997. Handbuch Qualitative Forschungsmethoden in der Erziehungswissenschaft.. Juventa Verlag, Weinheim zu München.

Friedrichs, J. 1990. Methoden empirischer Sozialforschung, Westdeutscher Verlag, Opladen.

Galat, G. and Galat-Luong, A. 1977. Démographie et régime alimentaire d'une troupe de Cercopithecus aethiops sabaeus en habitat marginal au Nord Sénégal. Revue d'Ecologie (Terre et Vie), 31: 557-577.

Garcia, G. and Goodman, S.M. 2003. Hunting of protected animals in the Parc National d'Ankarafantsika, north-western Madagascar. Oryx, 37(1), 115-118.

Gibson, C.C. 1999. Politicians and Poachers. The Political Economy of Wildlife Policy in Africa. Cambridge University Press. Cambridge.

Gippoliti, S. and Dell'omo, G. 1995. Status and conservation of Western Chimpanzee Pan Troglodytes verus in Guinea Bissau. African Primates 1, 3-5.

Gippoliti, S. and Dell'omo, G. 1996. Primates of the Cantanhez Forest and the Cacine Basin, Guinea Bissau. Oryx, 30(1), 74-80

Gippoliti, S., Embalo, D.S. and Souza, C. 2003. Guinea-Bissau. In: Kormos R., Boesch C., Bakarr M. I. and Butynski T. M. (eds.). West African chimpanzees: status survey and conservation action plan. IUCN/SSC, Gland.

Glaser, M. and da Silva Oliveira, R. 2004. Prospects for the co-management of mangrove ecosystems on the North Brazilian coast: Whose rights, whose duties and whose priorities? Natural Resources Forum 28 (3), 224-233.

Grigione, M.M. 1996. Observations on the status and distribution of the West African manatee in Cameroon. African Journal of Ecology, 1996, vol.34, No2, 189-195. 
Grieser Johns, A. and Grieser Johns, B. (1995) Tropical forest primates and logging: long-term co-existence? Oryx 29, 205-211

Grubb, P. 1993. Chapter 4: The Afrotropical Suids: Potamochoerus, Hylochoerus and Phacochoerus - Taxonomy and Description. In : William R. L. Oliver (ed.): Status survey and Conservation Action Plan - Pigs, Peccaries and Hippos. IUCN/SSC-PPSG

Hackel, J. D. 1999. Community Conservation and the Future of Africa's Wildlife. Conservation Biology, 13 (4), 726-734.

Hall, J. S., White, L.J.T., Inogwabini B.-I., Omari I., Morland H. S., Williamson E. A., Saltonstall K., Walsh P., Sikubwabo C., Bonny D., Kiswele K. P., Vedder A. and Freeman K. 1998. Survey of Grauer's Gorillas (Gorilla gorilla graueri) and Eastern Chimpanzees (Pan Troglodytes schweinfurthi) in the Kahuzi-Biega National Park Lowland Sector and Adjacent Forest in Eastern Democratic Republic of Congo. International Journal of Primatology, Vol.19, No.2, 1998.

Hakizumwami, E. 2000. Community Wildlife Management in Central Africa: A Regional Review Discussion Paper 10, IIED. University of Manchester. 61pp.

Haltenorth, T.H. and Diller, H. 1985. Mammifères d'Afrique et de Madagascar. Delachaux et Niestlé, Neuchâtel.

Ham, R. 1998. Nationwide Chimpanzee Census and Large Mammal Survey: Republic of Guinea. Brussels, Belgium: European Union. 50 pp.

Hart, T.B. and Hart, J.A. 1986. The ecological basis for hunter-gatherer subsistence in the African rain forest: the Mbuti of eastern Zaire. Human Ecology, 14: 29-55.

Hearn, G.W. and Morra, W.A. 2001. The approaching extinction of monkeys and duikers on Bioko Island, Equatorial Guinea, Africa. Arcadia University, Bioko Biodiversity Protection Program, Publication No7, Available online at http://www.bioko. org/2001ApproachingExtinctions5.pdf 
Howe, H.F. 1984. Implications of seed dispersal by animals for tropical reserve management. Biological conservation, 30:261-281.

Hulme, D. 1997. Community conservation research in Africa : principles and comparative practice. Working papers no $1 \mathrm{~A}$ framework for the study of community conservation in Africa. IIED, University of Manchester.

IIED 1994. Whose Eden? An Overview of Community Approaches to Wildlife Management. International Institute for Environment and Development (IIED). London, UK.

Infield, M. 2001. Cultural values: a forgotten Strategy for Building Community support for protected areas in Africa. Conservation Biology, 15(39 800-802).

IUCN 1992a. Protected Areas of the World: A review of national systems. Volume 3: Afro-tropical. Prepared by the World Conservation Monitoring Centre (WCMC). IUCN, Gland, Switzerland and Cambridge, UK

IIUCN 1992b. The conservation atlas of tropical forests. Africa. Sayer J., Collins N.M., and Harcourt C.S. (eds) . The Macmillan Press Ltd, London.

IUCN 2000. 2000 IUCN Red List of Threatened Species. IUCN Species Survival Commission, Gland, Switzerland.

IUCN 2002. 2002 IUCN Red List of Threatened Species. IUCN Species Survival Commission, Gland, Switzerland.

IUCN 2003. 2003 IUCN Red List of Threatened Species. IUCN Species Survival Commission, Gland, Switzerland.

Jones, B. T. B. 1999. Policy lessons for the evolution of a community-based approach to wildlife management, Kunene Region, Namibia. Journal of International Development 11:295-304. 
Kangwana, K. and Mako, R. O. 1998. The impact of community conservation initiatives around Tarangire National Park, Tanzania (1992-1997). Community conservation in Africa: principles and comparative practice. Discussion paper 16. Institute for Development Policy, Manchester University, Manchester, United Kingdom.

Karibuhoye, C. 2000. Biomonitoring in the support zone of Korup National Project, SW Cameroon. Unpublished Report on a three weeks stay in the Biomonitoring Unit/Nguti Centre for nature conservation - University of Göttingen, Germany.

Karibuhoye, C. 2001. Monitoring of primates and hornbills in tropical forests - Results and experience with "Distance sampling" in the forest reserves of South-eastern Côte d'Ivoire - M. sc. Thesis, Centre for nature conservation / University of Göttingen

Karibuhoye, C. 2003. Naturschutz ist kein Luxus - Über den Zusammenhang von Armut und Naturschutz in Guinea-Bissau. Querbrief 2/2003. Weltfriedensdienst e.V. Berlin.

Kingdon, J. 1997. The Kingdon Field Guide to African Mammals, Academic Press.

Kiss, A. 1990. Living with wildlife - Wildlife Resource management with local participation in Africa. World Bank Technical paper $N^{\circ} 130$. Africa Technical department series.

Kleymeyer, C. D. 1994. Cultural Traditions and Community Based Conservation. In : Western, D. and Wright ,R.M. (eds.): Natural Connection: Perspectives in Community Based Conservation, pp. 323-346. Washington DC: Island Press.

Kormos, R., Boesch, C., Bakarr, M. I. and Butynski, T. M. (eds.). West African chimpanzees: status survey and conservation action plan. IUCN/SSC Primate Specialist Group, Gland.

Koster, S.H. and Hart, J.A. 1988. Methods for estimating ungulate populations in tropical forests. African Journal of Ecology, 26, 117-126.

Kothari, A. 2001. Time to move Out of Africa! - A Response to Adams and Hulme.

Oryx, 35, 204-205. 
Kremen, C., Merenlender, A.M. and Murphy, D. D. 1994. Ecological Monitoring: a vital need for integrated conservation and development programs in the tropics. Conservation Biology, vol. 8, No. 2, June 1994

Kromrey, H. 1998. Empirische Sozialforschung. 8. Auflage, Leske \& Budrich, Opladen

Laake, J.L., Buckland, S.J., Anderson, D.R. and Burnham, K.P. 1993. DISTANCE User's Guide. Colorado Co-operative Fish and Wildlife Research Unit, Colorado State University, Fort Collins, U.S.A.

Lahm, S., 1993, Utilization of forest resources and local variation of wildlife populations in northeastern Gabon. In: Hladik, C.M., Hladik, A., Linares, O.F., Pagezy, H., Semple, A. and Hadley, M. (eds.). Tropical Forests, People and Food, Man and the Biosphere Series, volume 13, Paris, UNESCO and Parthenon Publishing Group.

Lahm, S. 1996. Gabon's village hunting: assessing its impact. African Primates 2(1), 2324.

Laidlaw, R.K. 2000. Effects of habitat disturbance and protected areas on mammals of Peninsular Malyasia. Conservation Biology, 14: 1639-1648.

Lannoy, L., Gaidet, N., Chardonnet, P. and Fanguinoveny, M. 2003. Abundance estimates of duikers through direct counts in a rain forest, Gabon. African Journal of Ecology, 41, 108-110.

Larivière, J. and Sylla, S. I. 1998. Les aires du patrimoine communautaire. Communication au Symposium du 50 e anniversaire de I'UICN Fontainebleau 3 - 5 novembre 1998.

Lewis, D.M., Mwenya, A. and Kaweche, G. B. 1990. African solutions to wildlife problems in Africa: Insights from a community-based project in Zambia. Unasylva No 161, Vol. 41 - 1990. FAO- Rom. 
Lewis, D. and Phiri, A. 1998. "Wildlife snaring - an indicator of community response to a community-based conservation project." Oryx 32(2): 111-121.

Limoges, B. and Robillard, M.J. 1991. Proposition d'un Plan d'aménagement de la Réserve de la Biosphère de l'Archipel des Bijagós, vol.I,II,III. DGFC-MDRA/CECI/UICN, Bissau.

Limoges, B. and Robillard, M.J. 1990. Proposition d'un réseau d'aires protégées en Guinée-Bissau (zone continentale). DGFC-MDRA/CECI/UICN, Bissau.

Limoges, B. 1989. Résultats de l'inventaire faunique au niveau national et proposition de modifications à la loi sur la chasse. DGFC-MDRA/CECI/UICN, Bissau.

Little, P. 1994. The link between local participation and improved conservation: a review of issues and experiences. Pages 347372 in : Western D. and Wright R. (editors). Natural connections: perspectives in community-based conservation. Island Press, Washington, D.C

MacDonald, K.I. 2003. Community-Based Conservation: A Reflection on History. IUCN/CEESP, Gland. Online at:

http://www.iucn.org/themes/ceesp/Publications/TILCEPA/CCA-KMacDonald.pdf

Mace, G. M. and Balmford, A. 2000. Patterns and processes in contemporary mammalian extinction. In : Entwistle, A. and Dunstone, N. 2000 (eds.): Priorities for the conservation of Mammalian Diversity. Has the Panda had its day? Cambridge University press.

Mackanga Missandzou, A. 1997. Utilisation des inventaires biologiques pour l'aménagement de la mosaïque forêt-savanne dans la Réserve de faune de la Lopé (Gabon). Projet Ecofac-Gabon. Earthwatch Institute.

MacKinnon, J.C., MacKinnon, C., Child, G. and Thorsell, J. 1986. Managing protected areas in the Tropics. Gland, Switzerland: IUCN.

MAFP/DGFC 2004. Projecto - Lei da caça. Bissau, República da Guiné Bissau 
MAFCP/DGFC 2004. Projecto do Regulamento da Caça. Bissau, República da Guiné Bissau

MAFP/DGFC - Federação KAFO 2003. Acordo preliminar para a gestão da floresta de Djalicunda (APGFC). Bissau, 10 de Julho 2003.

Maillard, D., Calenge, C., Jacobs, T., Gaillard, J. M. and Merlot, L. 2001. The Kilometric Index as a monitoring tool for populations of large terrestrial animals: a feasibility test in Zakouma National Park, Chad. African Journal of Ecology, Volume 39, Issue 3, Page 306.

Mainka, S.A. and Trivedi, M. (eds.) 2002. Links between Biodiversity Conservation, Livelihoods and Food Security: The sustainable use of wild species for meat. IUCN, Gland, Switzerland and Cambridge, UK. 135pp.

Malaisse, F. 1996. Caractérisation phytogéographique et écologique des forêts de Cantanhez (Région de Tombali, Guinée-Bissau). Iniciativa Cantanhez/AD, Cadernos do Meio Ambiente.

Mangold, W. 1973. Gruppendiskussionen. S. 228-259 in: König, R. (Hg.), Handbuch der empirischen Sozialforschung, Stuttgart (Bd. 2).

Marchesi, P., Marchesi, N., Fruth, B., and Boesch, C. 1995. Census and distribution of chimpanzees in Côte-d'Ivoire. Primates, 36(4): 591-607.

Marks, S. A. 1994. Local hunters and wildlife surveys: a design to enhance participation. African Journal of Ecology, 32 (3), 233-254.

Marks, S. A. 1996. Local hunters and wildlife surveys: an assessment and comparison of counts for 1989, 1990 and 1993. African Journal of Ecology, 34 (3), 237-257.

Maretti, C. C. 2003. The Bijagós islands - culture, resistance and conservation. Policy matters 12, September 2003. IUCN/CEESP.

Martin, C. 1989. Die Regenwälder Westafrikas - Ökologie, Bedrohung und Schutz. Birkhäuser Verlag Basel. 
McGraw, W. S. 1998. Three monkeys nearing extinction in the forest reserves of eastern Côte d'Ivoire, Oryx 32: 233-236. Cambridge University Press.

Mc Neely, J. A. 2000. Practical approaches for including mammals in biodiversity conservation. In: Entwistle, A. and Dunstone, N. 2000 (eds.): Priorities for the conservation of Mammalian Diversity. Has the Panda had its day? Cambridge University press.

MDR/DGFC 1991. Plan de conservation de l'éléphant en Guinée-Bissau. Ministério do Desenvolvimento Rural. Unpublished report. Bissau 37 pp.

MDRA/DGFC 1988. Lei quadro das áreas protegidas. Bissau, Guiné Bissau.

MDRA/DGFC 1988. Guia de identificação dos animais da Guiné Bissau. MDRA/DGFC, Bissau, Guiné Bissau

MDRA/DGFC 1988. Plano director florestal nacional. Bissau, Guiné Bissau

Mendes Fernandes, R. (coordonnateur) 1991. Etude socio-économique des îles Bijagós. INEP and PNUD. Bissau 1991.

Metcalfe, S. 1994. The Zimbabwe Communal Areas Management Programme for Indigenous Resources (CAMPFIRE). In: D.Western and R.M. Wright, eds. Natural Connection: Perspectives in Community Based Conservation, pp. 161-191. Washington DC: Island Press.

Meuser, M., Nagel, U. 1991. Experteninterviews - vielfach erprobt, wenig bedacht. Ein Beitrag zur qualitativen Methodendiskussion, in: Garz D. und Kraimer K. (Hrsg.), Qualitativ-empirische Sozialforschung. Konzepte, Methoden, Analysen. Opladen, S. $441-471$.

Mitani, J. C., Struhsaker, T. Lwanga, J. 2000. Primate community dynamics in old growth forest over 23.5 years at Ngogo, Kibale National Park, Uganda: implications for conservation and census methods. Intl. J. Primatology 21(2): 269-286. 
Monard, A. 1939. Résultats de la Mission scientifique du Dr. Monard en Guinée Portugaise 1937-1938. Separata dos Arquivos do Museu Bocage, T. X, Lisboa.

Montenegro, T. 1995. As enxadas do rei - Os animais no imaginário guineense. Kusimont Editora, Bissau.

MTAA / ICN 1997. Estudo do impacto socio-económico da criação do Parque Natural das Lagoas de Cufada sobre as populações residentes. INEP, Bissau. 38 p. + Anexos.

Muchaal, P. K. and Ngandjui, G. 1999. Impact of village hunting on wildlife populations in the western Dja Reserve, Cameroon. Conservation Biology 13(2), April, 1999: 385396.

Mühlenberg, M., Slowik, J., Wöll, H. and Waitkuwait, E. 1995. Strategies for restoration of tropical forests that incorporate wildlife protection; an example from the Ivory Coast, West Africa. Pp. 413-417, in: Integrating people and wildlife for a sustainable future (Bissonette, J. A. \& P. R. Krausmann eds.). The Wildlife Society, Bethesda, Maryland.

Mühlenberg, M., Slowik, J. and Waitkuwait, E. 1993. Réhabilitation des forêts classées dans l'Est de la Côte d'Ivoire - Rapport sur les mesures d'accompagnement écologiques dans la phase de projet 1991-1993. GTZ.

Mühlenberg, M. and Slowik, J. 1996. Bewertung der Ergebnisse im Ökologie-Sektor in Hinblick auf das Gesamtprojekt „Waldrehabilitierung“ - Programme d'Aménagement des forêts classées de l'Est et de protection de la nature/ Côte d'Ivoire. GTZ, Allemagne.

Murphree, M.W. 1994. The role of institutions in community - based conservation. In: Natural Connections: Perspectives in Community-based Conservation. Western D. and Wright R. M., eds. Washington DC, Island Press: 403-427.

Murphree, M.W.1996. The evolution of Zimbabwe's community-based wildlife use and management programme. In: Community-based Conservation in Tanzania. N. LeaderWilliams, J.K. Kayera and G.L. Overton (eds.). IUCN SSC Occasional paper No15. 
Murphree, M.W. 1998. Synergizing Conservation Incentives: From Local Global Conflict to Compatibility. Community Conservation in Africa: Principles and Comparative Practice, Working Paper No. 7, IDPM, Manchester, UK

Murphree, M. W. 2000. "The lesson from Mahenye", in: J. Hutton and B. Dickson (eds), Endangered Species, Threatened Convention: The Past, Present and Future of CITES, Earthscan, London, pp. 181-196.

Murphree, M.W. 2002. „Protected Areas and the Commons". Common Property Resource Digest, No. 60, March, pp. 1 - 3

Muruthi, P., Price, M.S, Soorae, P., Moss, C. and Lanjouw, A. 2000. Conservation of large mammals in Africa. What lessons and challenges for the future? In Entwistle, A.C. and Dunstone, N. 2000 (eds.): Priorities for the conservation of Mammalian Diversity. Has the Panda had its day? Cambridge University press.

Myers, N. 1988. Threatened Biotas: "hot spots" in tropical forests. Environmentalist, 8, 187-208.

Naga Silva, H. and Serra, A. 2001. Identificação, delimitação e cartografia dos corredores e zonas de pastagem da fauna grossa. Relatório preliminar. UICN/GP/AD. Bissau.

National Research Council 1981. Techniques of study of primate population ecology. National Academic Press, Washington D.C.

Navaza, R. and Burnham, O. 1998. Senegal manatees close to extinction. Sirenews 29: 7-8.

Nel, J.A.J. and Somers, M. 1998. The Status of otters in Africa: An assessment. Proceedings of the VII International Otter Symposium, 13-19 March 1998. Trebon, Czech Republic. 
Nelson, J. and Gami, N. 2003. Enhancing equity in the relationship between protected areas and indigenous and local communities in Central Africa, in the context of global change. TILCEPA report. Online at:

http://www.iucn.org/themes/ceesp/Wkg_grp/TILCEPA/community.htm

Newmark, W.D. and Hough, J.L. 2000. Conserving wildlife in Africa: integrated conservation and development projects and beyond. Bioscience 50, $585-592$

Noss, A.J. 1999. Censusing rainforest game species with communal net hunts. African Journal of Ecology 37(1), March, 1-11.

Noss, R. F. 1990. Indicators for monitoring biodiversity: a hierarchical approach.

Conservation Biology 4(4): 355-364.

Ntiamoa-Baidu, Y. 1987. West African wildlife: a resource in jeopardy. Unasylva, 39: 2735. FAO, Rom.

Oates, J.F. 1988. The distribution of Cercopithecus monkeys in West African forests. In: Gautier-Hion A., Bourlière F., Gautier, J. and Kingdon J. (Eds). A Primate Radiation: Evolutionary Biology of the African Guenons. Cambridge University Press, New York: pp 79-103.

Oates, J.F. 1994. The natural history of African Colobines. Pp. 75-128 in Colobine Monkeys: Their Ecology, Behaviour, and Evolution, A.G. Davies and J.F. Oates, Eds. Cambridge: Cambridge University Press.

Oates J.F. 1995: The danger of conservation by rural development - a case study from the forest of Nigeria. Oryx, Vol.29, No 2, 115 - 122.

Oates J.F.1996a. Habitat alteration, hunting and conservation of folivorous primates in African forests. Australian Journal of Ecology, 21:1-9

Oates, J.F., 1996b. African Primates: Status Survey \& Action Plan (Revised), IUCN, Gland, Switzerland 
Oates, J.F. 1997. African Primates Conservation: General needs and Specific Priorities. In: K. Benirschke (ed.) Primates- The road to self-sustaining populations. Springer Verlag.

Oates, J.F. 1999. Myth and reality in the rain forest. How conservation strategies are failing in West Africa. Berkeley, University of California Press.

Oates, J.F., Abedi-Lartey, M., McGraw, S.W., Struhsaker T.T., and. Whitesides G.H. 2000. Extinction of a West African Red Colobus Monkey. Conservation Biology. Volume 14, Issue 5, Page 1526.

Oates, J.F., Whitesides, G.H., Davies, A.G., Waterman, P.G., Green, S.M., Dasilva, G.L. and Mole, S. 1990. Determinants of variation in tropical forest primate biomass: New evidence from West Africa. Ecology 71: 328-343.

Odendaal, P.B., Cameron, M.J. and Priday, A.J. 1980. Track counts as a means of estimating populations densities of bushbuck. South African Forestry Journal No 113.

Olsen, K.B., Ekwoge, H., Ongie, R.M., Acworth, J., O'kah, E.M. and Takoe, C. 2001. A community wildlife management model from mount Cameroon. DFID/RDFN. Network paper No 5.

Owen-Smith, G. 1993. Wildlife conservation in Africa. Pages 57-70 in: Lewis D. and Carter N., editors. Voices from Africa: local perspectives on conservation. World Wildlife Fund, Baltimore.

Paris, B. 1993: Liste des espèces animales (moins les oiseaux) inventoriés dans l'Archipel des Bijagós. Planificação Costeira, Bubaque 1993. Unpublished report.

PASP 2001. Tabanca de Munhini, um exemplo de gestão da floresta comunitária. A Terra é do Povo- GFC, Proteger florestas para servir o bem-estar das populações. Bissau.

Pavy, J.M. 1993. Bafing Faunal Reserve. Biodiversity and human resource: Survey and recommendations. Unpublished Report, Cheverly, Maryland. 
Payne, J. 1995. Links between vertebrates and the conservation of Southeast Asian rainforest. Pp. 54-65 in Ecology, Conservation, and Management of Southeast Asian rainforests (Primack, R.B. \& Lovejoy, T.E., eds.). Yale University Press, New Haven, London.

Peres, C.A. 2001. Synergistic effects of subsistence hunting and habitat fragmentation on Amazonian forest vertebrates. Conservation Biology, Vol. 15 (6), 1490-1505.

Peres Carlos, A. 2000. Effect of subsistence hunting on vertebrate community structure in Amazonian forests. Conservation Biology. Feb., 2000; 14 (1): 240-253.

Perrin, W. 2001. Conservation status of the West African manatee. Sirenews 36.

Pimbert, M.P. and Pretty, J.N. 1997. Diversity and sustainability in community-based conservation. UNESCO-IIPA. Paper for the UNESCO-IIPA regional workshop on community-based conservation. February 9-12, India.

Plumptre, A.J. 2000. Monitoring mammal populations with line transect techniques in African forests. Journal of Applied Ecology, 37 (2): 356-368.

Plumptre, A.J. and Reynolds, V. 1994. The effect of selective logging on the primate populations in the Budongo Forest Reserve, Uganda. Journal of Applied Ecology 31: 631-641.

Powell, J.A. 1996. The distribution and biology of the West African manatee (Trichechus senegalensis Link, 1795). United Nations Environment Programme, Regional Seas Programme, Oceans and Coastal Areas, Nairobi, Kenya. 68 pp.

Prangley, M. and Barnett, A.. 1994. A survey of primates in the Kounounkan Forest, Guinea, West Africa. Primate Eye 53: 14-17.

PRCM 2004. Document de programme 1ère phase 2004 - 2008. WWF / IUCN / Wetlands / FIBA 2004. 
Rabinowitz, A. 1993. Wildlife Research and Conservation Training Manual. Wildlife conservation society.

RADI - Centro Camponês de Djalicunda 2001. Relatório técnico sobre a delimitação das florestas de 17 tabancas da Federação KAFO em GFC. Djalicunda

The Ramsar Convention on Wetlands 2002. Principles and guidelines for incorporating wetland issues into Integrated Coastal Zone Management (ICZM). 8th Meeting of the Conference of the Contracting Parties, Resolution VIII.4. Valencia, Spain, 18-26 November 2002

Redford, K.H.1992. The empty forest. BioScience1992, Vol.42, No 6 :412-422

Redford, K.H., Godshalk R. and Asher K. 1995. What about the wild animals? Wild animal species in community forestry in the tropics. FAO Community Forestry Note No 13. Rom.

Redford, K.H. and Sanderson, S.E. 2000. Extracting Humans from Nature. Conservation Biology 14:1362-1364.

Reiner, F. and Simões, P. 1999. Mamíferos selvagens da Guiné-Bissau. Projecto Delfim - Centro Português de Estudos de Mamíferos marinhos, Lisboa.

Renard, Y. 1997. 'Collaborative management for conservation.' In: Borrini-Feyerabend G. (ed.) : Beyond fences: seeking social sustainability in conservation. Gland, IUCN.

Robertson, S. A. and Luke, W. R. Q. 1993. Kenya Coastal Forests: The Report of the NMK/WWF Coast Forest Survey. WWF Project 3256, Coast Forest Status, Conservation and Management. Kenya: WWF.

Robertson, P. 2001. Guinea-Bissau. In: Important bird areas in Africa and associated islands. Priority sites for conservation. Fishpool, L. D.C. and Evans, M. I. (eds.). Birdlife Conservation Series No 11. 
Robillard, M. J. 1989. Utilisation et perception de la faune et du milieu naturel en Guinée-Bissau. MDRA/DGFC, Bissau, 106pp.

Robillard, M. J. and Limoges, B. 1994. L'exploitation durable des ressources fauniques en Guinée-Bissau. Repères méthodologiques. Etudes techniques, série "Agriculture et environnement rural" No5. CECl, Québec.

Robinson, J. G. 1993. "The limits to caring": sustainable living and the loss of biological diversity. Conservation Biology 7:20-28.

Robinson, J.G. and Bennett, E. L. 2000 (eds.) Hunting for sustainability in tropical forests. Columbia University Press, New York. 582pp.

Robinson, J.G. and Redford, K.H. 1986. Intrinsic rate of natural increase in Neotropical forest mammals: relationship to phylogeny and diet. Oecologia 68: 516-520.

Robinson, J.G. and Redford, K.H. 1994. Measuring the sustainability of hunting in tropical forests. Oryx 28. 249-256.

Roe, D. and Jack, M.2001. Stories from Eden - Case studies of community-based wildlife management. Evaluating Eden Series No 9. IIED 2001.

Roe, D., Mayers, J., Grieg-Gran, M., Kothari, A., Fabricius, C., Hughes, R. 2000. Evaluating Eden: Exploring the myths and realities of community-based wildlife management. Evaluating Eden Series no 8. IIED. September 2000.

Rosenbaum, B., O'Brien, T. G., Kinnaird, M. and Supriatna, J. 1998. Population densities of Sulawesi crested black macaques (Macaca nigra) on Bacan and Sulawesi, Indonesia: Effects of habitat disturbance and hunting. American Journal of Primatology, 44:89-106.

Rosenberg, D.K. 1995. Towards a definition of biological corridor. In: Bissonette \& Krausman (eds.). Integrating people and wildlife for a sustainable future. The Wildlife Society, Maryland. 
Rowe-Rowe, D.T. 1995. The distribution and status of African otters. Proceedings of the VI International Otter Symposium, September 6-10, 1993, Pietermaritzburg, South Africa.

Said A.R. and da Silva A. S. 1998. Subsídios para a elaboração de estratégia e plano de acção para a conservação da Biodiversidade na Guiné Bissau. INEP/PNUD/DGA, Guiné Bissau.

Said, A.R. and Ferraz L.P.M. (undated). La Réserve de la Biosphère de l'Archipel des Bijagós. Document d'information. UICN/ INEP/ UNESCO.

Said, A.R., Ferraz, L.P. and Marretti C.C. 1998. Plano de gestão da Reserva de Biosfera do Arquipélago dos Bijagós. CEATA/INEP, Bubaque

Said, A.R, Marretti C. 1993. Programa de acções para o Desenvolvimento sustentado da Região Bolama- Bijagós, futura Reserva da Biosfera. CEATA/INEP, Bubaque.

Salafsky, N. 1994. Ecological limits and opportunities for community-based conservation. In: D. Western, M. Wright, \& S. Strum (Eds.), Natural connections: Perspectives in community-based conservation (pp. 448-471). Washington, DC: Island Press.

Sambonino, P., Karibuhoye, C. and Proença, F. 2003. Relatório Final da Avaliação do Programa Trienal da Tiniguena. Unpublished evaluation report. Tiniguena. Bissau, Dezembro 2003.

Schaller, G. B. 2000. Foreword. In: Robinson, J.G. and Elisabeth, L. (eds.) Hunting for sustainability in tropical forests. Columbia University Press, New York. 582pp.

Schmidt, C. 1997. "Am Material": Auswertungstechniken für Leitfadeninterviews. In: Barbara Friebertshäuser, Annedore Prengel (Hrsg.): Handbuch Qualitative Forschungsmethoden in der Erziehungswissenschaft. Juventa, Weinheim und München, S.544 - 568 
Schnell, R., Hill, P., Esser, E. 1995. Methoden der empirischen Sozialforschung, Oldenburg Verlag, München

Schnell, R., Hill P., B. \& Esser, E. (1999). Methoden der empirischen Sozialforschung (6. Auflage). München: R. Oldenburg.

Schumann, H.J. 1995. Der Manati, Trichechus senegalensis, im Rio Geba, Guinea Bissau. Natur und Museum 125: 402-409.

Silva, C. 2002. Proposta de estudo para o conhecimento da situação actual dos mamíferos transfronteiriços no sul e Leste da Guiné- Bissau. Bissau, Marco de 2002

Silva, M.A. and Araújo, A. 2001. Distribution and current status of the West African manatee (Trichechus senegalensis) in Guinea-Bissau. Marine Mammal Science, 17(2): 343-352.

Sinsin, B., Tehou, A.C., Daouda, I. and Saidou A. 2002. Abundance and species richness of larger mammals in Pendjari National Park in Benin. Mammalia 66(3):369380 .

Sinsin, B., Daouda, I. and Ahokpe, E. 1998. Mammalian population abundance and richness in the Monts Kouffe forest reserves in Benin. Cahiers d'Ethologie 18(2): 261281.

Skorupa, J.P. 1997. Responses of Rainforest Primates to selective logging in Kibale Forest, Uganda: A Summary Report. In : Bernischke, K. (Ed.) : Primates - The Road to self-sustaining populations. Springer Verlag.

Smith, A.P., Horning, N. and Moore, D. 1997. Regional Biodiversity Planning and Lemur Conservation with GIS in Western Madagascar. Conservation Biology, Vol. 11 (2), 498512.

Songorwa, A.N. 1999. Community-based wildlife management (CWM) in Tanzania: are the communities interested? World Development, 27, 2061-2079. 
Spergel, B .1997. Compensation and substitution programmes. In: Borrini-Feyerabend (ed.): Beyond Fences: Seeking Social Sustainability in Conservation. IUCN, Gland (Switzerland), 1997.

Steinmetz, R. 2000, Ecological surveys, monitoring and the involvement of local people in protected areas of Lao P.D.R. Evaluating Eden Series discussion Paper No.13. IIEDLondon

Steinmetz, R. and Mather, R.1996. Impact of Karen Villages on the Fauna of Thung Yai Naresuan Wildlife Sanctuary: A Participatory Research Project. Nat. Hist. Bull. Siam Soc., Bangkok 44: 23-40.

Stiles, E.W. 1992. Animals as seeds dispersers. In Seeds: the ecology of regeneration in plant communities: 87-104. Fenner M. (Ed.). Wallingford, UK: CAB International.

Struhsaker, T.T. 1971. Notes on Cercocebus atys atys in Senegal, West Africa. Mammalia 35:343-44.

Struhsaker, T.T. 1997. Ecology of an African rain forest: logging in Kibale and the conflict between conservation and exploitation. University Press of Florida, Gainesville. 434pp.

Struhsaker, T.T. 2002. Guidelines for biological monitoring and research in Africa's rain forest protected areas. Unpublished report to the Centre for Applied Biodiversity Science, Conservation International. 55pp.

Strum, S. 1994. Lessons learned. Pages 512-523 in D. Western R. Wright, editors. Natural connections: perspectives in community-based conservation. Island Press, Washington, D.C.

Stuart, S.N., Adams, R.J. and Jenkins, M. 1990. Biodiversity in Sub-Saharan Africa and its islands: conservation, management and sustainable use. Occasional Paper No. 6. IUCN Species Survival Commission, Gland, Switzerland. Pp. 106-107. 
Stuart, C. and Stuart, T. 1997. Field guide to the larger mammals of Africa. Struik Publishers.

Sugiyama, Y. 1989. Population dynamics of chimpanzees at Bossou, Guinea. pp. 134145. In: Heltne, P. G. and Marquardt, L. G. (ed.), Understanding Chimpanzees. Cambridge: Harvard University Press.

Swissaid 2000. Gestion des espaces verts dans la région de Oio. Document de projet. Bissau Octobre 2000.

Swissaid 2003. Rapport d'activités du projet GB/2/00/09 Gestion des Terroirs villageois. Bissau. Mai 2003

Takforyan, A. 1994. "Conservation et développement local au Niokolo Koba", Politique africaine, 53, Mars 1994, 52-63.

Thomas, L., Laake, J.L., Derry, J.F., Buckland, S.T., Borchers, D.L., Anderson, D.R., Burnham, K.P., Strindberg, S., Hedley, S.L., Marques, F.F.C., Pollard, J.H. and Fewster, R.M. 1998. Distance 3.5. Research Unit for Wildlife Population Assessment, University of St. Andrews, St. Andrews, UK.

Thompson, W.L., White G.C. and Gowan C. 1998. Monitoring vertebrate populations. Academic Press. San Diego.

Tiniguena 1997. Cantanhez, Forêts sacrées de Guinée Bissau. Bissau.

Tiniguena 2003. Gestion participative des ressources de la zone côtière du complexe des îles d'Urok - Réserve de Biosphère de l'Archipel des Bijagós, Guinée Bissau. Unpublished project document.

Thibault, M. 2002. La participation locale dans la gestion des aires protégées en forêt tropicale : le cas du complexe d'aires protégées de Gamba, Gabon. Mémoire de thèse. Université de Laval, Québec. 
Tutin, C.E.G. and Fernandes, M. 1993. Composition of the diet of chimpanzees and comparisons with that of sympatric lowland gorillas in the Lopé Reserve, Gabon. American Journal of Primatology 30: 195-211.

Tutin, C.E.G., Ham, R.M., White, L.J.T. and Harrison, M.J.S. 1997. The primate community of the Lope Reserve, Gabon: Diets, responses to fruit scarcity, and effects on biomass. Am. J. Primatol. 42: 1-24.

UICN/DGFC-MDRA, 1993. Planificação Costeira na Guiné Bissau vol.1. Maretti, C. C. and Sales, R. R. (coords). UICN Bissau.

UICN, 2002. Projet de Conservation des Forets de Cantanhez (Guinée-Bissau). Plan d'action 2001-2005. Guinée Bissau.

UICN 2004. BRAO - Bureau Régional pour l'Afrique de l'Ouest. Annual Plan Report. IUCN, Gland.

UNEP-WCMC 2004. Animals of the world database. Online at: http://www.unepwcmc.org/species/ animal

Unesco-Breda 2003. Bureau régional de l'Unesco pour l'éducation en Afrique Rapport d'activités 2002 - Unité des Sciences naturelles et exactes. Online at: http://www.dakar.unesco.org/natsciences fr/rapport 2002/

Van Hooff, J. 1988. Meerkatzenartige. In: Grzimek, G. (ed) Grzimek's Enzyklopädie Säugetiere, vol 2. Kindler, Munich, pp 208-285.

Vanwijnsberghe, S. 1996. Etude sur la chasse villageoise aux environs au Parc National d'Odzala Programme de Conservation et d'Utilisation Rationnelle des Ecosystèmes Forestiers en Afrique Central (ECOFAC)/Agrer and Agriconsulting (AGRECO), Brussels

Vasconcelos, M.J.P., Mussá Biai J.C., Araújo A. and Diniz M.A. 2002. Land cover change in two protected areas of Guinea-Bissau (1956-1998). Applied Geography 22, 139-156. 
Vercammen, P. and Mason, D. R. 1993. The Warthogs (Phacochoerus africanus and $P$. aethiopicus). In: Status survey and Conservation Action Plan - Pigs, Peccaries and Hippos. William R. L. Oliver (ed.). IUCN/SSC-PPSG

Vercammen, P., Seydack, A.H.W. and. Oliver, W.L.R. 1993. The Bush Pigs (Potamochoerus porcus and P. larvatus. In: Status survey and Conservation Action Plan - Pigs, Peccaries and Hippos. William R. L. Oliver (ed.). IUCN/SSC-PPSG

Waitkuwait, W.E. 1994. L'évaluation écologique de la réhabilitation des forêts classées dans l'Est de la Côte d'Ivoire. In: Exposé du Séminaire sur la „Réhabilitation des forêts classées dans l'Est de la Côte d'Ivoire“. Fabrikschleichach, 02/03 Mai 1994

Walsh, P.D. and White, L.J.T. 1999. What will it take to monitor forest elephants? Conservation Biology, 13 (5), 1194-1202

Waltert, M., Lien, Koen, F. and Mühlenberg, M. 2002. Further declines of threatened primates in the Korup Project Area, south-west Cameroon. Oryx (2002), 36:257-265. Cambridge University Press.

Wells, M. and Brandon, K. 1992. People and Parks: Linking Protected Areas with communities. Washington D.C., World Bank.

Wells, M. and Brandon, K. 1993. The principles and practice of buffer zones and local participation in biodiversity conservation. Ambio, 22(2-3), 157-162.

Western, D. 1994. In: Natural connections: perspectives in community-based conservation. Island Press, Washington, D.C.

Western, D. 2001. Taking the broad view of conservation - A response to Adams and Hulme. Oryx, Vol. 35 (3), page 201.

Western, D. and Wright, R. 1994 (eds). Natural connections: perspectives in community-based conservation. Island Press, Washington, D.C. 
White, L.J.T. 1994. Biomass of rain forest mammals in the Lopé Reserve, Gabon. Journal of Animal Ecology, 63, 499-512.

White, F. 1983. The vegetation of Africa, a descriptive memoir to accompany the UNESCO/AETFAT/UNSO vegetation map of Africa. UNESCO, Natural Resour. Res. 20: $1-356$

Whitesides, G.H., Oates, J.F., Green, S.M., Kluberdanz, R.P. 1988. Estimating Primate Densities from Transects in a West African Rain Forest: A Comparison of Techniques. Journal of Animal Ecology, Vol. 57, No. 2: 345-367.

Wilkie, D.S., Sidle, J.G., Boundzanga, G.C. 1992. Mechanized logging, market hunting, and a bank loan in Congo. Conservation Biology, 6, 1523-1739.

Wilkie, D., Shaw, E., Rotberg, F., Morelli, G. and Auzel, P. 2000. Roads, Development and Conservation in the Congo Basin. Conservation Biology Volume 14 (6), 1614-1622.

Wilshusen, P.R., Brechin, S.R., Fortwangler, C.L. and West, P. C. 2001. Reinventing a square wheel: Critique to the Resurgent "Protection Paradigm" in International Biodiversity conservation. Society and Nature Resources, 15: 17-40.

Wright, S.J., Zeballos, H., Dominguez, I., Gallardo, M.M., Moreno, M.C., Ibanez, R. 2000. Poachers alter mammal abundance, seed dispersal, and seed predation in a Neotropical forest. Conservation Biology 14:227-239.

WWF 1983/84. WWF Yearbook. WWF, Gland, Switzerland.

Zeba, S. 1998. Community wildlife management in West Africa - a regional review. IIED - Evaluating Eden Series. Working Paper No.9. IIED.

Ziegler, S., Nikolaus G. and Hutterer R. 2002. High mammalian diversity in the newly established National Park of Upper Niger, Republic of Guinea. Oryx Vol 36 (1) 73-80. 
APPENDICES 


\section{Appendix 1. Known medium sized and large mammals of Guinea Bissau - Table38 Primate species}

\begin{tabular}{|c|c|c|c|c|c|}
\hline Family & Scientific name & English name & Creole/Portuguese & Habitat & International status \\
\hline Hominidae & P. Troglodytes & Western Chimpanzee & Dari/Chimpanzé & DF/GF/WS & $\begin{array}{l}\text { - Cites I, } \\
\text { - Afric. conv. B } \\
\text { - EN A3cd }\end{array}$ \\
\hline \multirow[t]{2}{*}{ Colobidae } & P. badius & $\begin{array}{l}\text { Temmincki's or Western } \\
\text { Red Colobus }\end{array}$ & $\begin{array}{l}\text { Fatango/Macaco } \\
\text { fidalgo vermelho }\end{array}$ & F/M/WS & $\begin{array}{l}\text { - Cites II, } \\
\text { - Afric. conv. B } \\
\text { - EN A1cd+2cd }\end{array}$ \\
\hline & C. polykomos & $\begin{array}{l}\text { Western pied colobus/ } \\
\text { Black and white Colobus }\end{array}$ & Macaco fidalgo preto & DF/GF & $\begin{array}{l}\text { - Cites II, } \\
\text { - Afric. conv. B } \\
\text { - LR/nt }\end{array}$ \\
\hline \multirow[t]{7}{*}{ Cercopithecidae } & C. campbelli & Campbell monkey & Santcho mona & F/M/GF & $\begin{array}{l}\text { - Cites II } \\
\text { - Afric. conv. B } \\
\text { - LR/lc }\end{array}$ \\
\hline & C. petaurista & $\begin{array}{l}\text { Lesser putty-nosed } \\
\text { monkey }\end{array}$ & $\begin{array}{l}\text { Santcho bijagó/ } \\
\text { Petaurista menor }\end{array}$ & F/GF/RW & $\begin{array}{l}\text { - Cites II } \\
\text { - Afric. conv. B } \\
\text { - LR/lc }\end{array}$ \\
\hline & C. a. sabaeus & Vervet monkey & $\begin{array}{l}\text { Santcho preto } \\
\text { /Macaco verde) }\end{array}$ & WS/RF margins/M & $\begin{array}{l}\text { - Cites II } \\
\text { - Afric. conv. B } \\
\text { - LR/lc }\end{array}$ \\
\hline & E. p. patas & Patas Monkey & Santcho fula & Open GL to dry WS & $\begin{array}{l}\text { - Cites II } \\
\text { - Afric. conv. B } \\
\text { - LR/Ic }\end{array}$ \\
\hline & Papio papio & Guinea Baboon & $\begin{array}{l}\text { Cão/Babuino da } \\
\text { Guiné }\end{array}$ & $\begin{array}{l}\text { WS/Sahelian } \\
\text { steppe/GF }\end{array}$ & $\begin{array}{l}\text { - Cites II } \\
\text { - Afric. conv. B } \\
\text { - LR/nt }\end{array}$ \\
\hline & $\begin{array}{l}\text { C. nictitans } \\
\text { stampfilii }\end{array}$ & Putty nosed Monkey & $\begin{array}{l}\text { Nariz branco/ Macaco } \\
\text { bijagó }\end{array}$ & DF/GF & $\begin{array}{l}\text { - Cites II, } \\
\text { - Afric. conv. B } \\
\text { - LR/Ic }\end{array}$ \\
\hline & C. a. atys & Sooty Mangabey & Macaco cinzento & Valleys along F/GF/SF & $\begin{array}{l}\text { - Cites II, } \\
\text { - Afric. Conv. B } \\
\text { - LR/nt }\end{array}$ \\
\hline Galagonidae & G. s. senegalensis & Senegal Galago & Concanhe/Chinchila & W & - Cites II \\
\hline
\end{tabular}

F: Forest, DF: Dense forest, GF: Gallery forest, W: Woodland, RiF: riverine forest, WS: Woodland savannah, RW: Riverine Woodland, GL: Grassland, CF: Coastal forest, M: Mangrove, CH: Coastal habitat, DS: Dry savannah, Ma: Marine habitat near coast, L: Lagoon, Aq: Aquatic environment, RF: River

Floodplain, RB: Reed beds, OC: Open country, SF: Swamp forest. Afric. conv.: African Convention on the Conservation of Nature and Natural Resources 
Table39. Ungulate species

\begin{tabular}{|c|c|c|c|c|c|}
\hline Family & Scientific name & English name & Crioulo/ Portuguese & Habitat & $\begin{array}{l}\text { International } \\
\text { status }\end{array}$ \\
\hline \multicolumn{6}{|l|}{ Bovidae } \\
\hline \multirow[t]{4}{*}{ Bovinae } & S. caffer & African Buffalo & Bufre / Búfalo & Humid F/WS & LR \\
\hline & T. scriptus & Bushbuck & Gazela pintada & $\begin{array}{l}\text { RW/ Bush near } \\
\text { water }\end{array}$ & LR/lc \\
\hline & T. derbianus & Western Giant Eland & Elan & $\begin{array}{l}\text { Densely WS } \\
\text { (Isoberlinia) }\end{array}$ & LR/cd \\
\hline & T. spekei & Sitatunga, Marschbuck & Sitatunga & $\begin{array}{l}\text { Reed beds } / \mathrm{M} / \text { well } \\
\text { vegetated } \mathrm{Aq}\end{array}$ & $\begin{array}{l}\text { LR/nt; Cites III } \\
\text { Afr. conv. B }\end{array}$ \\
\hline \multirow[t]{5}{*}{ Antelopinae } & C. dorsalis & Bay Duiker & $\begin{array}{l}\text { Cabra di mato/Cabrito } \\
\text { castanho }\end{array}$ & DF, undisturbed WS & $\begin{array}{l}\text { LR/nt } \\
\text { Cites II }\end{array}$ \\
\hline & C. rufilatus & Red-flanked Duiker & $\begin{array}{l}\text { Frintamba/ Cabra } \\
\text { vermelha do mato }\end{array}$ & F relicts/GF & LR/cd \\
\hline & C. silvicultor & Yellow backed Duiker & $\begin{array}{l}\text { Muntum/Cabra } \\
\text { grande do mato }\end{array}$ & $\begin{array}{l}\text { F/SW/ } \\
\text { Miombo }\end{array}$ & \begin{tabular}{|l|} 
LR/nt \\
Cites II
\end{tabular} \\
\hline & C. maxwellii & Maxwell's Duiker & $\begin{array}{l}\text { Cabrito azul/ Cabra } \\
\text { cinzenta }\end{array}$ & F/W & LR/nt \\
\hline & S. grimmia & Bush duiker & Cabrito cinzento & SW/Bush country & LR/lc \\
\hline Tragulidae & H. aquaticus & Water Chevrotain & Cabrito aquático & DF/SF margins & Data Deficient \\
\hline
\end{tabular}

F: Forest, DF: Dense forest, GF: Gallery forest, RiF: riverine forest, W: Woodland, WS: Woodland savannah, RW: Riverine Woodland, GL: Grassland, CF: Coastal forest, M: Mangrove, CH: Coastal habitat, DS: Dry savannah, Ma: Marine habitat near coast, L: Lagoon, Aq: Aquatic environment, RF: River Floodplain, RB: Reed beds, OC: Open country, SF: Swamp forest. Afric. conv.: African Convention on the Conservation of Nature and Natural Resources 
Table40. Ungulate species (continued)

\begin{tabular}{|l|l|l|l|l|l|}
\hline Family & Scientific name & English name & Crioulo/portuguese & Habitat & $\begin{array}{l}\text { International } \\
\text { status }\end{array}$ \\
\hline Bovidae & O. ourebi & Oribi & Gazela di pedra & GL & LR/cd \\
\hline & R. redunca & Bohor Reedbuck & Redunca & $\begin{array}{l}\text { RF/RB/ reg. Flooded } \\
\text { GL }\end{array}$ & LR/cd \\
\hline & K. k. kob & Buffon's Kob & Gazela di lala & RF/GL & LR/cd \\
\hline & K. defassa & $\begin{array}{l}\text { Defassa } \\
\text { Waterbuck }\end{array}$ & Sim sim & RB/GL/WGL & LR/cd \\
& Gedrons & Gazelle & $\begin{array}{l}\text { Gazela de fronte } \\
\text { vermelho }\end{array}$ & S & VU - A1a \\
\hline & A. buselaphus major & Korrigum & Damalisco & Flooded GL & VU - A1a \\
\hline & H. equinus & Roan Antelope & Boca branco & S/wooded GL/ & LR/cd \\
\hline Suidae & C. porcus & Red river hog & $\begin{array}{l}\text { Porco de mato } \\
\text { vermelho }\end{array}$ & F/WS & LR \\
\hline & P. africanus & $\begin{array}{l}\text { Common } \\
\text { warthog }\end{array}$ & Porco di mato & Open GL $/$ WS & LR/lc \\
\hline Hippopotamidae & H. amphibius & Hippopotamus & $\begin{array}{l}\text { Pis } \\
\text { cabalo/Hipopótamo }\end{array}$ & Ma/GL/L & LR \\
\hline & H. liberiensis & $\begin{array}{l}\text { Pygmy } \\
\text { hippopotamus }\end{array}$ & Hipopótamo anão & $\begin{array}{l}\text { DF/SF near water } \\
\text { bodies }\end{array}$ & VU - C2a, E \\
\hline
\end{tabular}

F: Forest, DF: Dense forest, GF: Gallery forest, W: Woodland, WS: Woodland savannah, RiF: riverine forest, RW: Riverine Woodland, GL: Grassland, CF: Coastal forest, M: Mangrove, CH: Coastal habitat, DS: Dry savannah, Ma: Marine habitat near coast, L: Lagoon, Aq: Aquatic environment, RF: River Floodplain, RB: Reed beds, OC: Open country, SF: Swamp forest. . Afric. conv.: African Convention on the Conservation of Nature and Natural Resources 
Table41. Proboscids, Sirenids, Cetacean, Tubulidentata and Pholidota

\begin{tabular}{|c|c|c|c|c|c|}
\hline Family & Scientific name & English name & $\begin{array}{l}\text { Crioulo or } \\
\text { portuguese name }\end{array}$ & Habitat & $\begin{array}{l}\text { International } \\
\text { status }\end{array}$ \\
\hline Elephantidae & L. africana & African Elephant & Lifanti/Elefante & All $F$ & $E N-A 1 b$ \\
\hline Trichechidae & T. senegalensis & West African Manatee & Pis bus/Manatim & $\mathrm{Ma} / \mathrm{M}$ & VU - A1cd \\
\hline Delphinidae & S. teuszii & $\begin{array}{l}\text { Atlantic humpbacked } \\
\text { Dolphin }\end{array}$ & Antoninho & $\mathrm{Ma}$ & Data deficient \\
\hline & Tursiops truncatus & Bottle-nosed Dolphin & Antoninho & \begin{tabular}{|l|l} 
Ma \\
\end{tabular} & Data deficient \\
\hline Orycteropodidae & Orycteropus afer & Orycteropus & Timba & \begin{tabular}{|l|} 
Open WL, \\
GL, but most \\
habitats
\end{tabular} & LC \\
\hline Manidae & M. (U.) tetradactyla & Long-tailed pangolin & Pangolim & RF/SF & LR/lc \\
\hline & $\begin{array}{ll}\text { Manis } & \text { (Smutsia) } \\
\text { gigantea }\end{array}$ & Giant pangolin & Pangolim gigante & F/Moist S & LR/lc \\
\hline
\end{tabular}

F: Forest, DF: Dense forest, GF: Gallery forest, RiF: riverine forest, W: Woodland, WS: Woodland savannah, RW: Riverine Woodland, GL: Grassland, CF: Coastal forest, M: Mangrove, CH: Coastal habitat, DS: Dry savannah, Ma: Marine habitat near coast, L: Lagoon, Aq: Aquatic environment, RF: River Floodplain, RB: Reed beds, OC: Open country, SF: Swamp. Afric. conv.: African Convention on the Conservation of Nature and Natural Resources forest. 
Table42. Carnivora

\begin{tabular}{|c|c|c|c|c|c|}
\hline Family & Scientific name & English name & Crioulo/ Portuguese & Habitat & $\begin{array}{l}\text { International } \\
\text { status }\end{array}$ \\
\hline \multirow[t]{3}{*}{ Canidae } & C. aureus & $\begin{array}{l}\text { Common (golden) } \\
\text { Jackal }\end{array}$ & Djurto comum & Dry OC & LR/lc \\
\hline & C. adustus & Side-striped Jackal & Cachorro de mato & S/ F edges & LR/lc \\
\hline & L. pictus & Wild dog & Mabeco/Ciniena & $\begin{array}{l}\text { S/W/GL/ } \\
\text { Steppes }\end{array}$ & EN - C1 \\
\hline Hyenidae & C. crocuta & Spotted hyena & Lobo/Hiena & S/WS & $\mathrm{LR} / \mathrm{cd}$ \\
\hline \multirow[t]{5}{*}{ Felidae } & P. leo & Lion & Leão & $\mathrm{S} / \mathrm{W} / \mathrm{GL}$ & $\begin{array}{l}\text { - Cites II } \\
\text { - VU A2abcd }\end{array}$ \\
\hline & P. pardus & Leopard & Onça & S/W/F & $\begin{array}{l}\text { - Cites I } \\
\text { - LC }\end{array}$ \\
\hline & F. (L.) serval & Serval cat & $\begin{array}{l}\text { Onça di baga- } \\
\text { baga/Gato lagar }\end{array}$ & $\mathrm{S} / \mathrm{RB}$ & LC \\
\hline & C. caracal & Caracal & Lince & S & LC \\
\hline & P. aurata & Golden cat & & & VU C2a(i) \\
\hline \multirow[t]{2}{*}{ Mustelidae } & A. capensis & $\begin{array}{l}\text { African } \\
\text { otter }\end{array}$ & Londre/Lontra & $\begin{array}{l}\text { Marshes, lakes, } \\
\text { streams, rivers }\end{array}$ & LC \\
\hline & M. capensis & \begin{tabular}{|ll} 
Honey badger \\
/Ratel
\end{tabular} & Ratel & $\begin{array}{l}\text { Open W, F, } \\
\text { steppes, CH }\end{array}$ & LR/lc \\
\hline \multirow[t]{5}{*}{ Viverridae } & G. thierry & Hausa genet & Gineta/ Gato lagaria & DS & LR/lc \\
\hline & G. genetta & Common gent & Gineta/ Gato lagaria & W/drier habitats & LR/lc \\
\hline & G. tigrina & Blotched genet & Gineta/ Gato lagaria & F/RiF/moist W & LR/lc \\
\hline & Viverra (c.) civetta & African Civet & Gato almiscarado & $\begin{array}{l}\mathrm{F} / \mathrm{OC}+\text { dense } \\
\text { cover }\end{array}$ & $\begin{array}{ll}\text { Abundant } \\
\text { entry) }\end{array}$ \\
\hline & N. binotata & African Palm Civet & $\begin{array}{l}\text { Nandinia/ Mangusso } \\
\text { das palmeiras }\end{array}$ & F/2dF/WS & No entry \\
\hline
\end{tabular}

F: Forest, DF: Dense forest, GF: Gallery forest, W: Woodland, RiF: riverine forest, WS: Woodland savannah, RW: Riverine Woodland, GL: Grassland, CF: Coastal forest, M: Mangrove, CH: Coastal habitat, DS: Dry savannah, Ma: Marine habitat near coast, L: Lagoon, Aq: Aquatic environment, RF: River Floodplain, RB: Reed beds, OC: Open country, SF: Swamp forest. Afric. conv.: African Convention on the Conservation of Nature and Natural Resources 
Appendix2. Study area

Table43. Mammal diversity and humid zone index ranking at different continental coastal sites, with 1: highest ranking (adapted from Robillard and Limoges 1994)

\begin{tabular}{|l|l|l|l|l|l|l|l|l|}
\hline Site & $\begin{array}{l}\text { Humid } \\
\text { zone } \\
\text { index }\end{array}$ & $\begin{array}{l}\text { Ungulate } \\
\text { diversity }\end{array}$ & $\begin{array}{l}\text { Primate } \\
\text { diversity }\end{array}$ & $\begin{array}{l}\text { Mammal } \\
\text { diversity } \\
\text { (large } \\
\text { and } \\
\text { medium } \\
\text { sized) }\end{array}$ & $\begin{array}{l}\text { Carnivore } \\
\text { diversity }\end{array}$ & $\begin{array}{l}\text { Large } \\
\text { mammal } \\
\text { diversity }\end{array}$ & $\begin{array}{l}\text { Medium } \\
\text { sized } \\
\text { mammal } \\
\text { diversity }\end{array}$ & $\begin{array}{l}\text { Small } \\
\text { mammal } \\
\text { diversity }\end{array}$ \\
\hline Cufada & 2 & 2 & 1 & 1 & 1 & 2 & 3 & 3 \\
\hline Cantanhez & 4 & 3 & 2 & 1 & 1 & 3 & 4 & 2 \\
\hline Pelundo* & 1 & 5 & 4 & 2 & 3 & 4 & 1 & 6 \\
\hline Corubal & 7 & 1 & 3 & 2 & 4 & 1 & 2 & 1 \\
\hline Mansoa & 5 & 2 & 3 & 1 & 2 & 6 & 5 & 4 \\
\hline Varela & 6 & 6 & 5 & 4 & 3 & 7 & 5 & 7 \\
\hline Xitole & 3 & 4 & 2 & 3 & 4 & 5 & 6 & 5 \\
\hline
\end{tabular}

$\left(^{*}\right)$ located within the Natural Park of Cacheu 
Appendix3. Mammal field survey

Table44. Recorded field surveys starting points

\begin{tabular}{|c|c|c|c|c|}
\hline & Transect & Point & Latitude & Longitude \\
\hline \multirow[t]{5}{*}{ Cacheu } & Belimbom & BALIMP & N 1217' $2 "$ & W $16^{\circ} 5^{\prime} 23^{\prime \prime}$ \\
\hline & Elia & ELIA4 & N 12०19'9.3" & W 16 ${ }^{\circ} 23^{\prime} 53.6^{\prime \prime}$ \\
\hline & Bechil-Fanho & TECA3 & 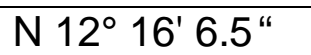 & W 16 ${ }^{\circ} 2^{\prime} 38.4^{\prime \prime}$ \\
\hline & Guncon & GU1 & $\mathrm{N} 12^{\circ} 11^{\prime} 45.7^{\prime \prime}$ & W $16^{\circ} 2^{\prime} 39.2^{\prime \prime}$ \\
\hline & Jopa & JOPA2 & $\mathrm{N} 12^{\circ} 14^{\prime} 45.2^{\prime \prime}$ & W 155' 2.9" \\
\hline \multirow[t]{9}{*}{ Cantanhez } & Amindara & AMI1 & N 11' 16' 15.3" & W 15०1'12.4" \\
\hline & Cafatch & CAFA1 & $\mathrm{N} 11^{\circ} 10^{\prime} 11.8^{\prime \prime}$ & W 15०6 $6^{\prime} 54.1^{\prime \prime}$ \\
\hline & Camarempo & KAMAR1 & N 11'12' 3.2" & W 15०4 '2.9" \\
\hline & Cambeque & CAMBE1 & N 11' $12^{\prime} 29.2^{\prime \prime}$ & W 15०1'13.5" \\
\hline & Canamina & CANA2 & N 11ㅇ 8 ' 40.8" & W 15०4'11" \\
\hline & Cabante & CABANT & N 11 ${ }^{\circ} 9^{\prime} 42.3^{\prime \prime}$ & W 15 ${ }^{\circ} 7^{\prime} 38.5^{\prime \prime}$ \\
\hline & Cugha & CUGHA & N 11ㅇ6 ' 29.9" & W 15 ${ }^{\circ} 8^{\prime} 50.9^{\prime \prime}$ \\
\hline & Cabessul & CAB2 & N 11ㅇ 15' 5.3" & W 15 ${ }^{\circ} 4^{\prime} 7.9^{\prime \prime}$ \\
\hline & Bodjol & BODJ1 & N 110 44'18" & W 14둥'52.5" \\
\hline \multirow[t]{4}{*}{ Cufada } & Cufada Lagoa & CUFAD2 & N 11연 $21.2^{\prime \prime}$ & W 15०1'40.6" \\
\hline & Ndjassane & NCASSO & $\mathrm{N} 11^{\circ} 44^{\prime} 30.1^{\prime \prime}$ & 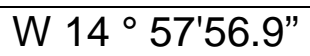 \\
\hline & Laman-Sanintcha & SANITC & 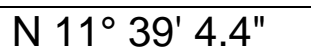 & W 15 ${ }^{\circ} 11^{\prime} 57.9^{\prime \prime}$ \\
\hline & Tira-Camisa & TIRA1 & N 11 ${ }^{\circ} 40^{\prime} 35.2^{\prime \prime}$ & W 154 $4^{\prime} 41^{\prime \prime}$ \\
\hline \multirow[t]{6}{*}{ Formosa } & Abu-Caminhate & ABU & $\mathrm{N} 11^{\circ} 27^{\prime} 40.1^{\prime \prime}$ & W 15०54'59.8" \\
\hline & Acuno & ACUNO & N 11 ${ }^{\circ} 29^{\prime} 13.2^{\prime \prime}$ & W 15 ${ }^{\circ} 55^{\prime} 52.5^{\prime \prime}$ \\
\hline & Ancadaque & ANCAD2 & $\mathrm{N} 11^{\circ} 28^{\prime} 53.2^{\prime \prime}$ & W 15०58'10.1" \\
\hline & Chedia & CHED1 & N 11 ${ }^{\circ} 34^{\prime} 26.7^{\prime \prime}$ & W 15०54'22.4" \\
\hline & Pandja & PA1 & $\mathrm{N} 11^{\circ} 28^{\prime} 16^{\prime \prime}$ & W 15 ${ }^{\circ} 56^{\prime} 47.7^{\prime \prime}$ \\
\hline & Uada & UADA & $\mathrm{N} 11^{\circ} 27^{\prime} 21.8^{\prime \prime}$ & W 16 ${ }^{\circ} 1^{\prime} 53.3^{\prime \prime}$ \\
\hline \multirow[t]{5}{*}{ Orango } & Ancaquia & Ancaquia & $\mathrm{N} 11^{\circ} 8$ ' $^{\prime} 22^{\prime \prime}$ & W 16 ${ }^{\circ} 6^{\prime} 20.6 "$ \\
\hline & Ancaquia2 & ANCAQU & N 11 ${ }^{\circ} 7^{\prime} 56.8^{\prime \prime}$ & W 16 $6^{\circ} 6^{\prime} 28.1^{\prime \prime}$ \\
\hline & Angôr & $\mathrm{A} 1$ & N 11ㅇ4 '32" & W 16 ${ }^{\circ} 13^{\prime} 27.9^{\prime \prime}$ \\
\hline & Imbone & $\mathrm{T1}$ & $\mathrm{N} \mathrm{11^{ \circ } 2 ^ { \prime } 4 3 . 2 ^ { \prime \prime }}$ & W 16 $5^{\circ}$ '53.3" \\
\hline & Imbone2 & T5 & N 11ㅇ3'33" & W 16॰6 '51" \\
\hline
\end{tabular}


Table 45. - Sampling locations with distance sampling and reconnaissance survey effort (km) in the Orango NP

\begin{tabular}{|c|c|c|c|c|c|c|c|}
\hline Study site & $\begin{array}{l}\text { Number of } \\
\text { census routes }\end{array}$ & $\begin{array}{l}\text { Census } \\
\text { route }\end{array}$ & $\begin{array}{l}\text { Line transect } \\
\text { segments }\end{array}$ & $\begin{array}{l}\text { Line transect } \\
\text { length }\end{array}$ & $\begin{array}{l}\text { Reconnaissance } \\
\text { walk segments }\end{array}$ & $\begin{array}{l}\text { Reconnaissan } \\
\text { ce effort }\end{array}$ & $\begin{array}{l}\text { Total } \\
\text { survey } \\
\text { effort }\end{array}$ \\
\hline \multirow[t]{8}{*}{$\begin{array}{l}\text { Orango- } \\
\text { Imbone }\end{array}$} & 5 & Angôr & $\begin{array}{l}\text { A1-A2 } \\
\text { A3-A4 } \\
\text { A2bis-A3 } \\
\text { A4-A5 }\end{array}$ & $\begin{array}{l}0.94 \\
1.54 \\
0.375 \\
0.755\end{array}$ & & & 3.6 \\
\hline & & Imbone 1 & $\begin{array}{l}\text { T1-T2 } \\
\text { T2-T3 } \\
\text { T3-T4 }\end{array}$ & $\begin{array}{l}0.90 \\
0.3 \\
0.70 \\
\end{array}$ & & & 1.9 \\
\hline & & Imbone 2 & $\begin{array}{l}\text { T5-T6 } \\
\text { T7-T8 } \\
\text { T6-T7 }\end{array}$ & $\begin{array}{l}0.66 \\
1.03 \\
0.4\end{array}$ & & & 2.1 \\
\hline & & Ancaquia 1 & $\begin{array}{l}\text { Anc5-AN6 } \\
\text { An6-An7 } \\
\text { AN7-AN8 }\end{array}$ & $\begin{array}{l}1.22 \\
1.5 \\
1.51 \\
\end{array}$ & & & 4.2 \\
\hline & & Ancaquia 2 & $\begin{array}{l}\text { An1-An2/ } \\
\text { An3-An4 } \\
\text { An2-An3 }\end{array}$ & $\begin{array}{l}1.53 \\
1.26 \\
0.9 \\
\end{array}$ & & & 3.7 \\
\hline & & Acagume 1 & Acagume 1 & 2.5 & & & 2.5 \\
\hline & & Acagume 2 & Acagume 2 & 2.5 & & & 2.5 \\
\hline & & Canero & Canero & 2.5 & & & 2.5 \\
\hline \multirow[t]{3}{*}{ Canogo } & 2 & Canogo1 & & & Canogo1 & 3 & 6 \\
\hline & & Canogo2 & & & Canogo2 & 3 & \\
\hline & & & & 23 & & 6 & 29 \\
\hline
\end{tabular}


Table 46. - Sampling locations with distance sampling and reconnaissance survey effort in the Formosa Islands' group

\begin{tabular}{|c|c|c|c|c|c|c|c|}
\hline Study site & $\begin{array}{l}\text { Number of } \\
\text { census routes }\end{array}$ & $\begin{array}{l}\text { Census } \\
\text { route }\end{array}$ & $\begin{array}{l}\text { Distance } \\
\text { sampling } \\
\text { segments }\end{array}$ & $\begin{array}{l}\text { Line transect } \\
\text { length }\end{array}$ & $\begin{array}{l}\text { Reconnaissance } \\
\text { walk segments }\end{array}$ & $\begin{array}{l}\text { Reconnaissan } \\
\text { ce walk effort }\end{array}$ & $\begin{array}{l}\text { Total } \\
\text { surve } \\
y \\
\text { effort }\end{array}$ \\
\hline \multirow{6}{*}{$\begin{array}{l}\text { Formosa/ } \\
\text { Chediã }\end{array}$} & 5 & Abu & Abu-Ab2 & 1.46 & Ab2-Ab3 & 2.8 & 4.26 \\
\hline & & Acuno & $\begin{array}{l}\text { Acuno-Ac1 } \\
\text { Ac1-Ac2 }\end{array}$ & $\begin{array}{l}0.593 \\
0.246\end{array}$ & Ac2-Ac3 & 1.93 & 2.77 \\
\hline & & Pandja & $\begin{array}{l}\text { Pan1-Pa2 } \\
\text { Pan3-Pan4 }\end{array}$ & $\begin{array}{l}1.14 \\
0.709\end{array}$ & $\begin{array}{l}\text { Pa2-Pan3 } \\
\text { Pa4-Pan5 }\end{array}$ & $\begin{array}{l}0.54 \\
0.69\end{array}$ & 3.08 \\
\hline & & Uada & $\begin{array}{l}\text { U1-Uada3 } \\
\text { Uafa3-Uada4 }\end{array}$ & $\begin{array}{l}0.812 \\
1.27\end{array}$ & Uada-U1 & 3.98 & 6.06 \\
\hline & & Chediã & & & Chedia-Ched1 & 2.07 & 2.07 \\
\hline & & & & 6.23 & & 12 & 18.23 \\
\hline
\end{tabular}


Table47. Sampling locations with distance sampling and reconnaissance survey effort in Cantanhez

\begin{tabular}{|c|c|c|c|c|c|c|c|}
\hline Study site & $\begin{array}{l}\text { Number of census } \\
\text { routes }\end{array}$ & $\begin{array}{l}\text { Census } \\
\text { route }\end{array}$ & $\begin{array}{l}\text { Distance } \\
\text { sampling } \\
\text { segments }\end{array}$ & $\begin{array}{l}\text { Line transect } \\
\text { length }\end{array}$ & $\begin{array}{l}\text { Reconnaissance } \\
\text { walk segments }\end{array}$ & $\begin{array}{l}\text { Reconnaissan } \\
\text { ce walk effort }\end{array}$ & $\begin{array}{l}\text { Total } \\
\text { survey } \\
\text { effort } \\
(\mathrm{km})\end{array}$ \\
\hline \multirow[t]{9}{*}{ Cantanhez } & 8 & Amindara & $\begin{array}{l}\text { Amin1-Amin2 } \\
\text { Amin3-Amin4 }\end{array}$ & $\begin{array}{l}0.470 \\
0.530\end{array}$ & Am2-Am3 & 3.20 & 4.2 \\
\hline & & $\begin{array}{l}\text { Lautchande } \\
\text { (Cabessul) }\end{array}$ & $\begin{array}{l}\text { Cab2-Cab3 } \\
\text { Cab3-Cab4 } \\
\text { Cab4-Cab5 }\end{array}$ & $\begin{array}{l}0.380 \\
0.150 \\
0.370\end{array}$ & $\begin{array}{l}\text { Cab5-Cab6 } \\
\text { Cab6-Cab7 }\end{array}$ & $\begin{array}{l}3.36 \\
1.00\end{array}$ & 5.3 \\
\hline & & $\begin{array}{l}\text { Camaremp } \\
0\end{array}$ & $\begin{array}{l}\text { Cam1-Cam2 } \\
\text { Cam2-Cam3 } \\
\text { Cam6-Cama7 }\end{array}$ & $\begin{array}{l}0.290 \\
0.280 \\
1.130\end{array}$ & $\begin{array}{l}\text { Cam3-Cam4 } \\
\text { Cam4-Cama } \\
\text { Cama- Cam6 }\end{array}$ & $\begin{array}{l}0.56 \\
2.00 \\
2.04\end{array}$ & 6.3 \\
\hline & & Canamina & Cana3-Cana4 & 0.920 & $\begin{array}{l}\text { Can2-Can3 } \\
\text { Can4-Can5 }\end{array}$ & $\begin{array}{l}1.52 \\
1.44\end{array}$ & 3.90 \\
\hline & & Cafatch & Cafa1-Cafama & 1.46 & Cafama-Cafa3 & 5.90 & 7.35 \\
\hline & & Canghode & $\begin{array}{l}\text { Cabant- } \\
\text { Canghode }\end{array}$ & 3,05 & & & 3.05 \\
\hline & & Cungha & $\begin{array}{l}\text { Cug1-Cug2 } \\
\text { Cug2-Cug3 } \\
\text { Cug5-Cug6 }\end{array}$ & $\begin{array}{l}1.20 \\
0.20 \\
0.80\end{array}$ & $\begin{array}{l}\text { Cug3-Cug4 } \\
\text { Cug4-Cug5 } \\
\text { CugB2-CugB3 }\end{array}$ & $\begin{array}{l}0.97 \\
1.65 \\
1.93\end{array}$ & 6.75 \\
\hline & & Cambeque & $\begin{array}{l}\text { Camb1-Camb2 } \\
\text { Camb3-Camb4 }\end{array}$ & $\begin{array}{l}0.430 \\
0.540\end{array}$ & Camb2-Camb3 & 2.10 & 3.07 \\
\hline & & & & 12.20 & & 27.70 & 39.90 \\
\hline
\end{tabular}


Table 48. Sampling locations with distance sampling and reconnaissance survey effort in Cufada

\begin{tabular}{|c|c|c|c|c|c|c|c|}
\hline Study site & $\begin{array}{l}\text { Number of census } \\
\text { routes }\end{array}$ & $\begin{array}{l}\text { Census } \\
\text { route }\end{array}$ & $\begin{array}{l}\text { Distance } \\
\text { sampling } \\
\text { routes }\end{array}$ & $\begin{array}{l}\text { Line transect } \\
\text { length }\end{array}$ & $\begin{array}{l}\text { Reconnaissance } \\
\text { walk segments }\end{array}$ & $\begin{array}{l}\text { Reconnaissan } \\
\text { ce walk effort }\end{array}$ & $\begin{array}{l}\text { Total } \\
\text { survey } \\
\text { effort } \\
(\mathrm{km})\end{array}$ \\
\hline \multirow[t]{6}{*}{ Cufada } & \multirow[t]{6}{*}{5} & Sanintcha & Sanin2-Sanin4 & 1.45 & $\begin{array}{l}\text { Sanitc-Sanin2 } \\
\text { Sanin4-Sanin5 } \\
\text { Sanin5-Sanin6 } \\
\text { Sanin6-Sanin7 }\end{array}$ & $\begin{array}{l}1.97 \\
0.44 \\
0.44 \\
0.85\end{array}$ & 5.2 \\
\hline & & Sibidjan & Tira-Tira1 & 1.96 & $\begin{array}{l}\text { Tira1-Tira3 } \\
\text { Tira3-Santan } \\
\text { Santan-exit }\end{array}$ & $\begin{array}{l}1.80 \\
1.80 \\
3.00\end{array}$ & 8.6 \\
\hline & & Lagoa & Cufad2-Cufad3 & 1.12 & Cudad3-Cufad4 & 1.87 & 3.0 \\
\hline & & Bodjol & Bodj1-Bodj2 & 1.71 & $\begin{array}{l}\text { Bodj2-Bodj3 } \\
\text { Bodj3-Bodj4 }\end{array}$ & $\begin{array}{l}2.73 \\
0.94\end{array}$ & 5.4 \\
\hline & & Ndjassane & $\begin{array}{l}\text { Nca3-Nca4 } \\
\text { Ndja5-Ndja7 }\end{array}$ & $\begin{array}{l}0.970 \\
1.07\end{array}$ & $\begin{array}{l}\text { Ncasso-Nca3 } \\
\text { Nca4-Ndja5 } \\
\text { Ndja7-Ndja8 }\end{array}$ & $\begin{array}{l}5.32 \\
3.30 \\
2.10 \\
\end{array}$ & 12.8 \\
\hline & & & & 8.3 & & 26.7 & 35 \\
\hline
\end{tabular}


Table49. Sampling locations with distance sampling and reconnaissance survey effort in Cacheu

\begin{tabular}{|c|c|c|c|c|c|c|c|}
\hline Study site & $\begin{array}{l}\text { Number of census } \\
\text { routes }\end{array}$ & $\begin{array}{l}\text { Census } \\
\text { route }\end{array}$ & $\begin{array}{l}\text { Distance } \\
\text { sampling } \\
\text { route }\end{array}$ & $\begin{array}{l}\text { Line transect } \\
\text { length }\end{array}$ & $\begin{array}{l}\text { Reconnaissance } \\
\text { walk segments }\end{array}$ & $\begin{array}{l}\text { Reconnaissan } \\
\text { ce walks } \\
\text { effort }\end{array}$ & $\begin{array}{l}\text { Total } \\
\text { survey } \\
\text { effort }\end{array}$ \\
\hline \multirow[t]{6}{*}{ Cacheu } & \multirow[t]{6}{*}{5} & $\begin{array}{l}\text { Bechil } \\
\text { Fanho }\end{array}$ & $\begin{array}{l}\text { Teca3-Fanho } \\
\text { Fanh5-Fanh6 }\end{array}$ & $\begin{array}{l}1.27 \\
0.603\end{array}$ & $\begin{array}{l}\text { Fanh3-Fanh4 } \\
\text { Fanh4-Fanh5 } \\
\text { Fanh6-Fanh7 }\end{array}$ & $\begin{array}{l}1.27 \\
0.72 \\
3.16\end{array}$ & 6.97 \\
\hline & & Belimbom & $\begin{array}{l}\text { Balimp-Pitcha } \\
\text { Pitcha-Balim3 }\end{array}$ & $\begin{array}{l}1.26 \\
1.32\end{array}$ & Balim3-Pitch2 & 3.4 & 5.98 \\
\hline & & Elia & & & $\begin{array}{l}\text { E4-E5 } \\
\text { E5-E6 } \\
\text { E6-E7 }\end{array}$ & $\begin{array}{l}2.52 \\
1.0 \\
1.264\end{array}$ & 4.8 \\
\hline & & Jopa & $\begin{array}{l}\text { Jop2-Jop3 } \\
\text { Jop6-Jofore } \\
\text { Jofore-Jopa1 }\end{array}$ & $\begin{array}{l}0.733 \\
0.675 \\
0.580\end{array}$ & $\begin{array}{l}\text { Jo3-Jopa5 } \\
\text { Jopa5-Jopa6 }\end{array}$ & $\begin{array}{l}2.236 \\
1.376\end{array}$ & 5.6 \\
\hline & & Guncan & $\begin{array}{l}\text { Gunc-Guncan1 } \\
\text { Gunc3-Gunc4 }\end{array}$ & $\begin{array}{l}1.63 \\
1.16\end{array}$ & Gun1-Gun3 & 0.89 & 3.7 \\
\hline & & & & 9.2 & & 17.8 & 27 \\
\hline
\end{tabular}


Appendix4. Density and abundance estimation

Table50. Results from line transect data analysis using Distance 3.5 programme for Cantanhez (combined multi-primate species analysis with post-stratification, Halfnormal/Cosine function)

\begin{tabular}{|c|c|c|c|c|c|}
\hline $\begin{array}{l}\text { Total } \\
\text { observations } \\
\mathrm{N}=33\end{array}$ & Estimate & Estimate & $\% \mathrm{CV}$ & df & $\begin{array}{l}\text { 95\% Confidence } \\
\text { Interval }\end{array}$ \\
\hline \multirow{4}{*}{$\begin{array}{l}\text { C. campbelli } \\
N=17\end{array}$} & DS & 7.2710 & 30.96 & 16 & $3.8287-13.808$ \\
\hline & D & 17.651 & 38.37 & 29 & $8.2712-37.669$ \\
\hline & $N / L$ & 1.3912 & 24.01 & 7 & $0.79488-2.4348$ \\
\hline & ESW & 95.666 & 19.55 & 15 & $63.309-144.56$ \\
\hline \multirow{4}{*}{$\begin{array}{l}P . \text { badius } \\
N=6\end{array}$} & DS & 1.1988 & 68.86 & 10 & $0.29915-4.8041$ \\
\hline & D & 7.3529 & 91.14 & 13 & $1.3704 \quad 39.452$ \\
\hline & $\mathrm{n} / \mathrm{L}$ & 0.49100 & 61.60 & 7 & $0.12842-1.8772$ \\
\hline & ESW & 204.78 & 30.79 & 5 & $94.477-443.88$ \\
\hline \multirow{4}{*}{$\begin{array}{l}\text { C. polykomos } \\
N=5\end{array}$} & DS & 0.59086 & 64.70 & 9 & $0.15508-2.2512$ \\
\hline & D & 2.2195 & 80.63 & 12 & $0.47485 \quad 10.374$ \\
\hline & $\mathrm{n} / \mathrm{L}$ & 0.40917 & 58.88 & 7 & $0.11263-1.4864$ \\
\hline & ESW & 346.24 & 26.82 & 4 & $166.56-719.78$ \\
\hline \multirow{4}{*}{$\begin{array}{l}P . \text { troglodytes } \\
N=4\end{array}$} & DS & 2.8469 & 65.68 & 10 & $0.74972-10.811$ \\
\hline & $\mathrm{D}$ & 4.4897 & 69.03 & 12 & 17.496 \\
\hline & $\mathrm{n} / \mathrm{L}$ & 0.32733 & 54.56 & 7 & $0.97894 \mathrm{E}-01-1.0945$ \\
\hline & ESW & 57.489 & 36.56 & 3 & $18.624-177.46$ \\
\hline \multirow{4}{*}{$\begin{array}{l}\text { C. aethiops } \\
N=1\end{array}$} & DS & 2.2731 & 65.54 & 7 & $0.55303-9.3434$ \\
\hline & D & 4.5463 & 65.54 & 7 & 1.1061 \\
\hline & $\mathrm{N} / \mathrm{L}$ & 0.81833E-01 & 65.54 & 7 & $\begin{array}{l}0.19909 \mathrm{E}-01- \\
0.33636\end{array}$ \\
\hline & ESW & 18.000 & & & \\
\hline
\end{tabular}

DS: group density, D: individual density, N/L: encounter rate per km, ESW: effective stripe width, CV: coefficient of variation, df: degrees of freedom 
Table51. Results from Distance analysis for Orango (combined multi-species analysis with post-stratification)

\begin{tabular}{|c|c|c|c|c|c|c|}
\hline $\begin{array}{l}\text { Total } \\
\text { observations }\end{array}$ & Estimate & Estimate & \%CV & df & $\begin{array}{l}95 \% \text { Col } \\
\text { Interval }\end{array}$ & dence \\
\hline \multirow{4}{*}{$\begin{array}{l}\text { C. aethiops } \\
N=25(H N / C)\end{array}$} & DS & 4.7388 & 41.36 & 12 & 1.9935 & 11.265 \\
\hline & D & 29.780 & 47.78 & 21 & 11.599 & 76.463 \\
\hline & ESW & 114.69 & 21.14 & 23 & 74.409 & 176.77 \\
\hline & $n / L$ & 1.0870 & 35.55 & 7 & 0.48076 & 2.4575 \\
\hline \multirow{4}{*}{$\begin{array}{l}\text { T. scriptus } \\
N=11(U / C)\end{array}$} & DS & 1.5977 & 59.36 & 16 & 0.49849 & 5.1205 \\
\hline & D & 2.2544 & 60.64 & 17 & 0.69225 & 7.3417 \\
\hline & ESW & 149.68 & 41.25 & 9 & 61.056 & 366.93 \\
\hline & $n / L$ & 0.47826 & 42.69 & 7 & 0.18176 & 1.2585 \\
\hline
\end{tabular}

DS: group density, D: individual density, N/L: encounter rate per $\mathrm{km}$, ESW: effective stripe width, CV: coefficient of variation, df: degrees of freedom; U/C: Uniform/Cosine, HN/C:

Half normal/cosine. 


\section{Appendix4. Development of monitoring programmes}

Table52. Mammal species to be monitored in the surveyed coastal forests of Guinea Bissau

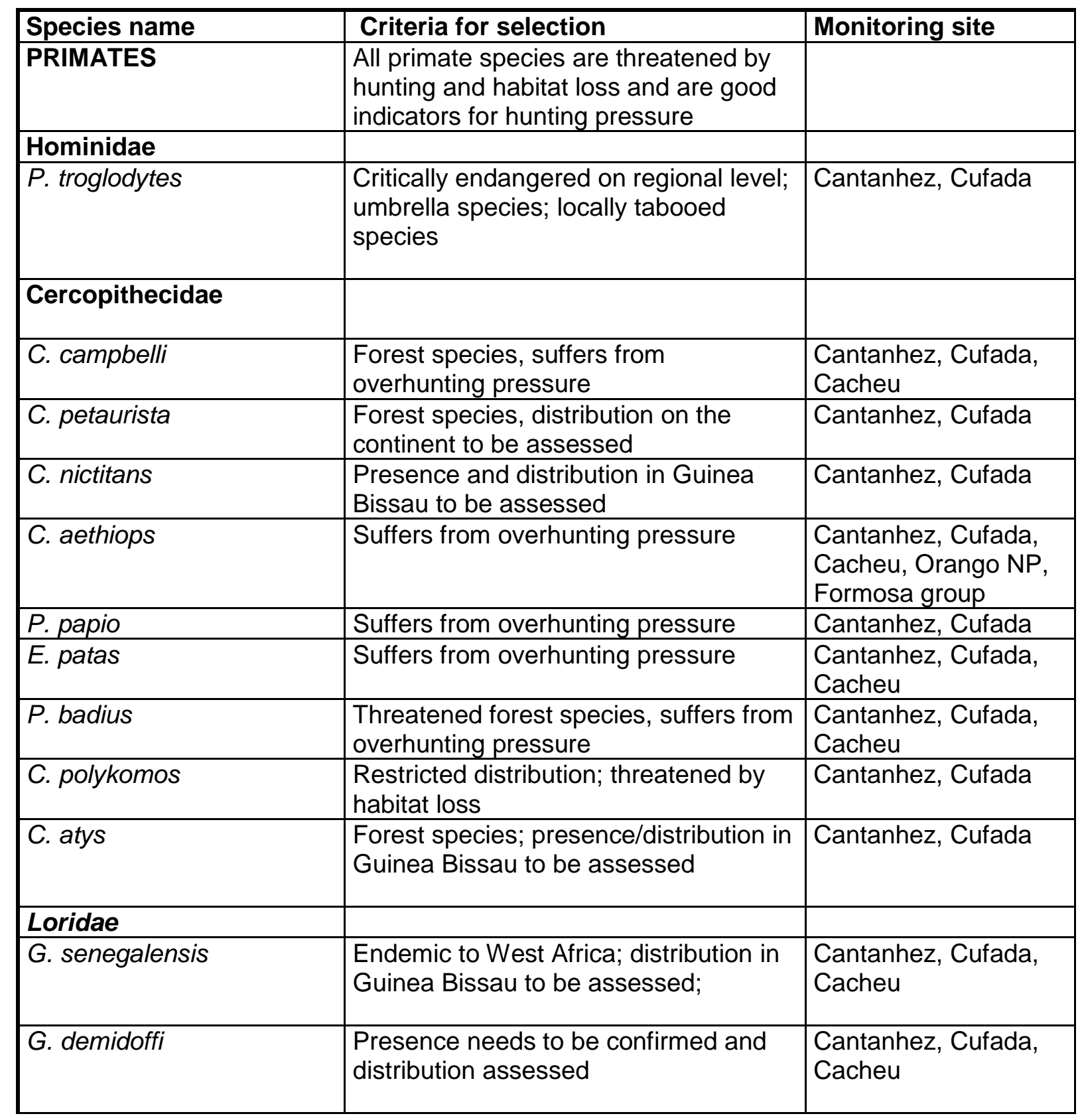


Table52 (continued) Mammal species to be monitored in the surveyed coastal forests of Guinea Bissau

\begin{tabular}{|c|c|c|}
\hline ARTYODACTYLA & & \\
\hline \multicolumn{3}{|l|}{ Suidae } \\
\hline H. meinertzhageni & $\begin{array}{l}\text { Distribution in Guinea Bissau to be } \\
\text { assessed, threatened species }\end{array}$ & Cantanhez, Cufada \\
\hline$P$. africanus & Suffers from hunting pressure & $\begin{array}{l}\text { Cantanhez, Cufada, } \\
\text { Cacheu }\end{array}$ \\
\hline P. porcus & $\begin{array}{l}\text { Forest species, restricted distribution, } \\
\text { suffers from hunting pressure }\end{array}$ & Cantanhez, Cufada \\
\hline \multicolumn{3}{|l|}{ Hippopotamidae } \\
\hline H. amphibius & $\begin{array}{l}\text { Keystone species, cultural interest, } \\
\text { Potential local flagship species }\end{array}$ & $\begin{array}{l}\text { Cantanhez, Cufada, } \\
\text { Cacheu, Orango, } \\
\text { Formosa }\end{array}$ \\
\hline H.(C.) liberiensis & $\begin{array}{l}\text { Forest species, endemic to West } \\
\text { Africa, vulnerable, distribution to be } \\
\text { assessed }\end{array}$ & Cantanhez, Cufada \\
\hline Bovidae & $\begin{array}{l}\text { All duiker and large antelopes are } \\
\text { heavily hunted; forest species most } \\
\text { threatened }\end{array}$ & \\
\hline C. maxwellii & One of the most hunted species & $\begin{array}{l}\text { Cantanhez, Cufada, } \\
\text { Cacheu }\end{array}$ \\
\hline C. dorsalis & $\begin{array}{l}\text { Rare; threatened, suffers from } \\
\text { overhunting pressure }\end{array}$ & Cantanhez, Cufada \\
\hline C. silvicultor & $\begin{array}{l}\text { Rare; threatened, Suffers from } \\
\text { overhunting pressure }\end{array}$ & $\begin{array}{l}\text { Cantanhez, Cufada, } \\
\text { Cacheu }\end{array}$ \\
\hline C. rufilatus & $\begin{array}{l}\text { Rare; threatened, Suffers from } \\
\text { overhunting pressure }\end{array}$ & $\begin{array}{l}\text { Cantanhez, Cufada, } \\
\text { Cacheu }\end{array}$ \\
\hline S. grimmia & Suffers from heavy hunting pressure & $\begin{array}{l}\text { Cantanhez, Cufada, } \\
\text { Cacheu }\end{array}$ \\
\hline T. scriptus & One of the most hunted species & $\begin{array}{l}\text { Cantanhez, Cufada, } \\
\text { Cacheu, Orango }\end{array}$ \\
\hline T. spekei & $\begin{array}{l}\text { Rare and threatened, restricted } \\
\text { distribution, suffers from hunting } \\
\text { pressure }\end{array}$ & Cufada, Cacheu \\
\hline K. kob & $\begin{array}{l}\text { Rare, restricted distribution, suffers } \\
\text { from hunting pressure }\end{array}$ & $\begin{array}{l}\text { Cantanhez, Cufada, } \\
\text { Cacheu }\end{array}$ \\
\hline K. defassa & $\begin{array}{l}\text { Rare, restricted distribution, suffers } \\
\text { from hunting pressure }\end{array}$ & Cantanhez, Cufada \\
\hline H. equinus & $\begin{array}{l}\text { Rare, seasonal occurrence, restricted } \\
\text { distribution, suffers from hunting } \\
\text { pressure }\end{array}$ & Cantanhez, Cufada \\
\hline S. caffer & Rare, threatened & Cantanhez, Cufada \\
\hline \multicolumn{3}{|l|}{ Tragulidae } \\
\hline H. aquaticus & Status and distribution to be assessed & $\begin{array}{l}\text { Cantanhez, Cufada, } \\
\text { Cacheu }\end{array}$ \\
\hline
\end{tabular}


Table52 (continued) Mammal species to be monitored in the surveyed coastal forests of Guinea-Bissau

\begin{tabular}{|c|c|c|}
\hline PROBOSCIDEA & & \\
\hline Elephantidae & Threatened & \\
\hline L. africana & $\begin{array}{l}\text { Keystone, umbrella and flagship } \\
\text { species; Seasonal occurrence; } \\
\text { threatened by habitat fragmentation } \\
\text { and destruction }\end{array}$ & Cantanhez, Cufada \\
\hline \multicolumn{3}{|l|}{ SIRENIDAE } \\
\hline T. senegalensis & $\begin{array}{l}\text { Strong cultural interest, threatened, } \\
\text { Potential local flagship species }\end{array}$ & $\begin{array}{l}\text { Cantanhez, Cufada, } \\
\text { Cacheu, Orango, } \\
\text { Formosa }\end{array}$ \\
\hline \multicolumn{3}{|l|}{ PHOLIDOTA } \\
\hline Manidae & $\begin{array}{l}\text { Distribution and status largely } \\
\text { unknown }\end{array}$ & \\
\hline M. tricuspis & Rare species & $\begin{array}{l}\text { Cantanhez, Cufada, } \\
\text { Cacheu }\end{array}$ \\
\hline M. tetradactyla & Rare species & $\begin{array}{l}\text { Cantanhez, Cufada, } \\
\text { Cacheu }\end{array}$ \\
\hline M. gigantea & Distribution to be assessed & $\begin{array}{l}\text { Cantanhez, Cufada, } \\
\text { Cacheu }\end{array}$ \\
\hline Orycteropodidae & $\begin{array}{l}\text { Distribution and status largely } \\
\text { unknown }\end{array}$ & \\
\hline O. afer & Rare species & $\begin{array}{l}\text { Cantanhez, Cufada, } \\
\text { Cacheu }\end{array}$ \\
\hline \multicolumn{3}{|l|}{ CARNIVORA } \\
\hline Hyenidae & Cultural interest, threatened species & $\begin{array}{l}\text { Cantanhez, Cufada, } \\
\text { Cacheu }\end{array}$ \\
\hline Felidae & $\begin{array}{l}\text { Distribution and status largely } \\
\text { unknown }\end{array}$ & \\
\hline P. pardus & Keystone species, rare, threatened & $\begin{array}{l}\text { Cantanhez, Cufada, } \\
\text { Cacheu }\end{array}$ \\
\hline P. aurata & $\begin{array}{l}\text { Vulnerable forest species, rare; } \\
\text { distribution to be assessed }\end{array}$ & $\begin{array}{l}\text { Cantanhez, Cufada, } \\
\text { Cacheu }\end{array}$ \\
\hline L. serval & Rare & $\begin{array}{l}\text { Cantanhez, Cufada, } \\
\text { Cacheu }\end{array}$ \\
\hline Mustelidae & $\begin{array}{l}\text { Distribution and status of the members } \\
\text { of this family are unknown }\end{array}$ & \\
\hline Aonyx capensis & $\begin{array}{l}\text { Distribution and status on the } \\
\text { continental part to be assessed }\end{array}$ & $\begin{array}{l}\text { Cantanhez, Cufada, } \\
\text { Cacheu, Orango, } \\
\text { Formosa }\end{array}$ \\
\hline Mellivora capensis & Rare, status unknown, to be assessed & $\begin{array}{l}\text { Cantanhez, Cufada, } \\
\text { Cacheu }\end{array}$ \\
\hline
\end{tabular}


Table52. (continued) Mammal species to be monitored in the surveyed coastal forests of Guinea Bissau

\begin{tabular}{|c|c|c|}
\hline Viverridae & $\begin{array}{l}\text { The status of all members of this group } \\
\text { is unknown and needs to be assessed }\end{array}$ & \\
\hline A. paludinosus & Status unknown & $\begin{array}{l}\text { Cantanhez, Cufada, } \\
\text { Cacheu, Orango, } \\
\text { Formosa }\end{array}$ \\
\hline H. sanguineus & Status unknown & $\begin{array}{l}\text { Cantanhez, Cufada, } \\
\text { Cacheu, Orango, } \\
\text { Formosa }\end{array}$ \\
\hline C. civetta & Distribution and status unknown & $\begin{array}{l}\text { Cantanhez, Cufada, } \\
\text { Cacheu }\end{array}$ \\
\hline Genetta spp. & $\begin{array}{l}\text { There is still some confusion on the } \\
\text { occurring subspecies }\end{array}$ & $\begin{array}{l}\text { Cantanhez, Cufada, } \\
\text { Cacheu, Orango }\end{array}$ \\
\hline N. binotata & & $\begin{array}{l}\text { Cantanhez, Cufada, } \\
\text { Cacheu }\end{array}$ \\
\hline Thryonomidae & Conflict with humans & \\
\hline T. swinderianus & $\begin{array}{l}\text { Suffers some hunting pressure due to } \\
\text { crop raiding }\end{array}$ & $\begin{array}{l}\text { Cantanhez, Cufada, } \\
\text { Cacheu }\end{array}$ \\
\hline Hystricidae & $\begin{array}{l}\text { Very important social role as frequently } \\
\text { consumed species }\end{array}$ & \\
\hline H. cristata & $\begin{array}{l}\text { Heavily hunted, negative trends, actual } \\
\text { status unknown }\end{array}$ & $\begin{array}{l}\text { Cantanhez, Cufada, } \\
\text { Cacheu }\end{array}$ \\
\hline Cricetidae & Social and cultural role & \\
\hline C. gambianus & $\begin{array}{l}\text { Suffers from hunting pressure, cultural } \\
\text { interest in the Bijagós islands }\end{array}$ & $\begin{array}{l}\text { Cantanhez, Cufada, } \\
\text { Cacheu, Orango, } \\
\text { Formosa }\end{array}$ \\
\hline
\end{tabular}




\section{Appendix5. Photograph section}

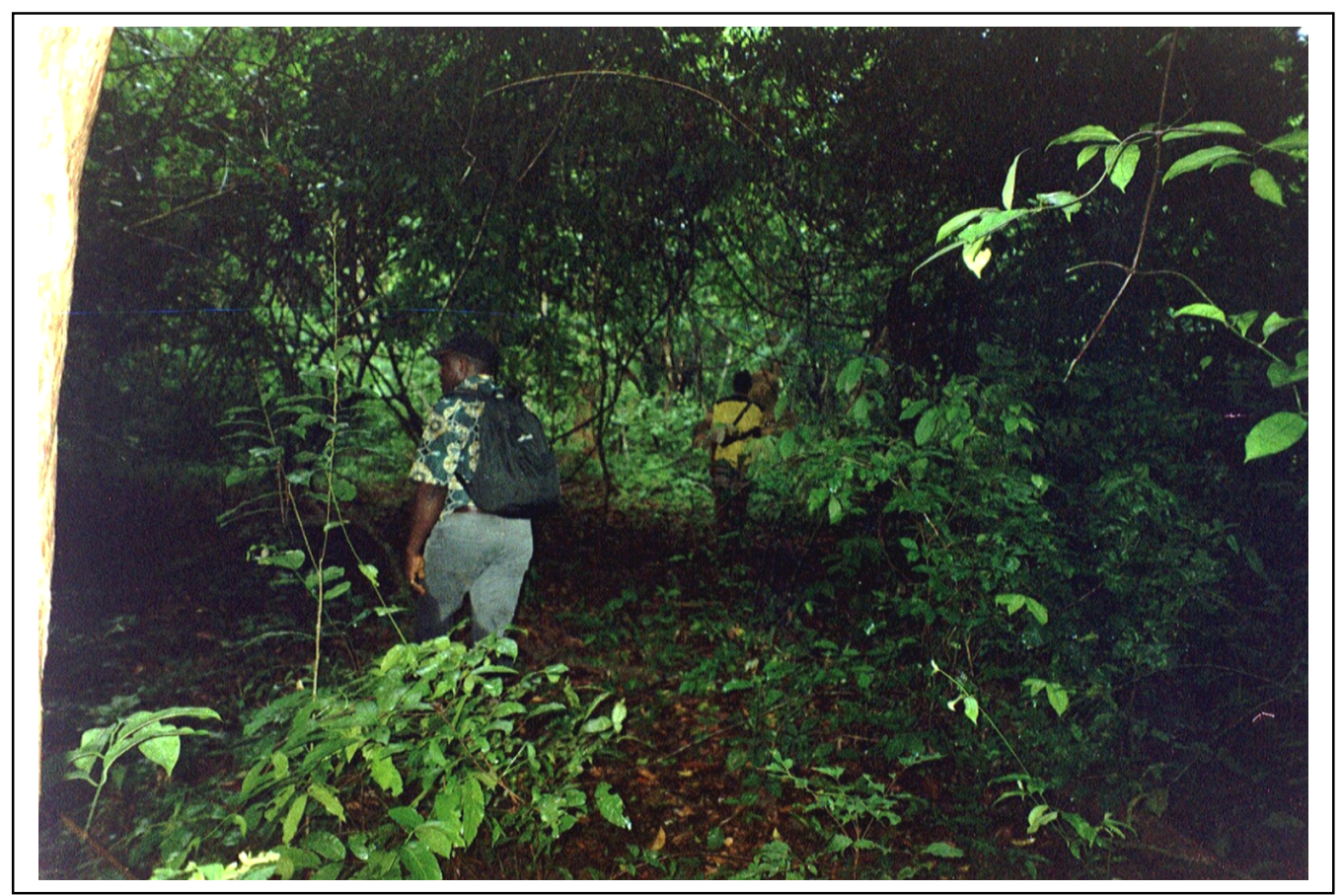

Figure24. Field survey in a humid forest area of Cantanhez (Photo: C. Karibuhoye)

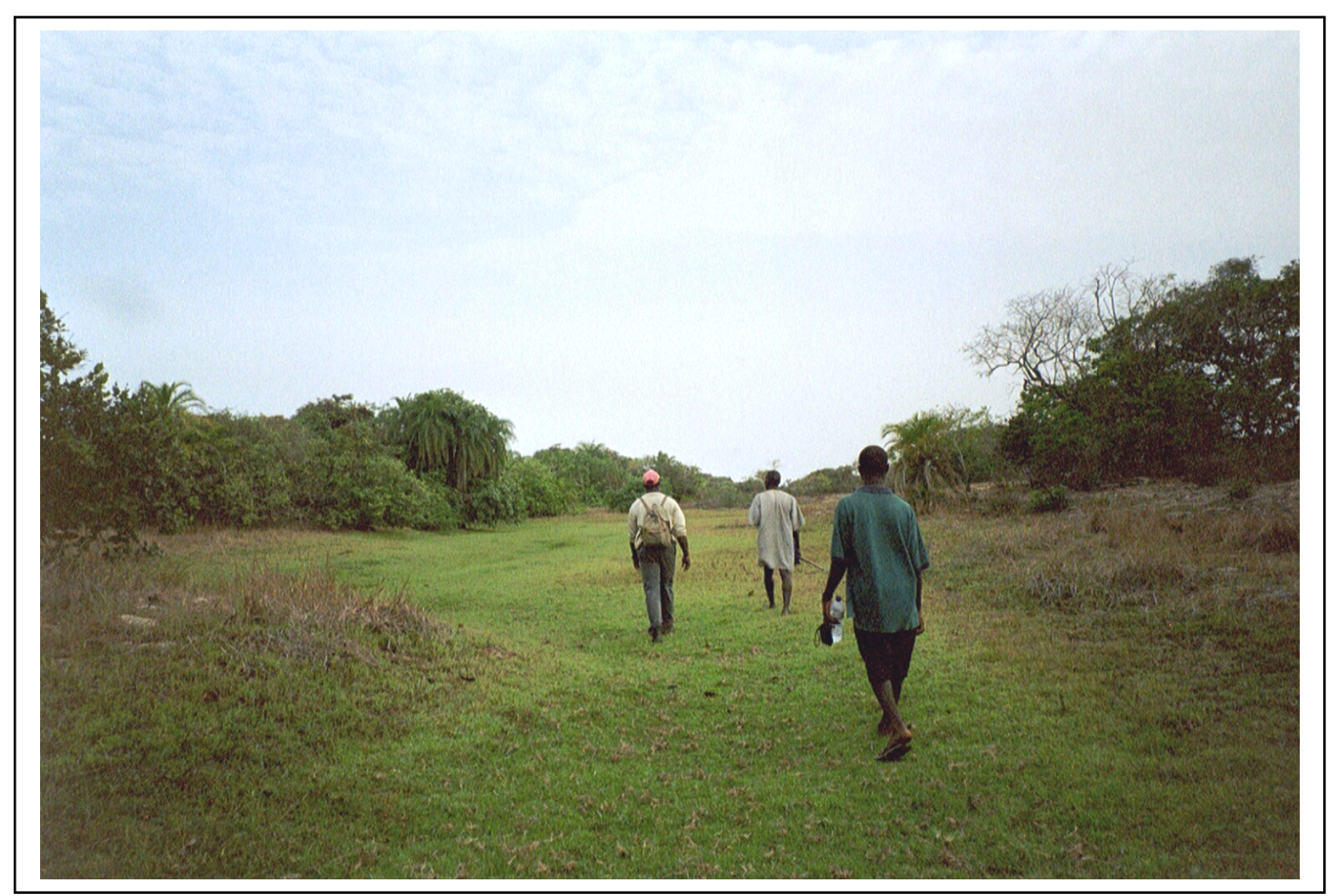

Figure25. Field survey in the Orango National Park (Photo: C. Karibuhoye) 


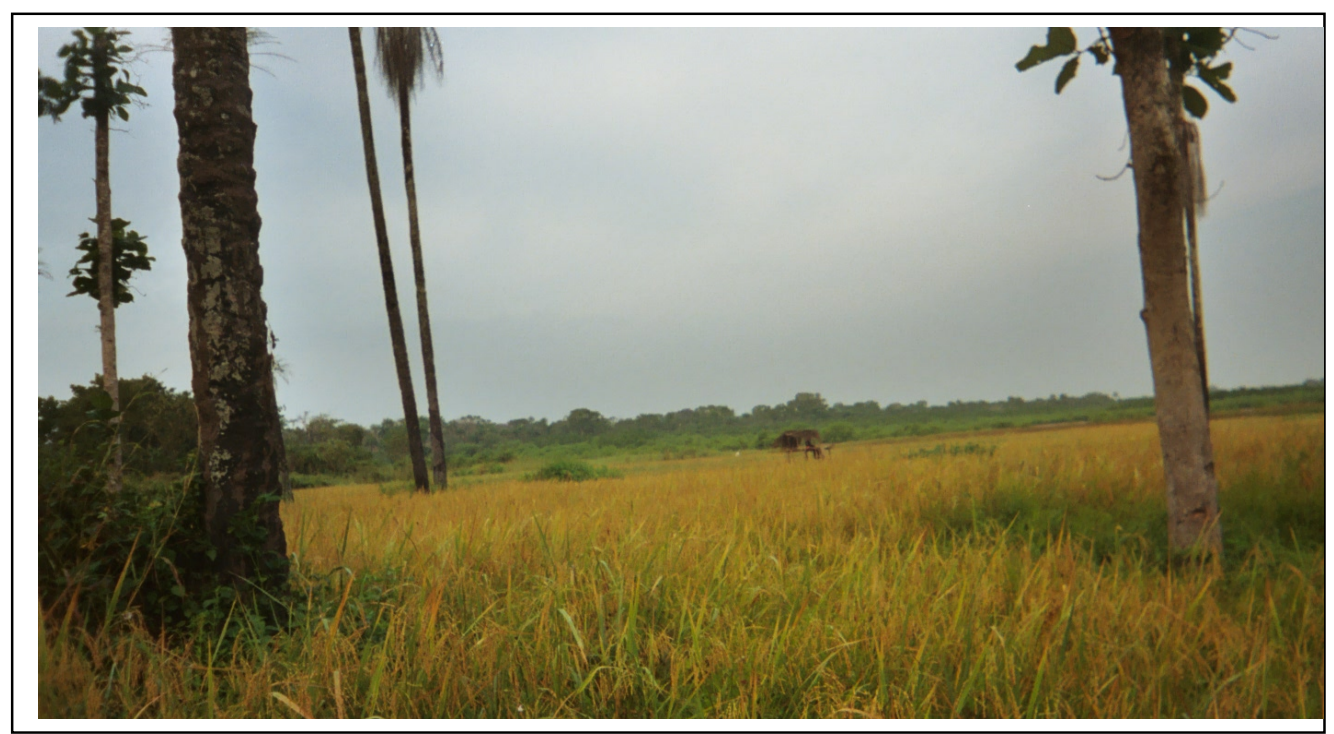

Figure26. Main conflicts between humans and wildlife arise from crop raiding, for example in rice fields (Photo: C. Karibuhoye)

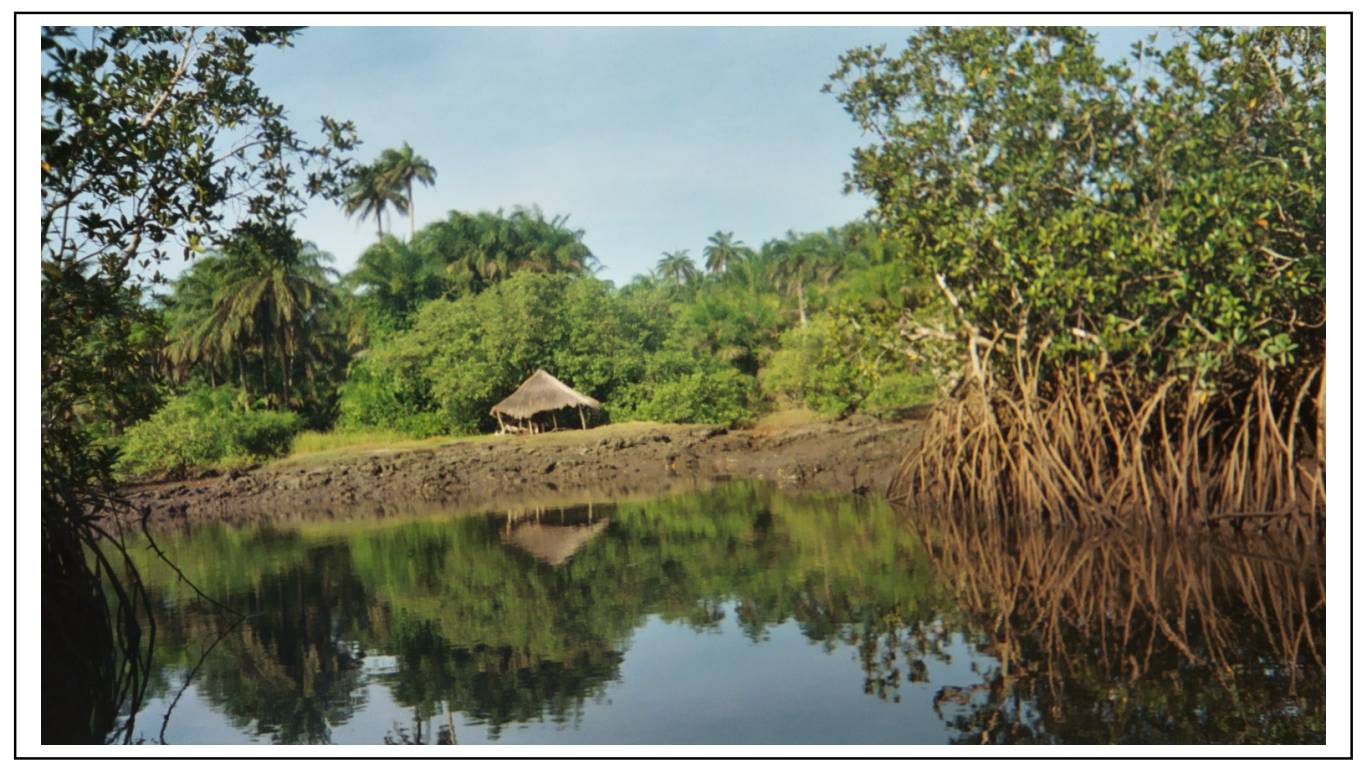

Figure27. Access and use of natural resources are partly still regulated through local traditional mechanisms (here a site for ceremonies at the entrance of an island of the Bijagós archipelago). (Photo: C. Karibuhoye) 


\section{LEBENSLAUF}

Name: Karibuhoye Charlotte

Geburtsdatum: $\quad$ 05. März 1963 in Bujumbura - Burundi

Familienstand: $\quad$ Verheiratet, eine Tochter

Nationalität: Burundi

\section{Schulbildung}

1967 - 1974:

Grundschule - Ecole Notre Dame, Bujumbura (Burundi)

1974 -1978:

Weiterführende Schule - Ecole Moyenne Pédagogique des Filles

Bujumbura (Burundi)

1978 -1981: $\quad$ Gymnasium, Lycée Clarté-Notre-Dame, Bujumbura (Burundi).

Abschluss: Abitur

\section{Studium}

1981 - 1982

Medizinische Fakultät - Universität Burundi

1982 - 1983:

Voruniversitäre Sprachausbildung Deutsch, Herder-Institut Leipzig

1983 - 1988:

Studium der Veterinärmedizin - Universität Leipzig. Abschluss:

Diplomveterinärmediziner

1989 - 1991: Weiterbildung, Tropische Veterinär-medizinische Parasitologie und

Pathologie - Universität Lüttich und Institut für tropische Medizin

Antwerpen (Belgien)

1998 - 2001 Magisterstudium - Tropenzentrum Universität Göttingen/ Schwerpunkt:

Naturschutz in den Tropen. Abschluss: M. sc. agr.

2001 - $2004 \quad$ Promotionsstudium - Zentrum für Naturschutz, Universität Göttingen

\section{Berufliche Tätigkeit}

1988 - 1989:

1991 - 1992:

1992 - 1999:

Seit Dez. 2004: Koordinatorin - Regionales Projekt zur Unterstützung von Küsten- und Marinen Schutzgebieten in Westafrika/ „PRCM-Projet d'appui à la création des Aires Marines Protégées“(Gambia/Guinea/Guinea Bissau / Kapverdische Inseln /Mauretanien/Senegal). 